\title{
Borderland Infrastructures
}

\section{Trade, Development, and Control in Western China}


Borderland Infrastructures 


\section{Asian Borderlands}

Asian Borderlands presents the latest research on borderlands in Asia as well as on the borderlands of Asia - the regions linking Asia with Africa, Europe and Oceania. Its approach is broad: it covers the entire range of the social sciences and humanities. The series explores the social, cultural, geographic, economic and historical dimensions of border-making by states, local communities and flows of goods, people and ideas. It considers territorial borderlands at various scales (national as well as supra- and sub-national) and in various forms (land borders, maritime borders), but also presents research on social borderlands resulting from border-making that may not be territorially fixed, for example linguistic or diasporic communities.

Series Editors

Tina Harris, University of Amsterdam

Willem van Schendel, University of Amsterdam

Editorial Board Members

Franck Billé, University of California, Berkeley

Duncan McDuie-Ra, University of New South Wales

Eric Tagliacozzo, Cornell University

Yuk Wah Chan, City University Hong Kong 


\title{
Borderland Infrastructures
}

\author{
Trade, Development, and Control \\ in Western China
}

Alessandro Rippa

Amsterdam University Press 
The research, writing, and editing of this volume was supported by generous grants and fellowships from the University of Aberdeen (Research Project Award "Religion and Politics in the Contemporary World"), the European Research Council (ERC Starting Grant 637764, "Highland Connections" at LMU Munich), The Henry Luce Foundation ("China Made" project at the University of Colorado Boulder), the European Regional Development Fund and the programme Mobilitas Pluss (MOBJD496), which also funded Open Access.

Cover illustration: The Houqiao border gate as seen from inside the new International Trade City (picture by the author, 2016)

Cover design: Coördesign, Leiden

Lay-out: Crius Group, Hulshout

$$
\begin{array}{ll}
\text { ISBN } & 978 \text { 94 } 63725606 \\
\text { e-ISBN } & 978 \text { 90 } 48543564 \\
\text { DOI } & 10.5117 / 9789463725606 \\
\text { NUR } & 754
\end{array}
$$

(C) A. Rippa / Amsterdam University Press B.V., Amsterdam 2020

All rights reserved. Without limiting the rights under copyright reserved above, no part of this book may be reproduced, stored in or introduced into a retrieval system, or transmitted, in any form or by any means (electronic, mechanical, photocopying, recording or otherwise) without the written permission of both the copyright owner and the author of the book.

Every effort has been made to obtain permission to use all copyrighted illustrations reproduced in this book. Nonetheless, whosoever believes to have rights to this material is advised to contact the publisher. 


\section{Table of Contents}

$\begin{array}{lr}\text { Acknowledgements } & 9\end{array}$

Introduction 11

\section{Part 1 Proximity}

1 Connections $\quad 37$

$\begin{array}{ll}\text { Interlude - proximity } & 67\end{array}$

2 Bridgehead $\quad 73$

$\begin{array}{ll}\text { Coda } & 105\end{array}$

\section{Part 2 Curation}

3 Dependency 111

$\begin{array}{ll}\text { Interlude - curation } & 137\end{array}$

4 Heritage 143

$\begin{array}{ll}\text { Coda } & 169\end{array}$

\section{Part 3 Corridor}

5 Control $\quad 175$

Interlude - corridor $\quad 205$

6 (Il)Licitness 213

$\begin{array}{ll}\text { Coda } & 237\end{array}$ 
Conclusion

241

Bibliography

Index

279 


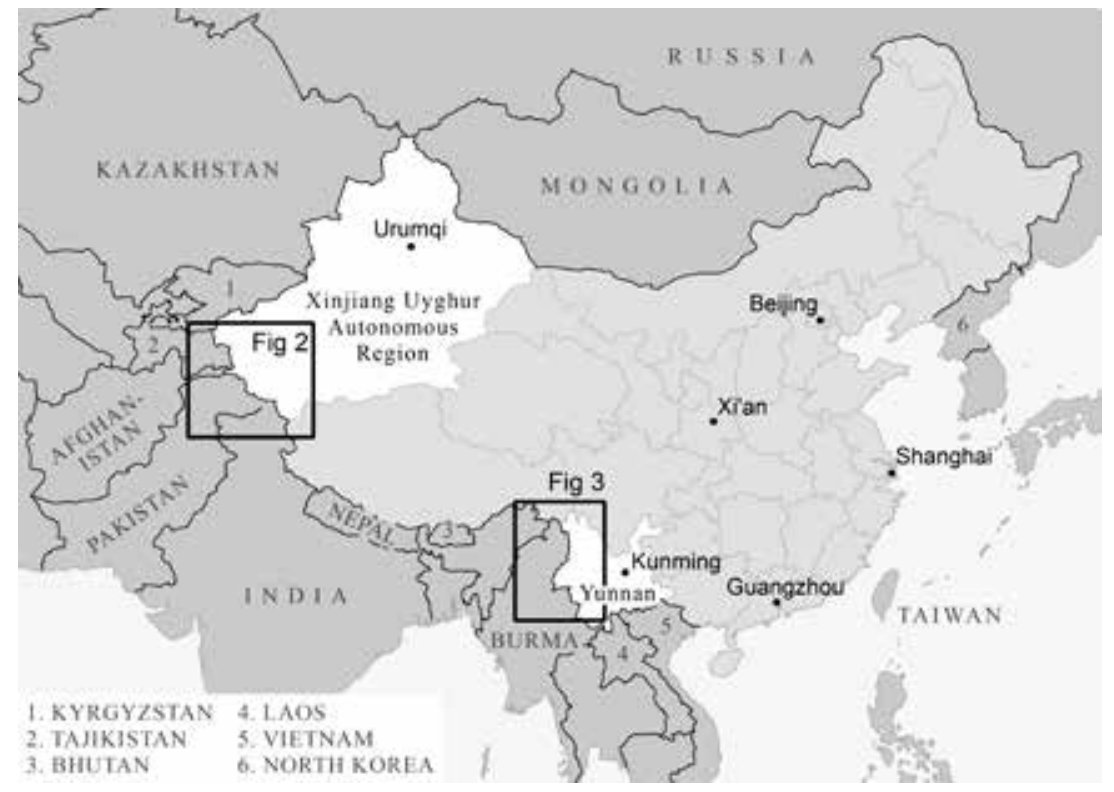

Figure 1: The People's Republic of China (map by Michael Athanson)

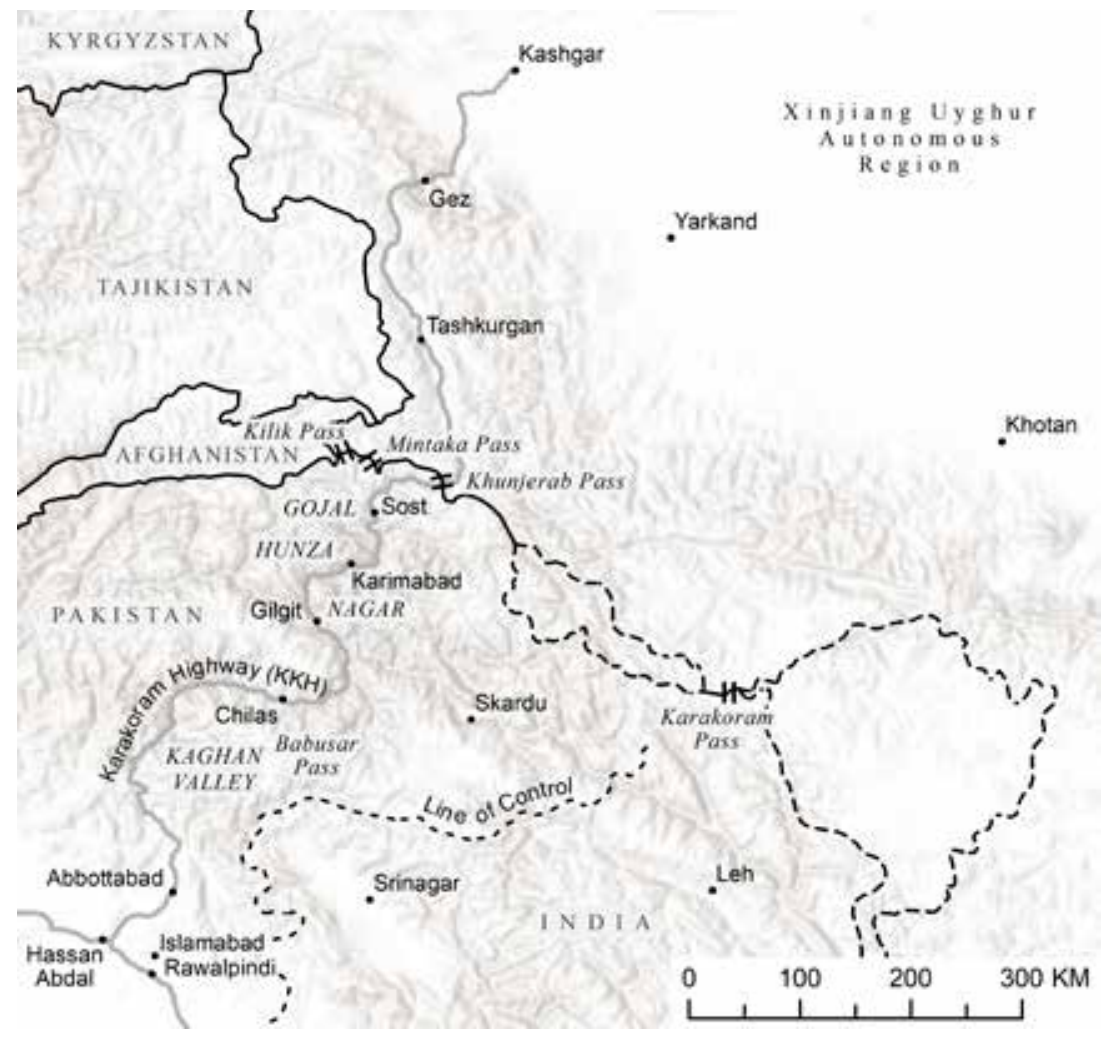

Figure 2: The Xinjiang-Pakistan borderlands (map by Michael Athanson) 


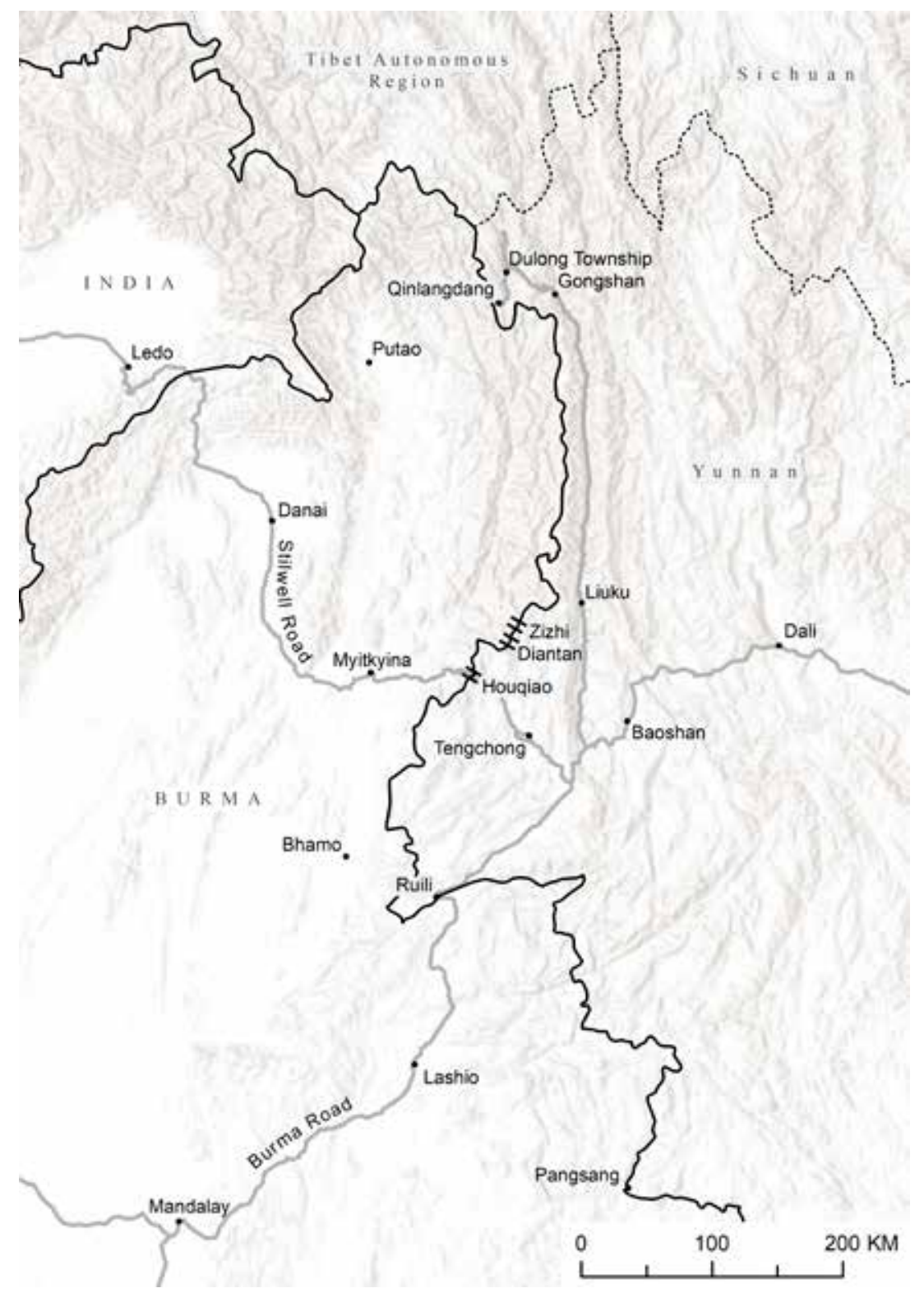

Figure 3: The Yunnan-Burma borderlands (map by Michael Athanson) 


\section{Acknowledgements}

As I see the fruit of over a decade of research take concrete shape in this manuscript, there is nothing I would like to do more than to thank all of those who have helped me throughout this time. While it is only my name that appears as the author of this book, not a single page of it would have been written without the support of colleagues, friends, mentors, and family.

As I write these words in the autumn of 2019, however, I realise that I cannot thank those who deserve my gratitude the most. I cannot name my friends, interviewees, and acquaintances from the Xinjiang Uyghur Autonomous Region, without whom my research in the region would have been pointless. I owe my academic career and, indeed, the life I currently live, to their generosity. Yet, I cannot name any of them for fear of possible repercussions that they and their families might encounter in the current political climate in the People's Republic of China.

Therefore, I have decided not to mention any names, but rather to let this book be a tribute to the un-acknowledgeable. To those who have been disappeared. To those who live in fear for themselves and their loved ones. May the future give you back some of the happiness that you deserve. 



\section{Introduction}

After months of denials amidst growing international scrutiny and concern, in October 2018 Chinese authorities publicly admitted the existence of a system of prison camps in the Xinjiang Uyghur Autonomous Region (XUAR). By that point, the camps, officially labelled as "re-education" facilities, had been exposed for several months in the international media. A number of scholars, based mostly in European and North American institutions, had uncovered the imprisonment of over a million people in Xinjiang through a combined analysis of satellite images, government websites, media reports, and long-term ethnographic engagement with local communities.

Following its admission of the existence of the camps, the propaganda machine of the People's Republic of China (PRC) began to produce a variety of stunning - both in terms of number and content - justifications for their existence. As part of this defence against international criticism, China's staterun news agency, Xinhua, released a lengthy interview with Shohrat Zakir, the Chairman of the XUAR, in which he expressed the Chinese government's views on the subject. Following the predictable Chinese Communist Party (CCP) line, he placed the camps within the framework of China's struggle against the "three evil forces" of terrorism, extremism, and separatism, deemed responsible of undermining "the stable and peaceful order and the atmosphere of solidarity and progress of Xinjiang." In order to fight terrorism and safeguard stability, Shohrat Zakir continued, "Xinjiang has launched a vocational education and training program according to the law." Such programme is supposed to help ethnic minorities in Xinjiang to "improve their ability in commanding the country's common language, acquiring legal knowledge and vocational skills, among others." Shohrat Zakir then mapped out the Party's vision for the future of Xinjiang, based on the transformation that this form of training will bring:

Next, Xinjiang will further implement the strategies and policies on the region, set by the CPC Central Committee with Comrade Xi Jinping at the core, adhere to the people-centered philosophy of development, properly handle the relations between stability and development, and concentrate on the three major tasks: construction of the core zone of the Silk Road Economic Belt, the implementation of the rural vitalization strategy and the development of the tourism industry. ${ }^{1}$

1 The full transcript in English is available at Xinhua (2018b). In the interview Xinjiang's "re-education" facilities are described in optimistic terms: the cafeteria offers "nutritious free 
Despite the propagandistic tone of the interview, what the Chairman of the $\mathrm{XUAR}$ laid bare is the connection between control and development that is at the core of CCP policies at China's borderlands. Xinjiang's prison camps, in this sense, cannot be seen as detached from their connections with the "three major tasks" that the Party has set for itself: the Belt and Road Initiative, modernisation of the countryside, and tourism development. This nexus is the main focus of this book. In particular, I show how the development of trans-border infrastructure, currently reflected in the ambitiousness and ambiguities of the Belt and Road Initiative (BRI), cannot be addressed independently of the CCP's broader aim to capture and control the Chinese borderlands and its people. According to the same logic, projects to "build a new socialist countryside" and to turn minority areas into tourist resources underscore an attempt to re-design the borderlands and the communities to which they are home according to a particular ideology. The aim, as Shohrat Zakir explicitly pointed out, is transformational: while borderland territories are secured through radical infrastructural interventions, ethnic minority subjects are re-defined according to the CCP vision of modernity. This book attends to both processes in the context of trans-border investment in infrastructure and trade. In so doing, it shows that, as investment has grown, small-scale traders have lost their strategic advantage and are now struggling to maintain their businesses. Concurrently, local ethnic minorities have become the target of radical resettlement projects, securitisation, tourism-related initiatives, and, in many cases, have become increasingly dependent on state subsidies. Borderland Infrastructures traces this uneven development over the past two decades, thus raising fundamental questions about the future of the Chinese borderlands and about China as a whole. How does infrastructure development affect cross-border livelihood in today's

diets"; the dormitories are equipped with all comforts, TVs, air conditioning, and a bathroom; and there are even sports venues for outdoor activities. The reality of what is happening in Xinjiang, however, is far from what Shohrat Zakir depicted. There is ample evidence that large numbers of Uyghur, Kazakh, Kyrgyz, Uzbek, and Hui are held against their will and without trial, thus circumventing Chinese law itself. Instead of "vocational training," as Shohrat Zakir claimed, what is taking place inside the camps resembles rather a brainwashing exercise, as part of which detainees are forced to abandon their native language and religious beliefs - obliged to learn Mandarin Chinese and to study Chinese Communist Party doctrine. The facilities themselves resemble well-guarded jails, secured by walls, fences, and state-of-the-art surveillance systems. Several reports point to various torture methods routinely employed inside the camps, ranging from physical punishments to bright lights left on throughout the night in overcrowded rooms, with inmates unable to exercise or go outdoors for weeks at a time. On the subject of mass internment of Turkic Muslims in Xinjiang, see Zenz (2018); The Economist (2018); Thum (2018); Bunin (2018); Brophy (2018). 
China? What is the place and role of ethnic minorities in larger processes of development? How are newly envisioned forms of connectivity as part of the BRI agenda affecting pre-existing mobilities and forms of exchange?

The idea that economic development will generate more stable societies has long underpinned the CCP's approach towards its border regions. In particular, the under-development of these areas, combined with the presence of sizeable ethnic minorities with kinship connections beyond China's borders, has traditionally been seen by PRC authorities as a major security risk. In the case of Xinjiang, for instance, Becquelin (2004) argues that this particular insecurity led to highly centralised policies in which Beijing plays a more important role in internal regional affairs as compared to other parts of China. ${ }^{2}$ Other scholars have focused on ethnic policies and ethnic relations in the context of the CCP's consolidation of power in its peripheries. These have included important works on ethnic identification, cultural politics, representation and resistance, and development. ${ }^{3}$ In showing how this nexus of development and security plays out across a number of transnational spaces, this book argues that processes of economic development - mainly implemented through infrastructure - along the Chinese borderlands are characterised by an active attempt to erase particular histories. Such processes encompass both the consolidation of CCP power in China's peripheries as well as the development of a geography of transnational connectivity through the BRI. Starting with the latter, I show how the imagined geography underpinning new Silk Road fantasies ignores pre-existing forms of mobility, exchange, and connectivity more generally. In this process, what I call proximity - the set of skills developed by cross-border communities to take advantage of their particular positionality - is jeopardised in an attempt to create legible conduits and transactions. The third part of this book engages with this particular outcome through the image of the corridor, one of the Belt and Road Initiative's main features. In its relations with ethnic minorities and minority regions, on the other hand, the CCP has embraced an approach that actively erases anything that departs from its own definition of minority history and culture. I define this selective, violent, and transformational approach as a "curational" intervention, drawing on the original meaning of the Latin word curare: "to heal." Chinese authorities, I argue, by projecting backwardness upon minority subjects,

2 On Xinjiang's "autonomy" and CCP "insecurity" in its historical claims, see Bovingdon (2010); Khan (2018); and Leibold (2019).

3 See for instance, Schein (2000); Litzinger (2000); Gladney (1991, 2004); Bovingdon (2010); Yeh (2013); Fischer (2014). 
cultures, and spaces, see their "civilizing" mission in the borderlands as a project with profound moral and ideological implications. Albeit framed within the language of economic development, then, curational interventions underpin a disciplinary - and not economic - objective. This, in turn, results in further marginalisation and dependency. The Xinjiang's prison camps, with which I began this book, can be understood as an extreme outcome of this particular logic of curation and cannot be framed outside of China's larger push for transnational connectivity as part of the BRI. As Shohrat Zakir remarked, and as I will show in this book, the construction of new Silk Roads and disciplinary measures to create - or "curate" - new minority subjects cannot be thought of as separate from one another.

The research upon which this book is based was conducted in the decade prior to the establishment of a prison camps system in Xinjiang. Nevertheless, the dynamics that I address help shed light on how we have come to this ultimate - and ultimately tragic - development. The story is not limited to Xinjiang; in fact, it characterises China's Western borderlands, from Yunnan to the Tibet Autonomous Region (TAR) to Inner Mongolia. In order to demonstrate this and to make a broader argument about China's development, I juxtapose the borderlands of Xinjiang and Yunnan as two specific case studies showing how marginalisation, control, and infrastructure development go hand in hand. ${ }^{4}$ In so doing, I do not aim to gloss over important regional specificities, but rather to address a common mode of ruling - a form of governmentality, to follow Foucault - that is characteristic of China's approach to its minority-populated borderlands.

\section{Researching the borderlands}

I travelled for the first time to one of China's border crossings in 2009. Standing at over 4600 metres, on the Khunjerab Pass, I walked through the imposing Chinese-built gate into Pakistan. Once across, I shook hands with a Pakistani border guard, who seemed to be inappropriately dressed for the brisk temperature and high altitude, took a picture in front of a border marker alongside a small group of Chinese tourists, and then walked back into

4 Both the Xinjiang Uyghur Autonomous Region and Yunnan Province, as territorial units, are recent creations. As this book is mostly concerned with the current situation at the borderlands of today's PRC, for the sake of clarity and convenience I generally use the names "Xinjiang" and "Yunnan", even though it might appear anachronistic or historically inaccurate in certain parts of the narrative. 
China. Not two hours later I was in my hotel room in Tashkurgan, less than a day's drive from Kashgar along the Karakoram Highway (KKH). Following that first visit, the Karakoram Highway became the focus of my doctoral research, and the Khunjerab Pass a recurrent destination. Between 2012 and 2013, I spent twelve months between Xinjiang and northern Pakistan, meeting cross-border traders in crowded bazaars, drinking endless cups of tea during idle mornings in their shops, visiting their relatives, business partners, and friends. In Pakistan, I interviewed prominent members of the Kashgari community - a group of Uyghurs who had migrated from Xinjiang to Pakistan throughout the 2oth century - and members of the Pakistan Army Corps of Engineers involved with the construction of the Karakoram Highway in the 1960 s and 1970s. In China, I visited traders in Urumqi, Khotan, and even Yiwu - a trading city in Zhejiang province, only three hours by train from Shanghai, and home to a large contingent of Pakistani traders.

While I returned to Xinjiang for brief periods of research in 2016 and 2017, by 2015 most of my research had shifted to another location: the China-Burma borderlands in Western Yunnan province. Over another 14 months of ethnographic fieldwork, I worked closely with Chinese officials and traders in the border town of Tengchong and lived with a Drung family in the Dulong Valley. I travelled extensively along and across the border, as did many traders, local officials, employees of Chinese companies working on infrastructure projects in Burma, and informants who helped with my research. ${ }^{5}$ On more than one occasion, we crossed it without the proper documents, yet nevertheless did so with the tacit consent of local authorities. These "permissive politics" (Zhang 2018) regarding cross-border mobility in Yunnan never ceased to surprise me, particularly when I counterposed them with the strictness of the border regime in Xinjiang. Yet, much of what I saw in Yunnan engendered productive connections with what I had experienced in Xinjiang: the ubiquity of Silk Road rhetoric, the push for transnational infrastructure projects aimed at re-designing the geography of cross-border mobility in the area, the marginalisation of local ethnic groups through development processes that were described in official rhetoric as beneficial to them.

Between 2009 and 2019, many of my informants became my friends. Our lives became intertwined in ways that would have been impossible to foresee. I still have regular conversations over Skype, or WeChat, even with

5 The military government changed the name of the country from Burma to Myanmar in 1989. However, both names are still widely used both within and outside Burma/Myanmar. As this book spans a period of time going back to the late 19th century, I have decided to refer to the country consistently as Burma. 
people I have not seen in years. Others, I have met in unexpected places: Beijing, Tokyo, Munich. As this research challenged the often perceived "boundedness" of fieldwork, the period of my research became impossible to define, extending into the present and further into the past. Thus, besides interviews and the personal engagements that can be understood under the broad methodological umbrella of what anthropologists call "ethnography," my research also took unexpected, textual turns. In order to gain a historical perspective of ambitious plans of transnational connectivity, I spent time in the British Library and in the National Archives in London. In China, I was given access to private archives in Tengchong. This latter phase of research has informed many of the conversations I have had throughout years of engagement in ways that cannot be underestimated.

Throughout these years, my own position as a researcher has been a constant object of reflection and consideration, particularly in relation to the different groups of people I was engaging with. When it comes to researching cross-border ties, mobilities, and informal exchanges, access can be a fundamental problem. For instance, while conducting research in Xinjiang, I did my best not to interact with local officials. Given the impossibility of obtaining a research permit for what would have been considered too "sensitive (mingan)" a topic, I did my best to avoid any encounter that might have jeopardised my access to the field and, more importantly, endangered my informants. This meant remaining highly mobile, avoiding long stays in small places where the persistent presence of a foreigner would likely have attracted unwanted attention. So, for instance, I never spent more than two weeks in Tashkurgan, a small border town near the China-Pakistan border. Instead of staying put for a long stretch of fieldwork, as in the established anthropological tradition, I travelled to Tashkurgan frequently but only for short periods of time. A week, ten days, sometimes only one night to catch up with someone visiting from Pakistan. In Kashgar, on the other hand, where I spent longer stretches of fieldwork, I avoided staying with Uyghur families, even when I had the chance to do so. Instead, I preferred hotels and hostels, in which I could be mistaken for a foreign tourist. In Tengchong, conversely, a significant part of my relations engaged with, and were made through, local CCP officials. I visited their houses and conducted formal interviews in government offices around town, and joined them on official visits to the border and to the construction sites of ongoing projects related to trade with Burma. I engaged with wealthy businessmen and was given access to the development plans for a new Border Trade Zone. Through them, I met their Burmese counterparts in Myitkyina and Mandalay, as well as Chinese businessmen operative inside Burma. 
This multi-sited (Marcus 1995) and itinerant (Schein 2000: 28) ethnographic experience presented both strengths and weaknesses. Concerning the latter, I did not experience the kind of deep, long-term, embedded access to a particular locale and community that has long characterised classical anthropological scholarship. On the other hand, I gained a multiplicity of perspectives on the same issues through interactions with actors that, I came to realise, were entangled in similar processes despite their apparent distance. By taking this particular approach, I was able to bring to the fore dynamics and connections that would have otherwise remained out of sight. Take, for instance, the connection between new projects of transnational connectivity now brought together under the BRI agenda, and processes of excluding local forms of trade across the borderlands that forms the backbone of the first part of this book. Or, as the second part shows, the ways in which radical resettlement projects motivated by ecological, developmental, and tourist reasons are inherently designed to create new forms of minority subjectivity. And lastly, the intimate connection between development and control in 21st-century China, which I highlight by putting Xinjiang's prison camps in conversation with the opening of a Border Trade Zone in Yunnan's Tengchong. These arguments, and the ethnographic research that informs them, would have not emerged in such clarity if it were not for my ability to travel along and across the Chinese borderlands, engaging with groups of people as diverse as Tengchong officials, Uyghur migrants in Pakistan, car parts dealers in Urumqi, and Burmese intellectuals in Mandalay.

The overarching aim of this book is to highlight some of the key dynamics that define life at the borderlands of China. Thus, to account for the interconnections of local histories, national development agendas, personal interests, and perceived foreign security threats that define how people live across the Chinese borderlands today. I do so through a "rush of stories" (Tsing 2015:37) - describing brief, and at times repeated, encounters with a small number of traders, officials, and migrants. Such examples are idiosyncratic - they refer to specific personal stories and places. Yet, they are also not entirely exceptional. Rather, they are representative of larger processes within which the Chinese borderlands are embedded. My selection of such stories is therefore not fortuitous. It rather points to the ways in which ethnography can be used to address, untangle, and interpret current dynamics of global impact and scale.

The issue of China's integration and administration of peripheral and multi-ethnic region has been examined by several excellent studies in recent years (cf. Bovingdon 2010; Yeh 2013; Fischer 2014; Lary 2007; Ma and Liu 1998; Ma 2000; Clarke and Smith 2016; Blum and Jensen 2002). Less attention has 
been devoted to the Chinese borderlands as particular zones of friction, encounter, and (dis)connection. ${ }^{6}$ This study, on the other hand, focuses on the areas along and across China's western borders as particular zones from which to examine the material manifestations of state territoriality, the evolution of China's ideas of development and connectivity, and the relations between the two. Border residents, as well as those who cross such national borders on a regular basis, deal with the "nation state" as a concrete reality, rather than as a line on a map or a set of mental images (Anderson 1991; Bhabha 1990; Gellner 1983; Chatterjee 1986; Thongchai 1994). As such, the book follows Veena Das and Deborah Poole's (2004) call for anthropology to look at marginal places and practices in order to gain a robust understanding of the state. Through such margins, I look at how state power is experienced, mediated, and enacted across China's borderlands today, and raise a number of crucial questions. What does the integration of the borderlands through infrastructural interventions mean for those who live along and across such borderlands? How does the seemingly paradoxical approach of extending a homogenising vision of development into the borderlands while branding difference for tourist consumption affect peripheral spaces? What does the borderlands' renewed "centrality," particularly through the Belt and Road Initiative, mean for local livelihood and long-term cross-border relations? And finally, what do China's attempts to monitor and control overseas minority communities tell us about the extension of CCP power in the 21st century?

\section{China's western borderlands from the Open Up the West Campaign to the Belt and Road Initiative}

In 1911, Archibald Rose, then British consul in Tengchong, a border town in western Yunnan province, submitted a report on the "Chinese Frontiers of India." The chronicle, based on years of service in Sichuan and Yunnan and on a journey to Central Asia through India and Kashmir, the Pamirs, and what at the time was known as "Chinese and Russian Turkestan," was later published in The Geographical Journal (1912). A short memorandum attached to the original report, however, remained confidential. ${ }^{7}$ In it, Archibald Rose proposed an exchange of territory to overcome an impasse in negotiations

6 Notable exceptions include Parham (2017); Evans, Hutton, and Eng (2000); Saxer and Zhang (2016).

7 The report is now available at the British library archive: IOR/L/PS/11/6. 
over the demarcation of a section of the border between China and British Burma, and to prevent major Russian interference in today's Xinjiang. According to his proposal, the British would make a concession over Pianma (or Hsipaw), a piece of territory west of the Gaoligong Mountains, at the China-Burma frontier, which both the Chinese and the British claimed as their own. ${ }^{8}$ In exchange, the British would take advantage of the small state of Hunza's claims over Sariqol, a high-altitude valley in the Pamir mountains today at the border between China, Pakistan, and Afghanistan. The aim was to bring under British control a strategic portion of territory that, Rose feared, the Russians were eyeing in order to expand their reach eastward, into southern Xinjiang. Henry McMahon, the recipient of Rose's report, did not take his proposal seriously. ${ }^{9}$ China never fully settled its border issues with the British, and Rose's proposal, connecting two remote regions at the extremes of the Tibetan plateau, was buried at the India Office.

The two border areas discussed by Rose, between China and the now independent states of Burma and Pakistan, represent the main focus of this book. What is of interest to me, however, is not so much a discussion of the territorial limits of each state's jurisdiction, but rather to understand how such power is deployed and experienced. China and Burma, to be sure, settled their border dispute already in 196o. China and Pakistan did the same in $1963 \cdot{ }^{10}$ Both settlements, while putting an end to decades of negotiations, stand-offs, and disputes, represent critical starting points in the affirmation of particular forms of state power in the borderlands. In his report, Archibald Rose describes China's historically troublesome relation with its frontiers and details how precarious its control over large sections of today's Xinjiang and Yunnan was. In the century following Rose's journeys, the borderlands of China were securely brought into the embrace of the Chinese Communist Party, its "frontier tribes" categorised into a system of minority nationalities (shaoshu minzu), and border areas made accessible to security forces, but also businesses and, more recently,

8 On Pianma and the "Pianma incident" following a British mission to seize Pianma in 1910, see McGrath (2003).

9 McMahon, in his role as foreign secretary of British India, later negotiated a boundary line with the Tibetan Government (known as the McMahon Line) at the 1914 Simla Convention (to which Archibald Rose took part). The line defines the boundary of Tibet and British India between Bhutan and what is today Burma. The line, however, was never agreed upon by the Chinese, and it is to this day contested and the site of conflict between India and China.

10 This agreement has not been recognised by India, which still claims sovereignty over portions of territory administered by Pakistan and China. See the seminal work of Alistair Lamb (1964, $1968,1973)$. 
tourists. An old Chinese saying on the peripheries of the empire notoriously states that "the mountains are high and the emperor far away" - referring to the traditionally unruly and relatively out-of-reach frontier regions. After seven decades of communist rule, the saying no longer holds true. The borderlands have been brought into the sphere of direct control of the state for the first time in China's history, and they are now integral parts of the national geo-body. ${ }^{11}$ They remain, nevertheless, particular places from which to observe how processes of inclusion and territorialisation take place. In particular, this book focuses on the latter phase of what, echoing James Scott (more below), could be termed the "last enclosure" of the frontier - a process that materialises mostly through infrastructure development since the turn of the millennium. To understand how this process unfolded, it is important to briefly detail the history of China's borderlands since the establishment of the People's Republic of China, in 1949 .

A fundamentally anti-imperialist force, the CCP unsurprisingly sought to restore what it considered China's territorial integrity following the establishment of the PRC. Such efforts need to be understood against the backdrop of China's late imperial and Republican history, in which foreign powers, particularly the British, Russian, and Japanese empires conquered and administered sections of Qing territory through open acts of aggression and "unequal treaties" (bu pingdeng tiaoyue) imposed upon the weak Chinese state. Following the so-called century of national humiliation (bainian guochi), CCP leaders thus made it their priority to restore the country's prestige. When the PRC was established in 1949, its leaders identified the borders of the newly formed communist state to coincide with the territory recognised to be Qing lands at the point of the empire's collapse in 1911. The challenge, to put it in the words of Benedict Anderson, was to stretch "the short, tight skin of a nation over the gigantic body of the empire" (1991: 86). Significantly, this territory included most of the late Qing's ethnic frontier, including parts of Xinjiang and Yunnan, which the Qing managed only intermittently, and for the most part indirectly. ${ }^{12}$ Thus, while such claims allowed CCP leaders to successfully inscribe the PRC into an imagined imperial geography going back thousands of years, the legacy of the Qing

11 In borrowing Thongchai (1994) famous expression, I understand the notion of geo-body as a process as much as a product. For a discussion of the issue of China's geo-body vis-à-vis Thongchai's work, see Klingberg (2017). See also Duara (1995) and Fiskesjö (2006).

12 On the Qing's administration of Yunnan, see Giersch (2006). On Xinjiang, see Millward (1998; 2007); Kinzley (2018); Perdue (2005). 
frontier presented several challenges for them. ${ }^{13}$ Two in particular are of interest here: the incorporation and management of an ethnically diverse, vast, underdeveloped, and sparsely populated periphery, ${ }^{14}$ and a number of territorial disputes with post-colonial nations such as India, Pakistan, and Burma. ${ }^{15}$

The Party's territorial objectives and anxieties materialised through particular development efforts and institutions across the country's most peripheral areas. Such processes were not uniform across China's diverse borderlands and vis-à-vis distinct neighbours. In Xinjiang, the initial task of asserting CCP control and overseeing the creation of a new administrative organ was led by the People's Liberation Army. To this end, Xinjiang saw the creation of a "peculiar institution" (Millward 2007: 251), the Xinjiang Production and Construction Corps, generally known as bingtuan. ${ }^{16}$ Designed to combine production with militia duties, the bingtuan were enshrined with the task of securing the borderlands and opening up Xinjiang's "wilderness" for agriculture and resource extraction. As such, the bingtuan played a major role in the settlement of China's western frontier and the integration of Xinjiang. As Tom Cliff put it: "the frontier can be seen as having moved beyond places where bingtuan farms have created a frontier of settlement in the past. The bingtuan and the frontier move in close alignment, the latter being swept along by the former" (Cliff 2009: 91). The situation was different in Yunnan, which, by 1949, was better integrated within the Chinese

13 China's approach to territorial issues and the production of a particular national geo-body by CCP authorities have been the object several studies. See in particular Callahan (2009) and Leibold $(2006,2007)$.

14 Many scholars have raised the question of what the construction of a Chinese nation meant for those who were "less authentic, more peripheral, and farther removed from a core Chinese tradition" (Gladney 1998: 5), thus expressing concerns about the role of ethnic minorities in China's contemporary nationhood (cf. Litzinger 2000; Schein 2000; Bulag 2002; Bovingdon 2010; Lipman 1997; Rossabi 2004). Importantly, this work explored the ways that China's ethnic populations have been territorialized in a Han national geography, not only as subjects of a hegemonic national vision, but also as knowledge-making groups that have affected that national conception.

15 On China's territorial disputes, see Fravel (2008).

16 Bingtuan is a short form for Xinjiang shengchan jianshe bingtuan, which is usually translated in English as Xinjiang Production and Construction Corps. The Corps system has its predecessor in the military-agricultural colonies of Han China, called tuntian, where it was employed to sustain troops and enhance control over the frontier. Established in 1954, today's bingtuan are a semi-military government organisation that "assumes the duties of cultivating and guarding the frontier areas entrusted to it by the state" (State Council of the PRC 2003). Subordinate to the leadership of the central government, the Corps operate schools, hospitals, courts, militia, and produce about one sixth of Xinjiang's GDP. On the bingtuan, see Cliff (2016) 
administrative system, particularly due to its importance for the Nationalist government's "great rear base" (dahoufang) strategy and the province's crucial role during World War Two. Economically, too, some urban areas in Yunnan had become an important base for industrial relocation following Japanese invasions of much of the country's coastal and northern provinces (Summers 2013: 45). The Yunnan borderlands too, however, presented a key security challenge to early communist rule. Following the end of the civil war, a number of Nationalist (Guomindang, henceforth KMT) troops fled to northern Burma. There, with the support of Taiwan and (most likely) the CIA, they attempted a number of forays into Yunnan in the early 1950s, without success (Gibson and Chen 2011).

During the first few decades of communist rule, both Xinjiang and Yunnan saw the implementation of a number of similar policies: land distribution, ${ }^{17}$ state-sponsored Han migration to the region, and the creation of autonomous minority areas. Externally, however, in their relations with their neighbouring states, Xinjiang and Yunnan faced rather different challenges with tangible consequences for their border population. In Xinjiang, in particular, as part of the Sino-Soviet split, China and the Soviet Union increased border security through military presence and border infrastructure deemed to protect the nation's boundaries in case of an attack. ${ }^{18}$ Vast areas along Xinjiang's western borders with present-day Tajikistan and Kyrgyzstan were turned into a constellation of no man's lands, an empty (or indeed, emptied) cushion between the two rivals. In Yunnan, on the other hand, while cross-border ties were not formally encouraged, small-scale trade and a fair amount of cross-border mobility remained major characteristics of the border areas. Furthermore, in 1968, China facilitated and supported the Communist Party of Burma's (CPB) invasion of large sections of the northern borderlands of the country. In the subsequent two decades, men, weapons, and supplies flew across what had become an open border, between Yunnan and the "liberated areas" of northern Burma under CPB administration.

17 Land reform in Yunnan occurred in two distinct phases. In 1950, the province was divided into two areas, an inland zone and a frontier zone (bianyanqu). The frontier zone included areas mostly along Yunnan's international borders, where the native chieftain (tusi) system was still in place. While land reform in the inland zone was completed by $195^{2}$, it was postponed in the frontier zone in the wake of the minzu identification project (minzu shibie) and completed only in 1956. See Yang (1972: 253-4).

18 Chinese deployment of military forces in Xinjiang was modest compared to that of the Soviet Union. As Shichor (2004) argues, the PLA viewed Xinjiang as "strategic depth" that would slow down a Soviet attack, rather than a vital piece of national territory to be defended at all costs. This, according to Millward (2007: 295-8), might be one reason for Xinjiang's relatively "late" development. 
Ma Dazheng, one of China's most prominent scholars of borderlands and frontier issues, remarked that China's peripheries are, simultaneously, frontlines of national defence and key places for today's open-door policy. "Prior to the 1980s," he elaborated, "the frontier served only in the first capacity; since then in both" (Ma and Shan 2012: 68). This statement is only partially true for Xinjiang and Yunnan. While, as this book highlights, the particular duality between openness and closure is a main facet of today's borderlands, for Xinjiang and Yunnan the 199os were significantly more eventful than the beginning of the reform period in the $1980 \mathrm{os}$. The borderlands of Xinjiang, in particular, did not witness any major shift until the collapse of the Soviet Union, in 1991, and the consequent formation of Central Asian states. ${ }^{19}$ In Yunnan, on the other hand, the borderlands were largely caught in the Cold War rivalry between communist and Burmese army forces until the implosion of the CPB in 1989. In both cases, it was only in the early 1990s that the promises of mobility, trade, and investment embedded in Deng Xiaoping's reforms took concrete shape.

By then, China's western provinces were markedly poorer and less developed than the rest of the country. ${ }^{20}$ To counter this gap, in 1994 the Chinese government launched a first major poverty alleviation campaign (the "8-7 strategy"), which ended up focusing primarily on China's central and western regions. As part of it, subsidies in the forms of loans and grants were distributed to poor counties for a total of US $\$ 13.6$ billion, or $5^{-6}$ per cent of total government expenditures. ${ }^{21}$ Poverty alleviation campaigns were followed by strategies explicitly targeting the western regions, particularly in the ninth five-year plan (1996-2000) and, notoriously, with the launch of the "Open Up the West Campaign" (xibu da kaifa) in 1999 in conjunction

19 As James Millward puts it, "Xinjiang had been relegated to a status of strategic buffer zone and economic cul-de-sac since the rise of Sino-Soviet tensions in the late 1950 and 1960 . In the new international context [that followed the dissolution of the Soviet Union] Chinese leaders moved simultaneously both to open the region as a conduit to the rest of Eurasia and to integrate it more tightly with the rest of China" (2007:289).

20 Already in the course of a visit to Tibet in 1980, Hu Yaobang, the CCP General Secretary, called for major reforms in minority areas. Deng Xiaoping himself, during a visit to Xinjiang the following year, stressed the importance of raising the standards of living in frontier regions. Both calls, however, must be understood within the broader objective of curbing separatism through development, which would become a major feature of China's borderland policies in the post-reform era. Deng's remarks, in particular, were explicitly referring to this fundamental aspect of China's policies in minority regions (see Millward 2007: 278-9). For an overview of China's security concerns in Xinjiang in the 1990s, see Becquelin (2000).

21 Wang, Li, and Ren (2004). On the role of subsidies in China's development of its western regions, see Millward (2000); Fischer (2015). 
with the tenth five-year plan. The xibu da kaifa represents a significant turning point in the CCP's efforts to develop its western borderlands, not least because of the discursive attention that it projected on China's least developed, minority populated, and resource-rich frontiers. The motivations behind the programme were conspicuous. After twenty years of economic reforms, the gap between fast-growing coastal areas and poor and under-connected internal provinces was widening. ${ }^{22}$ In practice, as part of the xibu da kaifa, most investments were initially dedicated to developing transportation, energy, communication, and improving urban infrastructure in the western regions. Some large-scale projects stood out, such as the Qinghai-Tibet railway and the West-East natural gas transfer project, for a cumulative investment on infrastructure of one trillion RMB between 2000 and $2005 .{ }^{23}$

The xibu da kaifa was also characterised by a security component whose ideological roots can be found in the so-called "security-development nexus", i.e. the expectation that economic development will reduce insecurity in states and societies (cf. Duffield 2001). Border region underdevelopment, combined with the presence of sizeable ethnic minorities, has been viewed as a security risk since the inception of the PRC. Hence, state-led development agendas, like the xibu da kaifa, sought to pacify social unrest by encouraging local governments to boost economic growth through developing trans-boundary economic ties. ${ }^{24}$

The spate and scale of investment further accelerated in 2008 when, in order to cope with the negative impact of the global financial crisis on the Chinese economy, the central government announced a fiscal stimulus programme of four trillion RMB. The largest share of the stimulus package went into infrastructure projects, including public utilities and affordable housing in rural areas (Schüller and Schüler-Zhou 2009: 169). While not only focused on western provinces, this new stream of financial transfers, combined with ongoing development projects initiated as part of the xibu

22 As Jiang Zemin put it in March 1999 at the Ninth National Party Congress in Beijing: "The Western area is large, and comprises over the half of the whole of the state's territory. But the majority is in a state of underdevelopment or wilderness. The West [of China] must sooner or later be developed. Otherwise, how could we reach a modernization of the whole country? How could China become a strong economic state?" (Yan 2001: 1).

23 Démurger (2014). On the xibu da kaifa, see also Holbig (2004).

24 Jiang Zemin himself made this connection clear in 1999: "The minorities are quite concentrated in the West [of China], and it is also a border area. Hastening development of the West would preserve political and social stability. Therefore, promotion of national unity and safeguarding of border security is of great significance" (Yan 2001: 2). See also Clarke (2008). 
da kaifa, led to major constructions across the Chinese borderlands, from Xinjiang to Yunnan, the TAR to Inner Mongolia.

It is argued in this book that through such explicit forms of "giving" (Yeh 2013), the Chinese state discursively re-positioned its western borderlands from under-developed backwaters to spearheads of investments and connectivity. Consequently, although principally focused on internal development, the xibu da kaifa reverberated beyond China's borders and led to a number of initiatives aimed at enhancing cooperation between China and its border nations. In Yunnan, plans to connect China with India, Bangladesh, and Burma through a network of state-of-the-art infrastructure were drafted at a high-profile meeting at the Yunnan Academy of Social Sciences in August 1999. In Western China, similar efforts culminated in 2001 with the creation of the Shanghai Cooperation Organization (SCO) between China, Kazakhstan, Kyrgyzstan, Russia, Tajikistan, and Uzbekistan. In the "Declaration of the Shanghai Cooperation Organization" that resulted from the founding meeting of the group, the main focus was on the strategic value of the SCO and its implications for regional security. However, a general call for "multilateral cooperation" and "trade and investment facilitation" between the member states was also included. ${ }^{25}$

This discursive shift, in which the borderlands had become embedded in China's broader mission to open-up, is particularly evident if we consider the coincidence of the Open Up the West campaign with the "Going Out" strategy (zouchuqu zhanlüe), also launched in 1999 to encourage Chinese investments abroad. As Yeh and Wharton have argued, the two overlapping strategies, while rarely considered together, "can shed light on Chinese development approaches" (2016: 288) due to their multi-faceted intersections. In particular, they identify the centrality of physical infrastructure as a key element of the country's development trajectory both within its national boundaries as well as outside of them. "Whereas Western countries' development programs have moved from modernization to a series of other approaches including basic needs, structural adjustment, and later a focus on governance and social goals," they point out, "Chinese development has remained much more constant in its focus on assistance for infrastructure and production" (2016: 297) ${ }^{26}$

25 People's Daily (2001); see also Rippa (2017).

26 According to Yeh and Wharton (2016), this form of development is also characterised by the imposition of specific "models" upon both frontier landscapes and foreign investments - be it the urbanisation of the countryside or the omnipresent Special Economic Zone. Such models, they argue, are not fixed, rather lending themselves to manoeuvring and accommodation, yet 
If approached from within this perspective, China's latest - and most ambitious - global campaign, the Belt and Road Initiative, is sticking for its remarkable continuity with China's approach to development over the past two decades. Not unlike the xibu da kaifa and the Going Out strategy, the BRI "largely consolidates and elevates already existing ideas and practices" (Yeh and Wharton 2016: 308), although re-packaged and re-branded into a major foreign policy priority. Whilst such acts of branding should not be underestimated for the discursive power that they hold and produce, the BRI needs to be understood within this particular history. In this book, I approach the BRI as the culmination of a particular development trajectory, rather than as a stand-alone, brand-new strategy. As such, it is useful to take some of the effects of the xibu da kaifa as critical starting points to address BRI projects in Xinjiang and Yunnan. The xibu da kaifa initially did not succeed in the reduction of regional disparities between east and west, or in attracting foreign investment, despite the creation of a network of cross-border Special Economic Zones (SEZs) and ad hoc preferential policies. Indeed, subsidies and centre-to-province fiscal transfers were the main resources through which western development had been approached (Becquelin 2004; Fischer 2015; Grewal and Ahmed 2011, Yeh and Wharton 2016). What the xibu da kaifa did succeed in, however, was a number of unstated goals, namely resource extraction (Oakes 2004), rent distribution (Shih 2004), and the consolidation of state power in the peripheries (Goodman 2004; Yeh 2013) through an increased Chinese in-migration in minority areas and the selective distribution of resources (Becquelin 2004; Jeong 2015). These, in turn, resulted in increasing discontent among ethnic minorities, fuelling unrest in a number of border regions (cf. Fischer 2014; Bovingdon 2010).

Building upon this research, this book brings to the fore another effect of two decades of large-scale investment in infrastructure development in the borderlands: the marginalisation of local forms of cross-border trade as a result of increased control. In particular, by focusing on the borderlands of Xinjiang and Yunnan, I show how the changing infrastructural landscape led to a re-configuration of cross-border mobilities and minority subjectivities, as well as to new forms of regulations and technologies of surveillance. These, in turn, curbed the quantity and quality of pre-existing forms of transnational connectivity, displaced - both physically and culturally ethnic minorities, and ushered in new forms of exclusion amidst trading communities. 


\section{From refuge to the infrastructure frontier: Perspectives on (China's) borderlands}

There are a number of words in English that refer to the edges of a nation state, with scholarly discussions often distinguishing between frontier, borders, and borderlands, among others. ${ }^{27}$ As Stéphane Gros (2016:15) notices, in the East Asian context, "frontier" evokes two prominent figures that have written on the topic: Owen Lattimore and Edmund Leach. In his Inner Asian frontiers of China (1940), Lattimore makes the case for understanding the frontier as a dynamic zone through which cultures meet, move, merge, and collide. In Frontiers of Burma (1960), on the other hand, Leach discusses the inapplicability of the concepts of frontier, state, and nation as defined by contemporary political geography and essentially based on the "dogma of sovereignty" underpinning the nation state. Conceived of together, these two works reveal a conception of the frontiers as peculiar zones in which boundaries are inherently unstable, and the geography of the nation state rarely corresponds to that expressed by indigenous notions and political systems. Such seminal works also speak to a more current debate in the social sciences in which the notion of frontier has been revived in order to capture and understand a range of developmental processes at the intersection of resource extraction, state-making, and different forms of social power (Moore 2000; De Angelis 2004; Watts 2014, 2015). Within this literature, the frontier is generally regarded as a "relational space" (Barney 2009), which is to say a space actively produced through the interactions of different actors and institutions. Frontiers, in other words, are understood as mobile spaces - a "permanent prospect" (Watts 2014:193) - that create the ecological, social, and political conditions for hyperbolic forms of exploitation and accumulation. As Anna Tsing put it: "Frontiers are not just discovered at the edge; they are projects in making geographical and temporal experiences" (2003: 5100; see also Tsing 2005). Borders and borderlands, on the other hand, refer more directly to that most uncanny bequest of the modern nation state: the Westphalian border-as-line. ${ }^{28}$ While we have become accustomed to the ways in which lines define national boundaries on maps, their physical presence is elusive at best. Border lines can hardly be found,

27 And perhaps more so between borderworlds (Sadan 2013) and border zones. There have also been attempts to identify a typology of borderlands, in particular, see Baud and Van Schendel (1997). See also Paasi (2014).

28 For an introduction to the vast body of literature on the subject, see Wilson and Donnan $(1998 ; 2012)$. For a definition of these different terms, see also Baud and Van Schendel (1997). 
identified, and followed. Despite a recent resurgence of border walls to materially claim - and allegedly "defend" - the edges of our nations (Jones 2012), their material presence does not seem to affect most citizens of such nations, if not in the spectacle of televised politics. National borders remain, in other words, a somewhat mysterious creation, yet one that maintains a fundamental social function. ${ }^{29}$ In Chinese, bianjiang encompasses the definitions of both borderlands and frontiers. As such, the term indicates a liminal space of confluence and encounter, as well as the physical limit of the nation state. As a concept, it seems to acknowledge some of the key features of a borderland: a zone defined by the presence of a boundary yet extending well beyond the border-as-line that defines a nation state's claims to territorial sovereignty (Calanca and Wildt 2006; Lary 2007: $5^{-6}$; Wade 2000).

Scholarship in the social sciences has, in recent years, shown several attempts to reconcile the "temporal" dimension inherent to the notion of frontier with the more "spatial" approach underpinned by borders and borderlands in the study of the national edges of nation states. To do so, scholars have stressed the need to study the histories of particular borders, how they have come to be defined, enforced, and represented. ${ }^{30} \mathrm{~A}$ particularly fruitful approach is that of seeing national borders as examples of more general processes of $\mathrm{b} /$ ordering - and in so doing, to analyse the practices surrounding borders and border-making rather than focus on borders as stable political entities (Paasi 1999; Van Houtum and Van Naerssen 2002; Wilson and Donnan 2012: 17). In such a conceptualisation, borders are understood relationally, as a process - as Sarah Green (2012) put it, more a verb than a noun. Such approaches allow us to explore the complexity in both form and function of contemporary national borders, including their displacement and materialisation at places that, geographically at least, do not often coincide with the border-as-line drawn on maps. ${ }^{31}$

29 As Ishikawa puts it: "in theory the full sovereign power of the state extends to this imaginary line, and there it stops completely. In practice, the space around the border becomes a special field, a threshold that accommodates a series of social, economic and cultural flows from one national arena into another, a zone where things are no longer what they were, but not yet what they will be" (2010: 5).

30 Recent examples include Nick Megoran (2017) "biographical" approach and Madeleine Reeves's focus on "border work” (2014) in Central Asia, Sarah Green's (2005) work on marginality and gaps in the Balkans, and Franck Billé's (2017) writing on the subject.

31 My understanding of and approach to the national boundaries of China that represent the core topic of this book, is deeply influenced by this latter body of literature. As such, the distinctions sketched above between border, borderland, and frontier, are not to be understood as fixed and rigid. Nevertheless, I use border when referring to the national boundary of the 
In the context of China's - and Asia's, more broadly - borderlands, another approach to the study of frontier spaces has been particularly influential. In The Art of Not Being Governed, James Scott put forward a bold argument claiming that the hills and mountains of upland Southeast Asia served as the last of a series of escape zones to which people moved to in order to avoid incorporation into oppressive agricultural states and empires. Accordingly, a significant part of highland population consisted of people who had chosen not to be part of a state. Groups such as the Naga of today's northeast India, or the Wa of the China-Burma borderlands, had acquired cultural inventories that were appropriate to this end: forms of agriculture compatible with frequent movement, the ability to shift between multiple ethnicities, non-hierarchical religious systems, and so forth. Scott's thesis of self-chosen refuge has been met with much criticism from scholars with experience in the area, pointing out numerous flaws and imprecisions in his rendering of historical highland life and politics. ${ }^{32}$ Nevertheless, Scott's work brought to the fore a crucial dynamic that has often been over-sighted: that highland communities are not the survivals of primordial cultural forms and bearers of timeless traditions, but are rather integral to larger processes of geopolitical transformation throughout history. ${ }^{33}$

Scott's thesis explicitly concerns pre-World War Two history. He argues that upland Southeast Asia as well as other escape zones have all by now effectively been incorporated into nation states, thanks in particular to what, echoing David Harvey (1989), he calls "distance-demolishing technologies" such as railroads, all-weather roads, and telephone networks. In the following decades this process all but expanded, in both scale and speed. In the Chinese context, the years following the turn of the millennium in particular have seen a frenzy of transportation infrastructure projects in the borderlands. Thousands of kilometres of roads and railways were built or upgraded - some of them meant to tie peripheries more closely into the nation state and secure its "core interests," others with the dedicated purpose of fostering border trade. Together with new roads came checkpoints, dry ports, and customs facilities, all of them accompanied by rhetoric of progress,

state, the physical edge of national territory. Borderlands, on the other hand, refer to the areas in proximity to such line. With frontier, on the other hand, I refer to two distinct notions. First, I use frontier when discussing pre-nation state borders - particularly in the context of border disputes in imperial times. Secondly, frontier refers to particular processes of accumulation as described above.

32 See for instance Jonsson (2014) and Sadan (2010).

33 For a discussion of Scott's thesis applicability to other contexts, see the Special Issue of the Journal of Global History edited by Jean Michaud (2010). 
order, and security. Outside of China's borders, Chinese companies have contributed to numerous infrastructure projects in neighbouring countries, from Pakistan to Burma, and constructed thousands of kilometres of feeder roads penetrating ever deeper into the last remaining jungles of Southeast Asia to access resources and turn sleepy rural villages into investment opportunities for agribusinesses, logging, and mining. Moreover, plans for even bigger infrastructural projects are on the horizon, many of them in relation to the Belt and Road Initiative (Callahan 2016; Johnson 2016; Sidaway and Woon 2017). Infrastructure - some promised, some built - has captured the minds and dreams of a vast portion of borderland residents across and along China's borders. The pace at which infrastructure developments are currently reshaping livelihoods, opportunities, and ambitions is staggering. However, as several anthropologists of infrastructure have noted, roads, corridors, and SEZs seldom live up to the promise of mobility and prosperity on which they are built or planned (Larkin 2013; Nyíri and Breidenbach 2008; Campbell 2010; Dalakoglou and Harvey 2012; Harvey and Knox 2015; Rippa, Murton and Rest 2020). At times, they even end up becoming obstacles rather than conduits for development and connectivity (Walker 1999; Pedersen and Bunkenborg 2012; Demenge 2013). In other words, roads and corridors do not always "demolish distance" - they rather create nodes of legibility and state presence, but in the process, they also increase the remoteness and illegibility of border areas outside their immediate scope (Saxer and Andersson 2019; Rippa 2019b).

This book represents a departure from Scott's narrow interpretation of upland areas as historical refuge in favour of a general reflection on state authority, development, and infrastructure at China's borders today. In particular, building upon the literature on b/ordering mentioned above, I address the nexus of cross-border mobility and infrastructure development that defines China's borderlands in the 21st century. Infrastructure, in the Chinese context, is a shorthand for development. Infrastructure is both an index of development and the conditio sine qua non in its implementation. Development, on the other hand, is for the most part understood and performed through new infrastructure. Such infrastructure also represents a civilising machine: something that puts people, things, and the state into new relations (Gidwani 2008). The Chinese borderlands, in particular, have come to be defined by state-led efforts to "open up" or "integrate" them through infrastructural interventions. Fostered by programmes such as the xibu de kaifa, this infrastructure has radically reshaped livelihoods in most borderland areas across the country. Through such projects, as I show in this book, 
the Chinese state itself is encountered, enacted, and represented by those living in proximity to the borders.

In order to account for China's borderlands unique role and position, I structure the book around three key notions: proximity, curation, and corridor. Each notion speaks to a particular body of literature that is central to the study of borderlands, namely: mobility, state power, and exchange. Proximity, curation, and corridor do not represent novel concepts through which I am to capture particular ways in which space is made, state power deployed, and transnational exchanges carried out. Rather, they represent an attempt to come to terms with the processual, historical, and contingent nature of cross-border relations that I have discussed above. In so doing, they aim to guide the reader by providing analytical tools to view China's borderlands in their complexity and multiplicity. They are starting points for approaching the borderlands, rather than totalising frameworks that fully embrace them.

\section{Outline of the Book}

The book is divided into three parts, with each part built around two chapters, an interlude, and a coda. For each part, one chapter analyses a case from the Xinjiang borderlands and one from the Yunnan borderlands. The interlude and coda serve the main purposes of connecting the two cases and making a general argument about, respectively, proximity, curation, and corridor, while helping the reader to navigate between the two different geographical contexts. Each chapter, and indeed each of the three parts of the book can be read independently: while some of the people, places, and conceptual references return throughout the volume, each chapter makes a specific point. There is, nevertheless, a coherence to the whole book that suggests a linear reading - one that acclimatises the reader to the line of argument that is developed throughout the text.

The first part of the book - proximity - departs from the following realisation. While there is a "strong association between borders and stopping things from happening" (Green 2012:576), it is equally true that the friction created and performed by national borders can create possibilities for people to take advantage of particular economic differences by virtue of personal relations and skills. As I show, many such skills and networks are not new, they are rather rooted in long histories of cross-border exchanges that are often obscured by current understandings of globalisation. Proximity, in this regard, rather than referring to a purely spatial condition is 
defined as something that needs to be constantly made and remade. ${ }^{34}$ In the context of cross-border interactions, this notion is used to address the set of skills that allows for particular exchanges to occur, and businesses to thrive. Chapter 1 introduces the notion of proximity through an analysis of China-Pakistan cross-border trade along the Karakoram Highway (KKH). As proximity defines the geographical, cultural, and historical closeness that characterises (at least some) border regions on China's peripheries, my argument is that this particular closeness became an asset for many traders in the aftermath of China's opening up in the 1980s, 199os, and still well into the 2000s. By way of such proximity, I show how Pakistani traders from the northernmost parts of the country managed, in those years, to set up successful cross-border businesses. This Chapter traces the lives of some of these traders and discusses the content of their businesses, as well as the skills necessary to operate in such environment. The second chapter tells a similar story of cross-border connections from Western Yunnan. Situated at around 10okm from the Burmese border, the city of Tengchong has a long history as an administrative, military, and trading outpost. Following the fall of the Communist Party of Burma in 1989, and the opening of official border crossings with Burma, Tengchong traders with long-term experience and overseas family connections profited from dealings in jade, timber and, most recently, amber. This chapter in particular details the story of the trade in timber to show how the state is embedded in processes of proximity. By doing so, I also show the intertwined nature of private and public interests, and how the definition of particular border infrastructure was the result of private initiative, rather than government decision.

Part two of the book is structured around the notion of curation. Not intended as a reference to the work of museum curators, with this notion I seek an alternative to reductive dualisms such as hegemony-resistance and ideology-practice in the study of development projects at China's borderlands. Rather, by stressing the moral and aesthetic components of such projects, the notion of curation points to infrastructural interventions' attempts to change the material and social space in minority regions - and by so doing, re-make minority subjectivities. Chapter 3 begins with an analysis of another Yunnan border community, the Drung of the Dulong Valley, in the province's north-west. I introduce the notion of curation through an analysis of the impact of China's state-led programme, the "Building a New Socialist Countryside," according to which all inhabitants of the valley have been moved into newly built houses in larger settlements. I argue that the state, 
by defining the Drung as primitive, sees a particular form of development as a "healing" process through which ethnic minorities can be lifted out of poverty and into modernity. Furthermore, "curation" refers to the aesthetic components of such development projects, where villages, in order to be modern, need to look modern. In the Dulong Valley, however, promises of development attached to this particular resettlement project are yet to materialise. For most local inhabitants, in fact, the new houses and the forced abandonment of traditional forms of agriculture have led to increasing reliance on state subsidies. For the Drung people, modernisation brought more rather than less dependency. Chapter 4 returns the book to Xinjiang and touches upon issues of tourism, cultural production, and cultural dispossession through the case of the reconstruction of Kashgar's old town. This project, which was at its peak during my doctoral research in 2012-13, involves over 30,00o households and has completely remodelled Kashgar's cityscape. Most parts have been rebuilt in a neo-traditional style meant to preserve, or rather redefine, an atmosphere of authenticity - and thus to determine what it means to be Uyghur today. In this context, practices of curation capture a particular mode of ruling that the Chinese state employs in its minority-populated borderlands. It thus evokes yet another meaning of the word: that of "taking out", or "selecting." Elements of Uyghur-ness that are not akin to the government vision, such as the importance of Islam, are simply left out of the display of Uyghur culture showcased in the newly built Kashgar old town. As such, curational interventions are particular relations of power that are expressed in aesthetic values defining notions of heritage-making and based on market-driven interests as well as the state's attempt to enforce legibility and control.

Issues of legibility and control at the juncture of proximity and curation are at the core of Chapter 5 , which addresses one of China's most ambitious projects under the auspices of the Belt and Road Initiative: the China-Pakistan Economic Corridor (CPEC). This chapter argues that together with spectacular promises of development, CPEC brought a renewed attention to security in Xinjiang's far west. Moving from fieldwork among Uyghur migrants in Pakistan, I show that securitisation has been part of China's strategy since the early 2000s, and that it represents an integral element of Chinese-style development in the region and abroad. In the case of Xinjiang, securitisation has had an uneven impact among the local population, targeting in particular Muslim Uyghurs, for whom it became increasingly difficult to obtain passports and visas to travel abroad. Therefore, despite BRI claims of inclusiveness and win-win outcomes, the development of cross-border infrastructures has hindered local traders' ability to partake 
in cross-border businesses in which they previously thrived, as described in Chapter 1. In general, this third part looks at some of the consequences of the ongoing corridor-isation of trade through BRI-related projects, namely: increased security (Chapter 5 ) and the institutionalisation of illicit practices (Chapter 6). As I discuss in the interlude, I address "corridor" as both a conceptual tool to unpack how infrastructure can act as a technology of exclusion, as well as the material devices through which such marginalising dynamics unfold. Chapter 6 , in this regard, focuses on recent research with amber traders in Tengchong to show that economic corridors and Belt and Road fantasies, while undermining small-scale businesses by making a claim to legality and transparency, foster the integration of illicit practices by state authorities. The amber case in Tengchong is particularly compelling, showing how, in recent years, wealth derived from amber concentrated in fewer hands, while pushing small traders into illegal undertakings, or out of business altogether. In the process, however, the "illegality" of the business - based on unregulated imports of amber from Burma - persists. 


\section{Part 1}

\section{Proximity}

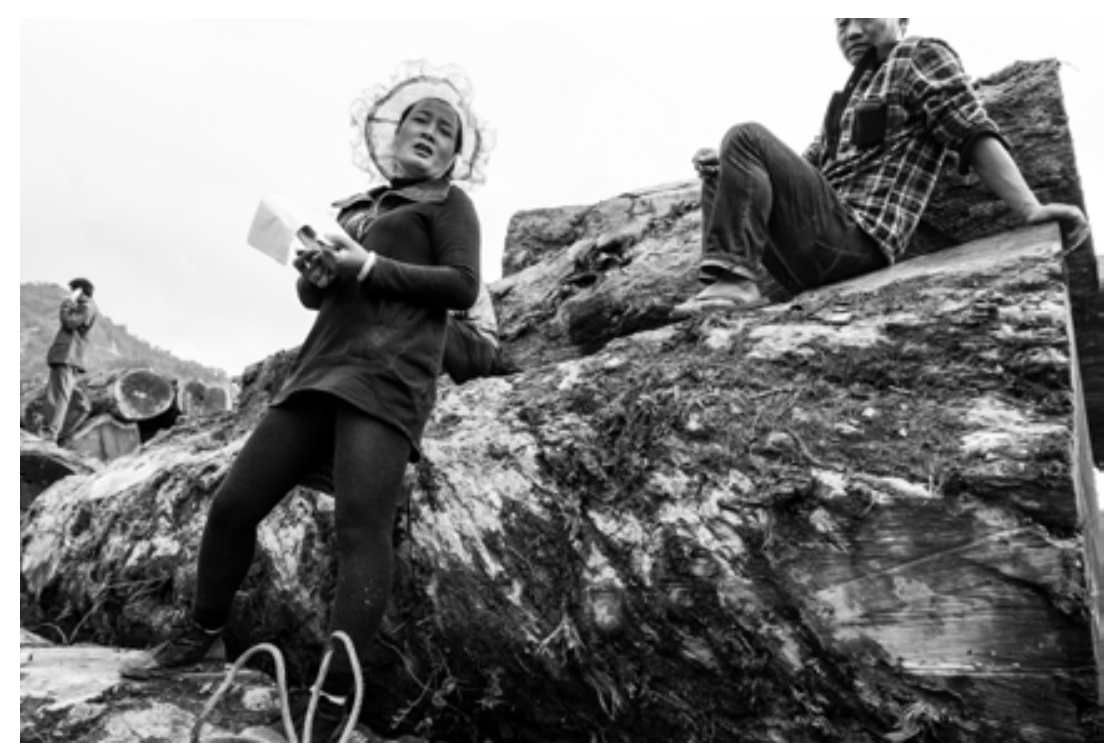

Figure 4: Chinese timber dealers at the China-Burma border (photo by the author, 2015) 



\section{Connections}

"China's hold upon her nomad population is of the slightest and, although a handful of men is maintained on the Pamirs at Tashkurgan, there is little sign of Chinese authority until one drops into the great plain of Central Asia, and finds at Kashgar a Chinese Taotai, a garrison, and a walled city on the regular Chinese

model, set in that green ribbon where the line of irrigation brings wealth and prosperity and the most luscious fruits to a dense Mohammedan population, on the very borders of the deserts of Takla Makan. Here we find the Chinese in their furthest outpost, their westernmost extremity, a position which they have lost and won time after time throughout the ages" — Archibald Rose (1912: 212-13)

"China's new "empire" will be an informal and largely economic one, posited on cash and held together by hard infrastructure" — Tom Miller (2017:17)

At the Kashgar Central \& South Asia Commodity Fair in 2013 an entire stand was dedicated to the new Kashgar Special Economic Zone. ${ }^{1}$ At the entrance of the stand, a large poster highlighted Kashgar's strategic position for crossborder trade. "Five ports (of entry) through eight countries, a road connecting Europe and Asia," the poster read, referring to the eight countries that share a border with Xinjiang and the five international ports of entry in Kashgar prefecture." According to a panel inside the stand, Kashgar was "China's great entryway to Central Asia, South Asia, the Middle East and even Europe." Beside it, another poster showed the vision for the city's new Finance and Trade district - a modern urban cluster with skyscrapers, highways, and green spaces on the shores of an artificial lake. Towering above all, a maxi-screen projected videos of Uyghur men and women dancing in traditional costumes, praising ethnic unity and Kashgar's world-famous cuisine. In the middle of the stand, two young hostesses explained the plans for the development of the Finance and Trade district while pointing at an impressive plastic model

1 Generally known simply as Kashi tequ 喀什特区.

2 Wu kou'an tong ba guo, yilu lian ouya 五口岸通八国, 一路连欧亚. The eight countries are India, Pakistan, Afghanistan, Tajikistan, Kyrgyzstan, Kazakhstan, Russia, and Mongolia; the five ports of entry are the Irkeshtam Pass (with Kyrgyzstan), the Torugart Pass (with Kyrgyzstan), the Kulma Pass (with Tajikistan), the Khunjerab Pass (with Pakistan) and Kashgar Airport. 
of the two "Development Twin Towers" - the main features of the ambitious project. They told me that the two towers were to be completed in three years, and with their 280 -metres they would be the tallest buildings in Xinjiang. "One of them will host the Kashgar Hilton Hotel," said one of the two girls, "while the second tower will provide space for high-end offices." Next to the towers, I was shown a model of a four-floor tax-free shopping mall, expected to open by the end of the year with brands such as Prada, Valentino, and Louis Vuitton. On the walls, more maps and posters showed Kashgar's favourable location in Eurasia, underlying its proximity to the various Central Asian capitals, as well as to Kabul, Islamabad, and Delhi. All of this, in the various panels, brochures, and presentations, was framed according to Kashgar's envisioned past, present, and future role as a major hub along the Silk Road.

For the first time, the 2013 instantiation of the Kashgar Central \& South Asia Commodity Fair was paired with another initiative: the "China Kashgar-Guangzhou Commodity Fair." This second fair was held in a different location, the Guangzhou New City, an exposition complex in the South-Western part of town, some 30 minutes by taxi from the main venue. Conveniently situated along the Karakoram Highway, the newly opened Guangzhou New City was envisioned to become a major trading hub for Pakistani and Tajik traders and companies - an entry point into the Chinese market. At the time of the fair, in fact, over 100 stands managed by Pakistani businessmen were located inside the Guangzhou New City and many traders were optimistic that the venue could turn into a major showcase for their products. I had met many of the traders over previous months of research, and some of them had shops in Tashkurgan - the last settlement before the Pakistani border some $300 \mathrm{~km}$ to the south of Kashgar, in a high mountain plateau. There, too, despite the remoteness of the small town, China had ambitious plans. Not long after the 2013 Kashgar Central \& South Asia Commodity Fair, in 2016, China began construction work on a massive China-Pakistan logistics complex in Tashkurgan as part as the China-Pakistan Economic Corridor (CPEC). The project would include "an Internet service administration center, a cross-border e-commerce enterprise incubator, and a modern warehousing and logistic center," in addition to an exhibition centre, hotels, and entertainment facilities (Xinhua 2016). The logistic centre, expected to cost three billion renminbi (US\$ 464 million), highlights China's commitment to investing in its border regions, fostering cross-border exchanges, and increasing its economic presence among neighbouring countries. For many Pakistani traders who were considering moving their business to Kashgar, Tashkurgan was soon to become not all that remote and isolated after all. 
Although the Kashgar SEZ and the CPEC have a history that precedes Xi Jinping's 2013 launch of the Belt and Road Initiative (BRI), both projects have now been subsumed in it. CPEC, in particular, is an ambitious project centred around a series of energy and infrastructure projects totalling upwards of US $\$ 62$ billion in grants and soft loans, which now features as one of the BRI's main economic corridors. It includes a major deep-water port and Special Economic Zone in Gwadar, on the coast of the Indian Ocean, as well as dams, roads, fibre optic cables, and a light railway in Lahore. While the financial feasibility of the project and the terms of the various contracts have been repeatedly questioned (cf. Fair 2017), Pakistan's previous government, led by Nawaz Sharif's Pakistan Muslim League-Nawaz (PML-N), had been a vocal supporter of the CPEC. Despite a campaign based on change and on the promise of fighting corruption at the highest levels, the current (2020) Pakistani government, led by cricketer-turned-politician Imran Khan, has shown support for the China-led initiative since its installation. In the course of his victory speech, Imran Khan stressed his desire to have good relations with China, defining CPEC as a "huge opportunity" to contribute to his larger goal of eradicating poverty (Al Jazeera News 2018a). Similar praises can be heard by politicians and investors in Gilgit-Baltistan, where CPEC has become a regular topic of discussion. Expectations run high.

Direct experience of cross-border trading practices along the $\mathrm{KKH}$, however, offers a sobering counter-narrative to the lofty promises embedded in projects such as CPEC. At the time of my primary period of fieldwork, for instance, between 2012 and 2013, the road on the Pakistani side was interrupted by a landslide that, in January 2010, caused the damming of the Hunza River near the village of Attabad and the formation of a $30 \mathrm{~km}-\mathrm{long}$ lake over the Highway. Following the disaster, lacking government support, local traders doing business with China established a boat service that reconnected, albeit at a particularly high cost, Gojal - the area north of the lake - with the rest of Pakistan (Sökefeld 2012). The reconstruction of the road around the lake was completed only in 2015 by the China Road and Bridge Corporation, a State-Owned Enterprise (SOE) that is responsible for many construction projects abroad. In the summer and fall of 2013, then, while Xi Jinping was launching his Belt and Road Initiative through two speeches in Kazakhstan and Indonesia and expectations connected with the CPEC reached their apex, traders along the Karakoram Highway were still loading and unloading their goods into wooden boats. Together, we conjured up dreams of frictionless corridors while slowing crossing the blue waters of the newly formed lake, in the company of local farmers, shepherds, and goats heading south after a summer in the high pastures of Gojal. Two 
worlds that could hardly be more radically apart, seemed, for a moment in time, intertwined in a common destiny.

Recent anthropological literature compellingly shows that infrastructures, as indexes of modernity and development, seem to possess the ability to trigger expectations even in spite of their recurrent failures (Anand, Gupta, and Appel 2018; Harvey, Jensen, and Morita 2017). Roads, in particular, can be seen as a priori failures: they never entirely fulfil the promises and expectations inscribed onto and into them (Harvey and Knox 2015). In order to understand how these promises are negotiated at the local level, Harvey and Knox (2012) apply the notion of "enchantment." They suggest that regular encounters with dereliction and abandonment, for instance, rather than diminishing people's faith in the positive impact of infrastructural projects, or in the government's ability to deliver them, "strengthens the desire for them and constantly renews the sense that sometime soon they will appear and life will change for the better" (534). The case of the Attabad landslide is emblematic of infrastructure's capacity to "enchant." During my research and travels along the KKH, the possibility of closure - whether due to landslides, snowstorms, strikes, or demonstrations - was ever-present. In discussions with traders, however, the persistence and recurrence of such obstacles was often overlooked in lieu of generous assessments of the potential of the highway as a transnational and trans-continental artery of exchange. How should we understand the role that fears and expectations play among cross-border traders? How can we disentangle the apparent paradox of recurring failures and growing expectations so pervasive when it comes to the KKH and CPEC? At first, I simply tried to ask these questions to the traders I was spending time with, while browsing products in a bazaar, waiting for customers behind a shop's counter, sipping sweet chai, or over warm plates of laghmen (a noodle dish common across Central Asia and a highlight of Uyghur cuisine). Their answers brought little insight, besides a distinct familiarity with unpredictable events. "Landslides are part of the business here," one driver told me just outside of Karimabad, in the Hunza Valley. Or as Monib, a trader from Rawalpindi who has been living in Urumqi for 15 years once phrased it: "maybe you are surprised, but it's normal for me, sometimes it takes two weeks [to get a truck to Islamabad], sometimes three, it doesn't matter." Raj, a Pashtun trader in Yiwu, used a more concrete set of images to picture the unpredictabilities that shipping goods via the KKH entails: "If you know the area, you know that the road goes through the biggest mountains in the world. It is not safe, there is always a problem. Now there is the [Attabad] lake, then maybe a landslide, then maybe a glacier will come down and there is nothing you can do. You don't know what will happen next." 
What should we make of this? In the remaining part of this chapter, instead of questioning the nature of such obstacles, I follow traders as they conduct their businesses. The questions, suddenly, become more practical: how do traders navigate obstacles? When facing a disaster such as the Attabad landslide, who continues trading with China, and who moves onto different businesses? How does a changing regulatory landscape impact small-scale cross-border trade at China's peripheries? Through such questions, this chapter brings to light a tension that, I argue, is characteristic of the Chinese borderlands at this particular moment in time: between future-oriented, state-led visions of connectivity and already existing connections that are rooted in the history of the borderlands. At the Kashgar Central \& South Asia Commodity Fair, such future-oriented visions were tightly rooted in a Silk Road imaginary supposed to give them historical resonance. Yet, the Silk Road imagined by authorities in Beijing, Urumqi, or Islamabad, connecting the extremes of Eurasia through broad and sweeping arrows, has little to do with the history of trade across China's borders. There, a combination of local practices, kinship relations, and the ability to navigate specific cultural, institutional, and physical landscapes mark the conditions of possibility for such connections to take place. This apparent contradiction between two different visions of transnational exchange underpins a tension that this chapter aims to explore, between two different and largely incompatible understandings of "connectivity." In particular, in the first part of this book I describe some of the existing practices of connectivity - embedded in what I call proximity - that define cross-border relations across China's vast and variegated borderlands. Such existing networks, I argue, are largely ignored by the current ideology of trans-continental connection embedded in China's plans for CPEC, or the Belt and Road Initiative more generally. I show, however, how the state is complicit in the existence and maintenance of such networks, while at the same disrupting some of these practices through its recent push for trans-border infrastructure development.

It is in the town of Tashkurgan, remote yet central to such visions of transnational connectivity, that I begin this discussion.

\section{A remote border town at the centre of the Silk Road}

One never has to look far to find scenes of change in China. Stories of consummate transformation have become a rather common trope, even among those who have never set foot in the People's Republic. Thus, Shenzhen, we 
are repeatedly told, the country's most famous and successful Special Economic Zone, went from being a fishing village to a fast-growing megalopolis of over ten million people in little more than three decades. The country's high-speed railway network, introduced in 2007, grew to consist of over 25,000 km of tracks in 2017. Overall, China poured more cement between 2011 and 2013 than the United States did in the entire 2oth century (Swanson 2015). The figures, as is so often the case in China, are overwhelming. They are on a scale that is, at times, impossible to grasp. They are also misleading, as they draw a totalising picture, one that suggests even-ness and fairness. In so doing, they reveal as much as they hide - the different speeds at which development occurs, and the frictions that it constantly generates.

Far from the skyscrapers of Shenzhen, at over 3500 metres in the Pamir mountains, a small border town tells a different story - another side to the much celebrated (and debated) "Chinese century." This contrast could have not been more striking than during my first visit to Tashkurgan, in the summer of 2009. Less than a year earlier, China celebrated the Beijing Olympics, an event that projected an image of modernity and wealth onto TV screens and newspapers around the globe. And yet, while walking around Tashkurgan what caught my attention was old loudspeakers. They were placed along the main roads and on the few intersections and squares the little town had to offer, broadcasting every evening two hours of propaganda about ethnic unity, the leading role of the CCP, and revolutionary songs in Mandarin that most local Tajik ${ }^{3}$ could not even understand. By 2012, at the start of my doctoral fieldwork, the loudspeakers were gone, and the town had undergone radical development. A construction frenzy brought new apartment blocks, hotels, model socialist villages, and a number of tourist attractions that apparently remained unused. The port of entry for the Khunjerab Pass, where immigration and customs operations for Pakistan take place, had moved into a newer and much larger building. ${ }^{4}$ The presence of the state, though not audible through loudspeakers, nevertheless remained strong and visible. Not only in the monumentality of infrastructure, but also

3 The meaning of the term "Tajik" significantly differs in the Chinese context from that in neighbouring countries. Within China, the Tajik minority group (shaoshu minzu) is composed of all speakers of Iranian languages who belong to the Ismaili denomination. Two groups are counted here: Wakhi and Sariqoli (Kreutzmann 2015: 384). For an overview of how the term "Tajik" became used in the region, see Saidula (2014: 16-2o).

4 Following the inauguration of the Karakoram Highway between Gilgit and Kashgar in 1982, the settlement of Pirali (over 8okm south of Tashkurgan) became the Chinese customs and immigration station for Pakistan. The checkpoint was shifted to Tashkurgan in 1992 (for more details on the area, see Kreutzmann 2015). 
in the obvious markers scattered around town. Chinese flags adorned each lamppost along the Karakoram Highway. Large posters praised ethnic unity and the role of the Party in the development of Tashkurgan. A small electric car with six to eight heavily armed soldiers patrolled the town throughout the day. The ubiquitous presence of the state was also a constant object of conversation among those living in the small town. A Uyghur shopkeeper whom I visited each day when I was in town, warned me once: "be careful, everyone in Tashkurgan works for the government (zhengfu). Whatever you do, it will be reported." Or, as a Pakistani trader who frequently visited Tashkurgan put it while walking down the town's main road: "Everybody here talks to the police, answers questions. I have a cousin who was born here, he's Tajik [Chinese], he always tells the police about our movements, the people we see, who is visiting us." The state, whether through infrastructure, policing, or rumours, seems to be everywhere in Tashkurgan. It is embodied by every single inhabitant of the remote town: "everyone in Tashkurgan works for the government." The state's presence, however, is at the same time indirect: though it functions as a threat it can be approached only at particular places and times. It is pervasive yet elusive, staggering in its material presence, yet intangible. While conjured up as powerful and omnipresent, the state remains fugacious and deceptive, particularly when one is attempting to locate it ethnographically.

Such puzzling contradictions have contributed to making "the state" a much-discussed object of analysis across the social sciences. In anthropology, the most recent work on the subject has generally been influenced by the writings of Michel Foucault on the topic of power. For Foucault, power is not something that can be held by particular individuals or institutions. Rather, power is a relation and an effect of particular disciplinary techniques, the ordering of space, hierarchical structures, and embodied knowledge. Power, as such, produces subjectivities - a theme that will be at the centre of the second part of this book. In China, as elsewhere, Foucault's writings led to a critique of the idea that state and society are distinct entities (Ferguson and Gupta 2002). For instance, anthropologist Frank Pieke powerfully argued against the idea of a state-society dichotomy in China, proposing instead to view the state itself as society (2004). In order to do so, he suggests that the state should be addressed according to the ways in which it is "discursively and practically constructed" (518) at the local level, accounting for "the complex interaction between higher-level policies, existing institutional arrangements, and the informal relations between current and aspiring holders of posts at various bureaucratic levels" (533). Moving from a similar set of questions in her analysis of a road in Peru, anthropologist Penny 
Harvey understands the state as an effect: something that, "given the way in which the state is entangled in mundane sociality" can be approached only "tangentially" through its material manifestations (Harvey 2005: 138). Both Pieke and Harvey, in other words, locate the state in situated practices, knowledge, and materialities through which it can be "ethnographically" approached. Also making this point clearly are Rasanayagam, Beyer, and Reeves in their introduction to an edited volume on Central Asian politics (2014), in which they claim that their main interest is not in the question of "what does the state do?," but rather in the question of "how is the state being done?" A focus on how, they argue, "allows for a multiplicity of action and interpretation, and it takes seriously the capacities for reflection of our informants," thus emphasising "contingency, ambiguity, and indeterminacy" (11). This book builds upon this literature, yet in approaching the state it pays particular attention to its concrete materialisation in specific places and at particular times. To this end, the question of the how of the state as brought to the fore by Rasanayagam, Beyer, and Reeves is integrated with the questions of the where and the when of the state. If, in fact, the state is understood as socially embedded - thus making it accessible to ethnographic inquiry - the question of the state's materialisation is both a spatial and temporal one. Such dimensions highlight a crucial element of the ways in which the state operates: its ability to appear and retreat at particular places and times (customs offices, checkpoints, police inspections, and so on). This dimension, as I show in this chapter through an analysis of the lives of cross-border traders along the $\mathrm{KKH}$, is a core characteristic of the state's "contingency, ambiguity, and indeterminacy," and plays a fundamental role in the ways it is experienced and understood.

The borderlands are a particularly compelling place from which to observe the state. As junctures and points of friction, borderlands offer a particular perspective on the complexities of contemporary global development - one that arrives not from the centres or necessarily from below, but rather from multiple edges, corners, and peripheries. Borders are not only key sites where social actors come to imagine state sovereignty in both its regulatory and its territorial dimensions. Borders are also always "under construction" fundamental sites of "on-going negotiation between society and the state" (Chalfin 2001). Despite its remoteness, harsh weather, limited size, and resources, Tashkurgan is at the forefront of the party-state's plans for the economic integration of Pakistan and Central Asia. It is thus an apposite place from which to analyse how the relations outlined above play out. In particular, my questions in this chapter revolve around the relationship between the party-state's vision for the development of its borderlands and 
local forms of connectivity that often emerge from two different sets of temporalities. As shall become clear, current imaginaries of transnational connectivity promoted by Chinese authorities are often at odds with local understanding of the history of the area. It is in these moments of friction, and the different discourses within which such narratives are embedded, that the border is continuously enacted and re-constructed.

The history of Tashkurgan presents a fascinating case from which to observe how such competing visions emerge. From being a sleepy administrative outpost, the small town has over recent decades become one of China's envisioned trade hubs, and the target of much investment. Tashkurgan's location, authorities reason, represents its main asset: the perfect gateway for China's growing investments in the region. In the eyes of many, the history of the region, if nothing else, proves this argument to be correct. Tashkurgan (which can be translated as "stone fort" or "stone tower") has often been identified with the "Stone tower" described by Ptolemy in his treatise on cartography: a major node of exchange between East and West along what German geographer Ferdinand von Richthofen called, in 1877, the Silk Road.

In today's Tashkurgan, the Silk Road features prominently on posters and investment brochures. At the same time, and for different purposes, the Silk Road has become a major subject of discussion among social scientists and historians alike. A major concern of this body of literature has become that of debunking established assumptions and myths. ${ }^{5}$ The Silk Road, historians tell us, was not really about silk - and nor was it much of a road. Rather, as James Millward (2013:6) recently argued, "there were many things traded and many ideas transmitted across Eurasia, some of which (the domesticated horse, cotton, paper, and gunpowder) had a far greater impact than silk." Furthermore, rather than a single road connecting East and West, historians have come to think of the Silk Road more as a network of routes linking many entrepôts across Eurasia. The Silk Road as it is imagined today, then, is little more than a recent invention: one animated by ideals of globalised exchange and one that serves as a "geopolitical chronotope, that is, a condition or strategy for geopolitical thought and action" (Chin 2013: 195). Today, places like Tashkurgan offer a stark example of how such collective imagination can mobilise political and economic capital. As this

5 See also Rezakhani (2010), who argues that historians should "do away" with the concept of the "Silk Road" altogether, as "the concept of a continuous, purpose-driven road or even "routes" is counterproductive in the study of world history" and "it has no basis in historical reality of records" (420). 
book will show, China's peripheries seem to be animated by a Silk Road fever promising investment and opportunities. If the old Silk Road represents China's entry into a world history made of "open" empires (Hansen 2012), the new Silk Road envisioned by the current leadership is meant to re-claim the country's primary position on a global scale. Instead of being peripheral outposts meant to guard the national territory from foreign threats, places like Tashkurgan thus assume a new centrality as spearheads of development and foreign investments (Rippa 2017, 2020).

The history of Tashkurgan, and of the area known as Sariqol (also Sarikul, Sarikol) of which it is part, while not quite as glorious and romantic as the Silk Road imaginaries might have it, testifies to several phases in which the remote valley played a role in long distance exchanges - although not always of the economic kind. ${ }^{6}$ In the 16th and 17 th century, for instance, following imperial expansions across Eurasia, the issue of new trading routes across the region became of central importance to officials in Beijing, Saint Petersburg, and London. One such route connected today's Xinjiang with Ladakh, and had its main hubs in Yarkand and Leh, respectively. From there, other routes went as far as Kashgar, Central Asia, Lahore, and Peshawar (Kreutzmann 1998; Rizvi 1996; 1999; Warikoo 1996). Until the 1930s, the main artery of this trans-Karakoram trade was via the Karakoram Pass, today the (sealed) border between India and the PRC. Tashkurgan and the Hunza Valley, further to the west, played only a minor role, and the Khunjerab Pass was rarely used for trading purposes. The settlement of Tashkurgan, in particular, was described by travellers who visited it between the end of the 19th and the beginning of the 2oth century, as a rather remote military outpost with little economic significance. ${ }^{7}$ Tashkurgan

6 Archaeological evidences show the presence of a very mobile population on the high plateaus from at least the 1st millennia BC. Objects unearthed across complex grave sites demonstrate long-distance interactions (Wang et al. 2016), as well as established trading relations with the population of the Tarim basin, in today's southern Xinjiang (Di Cosmo 1996; Mallory and Mair, 2000: 220; Barber 1999: 33-34).

7 Aurel Stein, who visited Tashkurgan in 1900, describes it with the following words: "A line of massive but crumbling stone walls crowns the edges of a quadrangular plateau of conglomerate cliffs, roughly one-third of a mile in length on each of its faces. A small portion of the area thus enclosed, on the east side facing the river, is occupied by the Chinese fort. Its high and carefully plastered walls of sun-dried bricks stand undoubtedly on far more ancient foundations. Outside them now all is silence and desolation. The rubble-built dwellings, whose ruins fill part of the area, were tenanted as long as the insecure condition of the valley made it impossible for the scanty cultivators to live near their fields. Since peace has come to Sarikol new villages have sprung up near all the cultivated patches of land, and the stronghold has become deserted" (Stein 1904: 68-9). 
was, however, a point of strategic interest for the British government, which installed a representative in the small town whose main responsibility was to collect information and ensure the safe passage of mail between India and the British consulate in Kashgar. Reports show concerns on the Chinese side regarding this presence, as well as the ongoing issue of cross-border smuggling in the area. Facing numerous insurrections within its own border, the nationalist government in Urumqi saw British interference as a possible cause of unrest, and the porosity of a border without defence as a major liability (Dillon 2014: 106-116). Attempts to reform the border guards and enforce a stricter border regime were hampered by a lack of resources and in-fights within the ranks of the Chinese administration - as well as by Tashkurgan's remoteness and the harsh terrain that characterise the area making it difficult to monitor and control.

In the aftermath of the communist so-called liberation of Xinjiang, the Tashkurgan Tajik Autonomous County was founded in 1954, before the establishment of the Xinjiang Uyghur Autonomous Region in $1955{ }^{8}$ Following the first census of the People's Republic of China (PRC), carried out in late 1953 and early 1954, and the completion of China's "Ethnic Classification Project," or minzu shibie, a project deemed to determine the precise ethno-national composition of the country, two groups were identified as permanently inhabiting the Chinese Pamirs: Kyrgyz (Ke'erkezi $z u$ ) and Tajik (Tajike $z u$ ). The Kyrgyz, according to this classification, are Sunni Muslims, speak their own language, and are pastoralists. Tajik, on the other hand, is a generic classification for all Ismaili and Pamirian speakers

8 The official version of the history of this period is, unsurprisingly, one of outstanding achievements: "In 1954, the Taxkorgan [Tashkurgan] Tajik Autonomous County was founded on the basis of the former Puli Count where the Tajik nationality lived in compact communities. [...] There was no factory or workshop in Taxkorgan before liberation, and even horseshoes had come from other places. Now more than 10 small factories and handicraft workshops have been built, such as farm and animal husbandry machine factories, hydroelectric power stations and fur-processing mills. Mechanization of farming and animal husbandry has expanded. Veterinary stations have been built in most communities. Tajiks have been trained as veterinarians and agrotechnicians. Tractors are being used in more than half of the land in the county. One breed of sheep developed by the Tajik herdsmen is among the best in Xinjiang [...]. In the town of Taxkorgan, the county seat, which is perched right on top of the Pamirs, wide streets link shops, the hospital, schools, the post office, bank, bookstore, meteorological station and other new buildings in traditional architectural style and factories under construction. Great changes have also taken place in many mountain hamlets, where shops and clinics have been built. The herdsmen and peasants are enjoying good health with the improvement of living conditions and medical care. Since 1959, schools have been set up in all villages, and roaming tent schools have been run for herdsmen's children. Many young Tajiks have been trained as workers, technicians, doctors and teachers" (quoted in Kreutzmann 2015: 392-3). 
in China. Tashkurgan, in this phase, became the administrative centre for the scattered population of the county, as well as its main supply point. With the nearby borders with Pakistan and Afghanistan closed for trade, Tashkurgan's development became strictly intertwined with the PRC's internal policy of collectivisation. In particular, as geographer Hermann Kreutzmann has documented in a number of studies (cf. 2012, 2015), the main outcomes of autonomy and minority policies in the Chinese Pamirs were the sedentarisation of nomads in permanent winter quarters. These processes of integration of the remote county within the emerging national economy experienced a sharp boost in 1958 with the inauguration of the road connection to Kashgar. The construction of the road was celebrated by Chinese authorities in the following way:

Taxkorgan [Tashkurgan] was a backward, out-of-the-way area before liberation, when it would take a fortnight by riding a camel or a week on horseback to reach Kashi [Kashgar], the biggest city in southern Xinjiang. In 1958, the Kashi-Taxkorgan Highway was completed, shortening the trip between the two places to one day (quoted in Kreutzmann 2015:395).

The county's main output was identified in this period as livestock production, and although Tashkurgan never became self-sufficient in terms of food supply, overall agricultural output seemed to have grown over the years. As in many other border contexts, state subsidies filled the gap, and indeed continue to play an important role today. ${ }^{9}$

With the reform period, outposts such as Tashkurgan took on a new role. Not just as supply hubs and peripheral army posts, but also as the bridgehead for new schemes of transnational connectivities. The 1980s, in particular, was a period of great change, in Tashkurgan as much as anywhere else in the country. First, in line with Deng Xiaoping's "four modernisations (si hua)," agricultural enterprises became increasingly commercialised, with significant parts of the population moving into service industries. Secondly, with the inauguration of the Karakoram Highway in 1982, new

9 The story of a remote outpost becoming a major supply hub is not uncommon in the highlands of Asia. Across the border with Tajikistan, only a few dozen kilometres away from Tashkurgan, during Soviet times marginal settlements such as Khorog and Murghab became central nodes to the system of "Moscow provisioning" (moskovskoe obespechenie) (Saxer 2016b: 124; Reeves 2014, 110-122). Not unlike in the People's Republic of China, roads and airports were built in the most unlikely of places. Unlike China, however, with the collapse of the Soviet Union this system of provisioning came to an end, quickly leading to new forms of exclusion and remoteness (Mostowlansky 2017). 
opportunities arose for cross-border activities. In 1992, the customs and immigration station was moved to Tashkurgan, transforming it from an administrative outpost to a gateway for cross-border exchanges, including trade, tourism, and migration. Hotels, restaurants, and shops opened within town, and the population grew as businessmen and government officials moved there. The implementation of the "Open Up the West Campaign (xibu da kaifa)" in the early 2000 brought a new spate of investments to the remote county. A major dam was built - the Xiabandi Water Control Project - north of Tashkurgan between 2001 and 2006, and the Karakoram Highway went through a significant makeover that was completed, on the Chinese side, in 2008. In the last decade, moreover, tourism has become a major target of investment in the county. In this period, a new museum was opened in Tashkurgan, an ethnic village was constructed in the northern part of town, the old fort renovated, and a complex system of walkways built on the riverbed wetlands, all with the aim of increasing tourist numbers.

\section{"What's more convenient?"}

The history I have outlined above is in no way lost on those who are trying to make a living out of cross-border trade in Tashkurgan. In 2013, during one of several trips to Tashkurgan over the course of my fieldwork, I was walking up the settlement's main road - Tashkurgan Road - planning to visit one of the traders in his shop. The cold winds were making my teeth chatter, as rain mixed with snow clung to my nose. It was already the end of May, the China-Pakistan border had only recently re-opened after the annual winter closure, yet on this high plateau the weather remained stubbornly unpredictable. For the previous two days, the Khunjerab Pass, at over 4600 metres, was shut due to a snowstorm, while a landslide in the Gez canyon had blocked all traffic into and out of Kashgar. At least, that was the story I had been hearing from the traders and truck drivers who were idly chatting and smoking around the town's small bus station. As I entered his shop, I found Karim sitting behind the main counter, shivering in his heavy coat, only his eyes turning from his computer towards me. "Pretty cold, isn't it?" he said as he pointed to a chair so that I could sit beside him. He was watching something on youku, one of China's largest video streaming websites, and I sat down next to him as I had done on several other occasions in the previous months. Karim was in his mid-2os when I first met him, in 2012. Tall and stout, with voluminous, curly black hair, thick eyebrows and a wide forehead, he went mostly unnoticed in Tashkurgan 
where he was often mistaken for a local Tajik. In Kashgar, however, Karim was clearly identified as a foreigner. At the time, he had a wife and young daughter in Pakistan (they would have a second child a few years later), yet his business kept him away from his family for a large part of the year. He was from Gojal, in the upper Hunza Valley, only a few hours' drive from the Khunjerab Pass and the Chinese border. Karim was Ismaili and his mother tongue, Wakhi, was shared by many Tajiks living in Tashkurgan, among whom he has a few relatives. ${ }^{10}$ It was in Tashkurgan that, nineteen years before, Karim's father and uncle started their business. According to Karim, they were the first Pakistanis to buy a property there: a two-storey house that they still use as a shop, warehouse, and domicile. Ten years ago, Karim's father opened another shop in Kashgar, near the Idgah mosque, which had been moved only a few months before our first encounter in a new shopping centre for jade and other semi-precious stones not far from Kashgar's People Square, in a new part of town. In 2016, they would open another shop in one of the main shopping streets of Kashgar's old town. Karim, who has a degree in software engineering, had been working with his father since 2010, and when I met him for the first time, he was in the process of designing the company's website.

Karim's business was a family enterprise and the two shops in Tashkurgan and Kashgar are managed by a number of his brothers and cousins. They mostly access China using the "Pak-China border pass," generally referred to simply as "border pass," a travel document that allows residents of Gilgit-Baltistan to make an unlimited number of annual visits to China, so long as they travel through the Khunjerab Pass and do not stay in the country for more than thirty days. Karim's relatives make use of their frequent trips across the border to take some goods with them, as everything carried in luggage is "tax free." Larger items, however, are typically sent in a single container and divided between the Kashgar and Tashkurgan shops. In China, they sell various handicrafts, mostly made out of marble and brass, but they also have an interesting selection of precious and semi-precious stones and carved wooden pieces. In the Tashkurgan shop, they also sell imported soaps, perfumes, and other health and beauty products. It is a "one-way business," Karim would often say, as most of the goods come either from Gilgit-Baltistan or Karachi - but he does not make it his business to

10 Most Tajiks in Tashkurgan speak Sariqoli, while about only a third speak Wakhi. Both languages are branches of eastern Iranian languages that, within Tajikistan, are simply known as "Pamiri languages" (for a recent, and rare, ethnography of Tashkurgan's Tajiks see Saidula (2014)). 
export Chinese goods to Pakistan. Some stones - such as the famous lapis lazuli from Badakhshan - are imported from Afghanistan and taken to Xinjiang via the Karakoram Highway.

The first time Karim and I met, he was working in the Kashgar shop. The following year he moved to the Tashkurgan shop, and as I visited him there, he would regularly complain about how boring the small border town was. Kashgar, on the other hand, was different, and he later spent part of the winter studying Mandarin in Islamabad with the purpose of returning there on a more regular basis. When I met him in Pakistan in early 2013, China was often part of our conversations. "China is our future," he told me once as we were speeding up Islamabad's Margalla hills in his cousin's jeep, "I think people in Hunza should study Chinese." He even told me that he was trying to teach his wife and mother back home how to use chopsticks. As he put it once: "for us, it takes two days to go to Islamabad, the capital of Pakistan. But if I leave my home in the morning, I can be in Kashgar in the evening. What's more convenient?"

That day, by the time I had warmed up my legs next to the electric stove in Karim's shop, the weather had cleared up, and the sun was peeking tentatively through the thick clouds. With no customers in sight, I suggested going out for a little walk, and Karim seemed happy at the idea of leaving the shop for a couple of hours. Despite having spent considerable time in Tashkurgan, I realised that Karim had never had a chance to visit the fort, which was possibly the town's main tourist attraction (Figure 5). We quickly headed there and as we approached it, I noticed that since the time of my previous visit a new, small structure had been built beside the steps leading up to the ruins of the fort. What turned out to be a ticket office seemed initially deserted, yet as we walked beyond it a voice called us back. A girl, seemingly busy sweeping the concrete floor on the back of the ticket office, asked us (in Mandarin) to pay the $30 \mathrm{RMB}$ entrance fee. As I reached for my wallet Karim began to talk to her in Wakhi - which I could not understand a word of. After a few moments, he turned towards me and told me that we did not have to pay any entrance fee. "We are Wakhi, we are all related here", Karim pointed out, "there is no need to pay," he added with a smile.

The ruins of the Tashkurgan fort ${ }^{11}$ rest on a rocky hill overlooking the wide meadows of the Taghdumbash River. What once must have been massive stone walls crowned the edges of the hill, giving shape to a quadrangular structure. On two of the four sides, the stone walls had been recently

11 The ruins of the fort were used for the shooting of some crucial scenes of the film The Kite Runner, from the novel by Khaled Hosseini. 


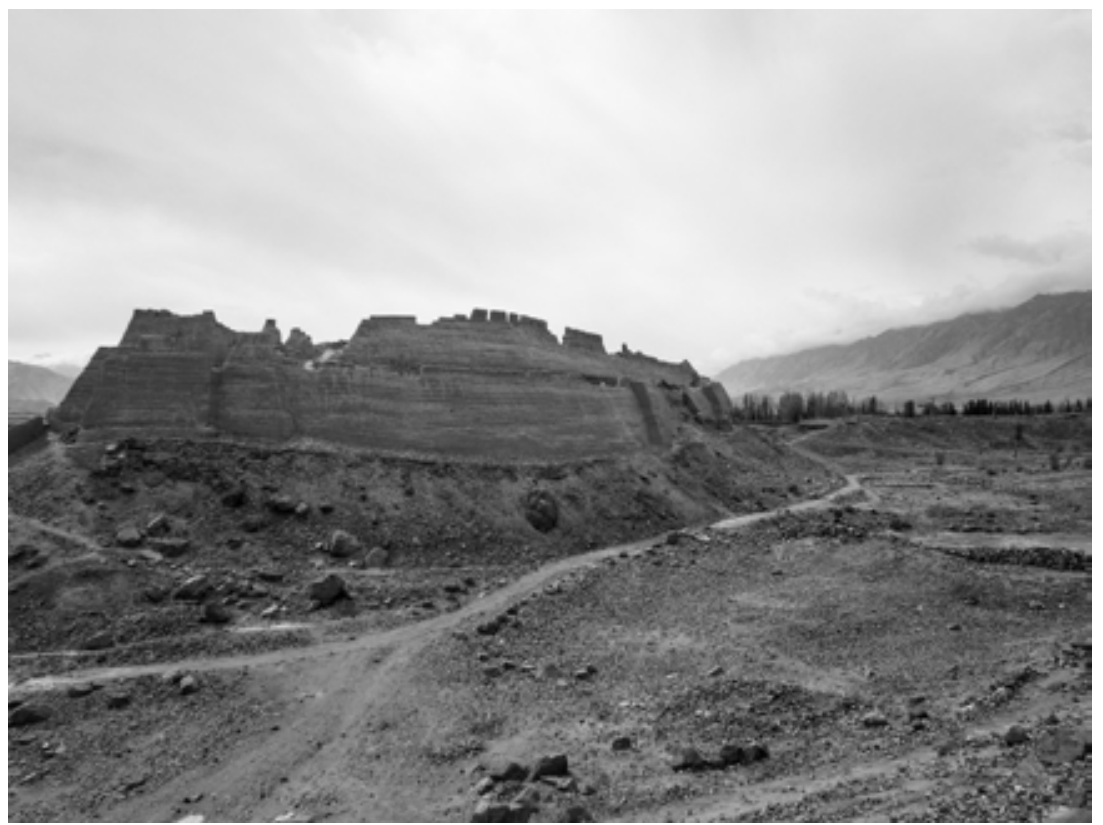

Figure 5: The Tashkurgan Fort (picture by the author, 2013)

renovated, and the small trail leading from the main entrance to the fort had been cleared for visitors. I told Karim that none of this was there the previous year, at the time of my last visit, when the stone fort looked not only abandoned - as it had been for decades - but also uncared for by local authorities. Tourism, we reasoned together, had yet to really pick up in the remote town, yet recent investments clearly displayed the intention to make it a more consistent part of the local economy. Karim, however, seemed to be more interested in the history of the fort than in its potential for tourist development. As we walked through its crumbling walls, he gave me a brief history lesson of the area:

Tashkurgan and all the land down to Gez used to be part of the Hunza kingdom. Then, in 1950, Mao [Zedong] occupied Tashkurgan with his army. The Mir of Hunza wanted to keep Tashkurgan under his control, but his counsel was against it. They thought that it was too much land to control for Hunza. So, they gave it up, but this [territory] all used to be part of Hunza.

What Karim was referring to was the fact that the Mir - or tham - of Hunza enjoyed grazing rights in the Taghdumbash Pamirs until 1936-1937. However, 
the town of Tashkurgan, and the land to the Gez canyon, remained under the control of Yarkand and Kashgar until the time of the communist revolution. In fact, as Stein reports following his travels in the area in 1900, locals in the Tashkurgan area were rather afraid of Hunza's raids in the valley $(1907: 35){ }^{12}$ While Karim's take on the history of the area might not have been entirely accurate, it nevertheless expresses an appreciation for dynamics that, when seen from a modern nation-state perspective, would remain largely hidden. Social scientists and historians have consistently shown how, for modern states, unlike many of their institutional predecessors, national borders assume a fundamental role in the construction of a national identity. While the nation is, as Benedict Anderson (1991) famously put it, an "imagined community" of individuals who share a common sense of identity, the nation state that informs this identity is essentially defined by its borders. Externally, borders mark the limits of sovereignty. Internally, they encompass a space in which a population is subject to the particular laws of the state. For the modern nation state, the cartographic and physical marginality of border areas are thus "central" - to borrow Sarah Green's expression (2005: $5)$ - to the ways in which a national community and space are imagined. Implicitly, then, this particular imaginary is based on an act of separation, or, as Bruno Latour would put it, of "partitioning" (1996). Like on the political maps of the world that we have become so accustomed to, different states are defined by different colours. There is no overlap (with the exception of contested territories) on these maps, as the current composition of the Westphalian world does not allow for any grey areas.

Karim's understanding of such history, on the other hand, seems rooted in another discourse. Not one that draws boundaries, but one that shows continuities. Not one of separation, but one of proximity. Similarly, recent scholarship on borders and borderlands has begun to look at these particular spaces as historical processes, less defined by the exceptionality of the border-as-line than by the historically and culturally informed practices of its coming into being on a daily basis. As Sarah Green puts it, "the literature on bordering (or b/ordering) has demonstrated that borders are more of a verb, a practice, a relation, and also importantly a part of imagination and desire, than they are a noun or an object" (Green 2012: 579-580). On a similar level, in her excellent work on Central Asian borders, Reeves notices that the "Westphalian logic of border-as-line" is often challenged by the - by

12 Work by Hsiao-ting Lin (2009a, 2009b) shows that it was in fact the Nationalist Chinese government that, in the immediate post-World War Two period, tried to bring Hunza under China's control, reclaiming imperial "tributary ties". 
no means exceptional - presence of "contested" and "decidedly nonlinear" borders in her area of research (2014: 9-10). Reeves, in particular, uses the expression "border work" to show how, when approached ethnographically, borders are contested spaces that require continuous negotiation. This focus allows Reeves to focus attention on the temporality of borders, "their ability to appear and disappear, to materialize at certain times of for certain groups of people with sudden intensity; to morph, or acquire the quality of permanent fixtures" (7). Speaking to this understanding of the border as a space in continuous becoming as well as to the historicity of borders that Karim had in mind while walking through the ruins of the Tashkurgan fort, Green invokes the image of the tidemark (2009). In linking space with historical time, while retaining the idea of the "line," the metaphor of the tidemark implies both divisions and connections within sites of ongoing re-territorialisations.

For Karim, as it became clear to me throughout our conversations in Tashkurgan, the "convenience" he referred to was not only a matter of geographical proximity. As he shared his views on the history of the region, he would repeatedly stress that Wakhis from the Hunza Valley and the Tajiks of Tashkurgan were, in fact, the same people. Old connections have not been forgotten in those dry highlands. For Karim, doing business in China was not merely a choice. Neither, as I was often told, was it a strict necessity - in different periods the same traders would resort to different activities, in other sectors and areas. Rather, it seemed like the inevitable outcome of the particular position, history, and cultural orientation of the region he was originally from. In this sense, as Green points out, the border as tidemark also "evokes the sense of trace" (2009:17), something inherently temporal. In the case of the China-Pakistan border, this temporality speaks to both the past and the future. For Karim, the "convenience" of Tashkurgan's geographical proximity speaks to a particular opportunity connected to China's rise and economic growth - an opportunity, however, rooted in the history of the area and the long-lasting connections between the two sides of the Karakoram. Similarly, Saxer (2016a) argues that contemporary trans-Himalayan trade must be understood against the background of old trade routes, seasonal entrepôts, and brokering practices. Focusing on two new roads in Western Nepal, Saxer convincingly argues that "rather than leading to modernity (for good or for bad), the new roads are primary conceived of as ways back to what is remembered as prosperous trans-Himalayan exchange" (2016a: 76). Although with significantly different economic asymmetries and border regimes, those "new" trades remain, at least initially, in the hands of the same "old" suspects: local dealers, brokers, and re-invented traders. 


\section{A matter of custom(s)}

Tashkurgan, like many small border towns across China, presents an interesting display of such local dealers, brokers, and re-invented traders. Take, for instance, the few Pakistani-owned shops in town, where traders like Karim spend most of their time. While most Pakistani traders - Punjabi and Pashtun from other provinces, as well as traders from Gilgit-Baltistan - doing business in southern Xinjiang travel via road through Tashkurgan, the only Pakistanis who own shops in Tashkurgan come from the Hunza Valley. In the course of many visits to the town, between 2009 and 2017, the number of such shops and their owners changed frequently. At the beginning of my doctoral fieldwork, in 2012, I counted six, yet by the summer of 2017 nine shops were selling various Pakistani imports: marble and brass vases, gemstones, jewellery, carved wooden handicrafts, pashmina shawls, prayer rugs, and European watches. While Karim's business was a family one, in other cases a few "partners" pulled together their resources to open a shop in China. Some of the shops, however, did not last for more than one or two seasons, and in the course of just a few years I had seen the same shops changing hands more than once. Karim's shop, with its 20-plus years of activity was, in this regard, an exception.

In the summer of 2016, returning to Xinjiang nearly three years after completing my doctoral fieldwork, I met Karim in Kashgar. His family had just opened another shop in the city (their third in Xinjiang), and he was overseeing the new business. After years of living in China, his Mandarin had become fluent, and he was the only one in his family who could effectively communicate with Han Chinese customers and officials. The new shop, in one of Kashgar's renewed shopping streets, was clearly targeting Chinese tourists and Karim's presence there was needed. Over tea, after some long overdue catching up, he provided me with an overview of the various shops his family owned in Xinjiang. "The Tashkurgan shop," he told me without any hesitation, "is definitely our best business." I was quite surprised, given Tashkurgan's remoteness and apparent lack of tourists and customers. Karim elaborated. "You see, in Kashgar there are many tourists, but they don't stop, they don't have time. In Tashkurgan they are free, they have time [to stop and look at our products], there's nothing else to do there." But that was not, as I was soon to find out, the main reason for the shop's profitability. "We have been in Tashkurgan for many years and we have very good relations with local officials. So, whenever some officials come to visit Tashkurgan, and this happens quite often, because it's a border town, the guest officials are taken to our shop. And they have a lot of money, and need to buy gifts, you know." 
Karim's relations with local officials had been a recurrent topic in our conversations since I first met him. I was particularly curious to learn more about the processes of moving goods in and out of Pakistan, as well as about customs clearance in Tashkurgan. Over the years, I had heard many tales related to these processes, and I knew that good relations with local officials were crucial to a successful outcome. While going through customs and immigration myself, I had noticed that at the Khunjerab port of entry, different traders were subjected to different inspection regimes. Some were simply waved through without much hassle, others were pulled aside and thoroughly questioned. All, myself included, were nevertheless questioned, however briefly, about the motive of their trip, its length and planned itinerary. Our bags and bodies were assiduously inspected and scanned. Upon entering China, travellers also had their laptops and phones opened and unlocked by border guards. ${ }^{13}$ Virtually all of the Pakistani traders I talked to complained about the strictness of Chinese customs officials and had several tales to tell about their pedantic attitude towards them. For instance, Abdul Wakel, a major Pakistani carpet dealer in Kashgar, told me that it can take days for a container of carpets to clear customs, as Chinese border guards unroll every single carpet checking for drugs. Tales such as Abdul Wakel's were common among Pakistani traders and, in several instances, I witnessed both the "strictness" of border guards towards them, as well as the traders' strategies to circumvent it.

In May 2013, when I travelled from China to Pakistan, I witnessed a significant scene at the Tashkurgan port of entry. The bus to Sost was meant to leave at 10.30am and I arrived at the port of entry at 10 only to find the gates still shut and a lone man waiting outside. He was surrounded by a number of boxes of various sizes and shapes, and I caught a glimpse of some pots and what looked like a rice steamer. He was a diminutive man from a small village in the Hunza Valley, with grey hair and a moustache, wearing a dark brown shalwarkameez. As we were waiting for someone to turn up, he told me that he had a small shop in his village where he was selling "everything that people need." He had been coming to China over the previous seven years in order to purchase, by himself, various things that he would then sell in his shops. "Mostly teapots and other small, cheap things," he told me. As the gates opened and we moved inside the parking lot, a crew from CCTV (China Central Television) showed up. There were three Han men and a large video camera. They explained that they were filming a documentary on the

13 Starting in 2018, travellers who enter Xinjiang via land are also forced to install a spyware app onto their mobile phone, which allows Chinese authorities to monitor the use of prohibited apps such as Facebook, Twitter, and Whatsapp. 
Khunjerab Pass. They were looking for some traders to interview, and the short man from Hunza - still the only one there - agreed to answer a few questions. The cameraman asked him to stand with his back towards the building of the port of entry, checked the light, adjusted the camera, and eventually began filming. The interviewer did not seem to speak much English, and he struggled to find the words to formulate a question. Eventually, he managed to ask the trader to talk about his experience as a businessman in this area. The man from Hunza was, by then, quite nervous, and although his English was fluent, he struggled to express himself. Eventually, he managed this reply: "The first thing I want to say is that the Chinese government has always been very helpful with me and other businessmen from Pakistan. I have been doing business with China for seven years, and border guards and customs officers have always been very kind and helpful. Every time I come here there are no surprises, everything is very efficient." The interviewer, seemingly pleased with this first answer, came up with another question after consulting the other members of his troupe: "What do you think of the Khunjerab Pass?" The trader, visibly uncertain over how to respond, eventually mumbled more of the same things as before: border guards are good, business is fine, government helpful. As the brief interview ended on this underwhelming note, and the troupe moved out of the "port" and back into town, the trader turned to me to ask how he did. I said that he did well and that hopefully he will see himself on TV soon. He shook his head, sat down beside his boxes and said: "you know, you always have to say that the [Chinese] government is good and things like that." He seemed embarrassed by what he had just said, and I told him that he did the right thing. "You have to be careful about what you say here," he continued, "I had to say that."

In fact, contrary to what the trader from Hunza told the CCTV troupe, the attitude of Chinese officials was seen as particularly disrespectful and annoying by many of my Pakistani informants. "Chinese people are generally good, but border guards are really bad," said one trader from Aliabad. "Every time I cross the border, I feel uncomfortable, it's like I'm a terrorist." Yet, at the same time, Chinese border guards' "strictness" was, for many traders, a sign of China's modernity and successful development. In particular, the situation at the Tashkurgan port of entry was often compared to that of Sost, on the Pakistani side. There, baggage was rarely inspected and, given the lack of equipment and frequent blackouts, it could not even be scanned. A trader from Karimabad, Hunza, once told me that he often brings beers and other alcoholic beverages into Pakistan, by simply lying to the customs official: "I usually bring a box of Red Bull, or some other soft drink, and a few more boxes with beers. Then, at the border I open the box with the Red 
Bull, and they never check the other boxes. It's easy." My fieldnotes from the same trip, in May 2013, elucidate this further:

Three hours after crossing the Khunjerab Pass we arrive in Sost. The small town lies at the end of a long, narrow and quite spectacular gorge, at the conjunction of two rivers. An old man with a long white beard in a black military uniform greets us and lifts a bar at the entrance of the village, to allow for the bus to pull into an unpaved square in front of the "Pakistan Customs" building. The building itself seems empty. As we leave the bus nobody comes out to receive us. I look back towards the old soldier but he has gone back to sit on a plastic chair beside the bar, now closed again. The driver eventually walks into the building and I follow him. The place is dark, I glimpse a large room with no furniture. It looks abandoned. After a short moment a man in a dark shalwar kameez walks out of a door, greets the driver and tells him to wait. The driver explains that there is no electricity at the moment, and that the man has to turn the generator on in order to get the computer running to process our passports. The man comes back and shortly afterward the light comes on too. He shows us into a small room with a wooden bench, two plastic chairs and three old computers. He turns one on and briefly processes the Pakistani traders' passports and border passes. It's my turn. He asks me a couple of questions: where are you going, how long will you stay, what is the purpose of your visit. He stamps my passport and tells me to wait outside. I'm not quite sure what we are waiting for, and the driver tells me that I have to "clear customs". And who's supposed to do it? I ask. He tells me that the man in charge of it is out praying, and that he should be back soon. Twenty minutes later a man arrives driving a motorbike. He's wearing a white shalwar kameez, a black waistcoat and a pair of dark Ray-Ban glasses. He has a short, trimmed beard and the dark skin of somebody from "down country". He tells the Pakistanis to go, without checking their luggage and boxes. He opens the bags of the two Uyghur travellers, gives a quick look and then tells them that they're "OK". Eventually he looks at me and asks me where I'm from. "Italy", I say. "Good", he says, "you can go". I grab my backpack and leave.

The contrast with the Chinese side could not be starker, as another trader from the Hunza Valley explained to me while leaving the Sost customs and immigration facilities:

In China they have modern machinery, $\mathrm{X}$-rays and things like that with which they can check everything. And they are very strict - very, very 
strict. In Pakistan there are no machines, nothing. Soldiers, as well, in China are all young and well-trained. I've heard they are posted there for two years and then go somewhere else. But in Pakistan people are old, and you know, you can give them some money and they don't even open your boxes. It's very different.

The difference between the two immigration services is often connected, and mirrored, in the differences between the towns of Tashkurgan and Sost. Modernity and development, on the one side, and abandonment and a sense of marginality on the other. Many traders shared similar feelings. In Tashkurgan, I once talked with Tariq, a trader from Sost who, with his brother, opened a small shop in Tashkurgan selling different products all imported from Pakistan. He mentioned Sost as we were talking about the different conditions of the road on the two sides of the border. "The road is bad, everything is bad," he told me, "if you look at here [Tashkurgan] and Sost you can understand. The Pakistani government invests only in urban and not in rural areas." Compared to Tashkurgan, therefore, Sost highlights the failings of the Pakistani government and its inadequate commitment to the development of the border areas. As if he wanted to stress this point, Tariq told me a joke. He asked me if I knew what "Tashkurgan" means, explaining that "Tash" means "stone," and that "Kurgan" means "to look like" - thus, Tashkurgan means something like "looking like a stone" (in fact, "Tashkurgan" is usually translated as "stone tower" or "stone fortress"). Sost, on the other hand, he told me laughing with his friends, means nothing more than "lazy." Tariq was playing with the Urdu word for lazy, sust, which sounds just like the name of the small border town. Yet, what he was stressing through this joke, as I discovered during further conversations with him, was Tashkurgan's economic strength and power, while highlighting Sost's poor conditions, its lack of development, and the scant investments made there by the Pakistani state. In an article that appeared on Gilgit-Baltistan's most famous blog at around the time of my fieldwork, the author compares the situation on the two sides of the border in similar terms, stressing how entering China felt like entering "the modern world" (Panah 2014). Chinese border guards and immigration facilities, then, with their new uniforms, modern machinery, and seemingly incorruptible behaviour, thus stand epitomize modernity and development. In other words, the materiality of the border and of the infrastructure connected to it lead to contextual - and often comparative - representations of the state(s). These representations are rooted in the particular material context from which they seem to emerge; yet, at the same time, they evade it and operate on a general, abstract level. 
It is in these places and at these particular moments - crossing a border, going through customs, inviting border officials for a banquet - that the state is enacted in particular ways. Such encounters, recurrent, ritualised, and thus "performative", in the sense indicated by Rasanayagam et al. (2014), objectify the state as a legitimate and singular political entity. They provide an example of how the state becomes an effect (Mitchell 1999) of mundane processes of negotiation and representation and, in doing so, it manages to distinguish itself from the material and social processes that continuously reproduce it.

That the state, following Mitchell, should not be understood as a coherent agent, is something that emerges clearly from the second major issued highlighted by traders along the $\mathrm{KKH}$ : the continuous changes in customs policies. As one trader put it to me: "it's not that they change every year, they change every month!" As I will show in the fifth chapter, new regulations introduced in 2016 and 2017 would provoke major changes in the quantity and quality of Pakistani imports; yet, even in the period 2012-13, the ostensibly erratic nature of customs regulations was a matter of discussion and concern among traders. For the most part, such changes were centred around the taxation of certain items, or over the amount of duty-free goods that each passenger was allowed to take on the daily Sost-Tashkurgan bus. Most of the time, in fact, the costs and small-scale nature of Pakistani businesses in Xinjiang did not allow traders to operate large quantities, and they only rarely resorted to container shipping. Most rely, in particular, on what is commonly referred to as shuttle trade (cf. also Karrar 2013, 2019; Ryzhova 2018; Ngo and Hung 2019). In the case of the Karakoram Highway, Pakistani traders generally take small quantities of goods with them on the daily buses to and from Sost, avoiding taxation, which does not apply to this kind of luggage. During 2012-13, each trader was allowed to transport $4 \mathrm{okg}$ of duty-free products, but this figure was largely negotiable on a case-to-case basis - and it was constantly subject to "new" regulations. This form of suitcase trade, well known to authorities in both countries, lead to regular outbursts following attempts by Chinese authorities to impose stricter regulations (Rippa 2018, 2019a).

During our conversation over tea in Kashgar, Karim offered a possible explanation for the sudden changes in border regime. "The Chinese soldiers and the immigration officials change all the time, they stay for one or two years, and then they leave. But the people in charge of customs, they never change, they are from here, some of them are." Karim continued: "But you see, the people in charge of customs have 20-day shifts, for 20 days they are in Tashkurgan and for 20 days they are moved to Kashgar or to other offices. Every time there is a shift, people change, and everything changes. 
Regulation, taxes. You can never know." During the course of my fieldwork, other traders offered similar explanations. Some, for instance, relied on personal connections with a specific customs official, and would wait for his shift to begin before attempting to move anything across the Khunjerab Pass. As I was repeatedly told, the difference in fee could be quite significant. For instance, Hammad, another small-scale trader from the Hunza Valley, told me that on a recent trip official customs taxes suddenly rose to $30 \mathrm{RMB} /$ $\mathrm{kg}$, regardless of the item transported. While, according to him, some of his fellow travellers had to pay such a high rate, he was only asked to pay a total of $500 \mathrm{RMB}$, less than half of what he was officially supposed to give. As an explanation, he pointed to his decade of experience in cross-border trade, and personal connection with that specific customs official.

For traders like Hammad and Karim, with many years of experience along the Karakoram Highway, new regulations and changes in tariffs are, for the most part, negotiable. Over the years, local, Wakhi customs officials have become central parts of their network. Karim, for instance, often invites them for dinner parties in Tashkurgan, during which he organises music from the Hunza Valley to be played. He also claims distant kinship relations with some. Similarly, other Wakhi shop owners in Tashkurgan often underlined that it was easy for them to open up businesses there as they could speak the same language as local officials. Moreover, they would stress that they shared many cultural elements with local Tajiks. On a number of occasions, for instance, I followed Karim as he was paying visits to Tajik friends in Tashkurgan. Once, we visited Ziwar, a retired customs official who used to be a close friend of Karim's father. The occasion was the construction of a new house, beside Ziwar's old mud house. Our host was particularly keen to show us the main room of the house, where he was planning to entertain guests, host parties, and weddings. The room was clearly designed according to traditional Pamiri architectural standards. Most notable, as Ziwar pointed out when we entered the room, were the five supporting pillars, symbolising the five members of Ali's family, and a skylight in the middle of ceiling, designed with four concentric square layers (chorkhona) representing, respectively, the four Zoroastrian elements of earth, water, air, and fire. Karim seemed pleased, and repeatedly complimented our host on the beauty of his new house. Turning to me and speaking English, however, Karim pointed out that the Tajiks of Tashkurgan had all but forgotten about traditional Wakhi architecture in the years following the area's incorporation into the PRC. "Only now that we travel here, they are learning again how to build these houses. We teach them what to do, otherwise they wouldn't know their own custom." 


\section{The art of moving stuff: Logistics, infrastructure, and the hardening of borders}

Karim's business, like that of Hammad, Abdul Wakhel, and many other shuttle traders along the $\mathrm{KKH}$, is centred around what they often define as a very simple operation: moving specific goods across the Khunjerab Pass, from Pakistan to China and vice versa. With the exception of the rare tourist and the odd anthropologist, in the course of my fieldwork virtually everybody crossing the border, on buses, in trucks, or in private vehicles, was involved in this operation of transport. As will be described in more detail in Chapter 5 , for Pakistani Uyghurs paying visits to family in Xinjiang, a trip to Kashgar was an opportunity for some small business. For traders from Gilgit-Baltistan travelling on a border pass, even a one-day trip to Sost was never done empty-handed. For Karim, and others like him owning businesses in China, it was a chance to bring new merchandise to Tashkurgan, or to carry some toys or gifts for relatives and friends in Hunza.

Logistics and infrastructure are tightly interwoven along the Karakoram Highway in particular ways. Not only, and most obviously, transport infrastructure, i.e. roads, bridges, tunnels, and so on. Small-scale traders, as Agar put it, rely on "webs of dependency" (Agar quoted in Walker 1999: 113) that incorporate both state and non-state agents, as well as digital infrastructure. Most traders on the Karakoram Highway in particular, operate on an individual or family level, within larger networks of traders, either family members or partners, located in various places: Yiwu, Guangzhou, Rawalpindi, Dubai and so on. Different technologies, such as Skype, Facebook (when available) or, more recently, WeChat, help traders maintain their transnational contacts and explore new business opportunities. Traders make extensive use of these technologies. WeChat, in particular, thanks to its translation service and voice message option, helps to overcome language barriers between groups of people who cannot either speak or write the same language. For traders from Gilgit-Baltistan, moreover, another kind of infrastructure, this time of a rather more bureaucratic nature, is of central importance: the "Pak-China Border Pass." The Border Pass is valid for one year, it is neither expensive (1500 Rupee, about 15 US\$), nor difficult to obtain, and it allows multiple visits for a maximum stay of one month each time. This kind of permit is not exceptional to the China-Pakistan area, but has been in use for border residents in other contexts such as Nepal (Shneiderman 2013), Vietnam (Schoenberger and Turner 2008), Laos, and Burma (Chapter 6). The situation on the Chinese side of the border is more complex. Border residents in Xinjiang are also, officially, entitled to the Border Pass. However, 
given China's concerns over security in Xinjiang (Roberts 2012; Starr 2004), they have de facto been excluded from obtaining it, thus leaving most opportunities for shuttle trade in Pakistani hands (Chapter 5).

That markets and trading practices are embedded in the social, institutional, and infrastructural worlds in which they take place is not news for anthropologists. More generally, it is not surprising to learn that the business of moving stuff (in the forms of shipping containers, suitcase goods, or financial products) is closely related to the history of modern nation states. Deborah Cowen (2014), in her recent book on global logistics, compellingly shows how military networks played a fundamental role in the establishment and maintenance of a transnational system of production and exchange. In fact, both English words for logistics and infrastructure have their roots in the military world. The Oxford English Dictionary entry for "logistics" begins broadly: "The detailed organization and implementation of a complex operation." Further, two more specific meanings of logistics are provided: "The activity of organizing the movement, equipment, and accommodation of troops;" and "The commercial activity of transporting goods to customers." The word itself is fairly recent, going back to mid-nineteenth-century France, where l'art logistique referred specifically to the business of "moving, quartering, and supplying troops." The English word for infrastructure shares a similar history. As anthropologist Ashley Carse recently pointed out, it also has its origin in nineteenth-century French civil engineering, and "when it was adopted in English in the early twentieth century, infrastructure referred primarily to the organizational work required before railroad tracks could be laid" $(2017,27)$. Since then, the meaning of the word expanded and multiplied - as in the case of logistics, which went from being a term used in a strictly military context to a more general way to refer to what makes something work, in the day-to-day (Guyer 2016). Even more interestingly, both logistics and infrastructure began to appear in general English-language dictionaries in the aftermath of World War Two, and quickly gained in popularity.

The historical etymologies of these two words point to something that for Karim, Hammad, or any other small-scale trader along the KKH is a rather obvious fact: the state, however defined, encountered, or experienced, plays a fundamental role in cross-border exchanges. This includes attempts to regulate, promote, forbid, enclose, open, tax, and provision. Whether as a major player against such forms of exchange - as was the case for periods of the Mao era - or, more recently, as an active promoter of cross-border developments, the state represents an integral part of the market along the KKH. Something that, through regulations, customs officials, and police 
officers at checkpoints needs to be dealt with on a regular basis. As I have shown in this chapter, such encounters between traders and "the state" produce particular visions of the state and entail different strategies for traders to deal with and take advantage of.

In the context of Western China and particularly the China-Central Asia borderlands, recent years have seen a growing interest in the notions of informality, shadow economy, and shuttle trade more generally (cf. Morris and Polese 2014; Karrar 2019; Steenberg 2016; Alff 2016a). As Steenberg (2016: 296) notes, this body of literature tends to focus on the relations between informal exchanges and the state and thus implicitly reinforces a paradigm according to which bureaucratic state institutions are seen as primary, while kinship, friendship, and neighbouring ties - or what he calls "social networks" - are only secondary. Against this view, he contends that in many contexts "social networks constitute central elements of society and are fundamental - not supplementary - parts of most people's daily lives" (2016: 297). In the case of cross-border trade, he observes, informal structures are at least as important as formal ones, to the extent that " $[t]$ he close intertwinement of state institutions with social networks is evident all over Central Asia, but which of the two can be considered primary or secondary is rarely easily decided." (2016: 297). If the issue of small-scale cross-border trade might lend itself to such interpretations, then recent anthropological investigations of the workings of global markets and logistics have led to similar results. The work of Caitlin Zaloom (2006) and of Karen Ho (2009), for instance, shows how financial markets are constructed through everyday experiences and practices that are inseparable from the particular social and material environments in which they take place and by face-to-face interactions in the trading room. A far cry from the abstract notion of a global market, such scholarship points to the embedded, embodied, and experiential creation of both a particular financial market, as well as its abstraction. Brenda Chalfin (2010), writing on the Ghanaian context, shows how the introduction of "neoliberal" reforms and regulations are always transformed, appropriated, and distorted on the ground in customs houses and offices. The market, far from abstract, is thus the result of constant negotiations between a wide range of actors - IMF economists, state authorities, "informal" traders, and customs officials among others.

My contribution to this body of literature is twofold. First, as I show in this chapter, "informal" practices of proximity are embedded in institutional and infrastructural landscapes that they contribute to re-making and legitimising through specific encounters with state authorities. Secondly, as will become clear throughout the book, a particular ideology of connectivity 
that forms the basis of China's current global expansion is deeply re-shaping such networks and the ways local traders conduct their business. On the one hand, as I have begun to show in this chapter, this new idea of connectivity that materialises in large-scale infrastructure projects across the Chinese borderlands does not reduce the presence of the state, but rather generates new conditions for its regulatory power to take hold and more space for it to grow. ${ }^{14}$ On the other hand, as this vision takes shape in the form of new roads, border gates, and logistics centre, it not only overlooks pre-existing networks and practices, but is often detrimental to them.

\section{Conclusion}

In this first chapter, I have sketched out a tension between two different visions and ideologies of connectivity that will become a recurrent theme in this book. One is the vision currently embraced, exerted, and exploited by the Chinese government. With its roots in a particular understanding of the history of trans-continental trade expressed via the image of the Silk Road, this vision underpins a particular ideology of connectivity as represented in the Kashgar SEZ stand at the Central \& South Asia Commodity Fair, described at the beginning of the chapter. Such ideology, as it materialises in large-scale infrastructure projects, entails legibility, order, and regulations. Its stated goal is to connect the main centres of political and economic power through a number of frictionless corridors, thus incorporating once-remote peripheries into an extensive network of state-of-the-art infrastructures.

On the other side of the spectrum lies another form of connectivity. One that is not rooted in Silk Road fantasies, but that is rather lived through practices and day-to-day encounters. One that slips through the cracks of today's Belt and Road Initiative as promoted by Beijing. To illustrate this, I have introduced the history of Tashkurgan and showed how existing cross-border ties in the region go back generations and have their roots in geographical and cultural proximity, as well as a sense of shared values and even kin relations. The examples of Karim, in particular, and of his family's long-term business interest in Xinjiang more generally, allowed

14 Walker (1999) has described a similar process enfolding in the China-Burma-ThailandLaos borderlands, arguing that "as trading and transport conditions become more liberalised, opportunities and incentives for regulation flourish" (5). Or, as Tina Harris puts it, "The opening of borders is often simultaneously a hardening of borders, bringing with it increased fences, walls, gates, security, and limitations of what can and cannot be brought across" (2018: 110). 
me to untangle the nexus of personal relations, economic opportunities, and familiarity that qualifies as "China trade" for many entrepreneurs from across the border. Furthermore, by detailing the quotidian processes of crossing the Khunjerab Pass and the different obstacles that traders encounter and must learn to navigate on a regular basis, I brought to light the combination of formal structures and informal practices that make this particular business possible.

My goal has been twofold. First, I aimed to provide an ethnographic understanding of how the state is perceived, represented, and engaged at the margins of its territorial power. Borderlands, I argued, are spaces in which the state acquires a particular materiality, one that is enacted at particular places and times. With the example of Pakistani traders' experiential engagements with state officials and infrastructures on both sides of the border, I have shown that, as an object of knowledge and practice, "the state" is not seen as a coherent agent, but rather as something that requires constant engagement. Building upon this discussion, my second aim was to introduce and begin a conceptualisation of the set of practices that define what I call "proximity." This notion is used to address and define the set of skills necessary for small-scale traders such as Karim to navigate the ever-changing landscape at the China-Pakistan border. I develop this notion in the next section, before moving into a discussion of how the state is embedded in such processes through the case of the China-Burma borderlands.

The ways in which the state is encountered, represented, and enacted, and the embedded practices of crossing and moving goods across national boundaries have been undergoing tremendous transformations in recent years. In Chapters 4 and 5 , I will return to the case of Xinjiang and the $\mathrm{KKH}$ to discuss how Uyghurs in Kashgar and Pakistani traders have been affected by massive investment in infrastructure development in the region. In so doing, I return to the tension that has underpinned this chapter, between two different visions and ideologies of connectivity. I will show, in particular, how the vision professed by elites in Beijing and Islamabad aims at fostering not only economic development, but also people-to-people ties and cultural exchanges. Yet, as I have begun to show in this chapter, by ignoring pre-existing relations and cross-border practices, the new Silk Road is detrimental to old, established connections. Rather than fostering, it destroys. In connecting, it separates. Before making this argument, however, I will return to and unpack some of the forms of connectivity already described in this chapter in order to define and details the notion of proximity. 


\section{Interlude - proximity}

It was Ali who introduced me to the big mosque, shortly after he arrived in Kashgar for the second time in the late summer of 2012. He asked that we meet in front of the Seman Hotel, where he usually stays during his frequent visits to the city, and I was quite surprised to see him walking towards me from the opposite side of the road. The Seman Hotel is one of Kashgar's landmarks. Formerly the abode of the Russian Consulate between the late 19th and the mid-2oth century, it lies at only a short distance from the Chini Bagh, the former British consulate, and today another major hotel in Kashgar. This important page of history in what has come to be known as the Great Game (Hopkirk 1992) seems forgotten in the cityscape of contemporary Kashgar - as lost as the two empires that were its main players. Only two old signs stand in front of the former consulate buildings, which, despite frequent rumours of imminent renovation, laid mostly abandoned between 2009 and 2017. Yet, both the Seman and the Chini Bagh are major hotels for foreign businessmen and tourists alike. Many Pakistani traders, in particular, are frequent guests. The new Chini Bagh Hotel also hosts two Pakistani-owned shops as well as the Kashgar liaison office of the Northern Areas Chamber of Commerce and Industry (NACCI) from Gilgit-Baltistan. The few Pakistani restaurants in town, moreover, are all located in close proximity to either the Seman or the Chini Bagh.

Like Karim, Ali is a trader originally from Gilgit-Baltistan. Unlike Karim, he is a Shia from the Nagar Valley, and his family does not claim any kinship relations on the north side of the Karakoram, nor does it own any shops in China. Since the early 1990s, however, Ali has been making regular business trips to Tashkurgan and Kashgar, trading mostly in dry fruit. "I've asked you to meet me in front of the Seman hotel because I knew you would know this place," he told me as we shook hands, perhaps sensing my puzzlement. "But I'm staying at the Sahar Hotel, across the street now. Come, I'll show you." As we crossed Xibei Road, Ali explained that prices at the Seman Hotel had become too high, and that he had to resort to a cheaper option: the big mosque. "The big mosque?" I asked, looking at him quizzically. Ali laughed, then told me that "the big mosque" was the nickname that he and some of his friends from Nagar gave to the Sahar Hotel, as most of its guests are Punjabi or Pashtun. "You see, they always wear their shalwar kameez, always pray. There's even a prayer room in the hotel, it's like being in Pakistan."

The Sahar Hotel was, indeed, quite an interesting discovery for me, and became a frequent destination on my daily strolls through Kashgar during 
the following months of fieldwork. Like the Chini Bagh, some of the rooms of the Sahar Hotel were permanently occupied by import-export companies advertising fast and secure shipping of goods between Pakistan and China - either via the Karakoram Highway or via sea, through Karachi and Guangzhou or Shanghai. As we sat in his room, Ali walked me through the various steps that running his business involves. In the following days, and over his subsequent visits to Kashgar and a couple of meetings in Rawalpindi, I witnessed first-hand the complex network of contacts, commodities, logistics and technologies that Ali makes use of in the course of the many ongoing transactions that comprise his business at any given time.

On a normal day in Kashgar, Ali would visit at least one of the city's bazaars. In recent years, he mostly traded in Afghan dry fruit, which he would purchase in Peshawar, Quetta, or Rawalpindi, and then bring to Kashgar via the Karakoram Highway. In a good year, he was able, together with one or two partners, to ship two, sometimes even three containers. Summers, however, are not the best time for the dry fruit business, and Ali was also trading in other commodities. He would perform a number of tasks during his visits to Kashgar's bazaars. He checked up on clients who still owed him money from previous deals. He visited current and former clients, shop owners, and fellow traders, who might have had one particular need or another. He checked the current prices of a number of goods, ranging from dry fruits to beauty products to cheap electronics. Lastly, he asked about new products that looked to sell well, and that he could possibly find for a cheaper price in Pakistan. All the while, he remained in contact with partners, suppliers, and clients from both China and Pakistan through his mobile phone. While in 2012 he used Skype, Viber, Facebook and WeChat with a similar frequency, already by 2013 most of his business transactions were carried out exclusively via WeChat. Through this platform, Ali could send pictures and videos of particular commodities to his suppliers in Pakistan, or show them to potential clients in Kashgar's shops. He was sending audio and text messages relentlessly, often making use of WeChat's translation function. While, after over a decade of experience in Kashgar, Ali's Uyghur language was fluent, his Mandarin was only basic and he was unable to read any Chinese characters. When we were together, he would frequently ask me to write a message in Mandarin to a Han Chinese client; when apart, he would occasionally send me a message to translate when the WeChat translation function failed him. ${ }^{1}$

1 WeChat's success is also tied to the Chinese government's current suppression of potential competitors, such as Facebook and, more recently, Whatsapp, which have developed similar functionalities to those described here and used by Ali. 
Back in Pakistan, Ali repeated many of these operations, travelling time and again from his hometown, in Nagar, to Gilgit, Rawalpindi, Peshawar and Quetta, with occasional visits to Karachi. As is often the case with transnational merchant communities (Marsden 2015a; 2015b), traders such as Ali operate within a larger network of contacts stretching across multiple locations. As I came to realise walking through Kashgar's bazaars with Ali, or sitting in Karim's shop for long afternoons, as well as through days spent at markets and fairs in Gilgit, Urumqi, and Rawalpindi, this network was far from stable. Not only because players, commodities, regulations, and technologies that constitute this network are constantly changing, but also because the relations between these different actors are in constant evolution. It is an established anthropological argument that, by reinforcing the relationships between different actors, these patterns of exchange are also productive of groups and of the boundaries between them (Sahlins 1974). $\mathrm{KKH}$ traders thus made it their business to keep themselves well-informed: from season to season they followed the fluctuations of the prices of goods in the bazaars of Kashgar and Rawalpindi. They were always quick to relay news to their friends through Skype or WeChat, and good relations with local officials ensured that they would get wind of any new regulation that might be implemented. This particularly unstable relationship, which I have elsewhere described as an intrinsic characteristic of what is locally understood as "the market" (Rippa 2019a), is a defining element of the lives of traders along the Karakoram Highway. As such, it is productive of social as well as spatial relationships, and conductive of various forms of mobilities.

Such relationships, and the forms of mobilities within which they are embedded and of which they are productive, are rooted in socio-spatial configurations that I call proximity. Proximity is not a heuristic invention that necessarily applies in any and every context in the world. Rather, the notion of proximity simply intends to highlight connections and continuities where we might otherwise expect none. As such, it follows John Agnew's fundamental conception of territorial states as "made out of places" (1987: 1). Accordingly, with the notion of proximity, I stress the need to shift the focus to the presence of diverse historical and socio-cultural trajectories from those often projected by today's borders, and by the promoters of current forms of transnational connectivity. As such, proximity is intended as an analytical starting point for addressing the multiple meanings and notions associated with the Chinese borderlands and the relations that characterise them today.

Proximity is a configuration that is both geographical and social, continuously made and remade. As such, it speaks to a particular understanding 
of space, one rooted in a processual and experiential ontology as defined by a number of scholars in the social sciences. Take, for instance, geographer Doreen Massey and anthropologist Tim Ingold, particularly their works entitled respectively For Space (Massey 2005) and Against Space (Ingold 2009). Despite the seemingly oppositional titles, Massey and Ingold share a similar vision. For both of them the world is essentially made up of relations, continually under construction and defined by interactions, multiplicities, and becomings. Massey calls this "space," Ingold prefers the term "lifeworld." Yet, both thinkers aim to move behind a flat and fixed conception of space, a two-dimensional canvas upon which connections take place. For Massey, space is the product of interrelations, it represents the possibility of the existence of multiplicity, and it is always under construction (2005: 9). Similarly, Ingold criticises the abstractness of the concept of space we have become accustomed to, and proposes instead an understanding of the world as defined by movement, openness, and a form of knowledge rooted in history, experience, and memories - or what he calls "a knot of stories" (2009: 41).

The world of traders along the Karakoram Highway closely resembles the world described by Massey and Ingold. Ali's visits to Kashgar's bazaars is a tale of simultaneous multiplicities: talking prices, browsing commodities, engaging in virtual conversations over WeChat, and so on. Karim's characterisation of the history of Tashkurgan and his personal commitment to a life across national borders, reflect the specific pathways he grew into, a kind of "trail-following wayfaring" (Ingold 2011: 143). Thus, moving from this understanding of space, the first part of this book makes a case for the importance of proximity. As such, the concept might appear obvious - and yet, in the current corridor-isation of global trade, elaborating on this notion is more important than ever. To put it simply, the argument - explicitly echoing Tobler's First Law of Geography - is the following: space is constituted by interrelations, but near things are more related than distant things and this proximity affords specific opportunities.

As mentioned above, proximity is both geographical and social. Let's start with the former. Proximity is rooted in a particular terrain, not in cartographic vicinity. This is particularly important when it comes to places such as the Karakoram, where mountains, landslides, availability of water, and altitude influence the ways people move and the place they inhabit. Despite radical infrastructural interventions and technological innovations, this terrain still plays a fundamental role in the highlands of Asia. Movement, here, is still very much the work of wayfaring - and to locate it with related scholarship by Saxer (2016a), it takes place along specific pathways. On the other hand, proximity is social in the sense that it is not defined simply 
by a passive geographical closeness, although it is rooted in a particular terrain that favours certain kinds of routes over others. Proximity also implies a degree of cultural familiarity, and an active effort to keep those connections alive. It is, in this sense, close to what Saxer and Zhang call neighbouring: a set of practices that "entails both a geographical reality of living in proximity, and a flexible construction of social relations that can be stretched across time, space, and distance" (2016: 23). As with neighbouring, what I call proximity implicates a certain effort, a "doing" that overcomes distance, political barriers, and generations.

The social and geographical components of these particular configurations, I argue, afford specific opportunities to these dwelling in proximity. In other words, because of this shared history and the geographical closeness, locals are often able to find and exploit new opportunities triggered by external decisions, such as the construction of a road or the opening of the border. For instance, in the aftermath of the Attabad landslide, it was local "China traders," as Pakistanis engaged in business with their powerful northern neighbour are called, who re-established the connection between Gojal - and therefore China - and the rest of Pakistan. At a moment of great economic difficulty, when many Punjabi and Pashtun traders went elsewhere, traders from Gilgit-Baltistan kept travelling to Tashkurgan and Kashgar, purchasing cheap Chinese manufactured goods or selling gemstones and Afghan dry fruit - and quite often both. To be sure, in the aftermath of the landslide, traders from other parts of Pakistan did not, in many cases, interrupt their business relations with Xinjiang. They did, however, rely on traders from Gilgit-Baltistan to arrange and manage the transportation of goods between Kashgar and Gilgit. The disaster, in other words, created a situation of uncertainty within which only a combination of local knowledge, social networks, and territorial rootedness made it possible for business relations to persist. Or, as I will show in Chapter 5 , the first group of people to take advantage of the opening of the $\mathrm{KKH}$ in the $1980 \mathrm{~s}$ was the Kashgari families who had left Xinjiang only a few decades earlier. Many of those traders came from families of mixed background, rooted in trans-Karakoram trade. For them, the decision to invest in China-Pakistan trade in the early 1980 s was triggered precisely by those experiences, and by the network of contacts and set of expertise that they entail.

To be sure, Ali and Karim make regular use of their particular positionality within the broader history of trans-Karakoram relations. Karim invests time and energy in cultivating his relations with his fellow Wakhis in Tashkurgan. Ali, on the other hand, has developed close connections with a number of actors across the region, with whom he entertains regular contacts 
through online apps and personal encounters. The history of cross-regional trade along China's peripheries, as recounted in the works of scholars such as Giersch (2006), Marsden (2015a), Van Spengen (2000), Rizvi (1999) and Saxer (forthcoming) among others, betrays countless examples of the role proximity plays in the activities of brokers, middlemen, caravan traders, and so on. Today, this history reverberates through the lives of traders such as Karim and Ali - and, as we will see in the next chapter, in places as distant and diverse as Tashkurgan and Tengchong. 


\section{$2 \quad$ Bridgehead}

“In order to develop border areas, we will make use of these areas' regional advantages and formulate and implement special "opening up" policies. We will speed up the construction of key ports, border cities, border (and cross-border) economic cooperation zones and key development and experimental zones. We will enhance the infrastructure and connection with the neighbouring countries

and develop "special outward industries" and industrial bases. Heilongjiang, Jilin, Liaoning and Inner Mongolia will be key in our "opening up" to North East

Asia; Xinjiang will serve as a base for our "opening up" up the West; Guangxi will be a new "highland" for cooperation with ASEAN; Yunnan will be built into a bridgehead for "opening up" to the South-West. We will also continuously improve the level of "opening up" along the coastal areas." — Twelfth Five-Year Programme (2011), Italics mine.

"The Chinese can be trusted to keep the mule-track between the frontier and

Tengyueh [Tengchong] in repair and they are considering the construction of a motor road [...]. The interest expressed by the Gov. of Burma in the maintenance of the road in good condition, seems in no danger of being neglected and indeed the Chinese in Yunnan appear at the moment to be bitten by a craze for communications" - Telegram to the Governor of India from the Tengchong British consular mission, 14 November 1929 (IOR/L/PS/11/301), italics mine.

In a paper from 1934, Chinese demographer Hu Huanyong famously drew the "Heihe-Tengchong line." The line stretches diagonally across China, from the city of Heihe on the border with Russia, to Tengchong, on China's border with Burma. This imaginary line divides China into an eastern half - making up 43 per cent of the national territory yet containing around 94 per cent of the population - and a western half making up the remaining six per cent of the population (according to data from 2002; in 1934, these figures were strikingly similar, 96 per cent and four per cent). Furthermore, while the overwhelming majority of the Han Chinese population live on the eastern side of the line, most ethnic minorities live in the western half. As Mao Zedong once put it: "We say China is a country vast in territory, rich in resources and large in population; as a matter of fact, it is the Han nationality whose population 
is large and the minority nationalities whose territory is vast and whose resources are rich." ${ }^{1}$

Within this particular geography, Tashkurgan and Tengchong occupy two different kinds of marginality. While the former lies at the westernmost edge of the People's Republic, the latter is located at the intersection between the symbolic margin of the Han world and China's territorial limits. The history of the town of Tengchong reflects this unique position. Founded as a military outpost, Tengchong grew in tandem with the Ming expansion in southwestern China. To this day, the majority of its population is Han Chinese and traces its roots to such military expeditions. Furthermore, Tengchong quickly developed as a trading outpost and became particularly famous in imperial times for its role in the trade of Burmese jade and amber. In the wake of the Communist Revolution, many Tengchong trading families migrated to Burma. Still today, in numerous overseas Chinese (huaqiao) communities from Myitkyina to Tachileik it is not unusual to hear Tengchong dialect spoken.

Tashkurgan and Tengchong represent two particular, yet complementary vantage points from which to observe cross-border interactions in present-day China. Unlike the historical cross-border cultural similarities that we have encountered in Xinjiang, with Karim for instance, the story of Tengchong is one of Han Chinese expansion and encounter with nonHan groups on both sides of the border. Moreover, while in Xinjiang the particular terrain and sensitivity of the region channelled cross-Karakoram trade into one particular route, the $\mathrm{KKH}$, the hills surrounding Tengchong are criss-crossed with trails and dirt roads that stretch all the way into Burma's Kachin State. While it is an over-simplification to counterpose a rigid, closed border in the case of the KKH with an open, porous one in the case of Tengchong, the very geographies where such encounters take place have shaped, and still shape today, the quantity and quality of exchanges in very particular ways.

Tengchong, like Tashkurgan, is no longer a marginal place. Not simply because of the quality of newly built transport infrastructure, but also due to its imagined role within Yunnan's development. Much of this narrative is encapsulated in the image of Yunnan as a "bridgehead (qiaotoubao)", hence this chapter's title. This image has become particularly popular since the early 2000s, when the province became the spearhead of China's aggressive economic engagement with Southeast Asia. The image of the bridgehead thus

1 Mao Zedong's "On the ten great relationships" (25 April 1956), quoted in Kau and Leung (1986: 47). 
underpins a particular vision of connectivity, one that is, once again, rooted in a particular understanding of China's history. Much like the Xinjiang case, the official version of this history, professed by Chinese academics and officials, positions Yunnan along the "southwest Silk Road." As such, they highlight the need to employ Yunnan's geographical proximity and historical ties with Southeast Asia in order to promote economic development and cooperation. Yunnan, accordingly, "is no longer to be seen as a peripheral southwestern corner of China, but the centre of wider links between China and its Asian neighbourhood to the south" (Summers 2013: 6o; see also Sigley 2016). As Xiaobo Su summarises, China's notion of qiaotoubao, "indicates that Yunnan's border areas are not only a zone of contact for people living in different territories, but, more importantly, a new state space of development where capital can pursue profit as long as trade barriers are removed and infrastructure is enhanced" (2013:1225).

Thus understood, the image of the "bridgehead" has been widely used in policy discussions and scholarly debates alike to illustrate the ways in which China envisions the future of its southwestern province. What this debate seems to assume, however, is that the Chinese state is the main driver of economic development in the region, and that it is exclusively responsible for the planning and execution of trans-border infrastructure. In this chapter, I tell a different story - one that shows how private interests in Tengchong were at the forefront of a process that led to the consolidation of the state's presence in the borderlands. In order to do so, I will draw a historical picture of Tengchong's role as a trading entrepôt, focusing in particular on the years following the fall of the Communist Party of Burma (CPB) in 1989. My purpose is threefold. First, I show how plans for transnational connectivity, now embedded within the Belt and Road framework, have a history that not only pre-dates Xi Jinping's initiative, but also the formation of the PRC. I thus put current Silk Road fantasies in perspective and show the persistence of such images of global connections throughout different historical phases. Secondly, I will show how the state is embedded in processes of proximity, not just as a regulator or an investor. On the contrary, in Tengchong, state and private businesses are both responsible for a particular definition and development of the borderlands. In particular, I detail this process through the example of the timber trade - my third aim in this chapter. I argue that the boom in Burmese timber imports in the late 1990s and 200os, together with the particular materiality of timber, played a fundamental role in the processes of state territorialisation of the Tengchong borderlands. By doing so, this chapter will show how scholarly accounts of road development in the Yunnan borderlands often omit the role of non-state actors in the 
planning and construction of particular border roads in the province. The Chinese state, in other words, is implicitly assumed to be the main - if not the only - agent of development in the region. Against this view, the case of Tengchong analysed in this chapter shows how private interests led to particular infrastructural formations at the China-Burma borderlands, which were only later incorporated into the national geography of border crossings.

Using Tengchong as an example, this chapter analyses the quantity and quality of such links. As in the case of Tashkurgan, what emerges is a history of connectivities that evades China's official version and that involves a number of surprising actors in seemingly out-of-the-way places.

\section{The quest for frictionless corridors}

The quest for frictionless corridors is not a new one. The late nineteenth century was a period of great change, in Tengchong as much as elsewhere in the country. As the British expanded their colonial reach into Burma, Yunnan fell into almost two decades of turbulent civil war - what the British called the Panthay or Muslim rebellion between 1856 and 1873 (Atwill 2005). By that time, Tengchong was already an established trading centre, particularly famous for its jade manufacturing businesses. As the British gained control over northern Burma and established a permanent garrison post in the town of Bhamo, on the Irrawaddy, Tengchong became an important node for British interests in Yunnan. ${ }^{2}$ By then, the Bhamo-Tengchong Road, which could be covered by pack animals in seven days, was already a "well-known trade-route" (Johnson 1908: 294). Early British missions to Tengchong in the second half of the nineteenth century report finding a formerly prosperous town whose economy was severely hit by the civil war, with only a few businesses in place (Anderson 1876; Gill 1883). ${ }^{3}$ All of these missions,

2 On Tengchong's prominence in cross-border trade in this phase, see Li (2017: 23-53); Hill (1998: 22-27); and Giersch (2006). On the role of overseas Chinese in the Southeast Asia trade, see Chang (2009, 2011, 2014); Tagliacozzo and Chang (2011); and Tagliacozzo (2005).

3 During the second (1975) expedition documented by Anderson, the British diplomat Augustus Raymond Margary was killed near Manwyne (today's Mang Yun 芒允). The murder sparked the so-called Margary Affair, leading to the Chefoo Convention, one of the unequal treaties signed by China with colonial powers in these decades. While Mang Yun town is today in the Dehong Dai and Jingpo Autonomous Prefecture, at the time of the assassination it was under administrative control of Tengchong, hence several reports state that Margary was killed in Tengchong. 


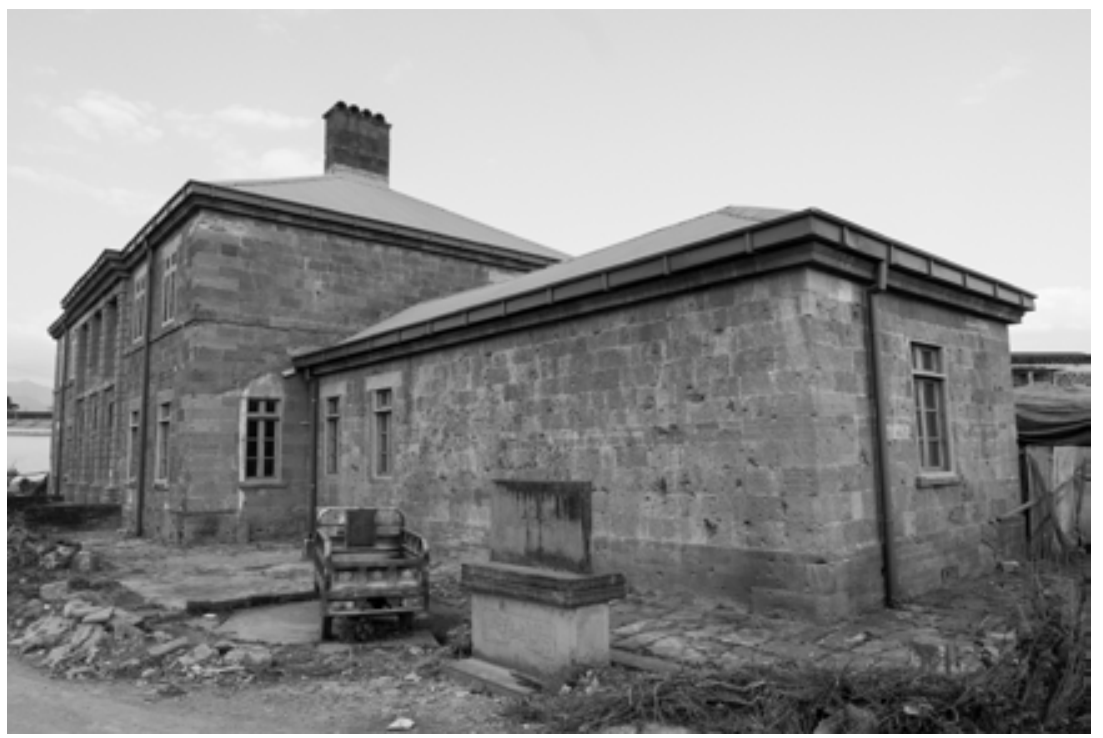

Figure 6: Former British consulate in Tengchong (picture by the author, 2016)

however, reported the potential for the opening up and development of trade with Yunnan, whose resources, particularly in the mining sector, seemed unlimited. ${ }^{4}$ In 1890 , the Qing government signed the Yunnan-Burma Business Treaty (dian mian shangwu tiaoyue), and only a few years later, in 1899, the British established a consulate (Figure 6) and customs house in Tengchong (Nield 2015: 234). ${ }^{5}$ In 1902, the Qing government established a customs house in Tengchong (Tengyue haiguan). The city, by all standards of the time, had become a fairly international trading hub. As Archibald Rose, then British consul at Tengchong, put it:

In spite of its far-away position, Teng-yüeh [Tengchong] is the great market of Western Yunnan [Yunnan], the distributing centre for foreign goods, the collecting centre for all the native produce coming down from

4 Captain Gill reports an interesting conversation with the Qing garrison commander (Chen-tai, or zhentai) of Tengchong from his 1877 mission, in which he claims that "the governor-general of Yün-Nan [Yunnan] intended to raise three million taels to work the mines in the province, under the superintendence of Europeans" (Gill 1883:281) Gill, however, notices quite poignantly, that "the mines of Yün-nan no doubt are exceedingly rich; but before they can be made to pay, communication must be improved, and the country better governed" (Gill 1883: 281; emphasis mine). On British mining interests in Yunnan, see also Fiskesjö (2010: 254-5).

5 On the construction and maintenance of a British consulate in Tengchong, see WORK 10/633; IOR/L/PS/11/205; FO $369 / 3087$. 
Ta-li Fu [Dali]. It is busy with Burma Caravans, its market thronged with tribesmen, and its streets gay with passing officials and their picturesque retinues, for it is in Teng-yüeh that the political and commercial life of the Yun-nan frontier finds its focus and its centre (Rose 1912: 1999).

Tengchong, as Rose summarises, was both "far-away" and "central" - a true frontier town with its diverse population, colourful visitors, and thriving markets. To be sure, despite its remoteness and location amidst notoriously dangerous hills and unruly tribes, at the turn of the century, Tengchong was a rather cosmopolitan place. Besides British officers and Burmese traders, one could find international explorers, botanists (Mueggler 2011), and missionaries (Crossman, [1982] 2002: 68). By then, ambitious plans for transnational connectivity had already taken shape.

In 1898, a British mission was in charge of surveying the region for a potential railway line. The report, written up by Captain Ryder, states that the Bhamo-Tengchong line was "the only" possible way for rail transport between Burma and China (Ryder 1903:112). At the time, the issue of railway lines in the region was a political one, owing much to the colonial rivalry between the British and the French. While an 1896 treaty between the two colonial powers stabilised the situation in mainland Southeast Asia, France's construction of the Tonkin-Kunming line between 1898 and 1910 (Rousseau 2014) became a major concern for British interests in the region. Years later, in 1906, as another British officer passed through Tengchong on his way to Bhamo, talks of a railway were still very much alive. He noted rather poignantly, however, that while "the trade between Burma and China by this route requires some stimulus [...] whether the railway will stimulate the trade to any very great extent is questionable" (Johnson 1908: 310-11).

Despite the fact that the railway was never built, at the end of the Qing Dynasty in 1911-12, Tengchong entered a positive period for trade, during which a number of multinational trading firms were set up, dealing silk, tin, and other raw materials through networks spanning from Shanghai to Rangoon (Giersch 2010: 231-2). While official records show the total value of imports and exports as being hundreds of millions of two-level silver, both British and Chinese authorities frequently voiced great concern over issues of smuggling, banditry, and road maintenance. ${ }^{6}$ Of particular concern for the British was the issue of the taxation of mule caravans - the so-called mule tax ${ }^{7}$ - which was initially connected to the development and 
securitisation of the Tengchong-Bhamo Road. ${ }^{8}$ In particular, as a British report from the time states, Chinese authorities revenues of the mule tax were initially supposed to be:

devoted by them to the maintenance of a Trade Protection Force and the repair of the road. In 1903 the amount of the Trade Protection Force was fixed at Taels 9ooo per annum and the remainder was handed over to a Road Committee, of which HM Consul at Tengyueh [Tengchong] was a member, for the maintenance of the road between the frontier and the Salween River. ${ }^{9}$

While plans for the construction of a motor road were frequently discussed in frontier meetings and conversations between British and Chinese authorities in Tengchong, the costs related to "the nature of the hills, which are of soft rock or sand and subject to frequent landslide" and the unstable political and financial situation in Yunnan, prevented such plans from taking a concrete turn. ${ }^{10}$

More ambitious plans for transnational connectivity were revived during World War Two and the Japanese invasion of Burma, when Tengchong was brought into the national spotlight. The town was conveniently located along the so-called Stilwell Road, built by Allied forces during World War Two as an attempt to by-pass Japanese-occupied territories in northern Burma and deliver supplies to KMT troops in Yunnan. The road was built under the supervision of American General Joseph Stilwell - hence the name - between 1942 and 1945, and once completed established a quick connection between the railway head in Ledo, then part of British India and today a sleepy town in Assam, and Kunming, where the KMT planned its moves against Japanese forces pushing from the south-west. The road, which has since fallen into disuse and has, for the most part, been swallowed up by the jungle, still represents a major symbolic reference for virtually any plan for cross-border connectivity in the region today (Zhou 2013). In Tengchong, where a key battle with the Japanese army was fought in 1944, a well-kept museum and a graveyard attract thousands of visitors every month, and the war of resistance has come to represent one of the most evocative moments in the city's history. 


\section{Integrating the frontier, exporting the revolution (1949-1989)}

Despite the war effort and the consequent construction of roads and airports, in 1949, Yunnan remained internally fragmented and poorly linked to the rest of China. In other words, it posed a major headache for CCP authorities eager to usher in a programme of national integration. To address such challenges at a national scale, communist authorities introduced a system of "Great Administrative Regions" as part of which Yunnan was included in the Southwest area together with Guizhou, Sichuan, and Sikang. ${ }^{11}$ Several factors determined the division - "distrust of the provinces, disparities between different areas, a shortage of cadres, military deployment, an unexpectedly rapid takeover, and a divide-and-rule strategy" (Solinger 1977: 29) - which was thus undertaken with the goal of fostering greater integration and centralisation. In particular, the new - and temporary - regional system was to account for difference, while promoting unification; or, in Mao Zedong's own words: "what can be made uniform and should be uniform are to be made uniform; what cannot or should not will not forcibly be made uniform" (quoted in Solinger 1977: 30). As a result, by 1952, the provinces, strengthened by material and ideological work, were considered ready to take over, paving the way for the dismantling of the regional system in 1954. This progress, as Solinger summarises, was particularly evident "in the construction of new transport facilities and in the creation of nationally homogeneous units - Party branches, autonomous areas, and trade organs" (Solinger 1977: 252).

As part of this broader process, the Yunnan borderlands presented unique challenges for the CCP. Besides the rough terrain, lack of reliable infrastructure, and ethnic composition, they had become one of the last stands for Nationalist (KMT) troops attempting to topple the new regime. Several thousand KMT troops had escaped across the border into norther Burma, yet made frequent forays into Yunnan province. Led by General Li Mi and supported by the Nationalist government in Taiwan (as well as by the USA), KMT troops were based in the Wa hills of northern Burma and, at least initially, enjoyed the support of a number of local ethnic groups on both sides of the border (Moseley 1973: 35; Han 2019). On the Burmese side, the presence of Nationalist forces was repudiated by the newly formed

11 Sikang would then be split into the TAR and Sichuan. Xinjiang, as part of the same process, was included in the Northwest Administrative Region together with Gansu, Ningxia, and Qinghai. Upon its invasion in 1951, Tibet was administered by a separate military administrative committee. 
Burmese government, despite it not having the military power to take any concrete measure for their actual removal. In China, on the other hand, the Nationalist threat was met with a dual approach. First, PLA troops were deployed to the frontier with the objective of eliminating "bandits." Secondly, "pacification" was carried out in conjunction with land reform and other programmes intended to win over the trust and support of local ethnic groups.

Similarly to Xinjiang, where the bingtuan played a major role in the securitisation and opening up of frontier territories, across Yunnan's mountainous regions the PLA was, at least initially, largely in charge of the development of basic infrastructure and of the distribution of staple goods to minority groups. PLA troops, in particular, were credited for the distribution of clothes, food, salt, for improving fresh water supplies, and for the construction of roads in remote parts of the province (Moseley 1973: 107). To an extent this approach bore fruit and, by the mid-1950s, the CCP seemed to have won the support of some of the ethnic groups that were initially openly against communist rule.

Despite the deployment of PLA troops at the frontier regions, in this initial phase the communist takeover appeared to have had little impact on cross-border mobilities. In fact, as I was repeatedly told throughout my fieldwork in Tengchong, locals were free to move across national boundaries without too much hassle, while communities living in areas in proximity to the border were, for the most part, left alone. This particular freedom was remarked on in the course of official friendship celebrations between the two countries. For instance, in 1956, at a high-level meeting in Mangshi, on the China-Burma border, reminiscent of British-era "frontier meetings," local participants reportedly "expressed the hope that the anticipated demarcation of the border would not prevent continued coming and going across the frontier" (Moseley 1973: 165). Chinese prime minister Zhou Enlai, who was present at the meeting, "stated that the nationalists of Yunnan must make an even greater effort than those across the border in working toward closer relations between them" (Moseley 1973: 165).

As exemplified by these encounters, initial relations between the PRC and the newly independent Union of Burma were good, reaching a peak with the settlement of the boundary issue in 1960 . The settlement was instrumental to China's fight against KMT troops based in northern Burma. By 196o, Nationalist troops had grown to approximately 9400, and were enjoying constant support from Taipei (Fravel 2008: 86-91). China was simultaneously facing problems in Eastern Tibet, as well as an uprising in Lhasa (1959) and a threat posed by CIA-trained Tibetan forces in Kalimpong (Conboy and 
Morrison 2002; McGranahan 2010). The time was ripe for a compromise, and Zhou Enlai moved quickly in early 1960 to settle the border issue with Burmese Prime Minister Ne Win. Following the settlement, China and Burma joined forces to drive the remaining Nationalist forces out of the borderlands. Military operations throughout the winter of 1960-1961 thus succeeded in destroying the primary KMT base, forcing the remaining troops to flee into Laos and Thailand. The frontier, as far as China was concerned, was pacified.

The phase of good neighbouring relations between China and Burma would not last long. ${ }^{12}$ China's pragmatic approach in its foreign policy towards Burma began to shift in 1966, following internal political developments and the CCP's efforts to export the Cultural Revolution through China's overseas communities (Fan 2012). Anti-Chinese riots, resulting from Chinese students' defiance of the Burmese government's ban on wearing Mao badges in school, broke out in Rangoon in June 1967. The riots contributed to the deterioration of relations between Beijing and Rangoon, with Chinese officials calling for the removal of Ne Win's government and openly supporting the Communist Party of Burma's (CPB) armed struggle against the Burmese government (Smith 1991: 224-227).

The situation worsened in early 1968, when the Communist Party of Burma occupied a long stretch of territory along the Chinese border. The attack, conducted from Yunnan with Chinese support, was to establish a communist enclave in the Burmese hills of Kachin and Shan State, extending from Banwa (across the Diantan border crossing in Tengchong county), to Mong La, next to the Laos border. ${ }^{13}$ Opposite Tengchong's current main border crossing with Burma, Houqiao, two local commanders of the Kachin Independence Army (KIA), Ting Ying and Zalum, defected to the CPB in 1968 with their men. This area was to become "War Zone 101" - one of several "War Zones" in which the CPB divided the territory brought under its control (Lintner 1999: 252).

In the years following the 1968 invasion, as the $\mathrm{CPB}$ consolidated its control over northern Burma, a large influx of Chinese provisions made it

\footnotetext{
12 for an overview of China-Burma relations, see Steinberg and Fan 2012; Holmes (1972)

13 China had been supporting the leadership of the Communist Party of Burma for quite some time. As Bertil Lintner reports in his (so far unmatched) history of the CPB, "the first batch of about thirty CPB cadres [...] left for Yunnan in 1951. In May 1953, Thakin Ba Thein Tin, then vice Party chairman, reached Tengchong after an arduous year-long journey by elephant and on foot. [...] They were well received by the Chinese and allowed to remain in Sichuan province where they were given political training" (Lintner 1990: 19). In the coming years, particularly following Ne Win's coup in 1962, China began to provide military aid and training to CPB cadres in China, and the $\mathrm{CPB}$ was allowed to print propaganda material in Beijing (Lintner 1990: 21).
} 
to the so-called liberated areas under communist administration. In these years, several accounts prove that local people were free to move across the national boundary (Lintner 1999, 1990). As a former member of the CPB, now in exile in China, once described to me: "there was no border, in fact, we could come and go as we pleased. There were Chinese everywhere in the liberated areas too." Moreover, thousands of Chinese "volunteers" joined the ranks of the $\mathrm{CPB}$. As Bertil Lintner, who visited the $\mathrm{CPB}$ headquarters in 1987 , describes:

The CPBs base are formed a de facto buffer state between China and the government-held areas of Burma. It had its own administration and tax system, police force and prison, schools, hospitals, markers and roads where trucks and jeeps displaying number plates issued by the CPB plied. Hydroelectric power stations were built with Chinese assistance at Möng Ko and Panghsang [the CPB headquarter], and the party's radio station continued to beam out daily broadcasts in a number of local languages. [...] A bridge has been built from Panghsang, across the Nam Hka River border to the Chinese side, and supplies were transported daily into the CPB's area: arms and ammunition, uniforms, radio transmitters, army jeeps, petrol, military maps, and even rice, other foodstuff, cooking oil and kitchen utensils (1999: 282).

The CPB also had to face some local resistance in its march into northern Burma. Until 1968, the CPB had little experience and support in the northern hills, and its members were for the most part ethnically Baman. As it swiftly conquered and began to administer a territory extending over 20,000 square kilometres $^{14}$ (roughly the size of Croatia) adjacent to the Chinese border, the CPB became a strongly multi-ethnic military body in which the top positions were occupied by Baman and Chinese, and many of the foot soldiers were local ethnic groups. In the early years, the CPB tactic was to build alliances with local warlords and chieftains, offering guns and ammunition in exchange for their support for its Marxist-Leninist policies. Initially, the plan was fairly successful, with the $\mathrm{CPB}$ winning the trust of a number of Wa, Shan, and Akhas leaders. The CPB, however, also had to face open armed resistance as they advanced through the hills of northern Burma. Pockets of KMT soldiers, mostly in charge of collecting intelligence, were also an early target of CPB military operations planned with Beijing's support. 
Despite China's military help, the CPB failed in its primary objective to connect its forces in the north with pre-existent pockets of communist resistance in Central Burma and in the hills of Pegu Yoma, the old CPB base north of Rangoon. By the mid-1970s, the initial momentum had vanished, and CPB and Burmese armies entered a stand-off that would last for over a decade. The plan to take over the whole country by military means had failed.

Further developments on the Chinese side of the border did not help the CPB cause. With the death of Mao Zedong in 1976 and Deng Xiaoping's subsequent ascent to power, China started to reduce its support for the $\mathrm{CPB}$, already recalling its "volunteers" in 1978 and extending pressure on CPB leaders to reconsider their policies and "retire" in China (Lintner 1999: 295). During these years, the People's Republic of China was deepening its relations with the United States and setting itself on a path of reform and opening up. A Maoist insurgency at its doorsteps was something it did not really intend to deal with. However, it would still be over a decade until the combined lack of resources and growing tensions within the CPB leadership would lead to a breakdown in 1989. The final nail in the coffin of the CPB armed struggle in northern Burma was hammered in by the various ethnic groups that made up the most of its rank-and-file soldiers. Dissatisfied with CPB policies, alienated by the Party's strictly Maoist ideology, and allured by the prospect of handsome profits in the narcotics business, which the CPB officially condemned, led a number of ethnic leaders to mutiny in early 1989 . The CPB's ageing leadership was forced to flee into China where they were given asylum by PRC authorities (Smith 1991: 374-381; Lintner 1990: 39-46).

The four decades between the establishment of the People's Republic of China and the fall of the Communist Party of Burma were particularly eventful in Tengchong. Following the incorporation of Yunnan into the PRC, and the PLA's efforts to integrate the borderlands into the national administration, many wealthy Tengchong traders fled to Burma. As I was told in a number of interviews, building upon their economic and trade connections and kinship ties, they permanently moved their businesses across the border, fearing repercussions due to their social status and (more often than not) sympathies for the KMT. Once in Burma, they joined a sizeable contingent of Tengchong families, scattered between Bhamo and Mandalay (Li Yi 2017; Hill 1998). While throughout this phase cross-border mobility and trade did not disappear, the borderlands were characterised by political struggles, rather than by developmental push. Plans for transnational connectivity developed by British and Yunnanese authorities prior to World War Two 
were largely forgotten, while infrastructure built during the war, such as the Stilwell Road and the Burma Road, lay abandoned. With the CPB invasion of 1968, cross-border exchanges became intrinsically political, and the nature of economic relations between the two sides were overshadowed by their ideological dimension.

With the fall of the CPB in 1989, however, such economic ties were to become prominent once again. The borderlands of Yunnan were, finally, set to join the reform and opening up announced by Deng Xiaoping a decade earlier. Within a short period, China signed several trade agreements with the Burmese government, officially opening up the border for business. While the era of communist revolution had ended, a new life for Tengchong trading families had begun - one characterised by ceasefire deals, ethnic conflict, and infrastructure development connected to resource extraction in northern Burma.

\section{Insurgency and ceasefire capitalism}

Following Burma's independence and largely in response to political exclusion in the creation of the Union of Burma, insurgencies spread across the country's frontiers in the early $1950{ }^{0 .}{ }^{15}$ In the north, along China's borders, a number of warlords and local chieftains controlled large sections of the territory, which the independent Burmese government, much like the British colonialists before it, failed to bring under its administrative power. The verdant, hilly landscape of northern Burma was an ideal place for an insurgency. Throughout history, the area had remained largely peripheral to any state apparatus, and in different phases offered refuge to those escaping lowland centres of power (Scott 2009). Secondly, it was rich in valuable resources, such as timber, precious gemstones and minerals, which could be used to finance an armed group. Thus, from the very beginning of its postcolonial history, the political economy of northern Burma was dominated by the extraction of natural resources to fuel ethnic armed struggles against the Burmese state.

15 The British, upon seizing control over Burma, had divided the colony into Ministerial Burma (the central area controlled from Rangoon) and the Frontier Areas (encompassing the hilly and mountainous regions that border China today). This particular administrative division was to significantly affect the way independence was achieved, and negotiations over the role of ethnic groups in the newly formed Union of Burma develop. British rule also had a significant impact in another way, that is, the definition and consolidation of particular ethnic identities (see Walton 2008; Smith 1991; Selth 2002). 
In the border areas across Tengchong, the main force quickly became the Kachin Independence Organisation (KIO) and its military wing the Kachin Independence Army (KIA), at present the country's second largest remaining armed group. The KIA was founded in 1961 and was quick to take over large parts of Kachin State in the 196os and 1970s. In November 1967, just a couple of months before the CPB invasion of northern Burma, CPB chairman Thakin Ba Thein Tin and representatives of the KIA signed an agreement in Beijing according to which the Kachin rebels were promised arms and ammunition if they joined forces with the CPB (Lintner 1999: 252). The CPB attack on parts of Kachin State that the KIA considered belonged to its sphere of influence, however, was seen by the Kachin leaders as a betrayal of the alliance. Fighting broke out between the KIA and the CPB, and tense relations between the two armies would persist until 1976, when a new agreement was signed in Kunming (Smith 1991: 331). Following the agreement, strengthened by new Chinese weapons supplied by the CPB, the KIA took over important government outposts and consolidated its positions in Kachin State. By 1989, when the CPB collapsed, the Kachin Independence Organisation and Kachin Independence Army (henceforth KIO/A) controlled most of the areas bordering Kachin State, with the exception of a stretch of territory under Ting Ying and Zalum - known under CPB as War Zone 101, and which, following 1989, became administered by the New Democratic Army-Kachin (NDA-K).

Thus, with the exception of the Cold War phase, in which the China-backed CPB controlled large portions of the borderland areas, ethnic politics continues to dominate the political organisation of northern Burma to this very day, shaping what has become the longest running civil war in the world. The years following the collapse of the CPB in 1989 were particularly momentous in establishing a new configuration of power across Burma's northern frontier. This was mostly achieved through a number of ceasefires, in which ethnic armies (some of which were responsible for the CPB break-up), entered into agreements with the Burmese government that included a suspension of fighting, while ethnic armies maintained administrative control of most of their territories. The first to sign up to such agreements were the four main armies that resulted from the disbanding of the CPB, namely the Kokang-based Myanmar National Democratic Alliance Army (MNDAA), the United Wa State Army (UWSA), the National Democratic Alliance Army (NDAA) in the area of Mong La, close to the Laos border, and the New Democratic Army - Kachin (NDA-K) of Ting Ying and Zalum across the Tengchong border crossing 
of Diantan. The KIO/A, on the other hand, did not agree a ceasefire with the government until 1994, when an agreement to retain arms but refrain from violence was eventually signed. In general, there were two external factors driving the signing of ceasefires by local ethnic armies. As Mandy Sadan summarises:

The first of these was the collapse of the Communist bloc, which saw also the collapse of the Communist Party of Burma or CPB. The CPB had long played a critical role in many of the conflict zones, especially along the eastern and northeastern borders of the country. The second factor was the changed orientation of Thailand and China in particular to negotiating with the Myanmar regime. Both nations increasingly sought to engage directly with the Myanmar Government to build political relations and to facilitate access to natural resources within the country. Previously, their concerns had been more with local security control in border areas, which had been effected through relying on ethnic nationality and opposition groups in the borderlands to contain local conflict zones. Most non-national armed groups agreed to ceasefires following these changes, relinquishing some territory while keeping other areas ostensibly under their control (Sadan 2015).

China, once again, played a major role in this phase on several fronts. Firstly, many of the ethnic armies that signed ceasefire agreements with the Burmese government were headed by former $\mathrm{CPB}$ members with close ties to the CCP. ${ }^{16}$ Secondly, China became a fundamental factor in sustaining local ethnic armies through the trade in a number of resources that followed the signing of ceasefire agreements. In Kachin State, for instance, the export of jade and timber boomed after 1989, while in Shan State the production and trade in narcotics became a major economic and social factor (Lintner 1999; Sadan 2016).

16 Peng Jiasheng, for instance, the leader of Kokang and of Sichuanese descent, frequently visited Kunming in the years around the mutiny and ceasefire. In several interviews with former members of the CPB in China and Thailand, I was frequently told that the CCP was probably aware of the mutiny prior to its occurring and gave a tacit consent to Peng Jiasheng to overthrow the CPB (see also Lintner 1990; Smith 1991). Further to the south, in what under CPB rule was called 815 War Zone, the ceasefire was brokered by Lin Mingxian. Lin Mingxian was born in Panghsai, where the Burma Road crosses the China-Burma border. Still a teenager, in 1966, he became a Red Guard after the launch of the Cultural Revolution, joined the CPB, and quickly rose the ranks within the Party to become the leader of the CPB 815 War Zone in the eastern Shan State (Rippa and Saxer 2016). 
As has been convincingly argued by Kevin Woods (2011a), the ceasefire years granted transnational actors and capital (in this case, Chinese) access to natural resources on an unprecedented scale. The timber and mining sectors, in particular, went through an extremely rapid expansion, a development that, paired with a lack of regulations, led to dramatic environmental and social damage (Global Witness 2005; KDNG 2010; Kramer and Woods 2011). Furthermore, the combination of military-state making, capital accumulation, and securitisation in ceasefire areas, which Woods calls "ceasefire capitalism" (Woods 2011a, 2016), contributed to the consolidation of Burmese state power in the resource-rich peripheries of the country. Large-scale resource concessions and the taxing of resource flows and trade, in other words, allowed for a new form of contested territorialisation in the borderlands, a process that eventually led to the resurrection of the conflict between the Burmese military and the KIO/A in 2011 (Sadan 2016).

The situation at the Tengchong borderlands after 1989 reflected much of the complexity resulting from the CPB break-up and the consolidation of ethnic armies in northern Burma. In the summer of 1989, a group of CPB loyalists travelled from the Wa areas facing Panghsang, the former CPB headquarters and now in the hands of the United Wa State Army, to Tengchong. From there, they made their way to Houqiao and crossed into Burma, setting up camp in the village of Kampaiti, where they entered into talks with Ting Ying and his newly formed New Democratic Army-Kachin. Their plan was to cross Ting Ying's territory, re-connect with Burmese leftists in the urban centres, and continue the CPB armed struggle inside the country. In December of the same year, however, Ting Ying - who had initially agreed to let CPB troops cross his territory - signed a ceasefire agreement with the Burmese government. As part of the agreement, he confiscated all weapons from CPB soldiers, yet offered them to stay in what, following the ceasefire, was to be called Special Region 1. This moment was to mark the end of the CPB's armed struggle in northern Burma. ${ }^{17}$

The ceasefire allowed Ting Ying to become "a major recipient of agribusiness and logging concessions in territory under his influence" (Woods 2016:130). As I shall describe later in this chapter, such concessions, and Ting Ying's personal ties with Tengchong companies, led to massive exploitation of Burmese forests in Special Region 1. Furthermore, given his close ties to the Burmese government, Ting Ying was also involved in a number of larger infrastructural projects that saw the involvements of authorities on both

17 This story was told to me by a number of CPB veterans now in exile in China. See also Lintner (1990, 1999). 
sides of the border. A similar argument could be made for the territories under KIO/A administration in the course of the ceasefire years. As analysed by Kevin Woods (2011b; 2016), in particular, logging and agribusiness concessions to Chinese actors became a principal means for the KIO/A to finance its armed political struggle. Yet, unlike the NDA-K, for which the ceasefire brought further integration with the Burmese state - a process culminated in 2009 when the NDA-K became a "border guard force" under the Burmese Army - the KIO/A maintained its independence. Eventually, in 2011, renewed conflict between the KIA and the Burmese army led to an end of the ceasefire.

\section{Border roads}

After over two years of frequent visits to Tengchong, in the summer of 2017, I still had many questions surrounding the history of cross-border trade in the area, the effects of the fall of the CPB, and the local government's involvement with resource extraction in nearby Kachin State. Through conversations with local traders and government officials, I gained a clear picture of what was happening in Tengchong at that particular time, but as long as the 199os and early 2000 s were concerned, I could hardly get anything more than broad comments about how "open" (kaifang) the border was, and how "easy" (rongyi) and unregulated the trade used to be back then. Few would go into more details, and my questions fell for the most part unanswered. Thus, when I managed to secure an interview with Chairman Zhou, my hopes were high.

Chairman Zhou used to be the head of the Tengchong Foreign Affairs office (waishi ban), until he retired only a few years before we met in 2017. As part of his tenure, he had overseen much of the development of cross-border trade since the 199os, and was one of few Chinese officials who could speak fluent Burmese. The meeting was arranged at the Tengchong Translators Association, of which Chairman Zhou was a member. The offices of the Association were in a new residential area of Tengchong, a few kilometres from the city centre. Chairman Zhou was an affable man in his early sixties. Tall, with a broad forehead and thick, black hair, Chairman Zhou spoke in short, rapid sentences. He would often interrupt a sentence, as if he were thinking something over, and then begin it again right where he had left off. As he invited me to enter the Association's office, we naturally got chatting about languages. How is it that I ended up learning Chinese, he wondered, before we began discussing the differences between Tengchong dialect 
and standard putonghua. I was invited to sit on a large, black, fake-leather corner sofa, while Chairman Zhou busied himself making tea. As in most Tengchong offices, hotels and restaurants, the tea was made on a large table carved out of Burmese tropical hardwood, complete with drainage and all traditional tea ceremony accoutrements: gaiwan, cups, tea scoop, tea tongs, tea needle, tea spatula, and tea sieve. Chairman Zhou grabbed a pu'er cake and broke it into bits, placing some of the dry leaves into the gaiwan. He gently poured hot water on it, applied the lid, and emptied the small bowl into the table's pull-out. After filling the gaiwan up a second time, Chairman Zhou poured the tea into a glass pot, repeating the operation a few times until it was full. From there, he poured it into two large glasses. After handing me one of the glasses, he finally sat down on the sofa and asked me what he could help me with. Soon, we were talking about the road.

Roads occupy a very special place in the imaginaries of those who live in marginal, under-connected, out-of-the-way places. Not just for what they promise - connection, integration, development - but also for the ways such promises transform how a particular place is seen. Thus, the mere planning of a road might produce an image of disconnection, marginality, or remoteness that did not previously exist, and its opening might contribute to narratives of "exclusion", rather than integration (cf. Mostowlanski 2017). In most cases, it quickly becomes difficult to imagine what life was like and how it functioned before "the road came" (Rest and Rippa 2019). And when they come, roads are seldom alone. During World War Two, allied forces laid a pipeline along the Stilwell Road, connecting the oil fields in Assam to Chinese forces in Yunnan. Today, Chinese road builders across the Gaoligong Mountains are accompanied by large bundles of fibre-optic cables. Perhaps more importantly, the road is accompanied by trucks and cement, blue tin panels for roofs, and plastic tubes for sewage.

In Tengchong, the road in question is the one to the Houqiao border crossings and, from there, to Myitkyina, the capital of Kachin State. This road is generally known in China as the "TengMi road": short for Tengchong-Myitkyina Road. Chairman Zhou tried to remember the exact date it was opened, and his best guess was 1992. "It's actually difficult to tell," he elaborated, "we [the Tengchong government] started working on the road in 1990 or 1991, but even after that the road was in bad conditions. You see, the weather is often bad around here, and the road was washed out regularly." Officially, motorised traffic between Tengchong and Myitkyina was inaugurated on 10 April 1991 (Che and Zhou 1992: 252) - barely a year and a half after the last failed attempt by CPB forces to regroup in Kampaiti, just across the Houqiao border - and launch an attack on northern Burma. The 
road changed everything. "Before that," Chairman Zhou recalled, sipping his tea, "the trail to Burma would go along the old Stilwell road," which, in the meantime, had been covered by thick jungle. All that was left was a trail for horses and mules. "After 1992," he continued, "we built a motorable road all the way to Myitkyina. It followed the old trail, for the most part, and it was very narrow. Right after it opened, we took a big truck with our art troupe, and went to Myitkyina to perform. [While on the way] we got stuck behind a curve, the truck could not go further, nor back, we were stuck on both sides. So, we had to dig up with a hoe, dig in front, in the back, and then eventually we managed to get the truck moving."

The opening of the road to Houqiao and Myitkyina was part of a broader process of opening up and geopolitical repositioning of Yunnan, in which foreign trade and the province's historical ties with Southeast Asia played a major role. ${ }^{18}$ As early as 1985 , the national government approved the establishment of border trade zones and began promoting the opening and development of port-of-entries (kou'an) with neighbouring countries. The State Council distinguished between two kinds of border crossings: first-class ports (yilei kou'an), directly authorised and controlled by the State Council, and second-class ports (erlei kou'an), which were placed under local management (State Council 1985). In the case of Yunnan, only five first-level ports were identified: Kunming, Wanding (Burma), Ruili (Burma), Hekou (Vietnam), and Mengla (Laos). The provincial government, however, following the establishment of the "Yunnan ports office (Yunnan sheng kou'an bangongshi)," divided all of Yunnan's ports into three categories: national-level ports (guojiaji kou'an), provincial-level ports (shengji kou'an), and local-level border people and trade passages (difang bianmin hushi tongdao). The law also stipulated that after the construction and development of the local-level trade passages, such border crossings could be upgraded to provincial-level ports. Similarly, provincial-level ports could, under the right circumstances, also be upgraded (Che and Zhou 1992: 246-7).

Geopolitical considerations played a role in this ongoing process of deepening economic relations with neighbouring countries. In the 199os, as Deng Xiaoping's "southern tour" prompted an acceleration in economic reforms, the collapse of the CPB in 1989 and the normalisation of China's relations with Vietnam in 1991 led to broader opening policies across Yunnan's borderlands. New transport infrastructure and investment in

18 Tim Summers has documented the processes underpinning the emergence of dominant ideas among academics and officials in Yunnan that the province should be repositioned as a bridgehead to Southeast and South Asia in the 1980s and 1990s (Summers 2012, 2013: 53-79). 
cross-border trade were soon promised by Yunnan officials as the latest spearhead of development. As Summers summarises:

Ideas of developing regional cooperation, using Yunnan's geographical proximity to and historical links with southeast Asia, and engaging across the province's international borders to promote economic development form the basis for many of the subsequent narratives which emanate from Yunnan. The main concept which emerges is repositioning the province towards regions based around southeast and south Asia. Implicit - and sometimes explicit - in this is the idea that Yunnan is no longer to be seen as a peripheral southwestern corner of China, but the centre of wider links between China and its Asian neighbourhood to the south (Summers 2013: 60).

As part of its re-positioning, in August 1991 the Yunnan provincial government approved Tengchong as one of twelve provincial-level ports. Given its location along the old Stilwell Road, and the fact that it marked the shortest - and easiest - route to Myitkyina, Houqiao was chosen as the main border crossing in the county and its only provincial-level port. The law, however, gave prefecture- and county-level authorities enough freedom to open and manage their own local-level passages (tongdao), and thus, in Tengchong alone, a number of tongdao were officially opened in these years. In addition to Houqiao, the three main tongdao identified by local authorities were Diantan, Zizhi, and Danza. With the exception of Houqiao, however, the other border crossings existed only on paper as they did not feature any of the infrastructure and state paraphernalia typical of official points of entry and exit. As Chairman Zhou and other Tengchong officials recalled, apart from Houqiao, there was no official immigration office or customs house at any of Tengchong's other border crossings throughout the 1990s. Back then, they were not even served by a road.

The case of Tengchong was reflective of the Yunnan government's goals with regard to the implementation of its three-level division of international ports. On the one hand, it was expected that local authorities would mobilise resources to build and upgrade border facilities along the selected routes. In so doing, the provincial government could concentrate its resources on a few ambitious projects. In particular, since Yunnan was integrated into the centrally designed highway system in 1985 , the provincial government concentrated its efforts "on a set of six paved, high-quality highways radiating out from the central axis of Kunming to three major border crossings (with Myanmar, Laos and Vietnam) and three other provincial capitals (Nanning, 
Chengdu and Guiyang)" (Donaldson 2009: 427). The main route to Burma was national road number 320 , which connected Kunming to Wanding (near Ruili) on the Burma border. The road via Tengchong to Houqiao and Myitkyina was considered a branch of this route, and was described as "relatively poor" by chronicles of the time (Che and Zhou 1992).

With the road in such conditions cross-border trade in Tengchong was slow to pick up, and it was mostly made of small, cheap items of everyday use. Light industrial products were sold into Burma, while medicinal herbs, animal parts, and opium were brought into China. Small quantities of Burmese jade would also make it to Tengchong from the infamous mines in Hpakant, but this did not seem to have any relevant impact, at least initially. There was one commodity, however, that would soon change the face of the China-Burma border: timber. Moreover, this particular commodity would re-design the geography of border-crossings in Tengchong County, and with it the infrastructural outlook of the Yunnan border region. To follow this story, it is necessary to move away from Houqiao and the Tengchong-Myitkyina Road. Other border crossings, particularly the two local-level passages at Diantan and Zizhi became relevant at this time. Both bordering Ting Ying's forest-rich territory, both fairly remote and isolated, they presented the ideal conditions for illicit trade to blossom. The story that follows is one of the creation of a particular resource frontier - and with it, a national border.

\section{How timber made the border}

In the summer of 1998, China suffered the worst floods in decades. At about a thousand kilometres north-east of Tengchong, in Hubei and Hunan provinces, the waters of the Yangtze River were pushed above cautionary levels by extreme rainfall, causing significant damage as it flowed into towns and villages. According to official estimates, over 3000 people lost their lives, and millions more were affected. Chinese meteorologists ascribed this excessive rainfall to the 1997-98 El Niño and subsequent La Niña events, while the high level of the Yangtze waters was also caused by the melting of the deep snow that had accumulated on the Qinghai-Tibet plateau. According to Chinese government officials, the disaster was also due to rampant deforestation, which caused serious soil erosion. This analysis led to one of the most significant changes in China's forest resource management. In the following two years, the government announced two major policies, funded as part of the xibu da kaifa: the Natural Forest Protection Program (NFPP, tianranlin baohu gongcheng), establishing a ban on all logging in 


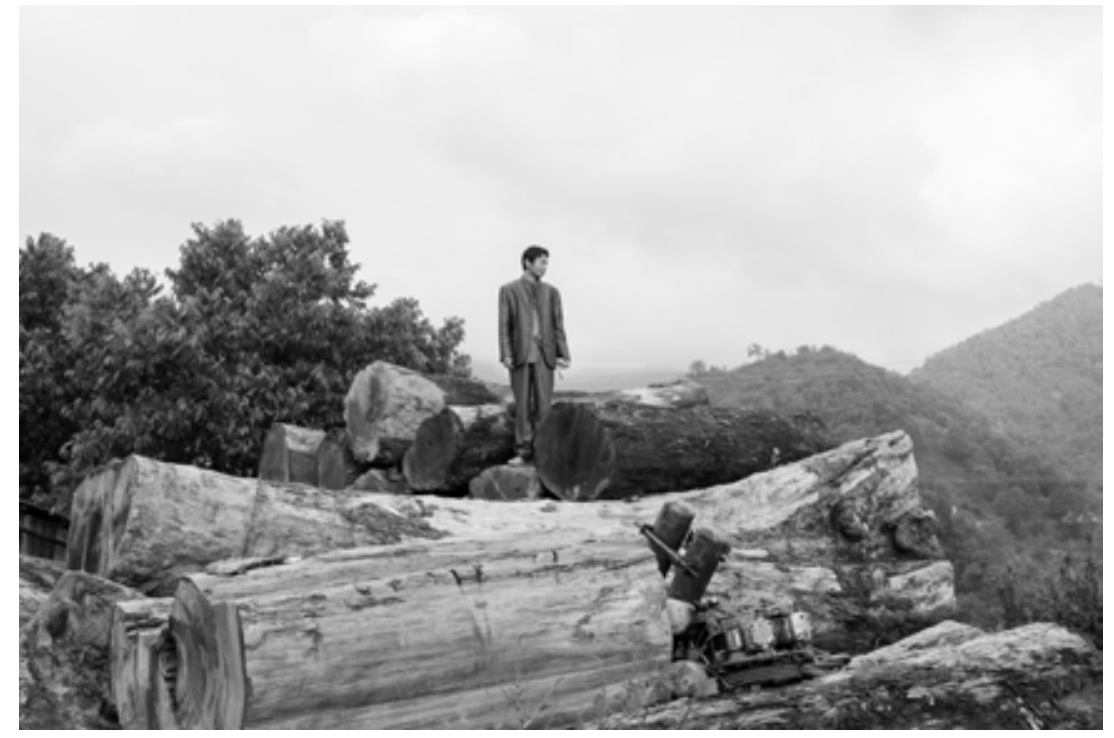

Figure 7: Burmese timber at the China-Burma (picture by the author, 2015)

the upper reaches of the Yangtze and Yellow Rivers; and the Sloping Land Conversion Program (SLCP, tuigeng huanlin huancao zhengce), or Grain for Green, a program to prevent cultivation on all slopes over $25^{\circ} \cdot{ }^{19}$

In Yunnan, the implementation of the NFPP and the SLCP brought to two major consequences for the rural population. As the next chapter will discuss, it drastically impacted communities whose livelihoods depended on the timber business or on the cultivation of steep land. Secondly, as this section elaborates, it radically changed Yunnan's timber industry. In particular, China's timber shortfall, following the implementation of the 1998 ban on logging, was met through imports. Bordering forest-rich Burma, Laos, and Vietnam, many border counties and municipalities in Yunnan soon became major hubs for the overland imports of tropical and sub-tropical timber (Figure 7). In Yunnan alone, between 1997 and 2002, imports in timber tripled (Kahrl et al. 2004). Helping this transition, in 1999, China reduced tariffs on roundwood and sawnwood imports to zero, and tariffs on plywood and veneer imports from 20 and 12-30 per cent to 15 and 5-8 per cent, respectively (Kahrl et al. 2004, 2005: 3).

The year 1998 was a turning point for Tengchong's timber industry. While the border had witnessed a growing timber industry since the late 1980 s, and in particular since the road to Houqiao was opened in 1991, the 
intensity of logging and the number of Chinese companies active across the Burma border boomed after 1998 (Kahrl et al. 2005). Changes in Tengchong's border towns of Houqiao, Diantan, and Zizhi, all major timber routes, were sudden and overwhelming. Kahrl et al. (2005) estimates that, following the boom in timber imports, in 2003, Diantan's fixed population of 20,000 was amplified by a 40,000-strong floating population of seasonal migrant workers. ${ }^{20}$ Similar number were estimated for Houqiao. The same study claims that, in Tengchong, " 50 percent of the county's population has, at some point, participated in the timber business." Unlike other contexts, moreover, "a significant portion of these are businesspeople rather than manual laborers" (Kahrl et al. 2005: 7).

Even today, in Tengchong, the early days of the timber trade are remembered somewhat fondly. Places such as Diantan and Zizhi, until that point little more than remote, sleepy outposts, suddenly became very busy (mang) and lively (renao). Mr Zhang, a Tengchong official posted to Diantan between 2000 and 2005 to oversee the trade in timber, described it as follows: "There were a lot of people there. Many would go out of the country to gamble. There is a big casino in Banwa [just across from Diantan]. We used to say that if a Chinese person wants to go to Burma, all he has to say is that he wants to play at the casino, and the Burmese border guards would let him through. There used to be so many people, so many." Chairman Zhou also recalled these days very well:

For about ten years the border areas were very lively (renao), big trucks carrying timber, in Diantan, Houqiao, it was all very lively. It's basically gone now. The liveliest times used to be the years of the timber trade. The timber industry drove many other industries and things [to these places], restaurants, services of all kinds. There used to be a lot of people working around the timber businesses. In Burma, the logging camps were like small towns, with a market and businesses, you would have hotels, massage places, restaurants, even KTVs.

With all these people and businesses rushing to the border to cash in on the timber boom, the turn of the millennium in Houqiao, Diantan, and Zizhi, also saw major infrastructural developments. After all, trucks full of timber require better and larger roads. The road to Houqiao, first built in 1992, was upgraded in 1997-98. Besides being the most convenient route between

20 The timber trade season is generally between November and April and many seasonal workers used to leave the borderlands in the summer and only return again in the autumn. 
Tengchong and Myitkyina, the Houqiao Road was the main recipient of government spending in this phase due to the peculiar situation on the Burmese side of the border. While most of the territory bordering Tengchong county was in the hands of either the KIO/A or the NDA-K, the Houqiao/ Kampaiti border crossing, as well as the road to Myitkyina, was controlled by the Burmese government. It was no surprise, then, that Houqiao would be the first - and, to date, the only-Tengchong border crossing to be approved as a national-level border crossing (guojia yilei kou'an) by the State Council in 2000.

The situation was different for the Diantan and Zizhi border crossings, which, until the timber boom, were not served by any motorable road. To understand the development of these places, I spent a morning with $\mathrm{Mr}$ Zhang, the official formerly responsible for the Diantan customs station, and $\mathrm{Mr} \mathrm{Li}$, the current (2017) head of the Tengchong branch of the China Council for the Promotion of International Trade (Zhongguo guoji maoyi cujin weiyuanhui). Mr Zhang recalled this part of history:

There had been timber coming in from Diantan since the 8os, early 90 s. But later, it was not the government that paid for the road [to Diantan]. Because Diantan borders [the territory of] Ting Ying [of the NDA-K]. It was the timber businessmen (mucai shangren), they needed transportation (yunshu), and they built the road because of transportation [issues]. Houqiao is different, there it was the government that opened that trading passage (ba zhege maoyi tongdao dakai).

Mr Li chimed in, offering more details on the reasoning behind the government's decision to invest in Houqiao.

It's like this, across the Zizhi port of entry it's all mountains, with very little villages. Diantan is the same, not many villages [on the Burmese side]. These two passages (tongdao) were at that time built by the timber companies. Only after [the road to Diantan and Zizhi] were built by timber businessmen the army was sent to be stationed there and [the government] recognised them as official border crossings. But the regular one (zhenggui), the national level border crossing which is recognised and agreed upon by the Burmese government is Houqiao, that's the regular border crossing.

As for the management of the various border crossings, Mr Li told me that, given Ting Ying's close ties with the Burmese government, and in 
particular following the recent (2010) inclusion of his NDA-K as a Border Guard Force under the supervision of the Burmese army, the border crossings of Diantan and Zizhi are essentially under government control. "They are all together, Ting Ying, the Burmese government, it's the same (shiyijia)."

As these conversations clearly elucidate, while the road to Houqiao was the result of government spending, the roads to Diantan and Zizhi were the result of private initiatives. Timber traders, eager to log Ting Ying's concessions and to avoid any possible issue and extra fees with either the Burmese army or the KIO/A at Houqiao/Kampaiti, took matters into their own hands. The Chinese government, however, was quick to respond to the private construction of these roads, establishing border facilities in both Diantan and Zizhi. New customs houses and border gates were built at all three border crossings. Chinese officials were sent to the border, associations of timber businessmen were formed. As has been documented, everybody had a stake in the business. ${ }^{21}$ Large Chinese companies bought logging permits in Burma and import permits in China. Smaller companies purchased such permits from larger companies. ${ }^{22}$ Authorities, on both sides, would turn a blind eye after securing their bribe. Contracts were signed between the Chinese government and the NDA-K as well as the KIO/A. Officers from the Tengchong foreign affairs office, such as Chairman Zhou,

21 For a supply chain analysis of Burmese timber imports into Yunnan, see Dong and He (2018). Particularly relevant to the argument that I develop in the first part of this book is their discussion of middlemen and the role of historical ties in the context of cross-border timber trade: "Different to the trade that emerged from other regions such as Africa and the Amazon Basin [.... the Sino-Burmese timber trade is based on a traditional border trade and it boomed following the change in Chinese policy and economic growth in the country. As also found with the cross-border trade of forest products elsewhere [...] the global value chain of the Sino-Burmese timber trade is typically influenced by historical, economic and social factors more so than political, institutional and international trade factors. As a result, the middlemen who have a particularly good understanding of both countries' cultures play a key facilitator role in the trade. These actors have also established strong social networks with both Chinese businessman and Burmese government authorities that have enabled their access to the value chain" (18).

22 In 2006, Yunnan authorities published the "Notification of Interim Measures on Using and Managing Burmese Timber and Minerals of Yunnan Province." According to this system, negotiated with Burmese authorities, Chinese companies need to gain authorization for and record all imports of timber in cooperation with the Burmese central government. To this end, border counties in China (such as Tengchong) are entitled to give permits every year to only five companies to conduct such business. In particular, these companies must apply for a "Timber Export Licence" from the Forestry Department of the Burma government and provide trade contracts with Burmese companies. In practice, however, such contracts were renegotiated and sold to smaller companies. 
were often dispatched to Myitkyina to oversee the smooth operation of the business. Problems were frequent. Logging concessions were often sold to two or more companies - the NDA-K would do this regularly, the KIO/A less so - and conflict would invariably arise. Should any such problems involve Chinese companies or Chinese loggers, officials like Zhou would take care of them. At that time, some Tengchong Chinese Communist Party officers were permanently stationed in Myitkyina, where the county administration maintains an office for liaison with both the Burmese government and the $\mathrm{KIO} / \mathrm{A}$. The Burmese government, which officially banned the overland export of timber, was complicit. Even in places such as Houqiao/Kampaiti, where the Burmese army was in control, timber went one way, money the other. Even after 2006, when China and Burma signed a bilateral agreement to strictly regulate exports over their shared land border, the trade declined in volume for a few years, only to pick up again in 2009 and reach record levels in 2013 (Woods 2013). ${ }^{23}$

Other infrastructures followed. In order to regulate the exit and entry of loggers and businessmen, in 1999 China introduced the China-Burma border area exit and entry pass (Zhong mian bianjing diqu chu rujin tongxingzheng) - generally referred to simply as the border pass. Like in Xinjiang, the border pass is envisioned for border residents, namely those living within $20 \mathrm{~km}$ of the border line. In fact, it did not take long for outsiders involved in the logging business to obtain border passes in Tengchong - whether they were from Yunnan, Sichuan, or Fujian, provenance mattered little. In fact, as $\mathrm{Mr}$ Li candidly admitted to me, border crossings were hardly controlled at all until at least 2004. All Chinese loggers had to do was sign an exit document at the border post, and they would generally be let into Burma unhindered. As he put it: "they like that we Chinese go to Burma and spend money. We have money, they welcome us." Since 2004, on the other hand, the border pass has become necessary in order to cross into and out of China. Yet, the pass, which is also available for Burmese border residents, was easily purchased by migrant workers and traders alike.

On at least some level, then, the opening of roads to Tengchong's three official border crossings led to the enforcement of certain rules over others. While, until very recently, timber was regularly imported despite Burma's overland export ban, Chinese authorities cracked down on other goods,

23 The bilateral agreement, "Interim measures to manage timber and mineral cooperation between Myanmar and Yunnan Province," was issued by the Office of Yunnan Provincial People's Government on 11 May 2006 (Policy reference number: Policy Office, Yunnan [20o6] 91). See also Xinhua (2006). 
most notably narcotics. As mentioned, opium was a rather common trading item in the 1980 s and 1990s. With the boom in timber trade, there seems to have been a surge in opium imports from Burma. As Mr Li recalled, "many people in the timber industry used to smoke opium, the loggers, the big bosses." Mr Zhang told me that in Diantan, at the time he was stationed there in the gos, there was a small room just by the border gate, on the Chinese side, where people would go and smoke. Then, at around the turn of the millennium, local officials began enforcing stricter controls on opium imports and consumption, under pressure from the prefectural and provincial government. Today, while it is difficult to gauge the extent to which the trade in narcotics still plays a role in the Tengchong area, opium use has all but been eliminated on the Chinese side of the border.

Timber has made the border in Tengchong county what it is today. As Chairman Zhou summarised, "if you look at the Tengchong borderlands, in terms of volume, the timber trade is certainly the most important one. The first reason is that there is abundance of timber in Burma, and demand of timber in China. The other reason is that since the gos China has restricted the exploitation of our local timber." With the wealth brought by Burmese timber, roads were built, people moved in, locals leased their land, and houses and sawmills popped up in the most unexpected of places. While the rhythm of booms and busts has left many ruins behind, the material, highly visible presence of the state in this once remote, inaccessible periphery, remains a legacy of the glorious days of the timber trade. At the time of our first meeting in Tengchong, Chairman Zhou kept a sign of this legacy in the backyard of the office of the Tengchong Translators Association. Placed in a dusty corner, behind his car and a few old planks, he showed me a border marker. Similar stone markers, across the Chinese borderlands, have become sites of frequent visits by Chinese tourists eager to take a photo at the edge of the nation - and to step, if only for a few metres, into foreign territory. While I had seen many such scenes over my years of research, the appearance of a border marker in the backyard of the Tengchong Translators Association still caught me by surprise. Chairman Zhou, laughing, felt compelled to explain. With the spate of investment that reached the border areas in the early 2ooos, he told me, the local government decided to replace all the old border stones with new ones. The one Chairman Zhou showed me had been placed in 1960, soon after the China-Burma boundary line was settled upon. As he was leading the mission to replace the markers in Tengchong county, Chairman Zhou took one of them home with him - a defining piece of his nation. As he showed it to me, however, his thoughts turned back to the timber. The timber that made the border. "It used to be," he pauses, in 
the manner that I had become accustomed to, "It used to be our forests, in China, that were bad, and the forests were nice in Burma. But now, we have good forests, Burma doesn't have any left."

\section{Material bordering}

If the boom in timber affected Houqiao, Diantan, and Zizhi in similar ways, its recent and sharp decline is contributing to drawing a different geography of cross-border exchanges in the county (this will be discussed further in Chapter 6). Both the boom and the bust, however, focus attention on the relationship between the materiality of a particular entity and the production of a specific regime of bordering. What I am interested in here is the when, how, and why of a particular border regime. The trade in timber has played a fundamental role in the material constitution of border infrastructures in Tengchong county in the 199os and 200os. These, in turn, came to define the border itself - both in terms of its material appearance but also in the practices of crossing it. While the boundary line remained the same, practices of bordering were radically changed in Tengchong county by one particular commodity - timber - and would later be re-defined by the decline of this particular trade.

As I pointed out in the first chapter, social scientists have consistently shown that borders - "that most paradoxical of human creations" (Gellner 2013: 2) - should not be taken for granted. Rather, borders should be analysed as social, cultural, and historical processes and as contested spaces of negotiation and imagination. If borders were to be represented as lines they should probably be regarded as "lines of becoming" (Deleuze and Guattari 1987; Ingold 2007). Recent contributions to this body of literature increasingly look at the material components of such processes of bordering. For instance, passports (Burrell 2008), border gates, and checkpoints (Ngo and Hung 2019) have become objects of scholarly exploration. My interest here, though, is slightly different. The argument I wish to make is that the very materiality of timber, its volume, weight, and the infrastructural bases that it requires (roads, trucks, oil, etc.) have real consequences for specific political processes. In other words, the infrastructures that define Tengchong's border crossings today are a direct consequence of the trade in timber - and of its particular material components. As this chapter has shown, while the China-Burma border line has not moved since it was established in 1960, the legal status and management of the border in Tengchong, as well as the practices of crossing it, have radically changed. 
Access to the border was dictated, in particular, by the construction of roads whose principal aim was to support and foster the growing trade in timber products. What followed - border gates, army posts, customs houses, border passes, and so on - is a typical expression of certain practices of state territorialisation that are informed by pre-existing geographies. B/ordering practices, in Tengchong, are as much the result of government initiative, as that of private ventures.

To be sure, the turn of the millennium saw a number of road projects all across China's borderlands. By 1990, benefitting from the central government funds as part of Yunnan's integration into the highway system plan, Yunnan was able to boost its road network to $56,536 \mathrm{~km}-$ a 28 per cent increase since the beginning of the reform period (Che and Zhou 1992). By 1996, the road network had extended to over 70,000 km (Donaldson 2011: 70), and by the turn of the millennium it had surpassed the 100,000 km mark (Niu 2001). The xibu da kaifa further fuelled road development across China's western region, Yunnan included, particularly through the construction of a national trunk highway system. Yunnan's annual investments in roads, as part of the xibu da kaifa, went from 10.1 billion RMB in 2000 to 26.2 billion in 2005: more than fifteen times the total investment in roads from 1950 to 1985. By 2008, "the total length of highways was $203,753 \mathrm{~km}$, double that in 1999" (Summers 2013: 132).

Nevertheless, while the xibu da kaifa provided the ideological and financial means for fast-paced road development in Tengchong, it does not account for the reason certain routes were chosen over others, and the particular timing of their construction. The Yunnan-Burma borderlands provide countless examples of border roads that were developed only at a later stage, in the late 2000s or 2010s. Yet, the roads to Houqiao, Diantan, and Zizhi, as well as similar road projects to the timber-rich regions of Burma built further south, in Dehong Dai and Jingpo Autonomous Prefecture, or north, in Nujiang Lisu Autonomous Prefecture, were built concurrently with the development of the timber industry. Tengchong is a particular case in point, as the roads to Diantan and Zizhi were not, at least initially, built with public money, but were entirely the result of private initiatives.

What is interesting here is how illicit practices, i.e. the trade in timber, inform processes of state territorialisation. Or, to put it differently, how the making of a resource-extraction frontier coincided with the making of a modern border. Kevin Woods, in his excellent work on resource extraction and state territorialisation in northern Burma, argues with regard to the timber trade that the "merging of Chinese national and provincial policy with private business interests provided a crucial state-sponsored incentive 
for the logging boom, while at the same time, like many resource-extraction frontiers in the world, created a space of scant government regulation" (2011b: 487). Woods uses the case of the border town of Pianma, in the Nujiang Lisu Autonomous Prefecture, which, in 1991, was designed as a Special Economic Zone and a "provincial level open port," paving the way for massive timber imports. Scant government regulations are, however, only part of the story. As I have shown in this chapter, the construction of roads and border facilities along Yunnan's border with Burma also created the possibility for a particular kind of state territorialisation through timber-led infrastructures. Furthermore, as I will argue in the third part of this book, while such infrastructure initially facilitated the exploitation of Burmese forests, they most recently contributed to bringing the timber trade to an end.

\section{Conclusion}

In 1992, as Chairman Zhou was travelling to Myitkyina on a truck for the first time after the completion of the road through Houqiao, a group of Chinese researchers published a book on Yunnan's international linkages. Edited by Che Zhimin, a Yunnan native, the book made a case for Yunnan's need to take advantage of its historical familiarity, geographical advantages, and cultural ties with nearby countries and develop a state-of-the-art network of cross-border infrastructure in order to increase economic relations and development (Che and Zhou 1992). At the time of writing, on the other hand, the authors argued that Yunnan has become a "dead end" in dire need of investment in cross-border transport infrastructure. Many such publications have appeared since, in which scholars and officials repeatedly stress the need for Yunnan to take advantage of its location and historical origins, often pointing to the presence in the province of many minzu with close ties to similar groups in Southeast Asia. ${ }^{24}$ And yet, as this chapter has explicated, the story of the timber trade that has developed in the years following the publication of Che Zhimin's volume, together with an expansion of cross-border infrastructure, is one in which the main protagonists and beneficiaries are Han Chinese. Inhabiting a different kind of "locality" from that described in the case of the KKH and Karim, Tengchong trading families, make use of a different kind of "proximal capital" in their business practices.

24 For an overview and an analysis of Che Zhimin's volume in the context of Yunnan's repositioning as a bridgehead over the past three decades, see Summers 2012. 
The state, in particular, emerges as a fundamental player in the processes of proximity, but not merely in the sense that traders need the state's support, or protection, for the success of their businesses. While state officials like Chairman Zhou or Mr Zhang have been crucial for the exploitation of Burmese forests by Chinese logging companies through securing permits, distributing licences, and taking care of conflicts among the various stakeholders, the trade itself has been fundamental to the creation of a particular border regime. In other words, the illegality of the timber trade did not succeed "in spite" of the state, or by keeping the state out. Rather, it brought the state in - through transport infrastructure - and took advantage of its regulatory power.

Today, the quest for frictionless corridors is more alive than ever. More than a century since the original British plans, Tengchong is still waiting for its railway. This time, however, China's infrastructural hubris is leaving little doubt that this task will soon be accomplished. The projected Kunming-Ruili railway has already reached Baoshan. From there, plans have been sketched out for the construction of the line's extension towards Tengchong. Officials in the city told me in 2017 that they were hopeful of securing funding by 2020. This, however, would only be one piece of a much larger plan for the development of the area. As Chapter 6 will show, such plans include a brand-new border trade zone in Houqiao, an international airport, and much-upgraded roads and border facilities. What I have shown in this chapter is that this story, from British imperial formulas to Belt and Road fantasies, has not followed a fixed developmental trajectory. Rather, by focusing on the post-ceasefire and post-opening up years, I have pointed out how Tengchong authorities have connived with local businesses to transform China's national boundaries into a resource frontier. This transformation, in turn, became a definitive moment in the current border infrastructure, upon which Belt and Road projects are based. While in this chapter I have focused on the materiality of border infrastructure, in Chapter 6 I return to the case of Tengchong - and, in particular, the new Houqiao border crossing - to discuss the issue of illicitness more specifically. In so doing, I will also detail what has happened in Tengchong since the mid-2010s, when the timber trade came to a close.

The history of how the roads to Diantan and Zizhi came to be built is absent from the current push for transnational connections within which Tengchong authorities envision the future prosperity of the city. As in the case of the KKH described in the previous chapter, the current development of cross-border infrastructure in Tengchong implies a particular form of erasure. Pre-existing forms of connectivity, or what I have defined 
through the notion of proximity, which in this case produced the particular geography of border-crossings in the county, are not accounted for by the current proponents of Belt and Road corridors. More generally, erasure is a fundamental process underpinning the ideology of development along the Chinese borderlands. The next section expands upon this discussion by engaging with a theme that has so far remained conspicuously absent from my analysis: the role of ethnic minorities in the phase of borderland development that this book addresses. In the third section, I will eventually return to the issue of connectivity that I have thus far sought to highlight. The last chapter, in particular, brings us back to Tengchong to show how the end of the trade in timber in the mid-201os and the promotion of the Bangladesh-China-India-Myanmar Economic Corridor through Houqiao led to new forms of marginalisation. 


\section{Coda}

In the early summer of 2009, after a few months of study and research in Urumqi, I took the long train journey to Kashgar for the second time that year. This time, my planned itinerary included a brief visit to the Pamir mountains around Tashkurgan, followed by a longer journey to Qinghai through southern Xinjiang. Little did I know, at the time, that the Karakoram Highway that I was travelling along for the first time, and the China-Pakistan border to which I made a short visit together with another group of tourists, would become the focal object of my doctoral work within a few years. The first part of the trip went rather smoothly. I spent a few nights camping and trekking around Karakul Lake, before continuing on my journey to Tashkurgan. The two checkpoints along the way represented minimal hassle: by early 2009 foreigners were not required to have any special permit to visit the region, so the checkpoints were little more than a chance to take a little stroll and acclimatise to the altitude. At the Khunjerab Pass, on the other hand, I was seen taking pictures of army facilities in proximity to the border, which I was later forced to delete. Even this little incident, however, did not make any lasting impression on me. On the contrary, the scenery along the drive up to the Pass at more than 4600 metres, would remain with me for much longer. Upon my return to Kashgar, I spent a couple of days resting, in preparation for what I was expecting to be a ten-day long trip to Xining, Qinghai province, through Khotan (Hetian), Charkliq (Ruoqiang), and Golmud. Then on the evening of 5 July, as I was walking to Kashgar's bus station to take a night bus to Khotan, a friend I was particularly close with called from Urumqi.

"They are shooting people, killing people," a scared voice cried as I picked up the phone. "There was a demonstration today, then the police began to kill Uyghurs." What followed, over that first, frightening night and the next few days, is widely known. According to the official version, violent Uyghur mobs, angered by the news that Chinese authorities had failed to address the case of two Uyghur factory workers killed in an ethnic brawl in a Guangdong factory, took to the street and attacked Han people, resulting in 197 deaths. Yet, what my friend was telling me over the phone, and as has been consequently been reported by several international news outlets, was that the demonstration was peaceful, and that it was the police who started to beat and then shoot Uyghurs. In one video that was circulated online soon after, I could see a person 
being shot near the intersection of Jiefang South road and Longquan Street, where I had lived for the previous four months. Had I still been in Urumqi, I would have seen that from my living room window.

While on the bus to Khotan that night, I did not get much sleep. I caught a few of my fellow passengers, virtually all of them Uyghurs, ${ }^{1}$ talking on the phone, clearly alarmed. Nobody, however, seemed to be in the mood to talk about what was at the moment unfolding in Xinjiang's capital. We arrived in Khotan at dusk, to find the bus station surrounded by heavily armed police vehicles. As I made my way to my intended hotel, both police and army vehicles were making the rounds of the empty street. I tried to ring a friend in Urumqi, but his phone was off. After a quick breakfast, I headed for Khotan's main bazaar, eager to find out more about what was happening. More police cars were patrolling the street. At the main bazaar, I only saw few people at what would have otherwise been a rather busy time. Still, some of the shops were open. At one point, a police car stopped about a dozen metres ahead of me. Four heavily armed officers exited the vehicle and approached a group of five or six Uyghur men who were chatting on the sidewalk. A brief discussion ensued, which I could not hear a word of. Then, suddenly, more policemen came from another vehicle parked nearby, and all the Uyghur men were taken into custody. Over the next few days, I would witness dozens of arrests, carried out in a similar fashion, for what to me seemed to be with no reason. I decided to walk to Tuanjie Square, a large space dominated by a statue of Chairman Mao shaking his hands with an old Uyghur man - Uncle Kurban, a recurrent propaganda trope on ethnic unity in Xinjiang. ${ }^{2}$ Yet, on that particular day, both the socialist grandeur of Tuanjie Square, and the prominence of the statue contained within it, were overshadowed by an impressive parade of nearly two dozen military tanks slowly moving along Beijing Road. People were rushing from the street in various directions, and I decided to head back to the hotel as well.

Over the next days, after considering the idea of a return to Urumqi, I decided to stick to my original plan, following the southern edge of the Taklamakan desert, and make my way into Qinghai. During the afternoon of 6 July, the internet service within Xinjiang was cut off. International calls were restricted, though it was still possible to call within China. As the picture of what was happening in Urumqi became clearer, more

1 On how the politics of mobility in Xinjiang are defined by ethnicity, see Joniak-Lüthi (2015).

2 On the story of Mao and Uncle Kurban, and how it came to be representative of the PRC ethnic policy in Xinjiang, see Chen (2016). 
and more armed police vehicles were patrolling the streets of every city, town, and small village I passed through. It took me twice as long as I had planned to get out of Xinjiang. Regular armed checkpoints made every bus trip slow and painful. My bags and I, along with those of my fellow travellers, were thoroughly checked several times every day. All the places where I had planned visits to archaeological sites or museums were closed. Private traffic, it seemed, had completely stopped. Streets and restaurants were largely empty, and a surreal quietness reigned over the small towns I was passing through. During my last visit to Xinjiang in 2017, almost ten years after this first trip, the pervasiveness of checkpoints had once again become a fact of life for millions of Uyghurs. Then, as now, Han Chinese were largely unaffected by the security measures put in place to, allegedly, "protect" them. Uyghurs, on the other hand, were and are stopped, their bags and phones checked, and their houses searched.

Connections in Xinjiang are a fragile matter.

Connections are dictated as much by the quality of infrastructure as they are by ethnicity and the security concerns of the day. While the second and third part of this book will deal with each of these aspects, respectively, my experience following the violence that unfolded in Urumqi in 2009 shows how tenuous and unstable promises of connectivity can be. Internet in Xinjiang was restricted for almost a year following the violence. Many checkpoints established in July 2009 became permanent. New restrictions on the mobility of Uyghurs were introduced, making it harder for people to obtain a passport, or even to travel within the region.

Connections across the Chinese borderlands are not meant for everyone. 



\section{Part 2}

\section{Curation}

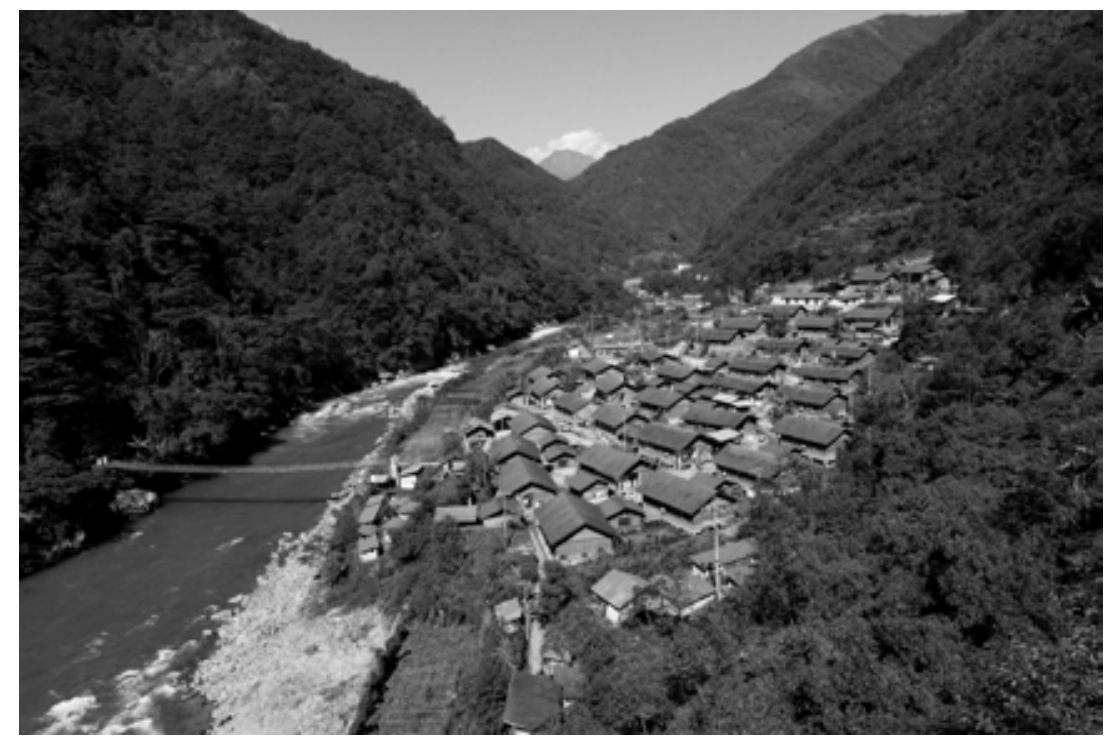

Figure 8: A New Village in the Dulong Valley (picture by the author, 2016) 



\section{Dependency}

"When drinking water, do not forget who dug the well.

Be forever grateful to the Party"

— Poster in the Dulong Valley.

"The idea of solving the problems of the countryside by replacing village housing with model villages had been promoted by a new generation of sociologists, educators, medical experts, and architects" — Timothy Mitchell (2002: 188), writing about Egypt in the 1930s and 1940s.

I first visited Tengchong in the summer of 2015, at the beginning of my postdoctoral fieldwork in Yunnan. As part of the same trip, I was looking for another field site that might offer a counterexample to those of Tengchong and Kashgar, with their historically established cross-border ties and ambitious plans for future development. I was looking for a remote periphery, a border area where echoes of Belt and Road fantasies had not yet materialised. From Tengchong, I thus travelled north, into the Nujiang Valley. My first stop was Liuku, the seat of the Nujiang Lisu Autonomous Prefecture. Squeezed in on two sides by steep mountains, Liuku is situated along the $\mathrm{Nu}$ (or Salween) River around small clusters of strikingly tall buildings. To the south, a new part of the city had just been built - its ten-storey apartment blocks were still standing largely empty. The bus station had just been moved there, and the new town was expected to attract people from the nearby villages and valleys. The new highway, one that would eventually connect Liuku to the Baoshan-Tengchong Highway, was under construction, and expected to open in a few years.

In Liuku, I inquired about my intended destination: the Dulong Valley. Some ten hours away by car to the north of Liuku across the Gaoligong Mountains, the Dulong Valley had only recently been connected by an all-weather road to Gongshan, seat of the Gongshan Dulong and Nu Autonomous County. The old road, inaugurated only in 1999, was opened solely during the summer months, when waterfalls would still make the journey treacherous. Until the completion of a tunnel in 2015, at around the time of my first visit, traffic in and out of the valley was blocked during the winter. To the other side of the tunnel, until then cut off from the rest of China during the winter months, the majority of the people living in the Dulong Valley are Drung, or Dulong, one of China's smallest ethnic minority 
groups (shaoshu minzu). In Liuku, many locals reinforced a particular view of remoteness connected to the Dulong Valley and its people. It is far (yuan), people pointed out, and the road is not safe (bu anquan). While none of the people I talked to had ever been to the valley, most would say that they had heard of its beauty (meili), but that the Drung were still very backward (luohou). Many suggested I go to Binzhongluo instead, a Tibetan settlement north of Gongshan were tourism has boomed in recent years.

Such answers were not surprising - if anything, they were echoing mainstream narratives of the Dulong Valley and the Drung produced both inside and outside of China, generally lingering around images of marginality and untouched beauty. As Ralph Litzinger noted, "remoteness" (pianpi) encompasses two particular meanings in the Chinese imagination: on the one hand, it denotes a degree of geographical distance, but also mystical beauty. On the other hand, the remote is stigmatised as a "site of lack, of uncivilized vulgarity, a land of economic and social malaise" (in Schein 2000: 5). A 2016 New York Times report seems to echo such double significance, describing the Dulong Valley as "one of the most remote and pristine in China" with its "rain-soaked forests above a river the color of jade" (Wong 2016). In the report, Chinese interventions bring modernity, but also new forms of exclusion. $4 \mathrm{G}$ internet, hydropower stations, tourism: these are the indicators of the rapid changes that the Dulong Valley and its people have only recently undergone after the new road and tunnel to Gongshan and the Nujiang Valley were completed. Before that, the article points out, the Drung were largely "cut off" from nearby valleys by the high peaks of the Gaoligong mountains. ${ }^{1}$

To an extent, my own interest in the valley was connected to this particular image. While my training as an anthropologist made me sceptical of any claim of the valley hosting an "original" and "untouched" form of culture, I was indeed looking for some degree of remoteness - or, at least, disconnectedness - that I had not encountered in previous research settings across China. Over three long-term visits to the Dulong Valley, between 2015 and 2017, this view would change. The Dulong Valley is, by many standards, still a faraway place. If one were to travel overland from Kunming, the provincial capital, it would take three days to arrive in Dulong. The nearest airport, in Baoshan, is a couple of days away. Should a landslide block the narrow road connecting the valley to Gongshan, Dulong would be cut off

1 For another recent example, see Aviram (2017), particularly the following quote: “As a traveler, visiting remote villages, and meeting people who have received little influence from our modern world is a mesmerizing experience." 
once again. And yet, through state-led development projects and government subsidies, the Drung of the Dulong Valley are intimately involved with larger processes of nation building. The valley itself, its fields, forests, non-human population, and villages, have been radically changed by the impact of national policies. ${ }^{2}$

This chapter addresses this particular tension, between remoteness and modernity, in the Dulong Valley. It does so by tracing the history of the valley's integration into the People's Republic of China and analysing the impact of a recent state-led programme, "Building a New Socialist Countryside", following which all inhabitants of the valley have been moved into newly built houses in larger settlements. In particular, I show how such intervention has generated increased dependency among the Drung on the Chinese state, while re-designing the valley as a showcase for ethnic unity and rural development. The Drung, in particular, have been mobilised to produce a particular narrative of national identity based on loyalty to the Communist Party, which is perceived and performs as a giving entity. To understand the premise of such programme and its implicit outcome, in this part of the book I develop the notion of curation. I argue that the state, by defining the Drung as primitive and the Dulong Valley as a wasteland, sees a particular form of development as a "healing" process through which ethnic minorities and the space they inhabit can be lifted out of poverty and into modernity. The same notion will be used in the following chapter to return to Xinjiang, and to describe the renewal of Kashgar's old town. Thus, unlike Part One, in which I analysed the impact of state-led development on local forms of trade, Part Two attends to the particular place assigned to ethnic minorities within larger processes of modernisation in the borderlands. In so doing, I show how development policies are embedded into particular ideological views of what ethnic minorities should be, and thus underpin particular programmes of "social engineering." The ideological component of such projects is what the notion of curation attempts to capture.

\section{A birthday party}

22 October 2016. My fingers were sticky with the fat of the barbecued porkchop I had just eaten. A number of chewed bones filled a plastic cup

2 Anthropologist Stéphane Gros has written extensively about these various issues. See, in particular, Gros $(2010,2014,2017)$. 
on the table. On the floor, sunflower seed shells piled up between the legs of the five of us, sitting around the small table on plastic stools. I couldn't remember how many rounds of cards we had already played. But I was winning - for a change. I counted the banknotes, arranged in an orderly fashion on the edge of the table in front of me. There had to be almost two hundred RMB. Axiang was visibly drunk, yet she kept filling up beer glasses and insisted I down one more. I tried to resist, then inevitably gave in. The warm Lancang beer was getting worse with every sip. Another round, then I'm out, I told myself as I was handed a new stack of cards. Fortunately, one of the players stood up to go to the toilet. It was as good an excuse as any, so I decided to follow him outside, where a few kids were playing around the small barbecue, teasing Jiang Yi, the improvised cook. The occasion was the third birthday of one of Axiang's nieces. Axiang, with whose family I had been staying for the previous month, had asked me if I wanted to join the party the previous night. We drove to the village of Bapo, where the party was taking place before lunch, yet when night fell, we were still busy playing cards and eating. It would be quite a while before we could return to Qinlangdang village, some $20 \mathrm{~km}$ down the road. I found a quiet spot just outside the house, on the side that looked towards the Dulong River - invisible in the darkness but a vivid presence due to the noise of its restless waters. I sat on a little concrete wall between two houses, beside a tiny vegetable garden, jotting down some notes about the conversations I had been part of. Despite the occasional light bulb, the new villages were still rather dark at night, and I made use of the light coming from the house to write. From where I sat, I could look inside one of the rooms of the house. Kids were playing, joyously unattended. The walls of the room were covered with colourful posters. One depicted the "ten supreme generals (shi da yuanshuai)"3 riding horses, complete with small captions listing their names, and places and dates of birth and death. Patriotic posters, most often depicting Mao Zedong or Xi Jinping, were a ubiquitous object of decoration in Drung houses, yet that was the first time I noticed one with the ten supreme generals. I spent some time looking at it, trying to read the names and the dates. Beside it, in sharp contrast, another poster represented two small babies wearing an odd, fluffy blue costume. On top of it, four capital letters: BABY. The posters were placed behind a new TV screen, aptly placed on a blue cabinet adorned with small red hearts. On

3 The rank of dayuan shuai was awarded to ten veteran generals of the PRC in 1995, namely: Zhu De; Peng Dehuai; Lin Biao; Liu Bocheng; He Long; Chen Yi; Luo ronghuan; Xu Xiangqian; Nie Rongzhen; Ye Jianying. 
top of it was a small vase with some plastic flowers. In rural China, this was as kitsch as it gets. Yet, as in many other rural parts of the country, in the Dulong Valley posters, shiny cheap furniture, colourful plastic flowers, and framed wedding pictures were a marker of modernity.

The birthday party itself was, after all, an eccentricity of the modern times people like Axiang struggled, but strived, to inhabit. As she had explained just a few hours before, on the way to the party, birthdays were not celebrated in the valley until two, maybe three years ago. I could not help but think that this was around the time when most Drung families were moved into new houses. And a good birthday party, of course, cannot be complete without a proper cake. But where, I wondered, could you possibly get a cake in the Dulong Valley? Despite the roads, the new villages, the mobile phones, Dulong was still a fairly long drive from Gongshan, and I could not recall seeing any bakery in the valley. Axiang was generous in her explanation. Just a couple of years before, a bakery had opened in Dulong Township, the main village in the valley and the seat of the local government. Perhaps, she wondered, people only began celebrating birthdays once the bakery had opened.

As I sat outside the small house, I struggled to reconcile that day, and indeed almost each day I had spent in the valley, with the image I had constructed from the literature on the Drung that I had become familiar with. Before my first visit, in May 2015, I was expecting a community struggling with China's new conservation policies, such as the ban on logging and swidden agriculture that had been implemented in the valley a decade earlier. I was curious to see the impact of the new road to the valley on the local population. I was wondering if tourism would (already) be a factor in such remote area. Yet, as so often appears to be the case around China's borderlands, I was not ready for what I eventually found. The pace of development, the scale of change, was something I had not foreseen. Nor was birthday cake, for that matter.

Sometimes, it takes an outsider's story to better understand some of the local dynamics. In Dulong, I found my conversations with Axiang's husband to be particularly enlightening. As we drove back to Qinlandang after the birthday party, with Axiang sleeping and her cousin Alisong throwing up in a small plastic bag in the back of the car, we talked about how he came to live here. Our driver, husband to Axiang and the only sober person in the car, had spent the entire day playing Mahjong with friends and relatives. $\mathrm{Mr} \mathrm{Bu}$, as I call him, was originally from a small town outside of Kunming. He first arrived in Dulong a decade earlier, working on the valley road. With his savings he bought a small van - what is known in China as a 


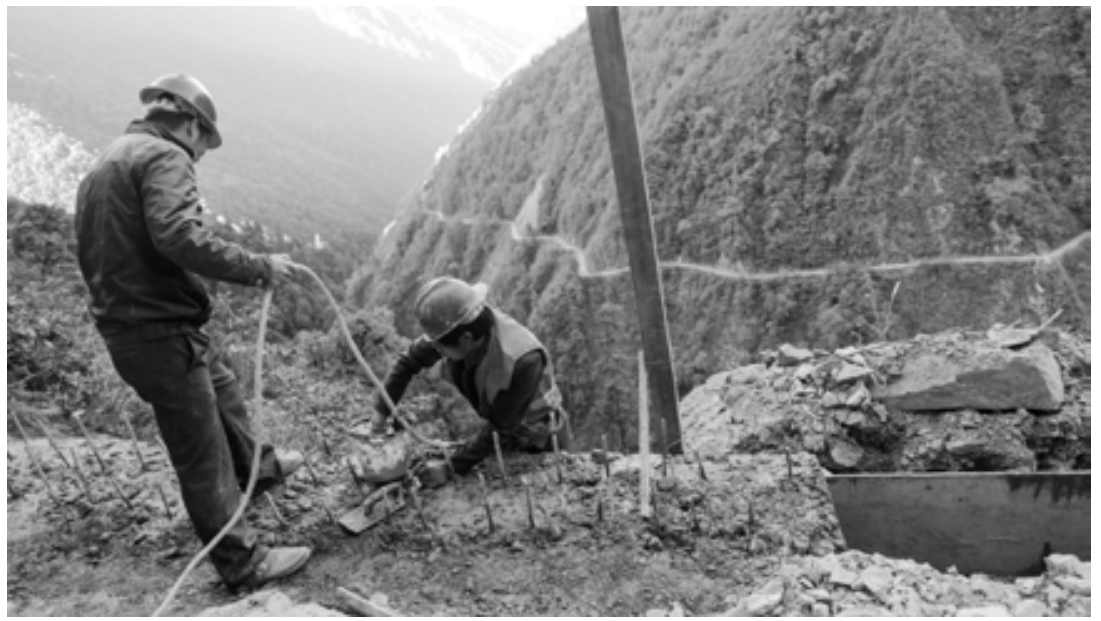

Figure 9: Construction work on the road between Gongshan and the Dulong Valley (picture by the author, 2016)

mianbaoche - and worked for a few years as a driver, shuttling passengers up and down the valley, and more often than not to Gongshan and back. He met Axiang, married her, and moved together with her family from their native village of Maku to the new village of Qinlandang, where all Maku residents were relocated. Always fond of cooking, once settled in the new village, $\mathrm{Mr}$ Bu opened a restaurant, and has since given up his job as a driver. He seemed to hope that the new road, the same road that brought him here in the first place, would bring tourists to his restaurant. In the meantime, as everyone else had fallen asleep in the back of the car, he lit up another cigarette before we finally reached home.

\section{Road to paradise on earth}

The history of the winding road (Figure 9) that leads to the Dulong Valley where $\mathrm{Mr}$ Bu used to work, tells a lot about the valley itself. First opened in 1999, it put an end to the use of China's last state-owned caravan, which used to connect Gongshan, in the valley of the Nu River, to Bapo, former seat of the local government. The caravan trail through the Gaoligong Mountains was rough business. Leeches, snakes, rain and snow - those who used to shuttle goods along the three-day route remember it today with a mixture of awe and longing. In a rare testimony from this recent, yet seemingly distant past, a Chinese documentary from 1997, called "The last caravan (zuihou de mabang)," shows one of the last caravans travelling from Gongshan, through 
the Gaoligong Mountains, into the Dulong Valley. Through a number of dramatic and spectacular scenes, the documentary details the perils of crossing the Gaoligong Mountains, as well as the immaculate beauty of the landscape. The caravan is defined as a "lifeline (shengmingxian)" for the Drung - one that the new road is bound to replace. While following the crossing of the Gaoligong Mountains by foot and on horseback, the documentary juxtaposes scenes from government offices in Gongshan, in which local officials discuss the need for a road to bring development to the remote valley. As a local government official points out, the situation in the Dulong Valley becomes more difficult (kunnan) every year, and the road is necessary to bring stability (anding) and unity (tuanjie) to the people of the valley. The new road, then, seems to entail a project that is markedly economic, but also social and moral. It is not just that the road is expected to bring modernity to one of China's most remote and underdeveloped people, but that its construction will also include the Drung in a project of national unity and solidarity.

Once the road was completed, the old caravan route was abandoned. The overgrown path is now largely indiscernible from the surrounding forests, and only the most experienced guide would agree to take an outsider along this route. As trucks, buses, and the occasional car replaced the role of horses, the project of national integration of the valley sped up. So momentous was the construction of the road that the valley is dotted with posters celebrating it. "The construction of the Dulong valley road brings benefit to the Drung," reads one. A small memorial placed in the main square of the newly built Dulong Township, on the other hand, celebrates it with the words of former CCP secretary Jiang Zemin: "Building the road to the Dulong River, promoting the economic development of Nujiang." The square, significantly, lies in front of the newly built Museum of the "Dulong nationality (Dulongzu bowuguan)." All around it, is the Dulong Township: a newly built village, neatly designed with shops, hotels, and offices that nevertheless maintain an unshakeable air of out-of-placeness. Unlike other villages in the valley - about which I shall say more later on - houses in Dulong Township are four or five storeys high. Painted in orange, they are embellished with geometric patterns evoking the colours and symmetries of local textiles. The roofs are covered with narrow strips of brown tin, resembling the thatched roofs traditionally used in the valley. Every house, moreover, as well as all of the lampposts in the village, is branded with a stylised image of the head of a Dulong cattle (Figure 10).

In today's China, road construction is part of an effort to build both a "material civilization" (wuzhi wenming) and a "spiritual civilization" 


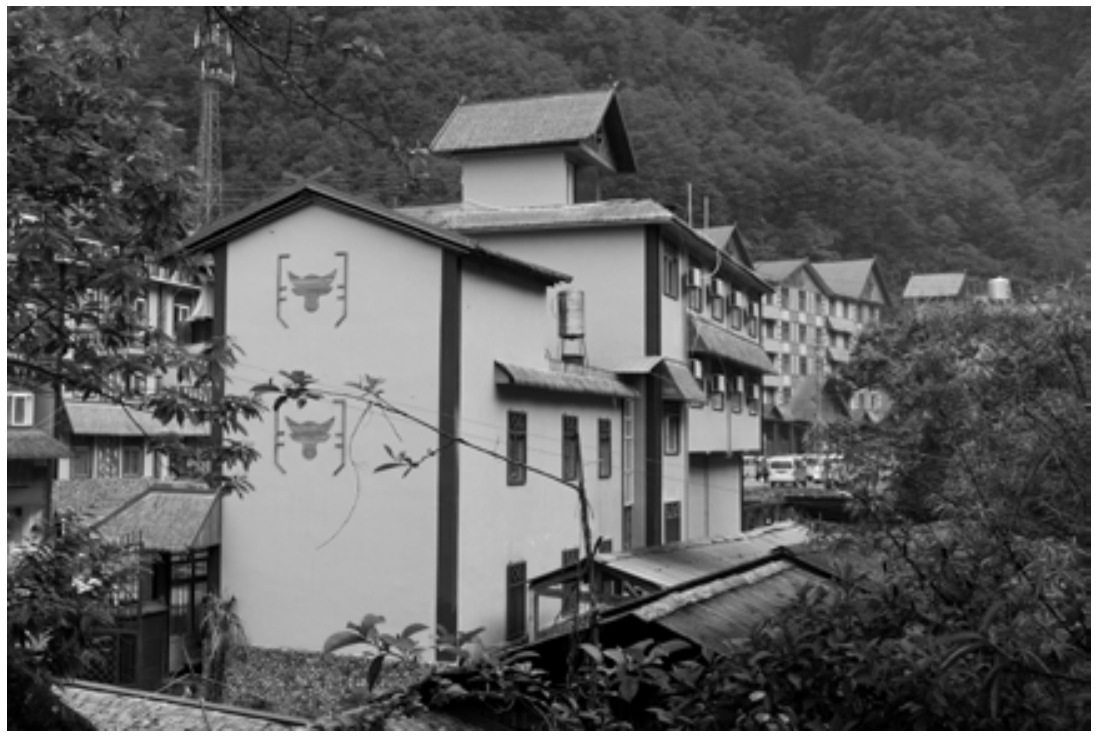

Figure 10: Dulong Township (picture by the author, 2015)

(jingshen wenming) (Flower 2004). By uplifting the material conditions of living, roads also bring rural, remote, and backward peasants into the embrace of modernity. Roads, as such, are not only economically beneficial, they are "civilizing" technologies. Thus, by establishing a connection, roads also reinforce a boundary - between the rural and the urban, the remote and the cosmopolitan, the backward and the modern. In so doing, as this chapter argues, roads also fuel an economy of dependence in the borderlands of the nation state, where a combination of strategic interests (often framed in terms of bianjing wending, or border stability), minority policy, conservation policies, and economic hardship single out the state as the exclusive "provider of goods."

Yet, while both the road and the new Dulong Township village project an image of modernity and connectivity, "remoteness" remains a powerful trope in both the way the Dulong Valley is described by outsiders and in how it is depicted by those living there. Visitors are struck by the natural beauty of the valley's seemingly immaculate forests, the pure waters of its rivers, and the peculiarity of the Drung people. Echoing such feelings, a promotional booklet by the Dulong Township CCP Committee and government, calls the valley renjian tiantang - literally, "paradise on earth." This definition, widely used for a number of tourist sites inside and outside of China, is quite fitting for the Dulong case. Not necessarily because of the paradisiacal quality of the valley, well represented by the word tiantang ("paradise, heaven"), but 
rather for the human character implicit in the word renjian, which explicitly refers to the human world - ren is the character for "person". The valley's landscape, in fact, while projecting an image of untouched wilderness, is the result of what I shall call a process of "curation." A brief history of the valley since 1949 is now necessary to shed light on how such processes unfolded.

\section{The benevolent state: From marginalisation to dependency}

Before the establishment of the People's Republic of China, north-western Yunnan was a place where several political legitimacies coexisted (Gros 2016). Tibetans, Naxi, and Chinese projected multiple and often overlapping claims over territory and population - a system of aspirational sovereignty from which the Drung were mostly excluded. In particular, the Drung were obliged to pay heavy taxes to Tibetan chiefs and to the Chinese empire. When unable to do so, they became dehumanised and devalued. As Gros has put it, "Drung women, men, and children were indeed at times exchanges for oxen or taken away to become slaves in an alien land" (Gros 2010: 31). Such deprivations, still a vivid part of local oral histories, define a phase of significant marginalisation for the Drung. They also define their ethnic identity vis-à-vis their powerful neighbours and the uneven political relations they entertained with them, thus influencing their sense of locality and belonging (Gros 2010).

With 1949 and the communist victory in China, this system radically changed, ending centuries of exploitation and re-defining political hierarchies in the area. The Drung, while liberated from their feudal obligations, were integrated into the PRC system of ethnic minority, and provided assistance according to their "backward" status. ${ }^{4}$ The PRC authorities' choice of name - Dulong - seems to reflect a recognition of local identity policy. Until then, the Drung were known in China as "Qiuzi" and by the British as "Nung." While the name Qiuzi was considered as a possible official name for the Drung, following the Sino-Burmese agreement over the location of the border between the two countries in 196o, the name Dulong - a Chinese

4 The nationalities identification project, or minzu shibie, was carried out according to both "ethnographic" and political concerns. The stated aim of the project was to classify each minority group according to Marx's schema as either primitive, slave, feudal, bourgeois-capitalist, socialist, or communist. The criteria according to which different ethnic group were identified and classified were borrowed from Stalin, and centred around the so-called four commonalities: common territory; common language; common mode of subsistence; and common psychological make-up. In practice, it was much more politically charged (cf. Harrell 1995; Mullaney 2010). 
transcription of their vernacular - was chosen (Gros 2004; 2010). In this way, the Drung were included in China's civilising project (Anagnost 1997; Mackerrass 1994; Harrell 1995; Gladney 2004), classified as a "primitive society" and identified as a primary target for socio-economic development. Thus, beginning in the early years of communist rule, the Party donated oxen, clothing, allowances, and work clothes to most inhabitants of the valley (Gros 2010: 40). Assistance was provided through the state-owned caravan mentioned above, which was in charge of transporting cereals to the valley until the road was opened in 1999. As Gros (2010) shows, this led to the characterisation of the party-state by local Drung as "the provider of goods" - a situation in which the party-state's legitimacy is valued against its generosity.

As part of communist China's interventions in the valley, the Drung's agriculture system, based on swidden cultivation, was identified as a major obstacle to economic development and, as a consequence, has been the target of a number of reforms. While initial reforms were simply aimed at improving agricultural techniques and increasing outputs, in the late 2oth century the focus shifted to conservation as the main policy driver in the valley. The Dulong Valley has been incorporated into the "Gaoligong Mountains National Nature Reserve," and, as part of the "Three Parallel Rivers of Yunnan Protected Areas," it has been a UNESCO World Heritage Site since 2000. While early protection policies were not strictly implemented (Gros 2014), with the Open Up the West Campaign of the early 2000s, new government interventions brought the issue of environmental degradation to the forefront. The Dulong Valley thus found itself part of a broader ecological movement (Hathaway 2013) that, over the past several decades, led to a number of "ecological construction" programmes intended to conserve and rehabilitate spaces like forests and grasslands (Yeh 2009a, 2009b). In particular, the implementation of the Sloping Land Conversion Programme mentioned in the previous chapter was fundamental in re-shaping the ecological outlook of the valley, as well as the livelihoods of its inhabitants. As most cultivable land in the valley is located on slopes with a gradient of over 30 degrees, "the program implied a massive conversion of nearly all cultivated land" (Gros 2014: 88). In return for reforesting their fields, locals have received government help in the form of cash and rice for sustenance - thus leading to dramatic changes in land use, a reduction of biodiversity and livestock numbers, and the erosion of traditional culture (Gros 2010; Shen et al 2010; Xiao 2005; Li 2008). Over the years, different attempts at growing cash crops have been introduced in the valley, including golden bamboo, medicinal herbs, and most recently black cardamom, with differing degrees 
of success. Yet, none of these attempts have managed to fully guarantee a sustainable livelihood in the valley, to the extent that most families in the Dulong Valley remain highly dependent on state subsidies.

Environmental conservation policies that exclude local modes of production are hardly a new and solely Chinese experience. Already in 19th-century Europe, at the outset of modern forest management practices, mountain populations were deemed "guilty" of mismanaging mountain resources, leading to environmental degradation (Debarbieux and Rudaz 2015: 96-7). Furthermore, in the following decades, in both Europe and the United States, the disqualification of local communities was further highlighted by the movement to preserve mountain environments through the institution of national parks or scenic areas (Debarbieux and Rudaz 2015: 106) - a pattern strikingly similar to what has been happening in the Dulong Valley. Such conceptions of the natural mountain environment led to two main consequences: "it cast doubt on the validity of [the mountaineers'] environmental practices and on their modes of production. But it also placed the inhabitants in a state of inferiority compared to those who were producing the naturalist and protectionist discourse." (Debarbieux and Rudaz 2015: 107) As this chapter elucidates, both consequences hold true for the Drung. However, what is different in the case at hand is that such policies took place within a paternalistic discourse of care for a small, marginal, and "primitive" ethnic group. What such polices accomplish, then, is not only an ecological goal, but an eminently political one: to re-affirm the Party's legitimacy through the act of giving. Yet, this very act, in turn, reproduces dynamics of dependencies that are at the root of the Drung's projected under-development.

The role of the state as a benefactor is extremely visible in the latest, and perhaps most striking development project that has affected the valley over the past decade, part of a nationwide policy called "Building a New Socialist Countryside" (shehui zhuyi xin nongcun jianshe). In the Dulong Valley, the implementation of this new policy led to a new phase of dependency, but also to a renewed sense of modernity in this remote borderland.

\section{New socialist villages}

During my first visit to the Dulong Valley, I was invited into the house of Ade, located in a new village near Bapo, where the old caravan trail to Gongshan used to depart and the location of the former administrative centre for the Dulong Valley until it was moved to Dulong Township (or 


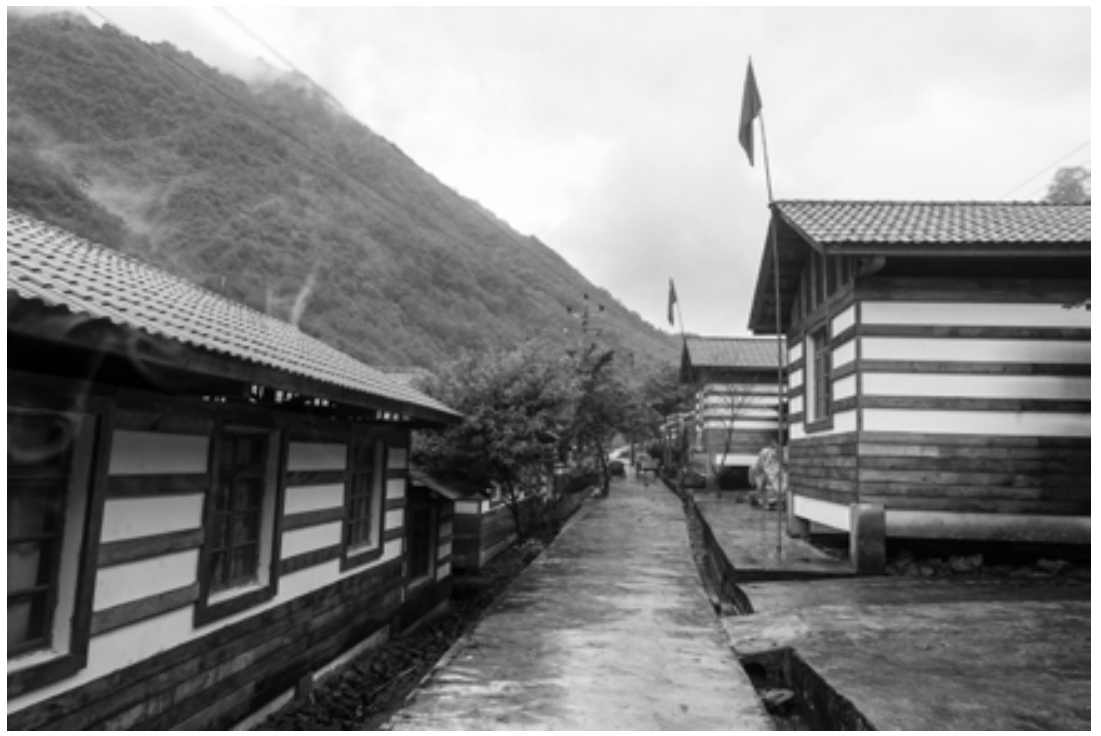

Figure 11: Inside one of the new villages in the Dulong Valley (picture by the author, 2016)

Kongdang) with the opening of the road in 1999. The new village was made up of about three dozen houses built in an orderly fashion on the slope between the new road and the Dulong River. The houses, all made out of concrete but equipped with ornamental bamboo panels on the outside walls, followed the same structure: a small outside patio, a living room, and three bedrooms in each. A smaller building, separate from the main house, served as the kitchen. Toilets were shared, and placed in a few small buildings at the edge of the village. Like in all other villages in the valley, a small building for communal activities and a basketball court completed the settlement (Figure 11). As I arrived at Ade's house, a few children were riding bicycles in the concrete alleys between the houses. While some of the houses seemed empty, others were clearly lived in. Chickens roamed the small spaces between the cramped houses. A motorbike was parked on one corner, beside a little vegetable garden next to one of the houses. Laundry was hanging out to dry on most balconies, and a red flag was flapping on each roof. Ade offered me tea, as I sat on a small wooden stool in the kitchen. Ade was an energetic man in his mid-thirties. Short, like most Drung, he always seemed to keep himself occupied: checking his phone, chatting with friends, checking in with neighbours. The life in the new village seemed to suit him, and it was odd to see him sitting still, for once, as we had tea. "These houses, you see," he said making a broad gesture with his right arm, pointing to the surrounding houses as much as to his house, "were all given to us for 
free by the state (guojia). The only thing we had to do was to help with the construction." So-called voluntary labour (yiwugong) was, in fact, an issue that would recur constantly during my fieldwork in the Dulong Valley. It was required during the construction of the new villages, of the schools, but also of the road and during the construction of hydropower stations in the 1990 (Gros 2010: 43). While other people would complain about it, Ade saw it as a fair price to pay for the generosity of the Party (dang) towards the Drung. "Now this house belongs to us," he told me, "this is how much the country cares for the ethnic minorities. We are a very small minority, you see, but the government (zhengfu) really cares for us."

Ade's new house was officially provided as part of the "Building a New Socialist Countryside" programme. The programme, officially launched in 2006, should be understood as a policy framework - or "macro-policy" whereby the central government provides slogans and rough guidelines to then be implemented independently at the local level. As such, "Building a New Socialist Countryside" is more of an ecosystem of initiatives broadly sharing a similar underlying logic, rather than a fully unified and integrated machine for rural development. As a policy framework, the initiative aims at tackling the "three rural issues" (sannong wenti): agriculture (nongye), villages (nongcun), and farmers (nongmin). At the local level, this "is primarily understood as infrastructural and agricultural modernisation linked to ecological sustainability and the provision of public goods such as social welfare and basic education at the rural level" (Ahlers and Schubert 2009: 36). To be sure, this results in a general promotion of urbanisation and a gradual reduction of the rural population, as farmers are moved into larger villages with schools, hospitals, and administrative facilities (see also Perry 2011; Ahlers and Schubert 2013; Harwood 2013; Rogers 2014; Looney 2015; Rosenberg 2015). Since 2013, these types of village infrastructure projects have been largely repackaged under the "Beautiful Countryside" programme (meilixiangcun), which places more emphasis on tourism development and ecological protection - two key elements in the case of the Dulong Valley.

For the people of the Dulong Valley, the "Building a New Socialist Countryside" programme meant the construction of a number of new villages where all families have been given a house. The first villages were built already in the late 200os, but the project picked up momentum only once the valley road was finished in 2013-14 and, by 2016, all Drung families had a new home. With the exception of the above-described Dulong Township, all other villages are quite similar to Ade's. Houses are single-storey structures, with a living room and two to three bedrooms. In some of the villages, houses have a small veranda; in others there is a small adjoining garden. So 
far, families have not actually been forced to move into the new houses and, in fact, many elderly Drung still reside in their old dwellings, which have the benefit of being closer to the little farmland that they are still allowed to cultivate. While the new villages are mostly placed along the new valley road, and generally run along the river, the old villages are further up the mountain slopes. ${ }^{5}$ To get there, villagers still need to walk for up to two hours. Despite this, many of the elderly Drung I met preferred the old houses for various reasons: they were warmer, quieter and closer to the fields. Perhaps most importantly, this was just what they were used to.

For young Drung men and women, such as Axiang and Ade, however, the new houses reflected a certain vision of modernity, which they increasingly have access to via their subsidised televisions and smartphones - given to them for free by China Mobile, a state-owned telecommunication company, together with a very cheap data plan. ${ }^{6}$ Since 2015, phone network coverage has reached almost every corner of the valley, projecting - if not delivering - a sense of integration within the fabric of a modern nation. Much like anywhere else in the country, young Drung spend hours watching videos, chatting with friends on WeChat, live-streaming their quotidian experiences on multiple online platforms. They are, in a sense, "plugged into" a certain vision of modernity that, as a result of the friction of the terrain and the burden of remoteness, has not yet come to full fruition in the valley. The birthday party described at the beginning of this chapter is an example of local attempts to accommodate this vision of modernity into the lives of individuals, families, and communities. Likewise, the flat-screen TVs, flashy furniture, and the colourful posters and plastic flowers that newlywed couples furnish their houses with all represent a materialisation of a certain modern aesthetic pervasive in the Chinese countryside.

The issue of new villages in the Dulong Valley also speaks to a larger trend within China's current war on poverty - a major hallmark of Xi Jinping's tenure. Resettlement, in particular, has been addressed in the context of infrastructure development, particularly hydropower (Tilt 2015; Tilt and Gerkey 2016), to foster the sedentarisation of herding communities (Ptackova 2016; Du 2012), and in response to environmental degradation (Heggelund 2003; Rogers and Wang 2006; Tan, Zuo, and Hugo 2013; Fan, Li, and $\mathrm{Li}$ 2015). On the other hand, the growing use of resettlement as a tool

5 When speaking Mandarin, people in Dulong usually refer to the movement to the new villages as "coming down" (xia lai).

6 Starting in 2015, each Drung has been entitled to an all-inclusive, unlimited data plan for $200 \mathrm{RMB}$ per year. 
for poverty alleviation has become a prominent yet less-documented issue (Merkle 2003; Xue, Wang, and Xue 2013). This is particularly significant as it is estimated that between 2016 and 2020 , up to 16 million people were resettled for poverty alleviation purposes (Rogers et al. 2019). While such resettlement generally includes some level of subsidies to contribute to the cost of the new house, the case of the Dulong Valley is exceptional in that the entirety of the expenses were covered by the government. Moreover, households receive individual subsidies.

\section{Moving out, cashing in}

Since the implementation of the "Building a New Socialist Countryside" programme, life in the Dulong Valley seems to be characterised by more dependency on the perceived benevolence of the Party. In the course of my fieldwork in the valley, I spent most of my time in the southernmost village of Qinlandang, living with Axiang, $\mathrm{Mr} \mathrm{Bu}$, and their newborn son. Qinlandang is also known as Maku, or "new Maku," as this is the new village to which families who used to live in Maku were moved to. Old Maku, where some families still have fields and, in some cases, still reside for at least part of the year, is located some $10 \mathrm{~km}$ to the north, along the new road towards Dulong Township. My choice of Qinlandang was dictated by its location, as the village lies only a few kilometres away from the Burmese border. Unlike other parts of the valley, where, in order to reach Burma, one must climb steep mountain paths for several hours, here, the first settlements on the Burmese side of the border were a comfortable two-hour walk along a small path following the Dulong River. My idea, initially at least, was to work with local traders to analyse cross-border relations in a place where the Chinese government had yet to enforce a strict border regime. In fact, during my time in Qinlandang, I followed traders and porters into Burma on several occasions, without much bother from Chinese authorities. Over time, however, I came to realise that such forms of trade - which involved, for the most part, medicinal plants, items of daily use, and the occasional wildlife - had very little impact on local livelihoods. While many families in Qinlandang had relatives among the Rawang ${ }^{7}$ living on the Burmese side, they considered themselves different. This difference, I came to understand, was not a matter of language, ethnicity, or culture - all of which, villagers in Qinlandang were eager to point out, they shared with Burmese Rawang. 
Rather, it was the material conditions of their living, provided by the Party, that set them apart. I realised that they perceived themselves to be a small, yet integral part of the Chinese world because of what was given to them in the forms of infrastructure and services: housing, roads, schools, hospitals, subsidies, and so on. Conversely, I came to appreciate how this dependency on government generosity is what binds the Drung to a particular national identity. As Gros puts it, "the Drung assume that claims to power must be validated by generosity. From this perspective, the various forms of aid coming from the state are an integral part of its legitimacy. Without these distributions, the state would lose its legitimacy" (2010: 42).

In Qinlandang, as in the rest of the valley, such relations of giving have raised a new problem in terms of dependency, albeit, this time, in the name of development. According to official documents I was given access to, the total population of Qinlandang was 288 villagers, comprising 79 households $(h u)$, almost entirely of Drung ethnicity. Of these, 161 were recorded as being engaged in agriculture (nongye renkou). According to the same statistics, in 2015, the annual income per capita of a farmer in Qinlandang was 4000 RMB. Subsidies play a major role in this regard. Villagers in Qinlandang are entitled to a subsistence allowance (dibao) that varies between 133 and 163 RMB per month (for a total of 1596 to 1956 RMB per year). To this, one must add the subsidies as part of the SLCP, which in Dulong are divided equally among farming households, and amount to around $18 \mathrm{okg}$ of rice per year/person. Unlike the northern parts of the valley, where medicinal plant collecting has become a very profitable activity, in Qinlandang the main source of income beside subsidies are small black cardamom plantations. Some families, like Axiang's, still keep fields in old Maku, and Axiang's younger brother spent most of his time in the old house. Limited farming, however, did not seem to provide any significant income, and most villagers simply relied on government subsidies.

At the same time, some outsiders had come to the valley - and to Qinlandang itself - to set up small businesses. As Rigg pointed out, "roads not only give opportunities for local people to get out and access new opportunities, but also for outsiders to get in" (2002: 625). In Qinlandang, there were three small eateries and two convenience stores, selling packaged food, alcohol, cigarettes, and basic kitchen utensils. Of the three restaurants, only one was owned by two local sisters. Another was opened by Axiang and her husband, who, as mentioned earlier, first came to the valley as a road worker. The third restaurant (with annexed hotel), on the other hand, belonged to a family from Hunan, who had spent a decade in Gongshan before moving to the Dulong Valley in 2014. The same Hunanese family also own and run 
two small convenience stores. A similar pattern can be found in Dulong Township, where a half dozen hotels have been opened between 2015 and 2017, mostly by outsiders.

As tourism is slow to pick up, and most of its revenue seems to fall into the hands of entrepreneurs from outside the valley, many Drung have moved out (cf. Harwood 2013). Stories of migrants are often told in the valley. In Qinlandang, I became particularly close to Aguo, a relative of Axiang. Then in her mid-20s, Aguo met her former husband while studying at a vocational school near Dali. A Han Chinese from Shandong, she married him and they had a child. Things did not work out, however, and they soon divorced. The case for the custody of the child went to court and the man - wealthier and well-connected - won it easily. Aguo had not seen her child in two years, and soon after I met her, she moved to Gongshan where she found a job in a mobile phone shop. Jiang Yi, the boy in charge of the barbecue at the birthday party I described at the beginning of this chapter, had just turned eighteen. Uninterested in continuing his studies, he kept himself busy with odd jobs on constructions sites and cardamom plantations. Soon after the birthday party, he also moved to Gongshan, working as an electrician and spending most of his evenings at a new internet café, playing video games. Like Aguo, he did not seem to care much about his current job, and he was not worrying about the possibility of losing it. Subsidies and a new house were waiting back home.

Education is also largely in the hands of outsiders. While the preservation of "Dulong culture" plays an important role in the rhetoric behind many development projects implemented in the valley, at the time of my last visit in 2017 none of the new schools in the valley were teaching the Drung language. In Qinlandang, the newly built primary school had only seventeen students, twelve of whom were from nearby Burma. After completing their first two years of primary education, at least some of the students from the village were expected to be sent to Dulong Township, where construction on a larger boarding school had recently been completed. The Qinlandang primary school had four teachers, none of whom were from the valley. Over the course of a number of visits, I became particularly close to two of them, Teacher $\mathrm{Xu}$, originally from Dali, and Teacher Yang, who grew up in Fugong, in the nearby Nujiang Valley and speaks some Lisu. Teacher $\mathrm{Xu}$, who, at the time, was new to the Dulong Valley and the school in Qinlandang, was particularly critical of the situation in the village. A tall guy in his early twenties, he spoke of his pupils with a detectable sense of hopelessness. "The learning environment is not good here, parents don't really care about their children's education," he told me, as he showed me one of the textbooks 
he was using. In it, he pointed to a brief text describing Beijing and the capital's main attractions. It was a rather easy and short text, he said, but it took him three classes to get the students to understand it. Teacher $\mathrm{Xu}$ also complained about his life in the village, where there is "nothing to do." Often bored, he always seemed pleased to have me over to the school for a chat - a much-needed distraction in otherwise monotonous and boring days. On one occasion, Teacher Xu invited me to join the teachers and the students for lunch at the school canteen. While he and I cut some garlic and potatoes, Teacher Yang fried some tomatoes and eggs and some beef with cabbage. Next, she put the shredded and green pepper that I had helped to cut into the wok with some vinegar, salt, and MSG. Teacher Xu, in the meantime, took the rice from the steamer into a large aluminium bowl, and started gathering the children who were playing in the courtyard. As we sat down in blue chairs around a small, plastic table, he pointed out the kids that were from Burma. "They barely speak Mandarin," he told me, "it's very difficult to teach these kids." I nod - this was certainly no easy task, particularly as none of the four teachers understood any Drung language. Teacher Xu went on. "You see, people here lack quality (suzhi), that's the problem. The government (zhengfu) gives them a lot, but the quality is still low (suzhi di)." He provided an example. "Yesterday," he told me, "a delegation came down from Dulong Township. They gave clothes to the children, and 100 RMB each." He nodded, thoughtfully, then added: "but you know what's funny, my salary hasn't yet arrived!" We all broke out in loud laughter as we went on eating, comparing salaries and conditions in different schools across Yunnan.

Dependency, however, is only one part of the story. The Dulong Valley has also become a showcase for the party-state efforts to modernise its borderlands. A measure of this success, however, might not be found in economic development; rather, one has to look at beauty and loyalty to understand the Party's vision for its minority-populated regions.

\section{The Dulong showcase: Beautiful and loyal}

24 October 2016. I was sitting in the small CCP building of Qinlandang, chatting with the village shuji, ${ }^{8}$ another local Party member, and a young Chinese graduate student conducting research on Drung kinship networks.

8 On the role of village committees and village-level Party leaders in post-reform China, see Pieke (2004); Alpermann (2001); Bernstein and Lü (2000); O’Brien \& Li (1999). 
The conversation, over a number of cups of tea, moved from the price of black cardamom to old marriage relations between different clans and families. While, for the most part, the gathering remained comfortably informal, the atmosphere changed for a moment when I asked about the persistent trade in wildlife with nearby Burma. The recent imprisonment of the former village shuji for his active role in the trade was too fresh a memory to leave the two men unaffected by the topic. The register switched, and I suddenly felt as if it were the voice of the party-state speaking through its two officers. "Burma is a mess (hen luan)," the shuji told me, "but here in the Dulong Valley is different." The other Party member took over, lecturing us that it was everyone's duty to protect the pristine nature of the Dulong Valley and to make sure that "our home remains beautiful." The shuji nodded, severely. I drank some tea, feeling a bit uncomfortable for having asked the question. After a moment of silence, the small lecture ended with the following sentence: "if you don't take care of your house, how can you be a patriot?"

Beside the slightly Confucian tone of the exchange, the insistence on keeping the Dulong Valley beautiful (mei) was particularly striking to me. It had been, in many ways, a recurrent theme throughout my time in the valley. Not only for the reference to the indisputable beauty of the valley, but for the human effort that this beauty clearly seems to entail. For many of the local CCP officials, as for many other Drung I had met, nature and its beauty was the result of human intervention. The consequence of curation, as I call it. In other words, the valley was to remain beautiful for only as long as it was looked after. Without care (zhuyi), your house (the family, the Drung community, the nation) would fall apart. Beauty, to be sure, was not an end in itself. For my Drung interlocutors, beauty was certainly not enough. Beauty was an asset, certainly, but one that needed to be developed, branded, and sold. But what story is this beauty supposed to tell?

A hint at the answer to this question lies in the shuji's explicit connection between keeping the beauty of the valley intact and being a patriot (aiguo, literally "loving your country"). In the Dulong Valley, the new villages display red flags on each rooftop, and posters of Mao and Xi Jinping are hanging on most walls. They are not empty symbols; rather, they reflect the feelings of gratefulness that many Drung have towards the party-state. While this loyalty might have been incentivised by subsidies and free services, it is nonetheless sincere. The state (guojia), here, seems to be fully merged with the Party (dang). As Xiang Biao reminds us, "guojia is a much broader concept that the state, and also encompasses the government, the country, and the nation. Guojia represents a totalizing order and an all-embracing 
framework for making sense of public life. It carries strong normative and moral meanings" (2015: 132). Yet, in the Dulong Valley, unlike other contexts analysed in this book, guojia and dang were often used interchangeably. More than any where else, then, the state is the Party as much as the Party is the state - there cannot be one without the other.

At the same time, the reforestation of the valley expresses the rediscovered environmental consciousness of the Chinese state. The seemingly immaculate beauty of the Dulong Valley's forests speaks to a larger commitment in which ecological sustainability is given primacy over economic development. Beauty and patriotism thus go hand in hand, showcasing the party-state's care for both the land and the people. Culture is not forgotten either. All new houses are branded with some symbol of ethnic identity, whether this is in the bamboo decorations or in the coloured patterns that adorn buildings in Dulong Township. This form of branding extended, most recently, to the new bridges that are being built across the valley, all painted in coloured stripes resembling the patterns of Drung textiles.

In the Dulong Valley, bridges, and infrastructure in general, are clear reflections of state power. As Gao Derong, the former county governor and celebrated Drung leader pompously declared in 2018, "The Dulong valley today longs for hopes of development and welcomes the dawn of a dream. Various undertakings are prosperous, infrastructure construction is in full swing, and the masses are in high spirit" (Xinhua 2018a). Here, the dreams and expectations of the Drung are connected to the successful development of material infrastructure. Funded by the state, such material endeavours reinforce the Party's legitimacy. Yet, if infrastructure construction is central to the livelihood of the valley, this most recent effort to brand them according to the aesthetic motives of Dulong craft, can be clearly interpreted as an attempt to ethnicise - or at least, localise - development. In so doing, the Dulong Valley becomes a perfect showcase for the party-state's vision of rural development in the borderlands. It is a showcase of a loyal, patriotic ethnic minority. Of a pristine valley where China's conservation policies are strictly enforced. Of an emerging local economy, perhaps. Of the benevolent role of the party-state, certainly.

\section{Suzhi, state, and market}

While the impact of subsidies and increased mobility on local communities goes well beyond mere economic considerations - high suicide rate, alcoholism, drastic changes in kinship patterns, increasing marginalisation, to 
mention just a few - the issue resonates with other contexts along China's borderlands, and speaks to the larger problem of politics of distribution in rural China. The problem with subsidies, to be sure, is not a new one for the People's Republic of China..$^{9}$ Overly subsidised development policies in China's western regions have been criticised by Chinese economists since at least the 1980s; yet, since the launch of the xibu da kaifa, dependence on state investments and subsidies has been exacerbated (Fischer 2015). Yunnan, in particular, has seen major public funding for agricultural projects that have proven profitable only for as long as subsidies lasted, leading some scholars to point out that such endeavours serve state policy priorities rather than economic development per se (cf. Rousseau 2018).

One of the main consequences of these economic strategies, and one that is clearly visible in the Dulong Valley, is the consolidation of state control through externalised patterns of ownership and state-led economic integration of these remote, peripheral regions, into the rest of China (Fischer 2015). In Dulong, this is evident through the role played by SOEs, with China Mobile, China Telecom, and China Southern Power Grid at the forefront of several projects in the valley. This pattern displays a contradiction that lies at the heart of China's development of its borderlands since the xibu da kaifa: the conflict between the prominent role of state investment and the discursive shift towards personal responsibility - in China, usually framed in terms of quality $(\text { suzhi })^{10}$ as one of the teachers in Qinlandang, Teacher $\mathrm{Xu}$, explicitly referred to.

The recent fortune of the term suzhi is inextricably linked to the issue of rural poverty in China. As Ann Anagnost (2004: 190) pointed out, the term acquired a "new discursive power" once discussion over population quality (renkou suzhi) began to appear in the 1980s, targeting the low quality (suzhi di) end of China's population. As she elaborates:

By the early 1990s, population quality had become a key term in the party-state's policy statements and directives to cadres, even as it began to circulate more broadly as a general explanation for everything that held the Chinese nation back from achieving its rightful place in the world. At the same time, as economic reforms increased privatization

9 The issue of subsidies for the borderlands precedes, in fact, the PRC. The Qing dynasty, for instance, subsidised Xinjiang for a long time, and a true financial crisis (leading to, among other things, the creation of a number of local currencies) ensued once these subsidies ended (cf. Millward 2000: 124-125)

10 There is no shortage of studies of suzhi in China, see for instance Anagnost (2004); Kipnis (2006, 2007); Judd (2002); Bakken (2000); Yan (2003). 
and dismantled the institutions and entitlements of state socialism, suzhi appeared in new discourses of social distinction and the discursive production of middle classness. Suzhi's sense has been extended from a discourse of backwardness and development (the quality of the masses) to encompass the minute social distinctions defining a "person of quality" in practices of consumption and the incitement of a middle-class desire for social mobility (Anagnost 2004: 190).

In producing new forms of social distinctions, suzhi replaced class as a major discursive tool for the implementation of economic reforms. While, in pre-reform China, emphasis was put on one's relation to the means of production, suzhi has been interpreted by many scholars as a distinctively neoliberal concept, through which responsibility has shifted to the individual (Murphy 2004; Anagnost 1997; 2004; Kipnis 2007; Yan 2003; Pun 2003). ${ }^{11}$ In the Dulong Valley, as elsewhere across the country, discussions about suzhi have become ubiquitous, as has mention of the term itself in both official and popular discourse. At the same time, in the Dulong Valley, state policies still seem to be aimed at changing the material infrastructure as a pre-condition for individual development. In the Chinese context, there is no contradiction between the two. If suzhi is, at least partly, innate, individuals can be transformed. Just as the wrong environment can be corrupting, the right one can lead to improvement. The approach appears to follow a Marxist understanding in which the only way to change the ideological super-structure is by addressing structural inequalities in the material process of production. Chinese authorities, in other words, seem to assume, borrowing from Lefebvre, that "spatiality is not only a product but also a producer and reproducer of the relations of production and domination, an instrument of both allocative and authoritative power" (Shields 1999: 153, from Soja 1985: 110). In the case of the new socialist villages in Dulong, however, the productive element seems to be solely ideological. Here lies, I find, the primary inherent contradiction of the Drung's development. How is it possible that reforms aiming at producing entrepreneurial subjects led to more dependency upon the state's generosity? Or, to put it the other way around, how should years of unconditioned aid and support foster the development of self-sufficient competing subjectivities?

11 For a critique of the use of neoliberalism in the suzhi discourse in China see Kipnis 2007. In this section, the term neoliberalism does not refer to the overall system of governance, but rather to the specific policies targeting individual responsibility that are embedded in the term suzhi. 
This particular discussion of suzhi thus echoes a larger debate about the relationship between state and market in China, and between an authoritarian mode of rule and a seemingly neoliberal discourse of entrepreneurship and self-reliance (Kipnis 2011). In the official rhetoric, with the reform period, China has entered a phase of economic growth and individual accumulation famously baptised as "socialist market economy with Chinese characteristics." Still, the question of whether China is a capitalist society looms large in many debates over the past three decades. Such debates often tend "to see a zero-sum game between the state and the market" (Osburg 2013: 2), in which both "state" and "market" are nevertheless understood in overly simplistic terms. Osburg's (2013) work with entrepreneurs in Chengdu shows, on the other hand, that moral economies of personal networks, as well as bureaucratic hierarchies and closeness to the CCP are at the core of China's current capitalist development. Hence the very notion of a free market is, for Osburg, rather questionable: capitalism, in China as elsewhere, is inevitably embedded in power structures and personal networks.

David Harvey (2005: 120) famously described China's political economy in the reform-era as "a particular kind of market economy that increasingly incorporate neoliberal elements interdigitated with authoritarian centralized control." While this might be the case in Beijing, Shanghai, or Shenzhen, in the Dulong Valley elements of pre-reform economic ideas go well beyond mere authoritarianism. Furthermore, far from being "nonpolitical and nonideological problems that need technical solutions," (Ong 2006:3) as Aihwa Ong characterises neoliberal governance strategies, issues of development in Dulong are essentially political. The aim, in Dulong, is not to "optimise," but rather to claim, perform, and showcase control over the well-being of a minority population and a protected area. Governing, here, is a technology of care, not a calculation of the state influence over the market.

This over-encompassing role of the state is inextricably linked, in the party-state ideology at least, to the projected primitiveness of the Drung. In ethnic minority areas the discourse on suzhi is still tied in with the idea of an inherent physical quality of the population, rather than pointing to an abstract, acquired quality. As such, "poverty has come to be understood as related not just to the changing historical conditions of market reform but to the 'tangible physical quality' of minority nationalities” (Zukosky 2012: 241). Quality, then, in minority areas become both an ordering and a disciplinary strategy through which under-developed ethnic minorities such as the Drung are re-imagined as modern subjects. Only, in Dulong, this specific vision of modernity well exemplified by the birthday party described above comes at the price of increased dependency on government support. Modernity and 
dependency, in the Dulong Valley, are two faces of the same coin. What, then, does the case of the Dulong Valley tell us about the party-state's engagement with its minority areas? Is there a specific modality of power that is at work here? What is the objective of development in the Dulong Valley? How do conservation, dependency, and quality relate to one another?

\section{Conclusion}

Following the first part of the book, in which I addressed an initial tension between two distinct yet interconnected forms of connectivity, in this chapter I have highlighted another underlying characteristic of China's borderlands: the implementation of a particular vision of modernity and the construction of remoteness. I introduced this second tension through a vignette describing a birthday party, in which I laid bare the struggle of many Drung to inhabit a modern nation in their self-characterised "faraway" homeland. Here, in an example striking even for the Chinese context, modernity is a temporal condition that seems to coincide with the recent construction of the road to the valley. Blurring the boundaries between the technical, the infrastructural, and the moral, the road to the valley becomes a civilising device that radically alters both the "material" and the "spiritual" conditions of the valley and its people.

Yet, even before the road was completed, as I described in the second part of the chapter, the Dulong Valley has been characterised by a history of aid since its incorporation into the People's Republic of China. Through a number of programmes designed to "modernise" the Drung, the Chinese state made the Dulong Valley into a national space by cultivating particular forms of dependency among the local population. The most recent project that I detailed in the chapter, the "Building a New Socialist Countryside" programme, can be seen as the apex of such efforts.

As I have further argued, however, what emerges from the Drung case is the political, rather than economic rationale behind programmes to "develop" ethnic groups in the borderlands. The state, by performing the role of a giving entity, assumes a fundamentally pedagogical role in which the Drung are relegated to passive recipients of the CCP's generosity and wisdom. The valley, then, is transformed into a particular showcase of ethnic policies in today's China. Yet what it showcases, I have argued, is not just loyalty. Rather, it brings to the fore the contradictions inherent in China's development model in minority regions, as reflected in the suzhi discourse as an ordering and disciplinary strategy. 
More broadly, I have argued that the Drung case clearly shows that market vs. state dichotomies are of little help for understanding rural development in minority regions. The combination of state investment, calls for increasing quality, market tourism, ecological conservation - all within the benevolent embrace of the state - requires a different conceptualisation of power. As shown in the first part of this book, socio-cultural and geographical specificities of China's borderlands require a different spatialisation of such relations (or what I call proximity); the nexus of interests and goals that the Drung case exemplifies requires a different approach to the way we understand power relations in this context. In particular, while the Drung case makes little sense when understood from the perspective of economic development, if approached as a showcase of a particular political will and discourse, new relationalities emerge. Economic development is not what is at stake in the Dulong Valley. It is, rather, only a part of a broader and eminently ideological discourse of sovereignty and control - or what I conceptualise as the notion of curation in the next section.

While, in the Dulong Valley, the role of the state as a benefactor is accepted and actively re-produced by the Drung, the effects of curation are far from even. To show this, after defining "curation" in the Interlude, I return to Xinjiang to examine the case of the reconstruction of Kashgar's old town. Curation, as a particular modality of power, acts by separation and exclusion. It is a violent performance - one that, in the case of Xinjiang, is bearing particularly tragic consequences. 



\section{Interlude - curation}

In The Will to Improve, Tania Li (2007) analyses how different development programmes overlap, producing unexpected and ultimately negative consequences for the communities they were designed to help. In particular, she describes the effects of relocation in the highlands of Sulawesi, Indonesia, starting from an early phase of development in the Dutch colonial period. Here, villagers were resettled from the highlands to lower areas in order to bring them closer to infrastructure such as roads, but also to take advantage of new farming techniques. While the resettlement programme was never particularly successful, it hit a notable barrier when bio-conservation became a national agenda item in the 1990s. Eventually, a park was established and access to land restricted. Farming techniques that were supposed to improve these communities' livelihood were banned, with, as a consequence, ongoing poverty and landlessness for the villagers. To add insult to injury, villagers were criticised for these very farming practices and held responsible for the ecological decline of the area. In recounting this story, Li's broader intention is to think about how power operates in relation to development. In order to do so, she conceptually builds on Foucault's concept of governmentality, Marxian political economy and Gramsci's conceptualisation of hegemony. By taking aim at neoliberal agendas of economic betterment through a Marxist framework, Li shows how growth and impoverishment are always intertwined.

In looking at the rationale behind such interventions, Li's use of the concept of governmentality is particularly useful in thinking relations of power in today's Chinese borderlands. Famously coined by Michel Foucault (1979a, 1991), governmentality defines any means of directing how subjects behave and act, and how specific forms of "truth" are invoked in the government of human conduct. The concept generated a prolific scholarship with regard to China (for a review, see Jeffreys and Sigley 2009), particularly in the analysis of the relations between the government and the everyday management of citizens through a number of technologies and practices. ${ }^{1}$ Governmentality has also been used in the analysis of particular forms of state territorialisation, in which "modern states divide their territories into complex and overlapping political and economic zones, rearrange people and resources within these units, and create regulations delineating how and by whom these areas can be used" (Vandergeest and Peluso 1995:387). 
Significantly, in this context, state territorialisation is understood as a deliberate strategy to transform both subjectivity and the landscape and in so doing establish state authority as an effect of power, rather than as a direct imposition (Yeh, 2013; Wang and Li 2016).

The concept of governmentality offers numerous opportunities to think about the case of the Dulong Valley described in the previous chapter. The re-making of the Chinese countryside more generally is also reminiscent of another analytical lens frequently used in the analysis of large-scale, encompassing development projects - what James Scott (1998), in his landmark book Seeing Like a State, calls authoritarian high modernism. With this notion, Scott combines the commitment to a high-modernist ideology, the administrative ordering of society and the state's willingness to employ coercion to realise such projects, which is typical of several modernising projects carried out by authoritarian regimes throughout the 2oth century. High modernism, in other words, represents an attempt to make spaces and populations legible to state-authorities while putting into practice a specific vision of modernity. Fundamentally aesthetic in their own rights, such projects, Scott argues, are not just generally inefficient, but also by disregarding local conditions and local knowledge are a recipe for disaster. This latter point is clearly illustrated by the cases of collectivisation in the Soviet Union and resettlement into villages in Tanzania and Ethiopia that he chose.

At first blush, the Dulong case would seem to fit quite soundly with Scott's analysis. The villages where Drung families have been resettled, one the one hand, certainly serve the purpose of disrupting social relations and traditional practices that remained inevitably illegible to state authorities. On the other hand, they represent the materialisation of a specific vision of modernity and an ideologically charged attempt to implement it. A similar argument could be made for previous interventions: from the Sloping Land Conversion Programme to the attempts at transforming Dulong's forest into economic forests via the introduction of various cash crops. Unlike the cases analysed by Scott, however, marginality and dependence are not necessarily charged with the negative attribute one might expect. Rather, the benevolent state, the "provider of goods," is seen as a caring entity. Here, once again, we are reminded of the complex nature of power in China and of the shortcoming of simplistic power-resistance frameworks in the analysis of government authority. Hathaway, for instance, in conversation with Scott's works on the topic $(1985 ; 1990)$ talks of "art of engagement", showing that "in fact many villagers exerted a good deal of effort trying to connect with and attract powerful outsiders" (Hathaway 2013: 79). Thus, 
writing against the "narrow view" of many "resistance models," Hathaway effectively shows how, in rural China, very often the biggest complaint is "the lack of state presence," rather than its contrary (2013: 114). Tim Oakes (2012) argues along similar lines while discussing the role of heritage and preservation in processes of modernisation and development. In particular, against models of hegemony and resistance, he shows how villagers are often embracing "the apparatus of improvement" (402) projected by local elites and officials.

Building upon this literature, and tracing the ways development, state control, and heritage-making affect China's minority-populated borderlands uncovers the contingent forces of what I call curation. This notion encompasses a rather intricate interplay between a particular ideology of development and its implementation in particular contexts. As such, it encapsulates particular forms of power relations that are at play at China's borderlands today. To be clear, curation here does not refer to the work of a museum or exhibition curator; rather, it takes the original (Latin) meaning of curare. On the one hand, curare means to heal, to cure, to make remedy. On the other hand, it also refers to the act of preservation, to make sure that something does not infect its surroundings. ${ }^{2}$

According to the first meaning, the aim of curation is not only that of building a different future - one that, in the eyes of the authorities, is clearly better. Curation also points to an erasure of the past. It implies a projection of backwardness, as much as a strive for "quality." Unlike improvement, curation as a "healing" process implicitly presupposes a disease - backwardness. Curation thus entails much of the CCP's effort to "lift" the Drung out of poverty and the ways this is implemented at the local level. Not, as high modernism implies, as a merely ideological implementation, but one that is rather embedded in a moral discourse resonating as much in Kunming's Party offices as in the borderlands themselves. The wording is interesting here. While the verb "lifting" is reserved exclusively for the state media's English-language publications (Schmitz 2017), Chinese official sources generally refer to tuopin, "shaking off poverty," jianpin, "reducing poverty," or xiaochu pinkun, "eliminating impoverishment." In the word tuo 脱, “to shed" or "to take off," 月 "meat" is a meaning component, referring to the original meaning of the word: to remove the skin and bones from meat. As such, it echoes another connotation of the word curare: to "cure" something

2 The development of this particular idea of curation owes much to the "Connecting Materialities / Material Connectivities" series of workshops organised by Martin Saxer and Philipp Schorch at LMU Munich between 2015 and 2017. See also Saxer (2016; forthcoming). 
by careful processes of cleansing, selection and preservation. The issue of cleansing is particularly evident in the word xiaochu, "to eliminate, remove, dispel." Xiao, in particular, refers to disappearing, or dying out, and it is used in a number of words indicating disinfection and decontamination. Thus, while healing, curational interventions attempt to prevent such disease from spreading, i.e. the second meaning of the word curare highlighted above. As the next chapter will show, curation thus implies a severe disciplinary regime with the aim to "preserve." Yet, preservation, tied with the language and practice of heritage-making in today's China, is always embedded in a selective process in which certain elements are chosen over others. Thus, in the case of Xinjiang, to which I will turn the discussion in the next chapter, Uyghur crafts, songs, and dances are promoted for tourist consumption, pious Islamic behaviour is persecuted. Curating particular subjects, then, implies the enforcement of a selective process that pathologises any behaviour that might pose a political threat (cf. Grose 2019).

In both meanings of the term, "curation" refers to an attempt to attend to particular material environments, which is both ideologically and morally charged and driven. As such, it also implies an effort that is both future- and past-oriented. Allow me to elaborate. High modernist planning, as Scott makes clear in his work, does not consider the cultural values, traditional practices, and aesthetic sensibilities of the local populations. More often than not, high modernist spaces are designed for "abstract" subjects: subjects that are emptied of any cultural specificity. While Scott's analysis addresses the fundamental question of the planning and its consequences, what is mostly left out of the discussion is how this "emptying" occurs. The concept of curation, on the other hand, helps to shed light on this process of erasure, where the focus on "healing" implies a projection of backwardness that has a disease-like quality to it, i.e. as something that needs to be eradicated. In other words, unlike high modernism, "curation" accounts for two kinds of temporalities: the construction of an imagined future, and the erasure and reconstruction of the past. In the case of the Dulong Valley, and in many other contexts around China's border regions, from Tibet to Xinjiang (Cliff 2013), dreams of modernity reflected in the new villages are always paired with a projection of backwardness onto the ethnic minority groups' traditional ways of living. And not only that: the very spaces that used to provide them with a living - the forest or the grassland - are re-defined as wastelands, unproductive, and stubbornly unmodern (cf. Yeh 20ogb). They are, in other words, "emptied" of both meanings and history.

Lastly, curation is ultimately tied to a culture of display, of performance, of exhibition. This is particularly important in the Chinese borderlands, 
where ethnic minorities need to be not only loyal, but also commodifiable. Yet, unlike cases in which the commodification of culture is understood as part of a capitalistic logic of accumulation (Comaroff and Comaroff 2009), along China's borderlands "improvement" is tied to ideology more than anything else - even if this comes at an economic cost. There are interesting historical parallels to this particular example. Discussing Soviet Russia, Pedersen argues that "[I]nvestment in infrastructure was [...] not rational in any narrow economic sense; instead building 'miniature metropolises' was understood as investing in a new being, a new humanity, a new cosmos" (2011: 45). The example of Soviet Russia is particularly insightful in discussing the role of infrastructural aesthetics for the construction of "modern" subjects. As art historian Vladimir Todorov claimed, "Communism created ultimately effective aesthetic structures and defective economic ones” (1994). Here the systemic building of spectacular infrastructures and systems of provisions (Saxer 2016) became the material and ideological foundations for the production of new social forms, values, and persons (Dalakoglou 2012; Humphrey 2005: 39-40; Schwenkel 2015).

Similarly, the rationale for the construction of new villages in the Dulong village, or the re-construction of old Kashgar, is not to be found in economic growth indicators. Pointing precisely to this aspect, curation describes a particular modality of power driven by ideological and moral instances. While co-existing and overlapping with other modalities of power, such as surveillance, control, or calculation, curation points to the processes of healing, selection, and preservation that ethnic minorities are the target of in today's China. By underpinning a disciplinary - and not economic objective, such expression of state power complicates established views of Chinese development in the borderlands. To show how the issue of ethnic subjectivity is embedded in such relations, in the next chapter I address the case of the Kashgar's old town and the Uyghurs of Xinjiang. 



\section{$4 \quad$ Heritage}

"(Social) space is a (social) product [...] the space thus produced also serves as a tool of thought and of action [...] in addition to being a means of production it is also a means of control, and hence of domination, of power." — Henri Lefebvre (1991: 26)

"Break their lineage, break their roots, break their connections, and break their origins" - Chinese government document on how to turn Uyghurs into better citizens, Al Jazeera (2018b)

While the previous chapter detailed the party-state's attempts to attend to a particular environment through ideologically and morally charged interventions, this chapter employs the conceptual lenses of "curation" to address the question of subjectivity within these larger projects. As Emily Yeh described in the case of the Tibet Autonomous Region, development in the Chinese context is a form of territorialisation understood as both a material and embodied process; that is, one that aims at the transformation of both landscapes and subjectivities. Thus, both in Yunnan and in Kashgar, as I will describe throughout this chapter, my argument is that curational interventions in the borderlands not only aim at the introduction of modern housing, cash economy, and conservation policies to improve the material living conditions of ethnic subjects, but most importantly represent an attempt at developing a new kind of subjectivity. As part of this project, renewed state presence in terms of both bureaucratic and social control consolidates what philosopher Jürgen Habermas (1981) has called the "colonisation of everyday life," while state-led attempts at developing new tourist sites assure discursive control over minority culture.

In order to make this argument, this chapter addresses the case of the reconstruction of Kashgar's old town. As mentioned in the first chapter, Kashgar has a long history as a major cultural and trading hub along the legendary Silk Road: an image that defines much of the region's past as well as its current touristic brand. Among a number of development projects connected to this imaginary, that of the reconstruction - or renewal (gaizao), to use the official parlance - of Kashgar's old town (Uyghur: kona shähär, Chinese: laocheng) has drawn significant media attention. My argument is that the 
implementation of such heritage preservation project in Kashgar cannot be understood outside of a larger plan to transform Kashgar into a modern hub on China's Belt and Road. By highlighting this particular connection, I further show that heritage in Kashgar is a project less concerned with the preservation of the past than it is about development and modernisation, or what Tim Oakes, following Tania Li, calls "improvement" (2012).

The case is not unique to Xinjiang. Martin Saxer (2012), for instance, shows an interesting policy shift in the Chinese official discourse on the TAR. Saxer argues that "while earlier positions predominantly highlighted development and progress in order to legitimize the Party State's policies, the Party State has recently begun to emphasize its efforts to promote and protect the 'fine traditional Tibetan culture' as heritage" (Saxer 2012: 67). Chinese efforts to modernise Tibet, in other words, are now increasingly framed within a narrative of heritage preservation, thus legitimising the party-state's role in Tibet as the true protector of traditional culture and highlighting the fundamental role of tourism in the development of the region. Significantly, in the eleventh Five-Year Plan (2006-2010), the same in which the "Building a New Socialist Countryside" policy was first mentioned, "the Chinese government adopted UNESCO's language of the protection of "cultural heritage" as part of its strategy to develop tourism and fight the deleterious effects of environmental degradation, urbanization, and economic development" (Pieke 2014: 130).

As part of this larger policy shift, Xinjiang has witnessed something similar to the case described by Saxer. As in Tibet, history in Xinjiang has been instrumental to justifying the CCP's rule since the time of the liberation, and accordingly manipulated for nationalistic purposes (Bovingdon and Tursun 2004; Bovingdon 2001; Rippa 2014a, 2015). In 2003, for instance, a government White Paper entitled "History and Development of Xinjiang" insists precisely on Xinjiang's role in the history of China, its deep linkages with the motherland, and the role of the Party in the development of the region (State Council 2003). The White Paper, however, does not reflect on those issues in terms of contemporary cultural policies; instead the focus is on countering the separatist discourse in the wake of the September 11 attacks and the subsequent American-led "war on terror". By contrast, the focus of a 2009 White Paper, entitled "Development and Progress in Xinjiang" is development (State Council 2009). A section of the White Paper is specifically dedicated to the "Preservation of Ethnic Cultures", highlighting the importance of "the inheritance and development of the fine cultural heritage of all ethnic groups". A more recent White Paper on Xinjiang (State Council 2015), entitled "Historical Witness to Ethnic Equality, Unity and Development 
in Xinjiang", goes even further in this direction, highlighting the importance of "promoting cultural prosperity" for the overall development of the region. As in the Tibetan case described by Saxer, then, Chinese authorities in Xinjiang seem to be framing their argument for the development of the region within a narrative of heritage preservation, insisting on the role of the Party in the management of local ethnic cultures.

More generally, as anthropologist Stevan Harrell (2013) pointed out, "China is in the middle of a cultural heritage preservation fever" $(287)$. In Kashgar, as in several other places, this "fever" took a rather radical turn, leading to the almost complete reconstruction of Kashgar's old town, which used to be "the best-preserved example of traditional Islamic city to be found anywhere in central Asia" (Michell et al. 2008). According to official estimates, since 2009, the programme, launched within the "Uyghur Historical and Cultural Preservation Project", has received RMB 3 billion in funding and has already involved 31,00o households (State Council 2015). Officially, the project aims at "renovating dilapidated houses" and making the structures in an earthquake-prone area such as Kashgar safe. In fact, with the exception of two small sections, entrusted to the Beijing-based Zhongkun Group to be managed as touristic scenic areas, Kashgar's old town has been entirely demolished and re-built in what authorities label "ancient Islamic architecture". However, as this chapter will describe, there are significant differences in the architecture and the layout of the old and the "new-old" Kashgar town.

This chapter builds upon a growing literature that sees heritage as both a means of authoritarian state power that alienates locals from their own socio-cultural resources (cf. Bendix et al. 2012; Bellocq 2006; Dicks 2000; Shepherd 2006) and as a particular function of development (Oakes 2012). In particular, I shift the analytical gaze to an examination of how the systemic efforts to redefine Uyghur-ness are integral to the reconstruction of Kashgar's old town and lay bare the material and ideological foundations for producing new Uyghur subjects. This chapter will argue that heritage has become a disciplinary tool in minority-populated Chinese borderlands. In particular, through the case of the renovation of Kashgar's old town - a particular kind of curational intervention - the party-state is aiming at the construction of new Uyghur selves. Here, Uyghur ethnicity is reduced to a culture of display that is made readily available for tourist consumption. While framed in the language of economic development, in this chapter I show how this attempt, accompanied by stricter disciplinary policies, led to the marginalisation and impoverishment of large portions of Kashgar's Uyghurs. I argue that this outcome is the logical consequence of the particular ways in which 
Uyghurs are portrayed in today's China. In other words, curation as a culture of display becomes a disciplining technology through which Uyghurs are reduced to a lesser kind of citizen.

\section{The new Kashgar old town: Renewing Uyghur identity}

1 November 2012. It was already quite late, but I felt like having some kewab before going to bed. I headed to my new favourite place, on Östengboyi Road (ch: Wusitang Boyi). It was a small kewab shop newly opened in a renovated house. It was small, but it offered the best kewabs in the area - I was particularly keen on the addition of a piece of liver and the smaller portion of fat. On that particular night, only two people were in the shop: the owner, Perhat, whom I had spoken to a number of times over the past weeks and another man I had never met before. I shall call him Ahmedjan. Ahmedjan turned out to be originally from Uzbekistan, born to a Uyghur family who moved back to Kashgar in the 199os. I wanted to ask him some questions, but this time I was the one being interrogated. First about Italy, Europe, my studies. Then about Xinjiang and Kashgar. He asked me if I liked it here. I most certainly did. "The place or the people?", they both asked me, at the same time. I said that I liked the people, and that I used to like the place, but not that much anymore. I said that I saw the place changing since my first visit. They started laughing, saying that all these new houses (pointing their fingers around) were very good - "yaxshiyaxshi," they kept saying, parroting the Mandarin pronunciation of the words (yakexi, yakexi) that had become somewhat popular since they appeared in a song in the CCTV spring festival gala (chunwan) in 2010. ${ }^{1}$ Then, Perhat looked at me, seriously, and pointing at his mouth said, "here we say it is good," and then pointing at his heart "but here it is not good."

Due to its proximity to the desert and the dry climate, Kashgar has always been a rather dusty place. In the early hours of the day, as men sit on carpeted

\footnotetext{
1 In the programme, singers and dancers, dressed in what the PRC deems as "traditional" Uyghur dresses, praise their happy life. The chorus line goes as follow: "What is yakesi, what is yakesi? The Chinese Communist Party's policies are yakesi." The programme was notoriously mocked by many netizens. See also Figure 12 to see how the expression has been used in propaganda posters and murals.

2 Upon returning to Kashgar in 2016 I learned that Perhat (a pseudonym), like many other Uyghur friends in Kashgar, had disappeared and was in prison. His family didn't know where he was, for what reason he was detained, and for how long he would be away. In the years to come, stories like Perhat's would make headlines in the international press. To this day, I don't know what has happened to him.
} 


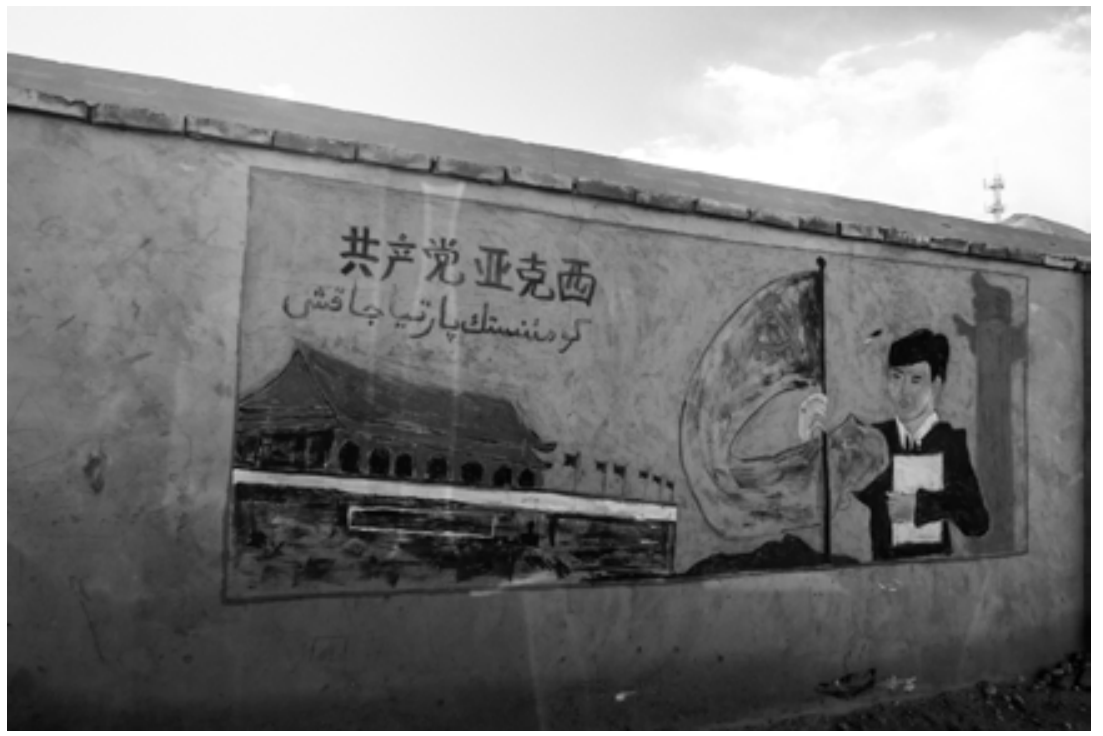

Figure 12: "CCP yakexi" on a school mural along the KKH (picture by the author, 2017)

benches lined outside cramped teahouses, dunking old pieces of naan bread into chipped porcelain teacups, women sweep the fronts of shops and houses with short straw brooms. They would repeat this activity several times over a single day, often pairing it with the watering of the same streets during the hot season. Dust, in Kashgar, clings onto your clothes, your hair, it silently and ceaselessly accumulates on every surface it can find. Dust and sand is what you wash off your face before praying, it is what makes your eyes shut while walking the streets. Yet, in Kashgar's old town, dust was not just a natural phenomenon due to the city's proximity to the desert. Dust, in Kashgar's old town, was also a major indication of ongoing destruction.

My first visit, in the spring of 2009, was one filled with excitement. Upon checking into my hotel, at the end of a 24-hour train journey from Urumqi, where I was based at the time for a semester at Xinjiang Normal University, I did not waste any time and went out roaming the narrow alleys of the old town. Most sections were strangely quiet, with life seemingly carrying on behind mud walls, in hidden courtyards, from where I could only hear the occasional voice emerge. The streets, on the other hand, were traversed by the occasional electric scooter, and mostly by groups of kids playing and asking tourists for a picture. Larger intersections, and the occasional square, were more crowded, with shops, restaurants, street pedlars. Just as I was starting to get a sense of the place, of its smells, its sounds, the faces traversing it, a cloud of dust hit me, behind a corner that looked just like 
any other. Sounds, here, were different, and so were the smells - what I was just starting to get used to was now completely erased by the powdery dust entering my nostrils, drying my mouth, clouding my view. Through the dust, I saw a scene that would become painfully familiar. A group of Uyghur men, equipped with shovels, hammers, and wheelbarrows, were clearing the fractured skeleton of an old house. I remember, vividly, that first encounter. A man bent over a pile of debris, in what must have been the main room of the house, two of its walls still standing. On one of the walls, a painted floral motif on a white background was still visible.

While the renewal (gaizao) of Kashgar's old town began in 2001, the project only gained momentum in the years following my first visit in 2009, and reached its apex when I was conducting my doctoral fieldwork in the region, during 2012-13. The timeline for the project sees its final completion only in 2020; yet, during short visits in the summers of 2016 and 2017, I could already appreciate how most sections of the old town had been renovated, with families who had already moved in. While some parts of the old town have been replaced by new multi-storey buildings, the focus of this chapter is on those sections that have been renovated and maintained in a seemingly "traditional" style. Or, to put it in the language used in a panel describing the old town's renewal standing at the intersection of Areya and Tuman Road, to those sections where "Uyghur style and flavour" had been "enhanced". Yet, the differences between the old town, and the new-old town, are quite striking.

Kashgar's old city is - or rather, was - a labyrinth of narrow, dark alleys squeezed between the walls of mud-brick houses (Figure 13). Over time, many houses were built over and across those alleys, generating intricate pathways without any apparent coherence. The houses themselves were generally accessible through a small door, and thus remained largely hidden from the outside. Once inside, on the other hand, one was often surprised by a green courtyard and carefully decorated rooms with bright carpets and pictures. The new-old Kashgar, on the other hand, has been carefully planned. Its roads are wide, bright, and paved, lined with trees, the houses built in tidy rows (Figure 14). In the new-old-Kashgar, the material of choice is concrete, which was virtually absent in the old buildings. The elements of "ancient Islamic architecture" are visible in the wooden decorations around doors and windows, and in the mud-hay mixture used to cover the concrete-brick walls. The most striking difference with the old town is, perhaps, the structure of the houses. Whereas in the old town the core of the house was the courtyard, generally invisible from the outside, in the new-old Kashgar the facades of the houses have large windows and terraces. They are in full view. In fact, it seems that one of the main characteristics 


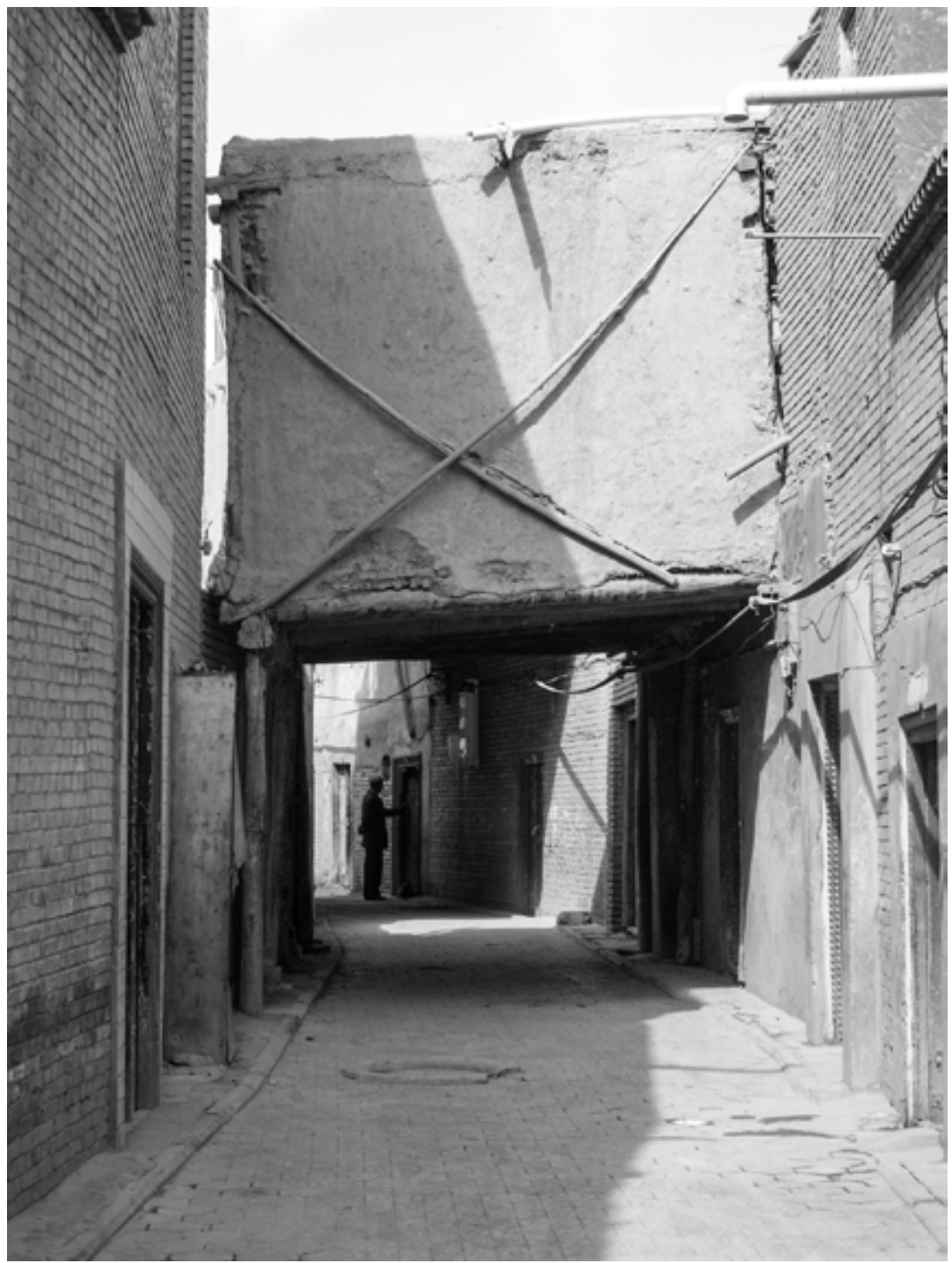

Figure 13: A typical section of old Kashgar, before the renewal (picture by the author, 2013)

of the newly planned new-old town is to put the beauty of Uyghur houses on show, to move ornamental elements out of the hidden courtyards and eliminate the outside walls. Furthermore, houses facing the main streets have their ground floors converted into shops-to-be: larger rooms opened towards the street. Along many of those roads, such rooms have already been converted into restaurants, offices, and shops of various kinds with signs in Uyghur, Mandarin, and English. 


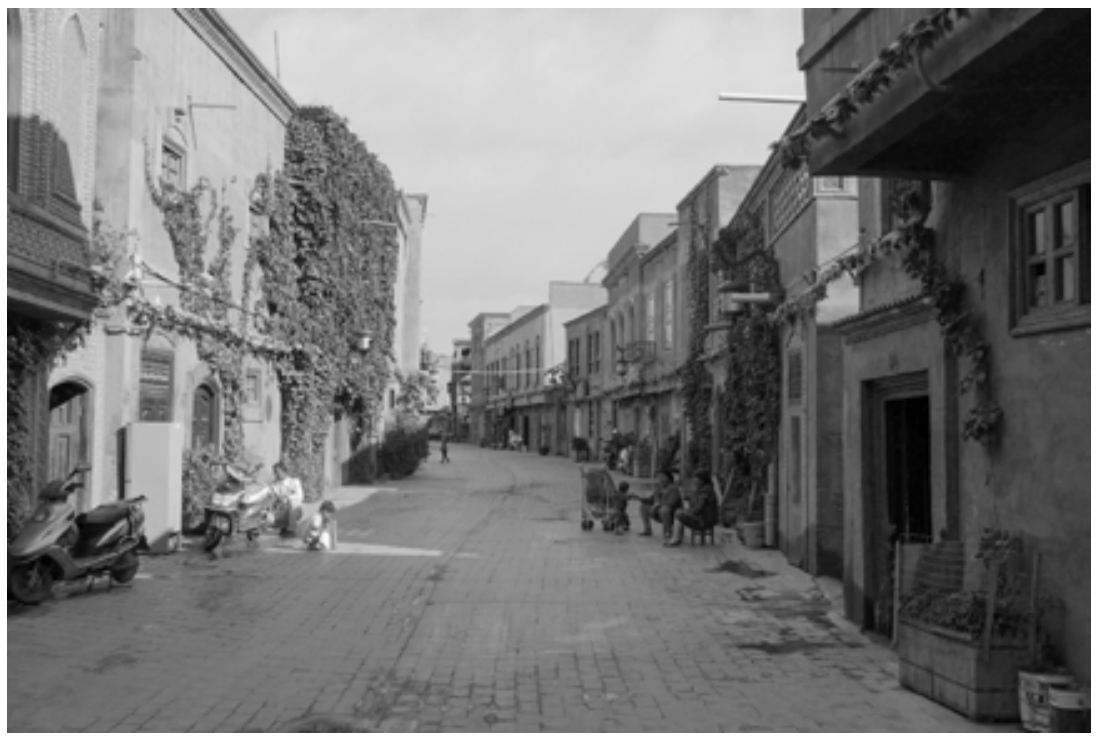

Figure 14: A section of the newly built Kashgar "old" town (picture by the author, 2017)

The stated rationale behind this reconstruction is an attempt to foster tourism in Xinjiang. Although this might sound counter-intuitive - why would one destroy one of Kashgar's main historical attractions to bring more tourism to the region? - there are several examples in China of cities that have experienced major tourist influxes after important renovation plans. Perhaps the most striking example - and one that has served as a model since its construction - is Lijiang, in Yunnan province. Lijiang's famous old city receives over eight million visitors every year, and it has emerged as one of China's most popular destinations. Its popularity increased significantly after it was designed as a World Heritage Site by UNESCO in 1997, following efforts to restore traditional buildings in the aftermath of a devastating earthquake in 1996. Today, Lijiang's old town is a maze of streets crowded with tourists, souvenir shops, bars and guesthouses, surrounded by the "new city," a modern town almost indistinguishable from any other provincial Chinese city. Lijiang, in short, became a major touristic destination due to at least three concurrent factors: careful planning and reconstruction of the old town, the international recognition of it as a heritage site, and the commodification of local culture in the form of traditional spectacles, souvenirs, and guesthouses and bars with "ethnic" elements. A similar process is currently unfolding in Kashgar - its reconstruction does not appear exceptional if analysed within the discourse of heritage preservation in China. 


\section{“If you haven't visited Kashgar you haven't been to Xinjiang”}

Preservation and reconstruction are often strictly interconnected in China. In recent decades new "old towns" and "ethnic parks" have appeared throughout the country, leading to what Oakes (1998) called a "manufacturing" of minzu culture. As part of this process, not only cities and villages, but also traditional practices such as dances (Xie 2003), festivals (Saxer 2012), and even old trade routes (Sigley 2013) have been re-branded and commodified (Gladney 2004). Within this context, Kashgar's attempts to attract more tourists from central China is evident. Since the early 2010s, the slogan "if you haven't visited Kashgar you haven't been to Xinjiang (bu dao Kashi bu suan dao Xinjiang)" has become ubiquitous, not only on posters and brochures in the city itself, but also on provincial guides and with tour groups visiting the region. Several sections of the new-old town, in particular, have been thoroughly re-branded, and, at a few tourist information booths, free maps with an overview of the renewed old town and suggested itineraries to visit it are freely available. It is also possible to tour the new-old town on an electric mini-bus, which leaves at regular intervals from the vicinity of "youth square (qingnian guangchang)."

An introductory panel in Uyghur, Mandarin, and English, called "Introduction of Kashgar old town," placed along a small section of newly re-built city walls, in proximity to the newly re-built Shamen, a city gate, and at the entrance of fully renovated Atush Lane, provides the following overview:

Located in the center of Kashgar City, Kashgar old town starts from Renmin Road in the south to Seman Road and Yarbagh Road in the north. YumlaqSheher Road is to the west of it and Tumen River sight-seeing area is to the east. The place covers an area of 1.57 square kilometres, and 26,575 households including 64,308 residents are living here. The old town is the soul place of Kashgar which has over 2,100 years of history as the most renowned historic and cultural city in Xinjiang. It is the only living ancient city among the 36 countries in the Western Regions, and is known as the "hometown of cate" [meishi], "hometown of fruits", "hometown of songs and dances", "hometown of bazzar" and "hometown of jade". As a place with the richest styles of Xinjiang folk-custom, if not in all of China, it is an "ecological museum" and "big natural stage" for travelers to experience the original folk customs here. Kashgar old town is one of the biggest raw soil buildings existing in the world, streets and lanes of which are as complicated as the buildings. It is the only labyrinth urban block that has been preserved completely in China. With a long 
history, abundant culture and unique style, Kashgar old town earns the reputation that "Kashgar is a must-go place for Xinjiang, just as the old town is a must-go place for Kashgar".

The panel, together with the new-old city maps placed alongside it, neatly indicates the limits of the old city, defining its exact size and number of inhabitants. Implicitly, by claiming that the old town has 2100 years of history, it links Kashgar with the Han dynasty conquest of Xinjiang, which, according to Chinese scholars, represents the moment the region was incorporated into the Chinese world (Rippa 2014a, 2015a). The references to fruits, songs and dances, "bazzar" [sic], and jade, on the other hand, are a clear attempt at tourist branding. None of these names - perhaps with the exception of the bazaar - would sound familiar to any Uyghur resident of Kashgar. Yet fruits, songs and dances, jade, and bazaars are frequently identified with Xinjiang and Uyghur culture by Han tourists and Chinese media alike. The renewed old city of Kashgar, then, with its branded alleys, tourist shops, organised cultural performances, becomes a "must-go" - a place of tourist consumption par excellence.

Furthermore, the reconstruction of Kashgar and the particular visions of Xinjiang history and Uyghur culture that it is embedded with, points towards a more productive aspect of projects of preservation in China. As Harrell (2013) argues, "the effort to preserve is not simply a feeble, rear-guard reaction to the effort to modernise. It is very much a part of the modernizing effort, which in turn is a part of China's continuing process of nation-building" (287). This point applies particularly well to the case of Kashgar and the Uyghurs, where, through an active process of heritage-making, the Chinese government is attempting to modernise not only Kashgar as a town and tourist destination, but also an entire ethnic group. As Jenny Chio noticed in the contexts of tourism in rural China, there is a tight connection between Chinese policies of rural development and the promotion of tourist sites. In particular, they are both part of "an effort to increase rural incomes and also to raise the suzhi [quality] of ethnic minorities by modernizing them" (Chio 2014: 98) In Kashgar, too, the re-development of the old city cannot be analysed outside of a particular attempt to transform Uyghurs.

The reconstruction of Kashgar represents an important step in the materialisation of the CCP vision for the future of Uyghur ethnicity, and reflects a particular view of a "modern" ethnic subjectivity. Heritage, in other words, becomes a technology of government. As Tim Oakes put it, "To baohu something in rural China these days is not so much to "preserve" it, but to prepare it for development, to turn it into a visitable attraction, 
a display of itself" (Oakes 2012: 389). As such, projects of heritage-making must be tightly connected to wider discussions about rural development in China. In Kashgar, as much as in the Dulong Valley, the creation of a culture of display and the commodification of a particularly curated minority culture, is a major feature of modernisation. Uyghurs and Drung can be modern only to the extent that they embrace such visions of their own culture, and with it their particular place within the Chinese nation state. Furthermore, in the case of Kashgar, what clearly emerges is how processes of heritage-making, development, and control are closely intertwined. As a technology of government, heritage, here, is not simply aimed at a specific form of development, but even most importantly it sets up a particular regime of control over Uyghur subjectivities and landscape. By re-designing Kashgar, a symbol of Uyghur identity, and defining what Uyghur culture is and how it should be performed, Chinese authorities are claiming control over a particular space and people as well as over their past and future.

Before detailing how this process takes place, let me briefly introduce the broader context of the development of Kashgar within which the discussion of Uyghur subjectivity needs to be understood.

\section{Shenzhen of the West}

Around the old town, within the limits of the Special Economic Zone, another form of development has strongly emerged over the last decade. Here, Kashgar resembles many other Chinese provincial towns, with large roads, apartment blocks, and even a lake with an amusement park and a few bars along its shore. The Beijing Zhongkun Investment Group, a major real estate developer, is also in charge of building a 160-metre-high tower with a youth hostel, "minority culture street", and bars, alongside a new golf course and a tourist resort. Not far from the town centre, moreover, a new "Economic Development Zone (jingji kaifa qu)" is currently under construction, extending over an area of 50 square kilometres. The Zone is divided into three main areas: a Finance and Trade district (chengdong jinrong maoyi qu) in the east, an area under bingtuan administration in the north, and a logistics centre by the newly expanded international airport. For anyone familiar with China, those plans are all but originals. Golf courses and exclusive shopping malls have been mushrooming in most 2nd and 3 rd tier cities, the "Development Twin Towers" plan follows similar projects in other provincial cities, while "minority culture streets" can now be found in most touristic destinations across the country. In other words, Kashgar's 
development is following the familiar "zone frenzy" that took over China in the 1990s and then later in the early 2000s (Cartier 2001; Hsing 2010), only this time with a markedly "ethnic" element imbued into it. As the posters and models at the Kashgar Central \& South Asia Commodity Fair that I described in Chapter 1 show, such plans were embedded within an imaginary of transnational connectivity brought to the fore by Xi Jinping's Belt and Road Initiative. As far as Kashgar's Finance and Trade district goes, I was keen to see how such dreams materialise in concrete forms.

Thinking back to the images I saw at the Kashgar Central \& South Asia Commodity Fair, as well as to what I had been reading about the Kashgar SEZ, my expectations were rather high as I made my way towards the Finance and Trade district in the summer of 2013. I knew that construction had just begun, but I was curious to see the size of the site and perhaps talk with some of the engineers and construction workers. Overall plans for the development of the SEZ were not, in fact, particularly old. The most recent part of the plan was first laid out during a high-level Xinjiang Work Conference held in Beijing in late March 2010. The Conference outlined a new approach for the Party's administration of Xinjiang, a particularly significant development given the Urumqi incidents of the previous year (Bovingdon 2010, 167-170; Millward 2009). The new approach abandoned the "stability above all else" formula that has defined the era of Wang Lequan as governor first and then CCP secretary of Xinjiang, and moved to one of "expedite development" (Shan and Weng 2013: 73; Li 2018). Furthermore, the Xinjiang Work Conference arranged a "pairing assistance" model according to which nineteen affluent provinces and municipalities were "each required to help support the development of different areas in Xinjiang by providing human resources, technology, management and funds" (Shan and Weng 2013: 73). Similar schemes have been employed throughout other border regions such as Yunnan and the TAR. In the case of Xinjiang, Kashgar was paired with Shenzhen, China's most successful Special Economic Zone (SEZ). This new policy was eventually defined during a second conference in May 2010, attended significantly by then President Hu Jintao and Premier Wen Jiabao, as well as the future President and Premier Xi Jinping and Li Keqiang. The conference once again highlighted that in order to solve Xinjiang's problems it would be necessary to focus on economic development. The objective was then termed "leapfrog development", with the aim to eventually achieve "long-term stability" in the region. As part of it, "the 19 provinces and cities that joined the "pairing assistance" program were required to grant $0.3 \%$ to 0.6\% of their annual budget to Xinjiang every year" (Shan and Weng 2013: 75). Two other important measures resulted in a favourable tax system 
and the establishment of a new Special Economic Zone (SEZ) in Kashgar, expected to be fully operational by 2020 (Cappelletti 2014: 16).

Given the scale of investments and commitment, what I saw in the summer of 2013 was rather disappointing. As I moved away from the city centre, I found myself surrounded by cluster after cluster of apartment blocks. Roads appeared to become wider as traffic became sparser. The bike lanes and sidewalks remained largely empty under the scorching sun. When I finally reached the site of the area where the Finance and Trade district was supposed to be, I was out of the city, surrounded by poplar trees and fields. Along some of the dirt roads, kids were playing outside of mud-brick houses - their walls covered with the ubiquitous character 拆 (chai: to tear down), an indicator that the building was set to be demolished. The new district, while seemingly still far in the future, was a lived presence for Uyghur families in this part of Kashgar. I was told that they were about to move into new apartment blocks. Some in a week, some in a few months, some were hoping to stay until the winter. All, however, willingly or not, had to make room for the development to arrive. In the following months, I continually returned to this part of Kashgar, noticing that construction works were slow. By the time I left Kashgar, in September of the same year, none of the families I had talked to had yet moved out of their old houses. It would be nearly three years before I visited the same area again. Yet, in August 2016, I was to be disappointed once again. Instead of high towers and duty-free shops, all I could see were more, mostly empty apartment blocks and two large highways running through the small neighbourhoods I had become familiar with. At a short distance, a new, large boarding school, surrounded by barbered wire and cameras, seemed to be the only building in use.

The next chapter will address in more detail the interconnection between infrastructural development, technologies of control, and the apparent failure that the emptiness of many SEZ projects in Kashgar seem to reflect. For now, it is important to notice that even while remaining empty and underdeveloped, many development projects within the Kashgar SEZ, together with the re-making of the old town into an Islamic Disneyland for mainland tourists, accomplished a different goal from that of economic development: they materialised a particular vision of the future for both Kashgar and the Uyghurs. ${ }^{3}$ Ildikó Bellér-Hann (2013) employs the metaphor

3 Another well-established argument posits that SEZs and large-scale development projects in China have often become powerful assets to fuel real estate booms, foster GDP numbers and thus benefit the careers of local officials (Cartier 2001; Ong 2011). "Profit" here is not just for the 
of the "bulldozer state" to describe the large-scale irresistible destruction of old structures that seems to accompany development projects in Xinjiang. The bulldozer state, here, refers simultaneously to a process of erasure and to one of (re)construction and selective preservation. It "[reinforces] the self-image of the Chinese state as carrier of a mission civilisatrice in frontier regions inhabited by backward minorities" (188). From a modernisation perspective, the "bulldozer state" is thus more about active construction than mere destruction. Bellér-Hann, drawing on Schumpeter (1934), terms this "socialist creative destruction": the tearing down of houses is done in order to create something new. In Kashgar, both the new-old-town, the Special Economic Zone, and the ambitious Finance and Trade district represent a materialisation of such efforts to create a new kind of future. In this particular vision, the city of Kashgar, in order to exist, needs to be turned into a "development zone," while the old town, renovated as it is, has reasons to exist only as a scenic spot (jingqu). This, together with the disciplinary measures at work in the region define the future of the Uyghurs.

\section{Curating Uyghur subjects}

One of the immediate results of the reconstruction of Kashgar is that of making the city more "legible" to Chinese authorities. The purpose for such an operation is generally twofold. First, "Historically, the relative illegibility to outsiders of some urban neighborhoods (or of their rural analogues, such as hills, marshes, and forests) has provided a vital margin of political safety from control by outside elites" (Scott 1998: 54). By re-designing Kashgar, transforming its narrow and dark lanes into wider, well-structured roads with a carefully planned system that allocates housing only to certain families, Chinese authorities have attempted to eliminate this element of illegibility that provided shelter for groups and individuals that might oppose Chinese rule in the region. Furthermore, as anthropologist Jay Dautcher (2009) has demonstrated, Uyghur residential neighbourhoods - known as mähälla - are critical units of social identity, and thus serve an important function in the creation and strengthening of community bonds and mutual solidarity among Uyghur families. By re-designing those mähälla, Chinese 
policymakers thus probably envisioned the possibility to re-arrange, and in certain cases indeed destroy, those networks. ${ }^{4}$ The second objective is transformational. The objective of making its domains and subjects more legible is for the state the precondition to another, more important task: to create a terrain and a population with precisely these standardised characteristics, easier to monitor and manage. Legibility thus becomes "a condition of manipulation" (Scott 1998: 183), an active attempt to foster change in the community, beside the environment which they inhabit. It is to this objective that I now turn my attention.

Besides Shamen, and in front of the panel introducing the history of Kashgar's old town quoted above, is a ten-metre long bronze bas-relief depicting scenes of daily life in the old town. On the left-hand side of the relief an electric cart is parked in front of a butcher's shop, where half a dozen sheep carcasses are hanging. Moving to the right, an elderly Uyghur man is selling what appears to be figs, while another man looks at the products on display. In the background is the typical layout of Kashgar's old town, with its cramped houses, small balconies, and wooden-framed windows. Further to the right, a Uyghur man is sitting on his e-bike, while three other young Uyghur men are busy baking naan bread. In front of them, sitting on one knee, wearing a cowboy hat and a backpack, a tourist is taking a picture of

4 Such destruction occurred, more often than not, along class divides. While wealthy Uyghurs were able to afford renewal of their old house and thus remain in the same neighbourhood, poorer families were left without choice (Steenberg and Rippa 2019). Madlen Kobi also discusses this issue at length. For instance: "Some parts of the old town have been completely replaced by new multi-story buildings, while others are being renovated and maintained. In both cases, house owners affected by renewal plans can choose between financial compensation and a new apartment in a residential compound on the outskirts of Kaxgar. Residents who decide to stay must renovate their houses, either with their own money or with subsidies from the government. The lack of financial means is the main reason why many residents move out of the old town areas. On one of my walks through the old town, I met a group of men who were renovating a house. They told me that, since homeowners have to cover most of the costs themselves, many of their former neighbors could not afford to renovate their inherited or rented houses. Of course, they can apply for a government subsidy - but this money only covers the costs of a building's exterior, while the interior renovations are the owner's sole responsibility. When a friend later mentioned that renovation could cost up to 7,000 or 8,00o Yuan [RMB] per square meter, I understood why the lower- and lower-middle-class inhabitants can barely afford it and prefer to obtain an apartment on the outskirts of town. Middle- and upper-class residents, in contrast, can afford to renovate their houses and thus remain living in the centrally located old town. Some of them even add additional stories or build balconies, terraces, glass houses, or other previously unknown architectural elements. Moreover, as well as having the financial means to renovate their old town houses, they can also afford to buy an apartment (or even several apartments) in the newly built residential compounds replacing the old town areas" (Kobi 2016: 156). 
them with a big camera. In the relief, not one of the Uyghur men has facial hair. All, however, are performing some kind of craft: baking naan, filling manta (a type of dumpling), welding metal, or decorating teapots.

The relief depicts a familiar scene. In the new-old Kashgar, a few sections are dedicated to traditional crafts, mostly catering for the tourist crowd. Its main protagonist, however, seems to be the tourist taking pictures. The bas-relief thus appears to imply that traditional crafts are not good in themselves, but only insofar as they are available for tourist consumption. Implicitly, this scene seems to indicate what Uyghurs in the new-old town are supposed to be and do: a display or traditional craft for the benefit of outsiders. A showcase of culture - or at least, of what the party-state defines as Uyghur culture.

If this bas-relief clearly exemplifies what the party-state dictates Uyghurs and Uyghur culture to be, the city of Kashgar is filled with other normative explanations of what Uyghurs are not supposed to be - and implicitly, of what Uyghur culture itself is not. While certain crafts and aesthetics can and should be put on display, other elements that some might consider an integral part of what it means to be Uyghur must be removed. Take, for instance, a list of several signs of "religious extremism" that has been widely circulated in Xinjiang since early 2017 , and that appeared on posters all around Kashgar. ${ }^{5}$ These instructions warn against men who grow long beards or women who cover their faces, but also against people who abstain from drinking alcohol, boycotting non-halal food, or avoiding singing and dancing during wedding ceremonies. While filling up manta and welding kewab sticks are integral parts of Uyghur culture, this list seems to imply, a certain form of religious piety is not.

These examples show that two normative discourses are at play in Xinjiang. On the one hand, the heritage discourse points to a specific vision of Uyghur culture that people in Kashgar are supposed to embody, mostly for tourist consumption. On the other hand, there is a disciplinary apparatus set to identify and correct all kinds of behaviours that do not fit the party-state vision of what it means to be Uyghur in 21st-century Xinjiang. These are not, I argue, two separate, contrasting discourses. Rather, I see them as integral to a particular vision of society, and of the role of ethnic minorities in it.

5 The list followed remarks by Xi Jinping made in 2017, when he urged to build a "great wall of iron" to protect Xinjiang. Shortly after, the CCP announced the Xinjiang Uyghur Autonomous Region's Articles on Eliminating Extremism, as part of which fifteen unlawful manifestation of extremism were identified (available here: http://www.xinjiang.gov.cn/2017/03/30/128831. html.). See also Klimesh (2018). 
Here, Uyghurs, like Drung, can exist only insofar as they are both loyal to the party-state and its vision of modernity, and "ethnic" to the extent that their minzu-ness can be easily commodified for tourist consumption. Heritage becomes a tool of control - any behaviour that does not fit China's normative discourse on Uyghur-ness is neither acceptable, nor it is considered ethnic. Rather, it represents a betrayal of minzu custom.

In order to build this particular form of Uyghur subjectivity, both discourses - heritage and control - are at play in Xinjiang. This mission is akin to one of social (or human) engineering: "projects to create new kinds of subjects for political and economic transformation" (Anagnost 2013: 8). This particular notion has recently gained some traction among Xinjiang scholars trying to grapple with the party-state's attempts to re-define Uyghur identity in the region and beyond (Zenz 2018; Byler 2017; Byler and Grose 2018). Darren Byler, for instance, builds on this notion to describe how the state in southern Xinjiang is attempting to project and impose an image of secular Uyghur-ness struggling against the tyranny of religious dogmatism. This idea of engineering seems implicitly based on a Foucauldian view of the subject. Specifically, Foucault identifies two different meanings attached to the word subject: "subject to someone else by control and dependence, and tied to his own identity by a conscience of self-knowledge" (Foucault 1982: 781). In every human encounter, therefore, there is a tension and an oscillation between being an actor and being acted upon. Yet, what is even more interesting for Foucault is the problem of the constitution of the subject, that is, how human beings are made into subjects. (Foucault 1996 [1984]: 452). According to this line of thinking the subject does not pre-exist history or the social processes it is embedded in. Individuals are rather constituted by power relations (practices of subjection), which eventually define their "conscience of self-knowledge". Accordingly, human beings are made into subjects through a complex network of power relations (the microphysics of power), which act primarily on the living body as the site of subjectivity (biopolitics). It is through those techniques of control that, according to Foucault, specific types of knowledge (truth) about the subjects are produced, generating the "normative" aspect of power relations (Rabinow 1984; Hoffman 2006; Kipnis 2011). In the case of Xinjiang, as with the case of Dulong, by resorting to over-encompassing aesthetic projects of renovation, as well as to an over-production of symbolic meanings connected to minzu identity, the party-state is clearly trying to re-frame what it means to be a minority subject in the People's Republic. As Byler bitterly concludes, "the current engineering project seems so totalizing, so extreme, that it is becoming increasingly difficult to imagine a way out. It is becoming difficult to think beyond the state's imagination of Uyghur Muslims" (2017). 
While "social engineering" captures an important aspect of the processes through which the state projects and develops certain ideas of subjectivities in China, the notion of curation refers to a selective process, one that is productive only to the extent that it is also simplifying. As in the Dulong Valley, in Kashgar a process of curation is also one of erasure. As described above, while certain aspects of Uyghur identities are put on display, others are criticised. Uyghurs can sing and dance, a characteristic of most minority cultures in China (Gladney 1994; Schein 1997), but should not pray, fast, or refuse alcohol. Yet, even the former should not be confined to the privacy of the courtyard, or limited to particular ceremonial times like weddings. Rather, as the architecture of the new Kashgar implies, the sociability of Uyghur custom should be openly shown to tourists and visitors alike. Conversely, mosques, when they are not destroyed (Kuo 2019) have become spaces of secular education and tourist consumption. ${ }^{6}$ Starting in 2016, all mosques in Kashgar and southern Xinjiang display a red flag, together with a banner saying "aidang aiguo" - love the Party, love the Country (note the order). Islamic teachers or mollas and their followers are being imprisoned and placed in indefinite detention. The Party's definition of what Uyghur culture is includes specific views over the ways Uyghurs should dress. Ethnic costumes, such as colourful textiles or doppa hats are encouraged, while for women to fully veil their heads is considered a "betrayal of ethnic culture" (Byler 2017). For young men, the simple fact of having a beard might spell trouble, while moustaches are accepted as an expression of local culture. Furthermore, a number of programmes have been launched in order to prevent individuals from joining or supporting "extremist" groups. Such programmes include a "beauty project," directed at discouraging Uyghur women from wearing veils (Zhou 2017), and a "becoming kin" programme according to which a Han cadre is "adopted" by a Uyghur family. ${ }^{7}$ Paired with an increasingly intrusive system of surveillance, these and other programmes play a fundamental role in Uyghurs' everyday lives.

The language used in the renewal of Kashgar's old town is itself embedded within that of curation. Gaizao can be translated as transform, modify, remould. What it refers to, however, is to a radical change, one that replaces something old with something that can meet the needs of a new situation.

6 Recent reporting from Kashgar showed that at least one mosque had been re-converted into a bar (Wen and Auyezov 2018).

7 The official is supposed to visit the adoptive family regularly, and even to live with them for short periods - at the same time collecting information and reporting on them. As per The Economist, "1.1m officials have been paired with 1.6m families. That means roughly half of Uighur households have had a Han-Chinese spy/indoctrinator assigned to them" (The Economist 2018). See also Byler (2018). 
One can remould ideology (gaizao sixiang), nature (gaizao ziran) but also "reform" a criminal into a new man. As such, gaizao itself seems to point to the second meaning of "curation" that I have detailed in the Interlude: to cleanse, to prevent something bad from spreading an infecting its surrounding. Accordingly, Uyghur identity is not fully erased. Rather, it is cleansed of the elements that do not meet the Party's vision of modernity and secularisation. In this regard, Islamic faith, or any behaviour that reflects an ideology in contrast to that of the CCP, is described in seemingly clinical terms. Islam, in particular, is characterised as having "infected (ganran)" (Grose 2019) and "sickened" (Samuel 2018) the Uyghurs. This aspect has become even more pronounced in the course of China's ongoing "war on terror," yet it is by no means limited to "terrorists." As Sean Roberts argues:

[T]he "terrorist" label evokes the presence of a biological threat to society, akin to a virus that must be eradicated, quarantined, or cleansed from those it infects. If such attitudes were not immediately apparent in the PRC's transition from its 1990s anti-separatist campaigns in the XUAR to its counter-terrorism ones in the early 200os, they have become increasingly pronounced in PRC policies combating "Uyghur terrorism" over time, resulting in a situation in which Uyghurs as an ethnic group are increasingly excluded from PRC society as a biological threat to the social order, quarantined so as to not infect the population of the country as a whole. (Roberts 2018: 234).

Thus, Islamic extremism, and by extension, Muslim Uyghurs, can "infect" people like a "virus" and terrorists are "rats" (Reuters 2014) that spread diseases. They represent a threat to the entire community and should be transformed - cur(at)ed into new subjects. ${ }^{8}$

\section{Heritage, control, and the culture of display}

One evening at the beginning of November 2012, I went to the Pakistan Café for dinner. The small establishment had become a routine visit for me, and

8 On the CCP use of the language of pathology to approach minority cultures, see Grose (2019). In a recent (November 2019) and astonishing set of leaked documents obtained by the New York Times, official directives clearly frame the state's distrust of Muslim minorities in Xinjiang in chilling clinical terms, explicitly identifying religious extremism with a virus to be treated through "transformation through education" in Xinjiang's prison camps, so that it will not infect one's family (see Ramzy and Buckley 2019). 
on that particular day I was hoping to catch some of the Pakistani traders I had befriended in the previous months. Once I arrived, however, the small restaurant was empty, except for a table where a middle-aged man and a boy, probably about ten years old, sat together. After ordering my usual meal - a plate of beef keema and a couple of chapatis - I looked at the man, trying to figure out where he was from. His features were clearly Central Asian, but somehow, he didn't strike me as a Uyghur. All of his front teeth were made of gold, his face darker and more sun-burned than most people in Kashgar. My guess was that he was Tajik, probably a truck driver, coming to Kashgar from Dushanbe through the Kulma Pass. Over the previous weeks I had seen more and more Tajik drivers and, in order to cater to them, the Pakistan Café had recently changed its name to "Pakistan Café - Tajikistan Café." While most of the clientele remained Pakistani, on a couple of occasions I had encountered groups of Tajik men eating shurbo - a sheep meat-based soup - with Uyghur naan. Perhaps my glances had become too evident, and the man started to make insistent eye contact. Uncertain on whether I should greet him in Uyghur, English, or perhaps Russian, I decided to go for a more international "As-salāmu 'alaykum." "Waćalaykumu as-salām," the man promptly replied, then adding, in Uyghur: "Amerika-lik?" - are you American? I replied, in Uyghur, that I was not American, but Italian. "Do you speak Uyghur?" he asked. "Not much, my Mandarin is better." The man - whose name I was soon to discover was Dolkun - switched to Mandarin, with which we stuck to for the rest of our conversation. Dolkun, it turned out, was not Tajik, but a Uyghur originally from Kashgar. My guess, however, was not too misplaced, as I realised when he began to tell me his story. Dolkun spent several years as a truck driver and in the 199os he was often travelling to Pakistan. Since the Karasu port of entry opened in 2004, Dolkun crossed the Kulma Pass into Tajikistan several times a year, operating his own business in cars and spare parts. His fortune was made with what in Tajikistan is generally known as tangen (or marshrutka): small Chinese minivans, which were imported from China in the mid-20oos and which now serve as taxis in towns around the country. Dolkun and I remained in touch throughout my time in Kashgar, in 2012 and 2013. I visited his house and a couple of his new properties in the new apartment blocks where many former old town residents were being re-settled. For him, it was just another real estate deal. As he once put it to me, we were in the "era of money (qian shidai)," in which all that matters was to get rich. "If you have money any place is good, if you don't have money any place is bad." For him, Kashgar was good, only insofar as it provided new opportunities to get rich. At the time of our first meeting, these opportunities were plentiful. With the scale 
of investment connected to the renewal of the old town, new properties in the outskirts of Kashgar became available for low prices, and many people like Dolkun invested in them.

More generally, between 2012 and 2013, I saw expectations about the high number of tourists that would visit Kashgar as the new-old town was completed unfolding in very concrete ways. Several Uyghur friends invested in shops and hotels, renting and renewing properties within the new-old town. My favourite carpet shop moved to a new and larger venue, an old teahouse went through important works of renovation to lure tourists with a cleaner setting and a trilingual menu (and a completely new name: "100 years old teahouse"), souvenir shops started to replace local businesses in the most central parts of the new-old town, while restaurants popped up at every corner. Others, wealthy Uyghur friends such as Dolkun, invested in the real estate market in the new parts of town, buying up apartments in residential complexes with the hope that prices would keep rising. Investment in tourism promised new revenue, and despite the ongoing crackdown on so-called religious extremism and a very visible ethnic discrimination, many of my contacts were optimistic about their economic situation.

These stories are important in that they show that what was happening in Kashgar at the time could not be dismissed as a simple consequence of ethnic discrimination. While an element of that is undeniable, the political economy surrounding the renovation in Kashgar went, at least initially, beyond the minzu divide. The story, in many ways, was a common one of gentrification. Wealthy Uyghurs benefited from the renovation, oftentimes finding themselves living in larger houses partly paid for by the government, and with the resources to invest in the real estate boom ongoing in new parts of town where apartment blocks were being built at incredible speed. Poor Uyghur families, on the other hand, who could not afford to contribute to the renovation of their old-town house, were forced out of their traditional neighbourhood and into poor-quality apartments in faraway parts of town (for a more detailed analysis of these processes, see Steenberg and Rippa 2019; Cappelletti 2015).

This particular situation did not last, however. Following what the party-state perceived as a renewed threat from Uyghur extremist groups in the region, in 2014 Xinjiang authorities launched a new "strike hard" campaign, this time in the form of a "People's War on Terror" (Byler and Zolin 2017). During the same year, the number of police and military checkposts in southern Xinjiang increased dramatically, street controls of mobile phones and bags became common place and house searches were conducted on a regular basis, often at night. Uyghur residents of southern Xinjiang were 
required to carry an extra type of ID card, popularly known as the Green Card, in order to travel between the region's towns. Restrictions on mobility made it particularly difficult for Uyghur traders to maintain their businesses. The tensions, checkpoints, and heavy military presence on the streets was particularly detrimental to the tourism industry. Tourists both from Inner China (neidi) and from abroad largely abandoned their plans to visit to Kashgar. The trend is demonstrated by government statistics too, which indicate a decline for 2014 in both the number of tourists and tourism revenue of about 20 per cent after years of steady growth. ${ }^{9}$ Restaurants closed and souvenir shops were left empty. The large tourist infrastructure that had been built up was left void. Not only did tourists stay away, but local people burdened by the difficulty of travelling amidst slumping incomes, government restrictions on movement and a generally bleak and suspicious atmosphere were now much less likely to go out to eat or travel locally. Local incomes fell for all but government employees. Consumption halted, business suffered. The real estate prices stagnated or fell (Zenz and Leibold 2017). Furthermore, the renewed focus on policing and surveillance killed off economic momentum, curbing investments and severely limiting opportunities for Uyghur businessmen to make a profit. As recently calculated by AFP using government statistics, the economic gap between Xinjiang and the rest of the country grew significantly after 2014. Despite higher growth in 2010-2014, the per capita GDP was estimated to have expanded about eighteen per cent more slowly than the nation as a whole since 2010 (AFP 2017; Zenz and Leibold 2017). Many of the development project infrastructures stood empty and seemingly abandoned in the outskirts of town. The situation worsened in 2016 and 2017. The scale of the crackdown had significantly expanded, and so did the surveillance infrastructure throughout southern Xinjiang. In Kashgar, business was not going well. Dolkun was nowhere to be found, his mobile turned off, his house locked. My questions around the neighbourhood did not lead anywhere, and I soon gave up on the idea of re-connecting with him. If he were not already in trouble, my questions might harm him, I thought. Other friends who had heavily invested in the real estate market during the previous years were lamenting losses. Many of the restaurants I came to like, such as Perhat's kewab place, were closed. Many of their owners, my friends, gone.

There seems to be a contradiction at the heart of such policies. For years, the party-state had funded the renovation of Kashgar with the explicit aim of opening it up to mass tourism. This, the official rhetoric implied, would

9 Data is available on the Kashgar government website, kashi.gov.cn. For the year 2014, see in particular: http://www.kashi.gov.cn/Item/24263.aspx (accessed May 2019). 
bring benefits and opportunity to the Uyghur population of Kashgar. Yet, since 2014, due to the state's renewed focus on security, such opportunities dwindled, and the small but growing tourist economy collapsed. This, however, is a contradiction only insofar as we accept the premise that the aim of the renovation of Kashgar was that of the economic development of the region. What this chapter has shown, on the other hand, is that this particular form of curational intervention in Kashgar has a mainly disciplinary goal: that of turning Uyghurs into loyal, ethnic subjects. The principal aim of Kashgar's renovation is not economic development. As the only form of subjectivity that is deemed acceptable is one that complies with China's paternalistic view of its ethnic minorities, Uyghur-ness is turned into a mere culture of display in which crafts, traditional clothes, songs and dances become exclusive markers of minzu identity. The normative aspect of power relations in Xinjiang, through which Uyghur subjects need to navigate on a daily basis, is ubiquitously visible and audible through banners, paintings, TV ads, and propaganda slogans played by loudspeakers or moving police vehicles. By showcasing, in detail, what Uyghurs should do and should not do, the party-state is clearly defining how Uyghurs should behave - what kind of subjects they are supposed to be. As Uyghur culture is reduced to such aesthetic elements, the Uyghur subject is constrained by this particular culture of display. The outcome, then, is disciplinary, not economic, despite the fact that it is often framed in the language of development.

This particular outcome, in which planned interventions turn into a tight system of control, echoes a number of works associated with the thinking of Foucault, and particularly his famous account of the genealogy of the prison (1979b). While, Foucault shows, the aim of the prison system was that of "rehabilitating" individuals, its actual outcome seems to reinforce and reproduce a discourse of criminality. In so doing, however, the prison system does not simply fail. Rather, it reaches a different kind of target, "in so far as it gives rise to one particular form of illegality on the midst of others, which it is able to isolate, to place in full light and to organize as relatively enclosed" (1979b: 276). The point here is that while some kind of planned interventions might, seemingly, produce unintended outcomes, they remain integral to larger constellations of control bearing concrete political effects. In Kashgar, too, the reconstruction of the old town might have not achieved economic development through the expansion of the tourist industry to the benefit of the city's population. What it achieved, however, is the expansion of a particular kind of state power into the lives of Uyghur subjects. This, in turn, reinforced the views of ethnic minorities as lesser kinds of citizens. 


\section{Conclusion}

In a section of The Rule of Experts (2002), Timothy Mitchell addresses the forms of violence that underlie the making of the modern nation. Here, Mitchell follows many historians of nationalism in showing how the project of building a new nation state is tied to an active attempt at producing a past. Mitchell's argument, however, differs in that he suggests that the nation emerges not out of the growing self-awareness of a particular community, but rather from violent encounters and interventions (Mitchell 2002: 183). In particular, he describes the case of the reconstruction of Gurna, a village near Luxor, in which the creative process of heritage-making and the definition of the nation's past is based upon an act of destruction. In 1945, it was decided to move the village to a new location as villagers were accused of plundering nearby archaeological sites and harassing the tourists visiting it. The project of relocation was in the hand of a "visionary" architect, Hassan Fathy, who strongly advocated for the use of "vernacular" architectural techniques and material. This appeal for tradition, Mitchell recounts, was made for the sake of progress, aiming at restoring sanitary condition and ensure a more rational form of energy consumption and food distribution. In particular, "this approach to social problems was founded on the belief that the recovery of a vernacular national heritage - a heritage that was pure and undebased, and thus clean and sanitary - would provide a means to the recovery of social energy, health, and purpose." (Mitchell 2002: 189). Fathy's project largely failed due to the villagers' resistance to the economic and practical shortcomings of his vision, yet this experience did not dissuade Egyptian authorities from re-launching the relocation project in 1998. The rationale, once again, was found in the attempt to protect the archaeological heritage from plundering peasants, but also to improve their "unhygienic" living conditions. The new project, moreover, was closely tied to the tourism industry and the government's plan to turn Gurna into an "open-air museum," according to which its population were to move out and its houses destroyed, with the exception of a few houses that were to stand as examples of local architectures and used by artisans and craftsmen producing tourist artefacts (Mitchell 2002: 200).

In both cases, Mitchell strongly posits that the attempted evictions of Gurna villagers were justified as a project of producing the nation: "to preserve the heritage of the nation, and to turn those portrayed as lawless and uneducated into honest citizens of the state, they must be expelled from their homes." (Mitchell 2002: 205). More specifically, through this particular project of spatial re-territorialisation the nation creates itself 
by making a particular other: "the performing of the nation required that every one of its rural inhabitants be declared outside the nation, uncivilized and unhygienic, so that in rendering them civilized and clean, the nation could be made" (Mitchell 2002: 192). The village of Gurna, in other words, was to be destroyed in order to be preserved. Its people had to be cast as others - "ignorant, uncivilized, and incapable of preserving their own architectural heritage" (Mitchell 2002: 191) - in order for them to enter the national politics. This act of violence that lies at the core of the modern nation, Mitchell argues, is tightly connected to one of destruction, in which the past needs to be rebuilt in order to become heritage.

As in Mitchell's Gurna, in the case of the re-construction of Kashgar and of the new villages in Dulong, "planning and rebuilding would [...] lead to the construction of new peasant selves" (Mitchell 2002: 189). Here, too, the violence implicit in such an attempt is evident. Much like the old city of Kashgar, Uyghur culture needs to be destroyed in order to be preserved. The state, through such acts of destruction, presents itself as the protector of local heritage, without whose support locals would not know how to recognise or to value. Yet, what is protected (or invented) as Uyghur heritage is only what can be put on display for tourist consumption. Everything else finds itself in an ever-expanding list of forbidden behaviours. The case of Kashgar thus presents, in a nutshell, how future-oriented nation-state politics create real everyday grievances in the here and now: in order to promote an ideologically charged future harmony, a particular culture of display in which ethnic differences are reduced to mere aesthetic choices, a violent regime of control is imposed on borderland populations. In so doing, ethnic minorities are not only marginalised, imprisoned, or violently killed, but they are also clearly marked as a lesser kind of citizen in what is supposed to be a multi-ethnic nation state. In Xinjiang, to be sure, ethnicity has become a driver of discrimination and a tourist destination.

Furthermore, as I show in the next chapter, practices of heritage-making and the transformation of Uyghur-ness into a culture of display are part and parcel of China's attempts vision of transnational connectivity. To do so, I return to the issue of connectivity that I introduced in the first part of the book, and use the image of the corridor to conceptualise the ideology underpinning such vision. In particular, I show how the securitisation of Xinjiang impacted cross-border relations and practices of proximity. In so doing, I place the plight of the Uyghurs - and other Turkic groups in Xinjiang - within the broader context of cross-border development now framed in the language of the Belt and Road Initiative. 



\section{Coda}

Autumn 2016. After my second and longest stay in the Dulong Valley, it was time to leave. The driver of the mianbaoche headed to Gongshan and that I was sharing with five other people, Jiang He, was a local Drung man whom I had grown to like throughout the previous weeks for his honesty and kindness. A short, hardworking, red-faced fellow, Jiang He always had a smile and a good word for all of the people - mostly construction workers and the occasional shepherd - that we met on the four-hour drive to Gongshan. The sun had yet to rise and the air was crisp as we wound up the western side of the Gaoligong Mountains. We had to stop our car for a few minutes at a little construction site, and most passengers got off for a smoke, shivering in the cold and chatting with the friendly road worker handing out cigarettes to his Sichuanese colleagues. Jiang He did not smoke, but the short stop did not seem to bother him and he joined the rest of the group outside. "This road," he told me, "was paved only three years ago. Before, it was one pothole after the other, it would take us a day to reach Gongshan, it was very dangerous." I looked down the steep mountain slope along which the road was built and nodded, grievously. Besides myself, there were two other outsiders making the trip to Gongshan today, two middle-aged men from Taiwan. One of them approached Jiang He with a question: "now that the road is good, why don't you get into the tourism business? You are smart, you speak good Mandarin, you know people, why don't you open a hotel? It sure is better than driving a mianbaoche." Jiang He listened with the attitude of someone who had been thinking through that very question more than once. "I know," he said. "What I think would be a good business," he said pointing up-road, towards Gongshan, "is a hotel near the new tunnel. From there you can hike in the Gaoligong Mountains, it's beautiful. Foreigners like to hike, and now it's difficult to find someone to go with. I know this place, I could bring people up there (dai ren qu)." For a moment, we all seemed to think that Jiang He had a plan, that he was about to tell us where the hotel will be, how big it should be, how much it would cost him. However, he uttered none of this. Instead, he shrugged and walked off, towards the car. "We can go on now." A few turns up the road, as we got closer to the tunnel, I returned to the topic. "Why don't you open such hotel?" I asked. He seemed to think about it for a second, but then replied with the voice of someone who is stating the obvious. Maybe he was just annoyed by the question. "It's not easy (bu rongyi), you need money, contacts (guanxi), 
it's not easy." "But sure," I insisted, "the government is investing a lot in Dulong, I am sure they would help." He nodded, then said: "yes yes that's correct. But we Drung are not good at business." Another sentence I had heard a number of times before. It was time for a different conversation.

In Give a Man a Fish (2015), anthropologist James Ferguson focuses on the extension of state social welfare programmes, forms of social protection, and cash transfers within a move to a Basic Income Grant in South Africa and the Global South more broadly. He makes a case for conceptualising such transfers not as gifts, charity, or market exchange. Rather, he argues, they should be understood as a rightful share - parts of a broader distributive turn recognising that distribution has overtaken production as the most significant economic practice of our time. As part of this discussion, Ferguson argues that the claim that cash transfers are de-mobilising is "unproven at best." Further, he contends that programs of direct distribution may give "the poor" a positive relation to the state, turning them into rightful claimants, providing new grounds for mobilisation and thinking new kind of politics (2015: 207). This, in turn, can challenge the structural inequalities inherit to the current system based on production. What is missing in Ferguson's analysis of distributive politics in the Global South is the People's Republic of China - a country that, in many ways, has been at the forefront of such distributive efforts. Like in Dulong, poverty-stricken households across the Chinese countryside are the recipients of various kinds of subsidies, often framed simply as dibao. Yet, unlike Ferguson's argument, the Dulong case shows the strengthening of the role of the state as the almighty distributors of goods. As Jiang He's dismissive comment that "we Drung are not good at business" highlights, this particular relation to the state is paralysing, rather than empowering.

In this regard, Dulong is not an isolated example within the Chinese context. Take, for instance, Andrew Fischer's (2009) insightful work on the effects of highly subsidised development on Tibetan communities in the Tibet Autonomous Region. Fischer shows how state investments (in the forms of both government subsidies and subsidised investments by private Chinese companies from outside of the region) "accentuated the already highly externalised orientation of wealth flows in the economy, resulting in a socio-economic structure that rewards a small upper stratum, which includes a small minority of Tibetans and a large proportion of non-Tibetan migrants, mostly concentrated in urban areas and well positioned to access the flows of wealth as they pass through the region with increasing velocity" (Fischer 2009: 38). Thus, in contrast to Ferguson's argument, in 
China's ethnic minority-populated peripheries, cash transfers, and other forms of subsidised help accentuate, rather than reduce, pre-existing social and economic inequalities within particular groups. The environment of "extreme dependence" thus emerging from China's development model in the region leads to Tibetans' exclusion from economic opportunities that favour Han Chinese migrants (Fischer 2014: 180-183). For them, this form of aid is, in essence, "disempowering" (Fischer 2014) rather than mobilising. Why, then, does the Chinese case so clearly indicate a conclusion antithetical to Ferguson's analysis? One answer, as it emerges from the last two chapters, lies in the position of ethnic minorities in the Chinese context. Here, the minzu system's hierarchical structure coupled with policies based on an inherent understanding of suzhi underpin a patronising approach to development and modernisation. This approach, as I have described it through the conceptual lenses of curation, empties ethnic places and subjects of any cultural and social meaning, thus making the state the only possible "provider of goods." This, in turn, makes any localised form of mobilisation not only unlikely, but essentially criminal(ised). 



\section{Part 3}

\section{Corridor}

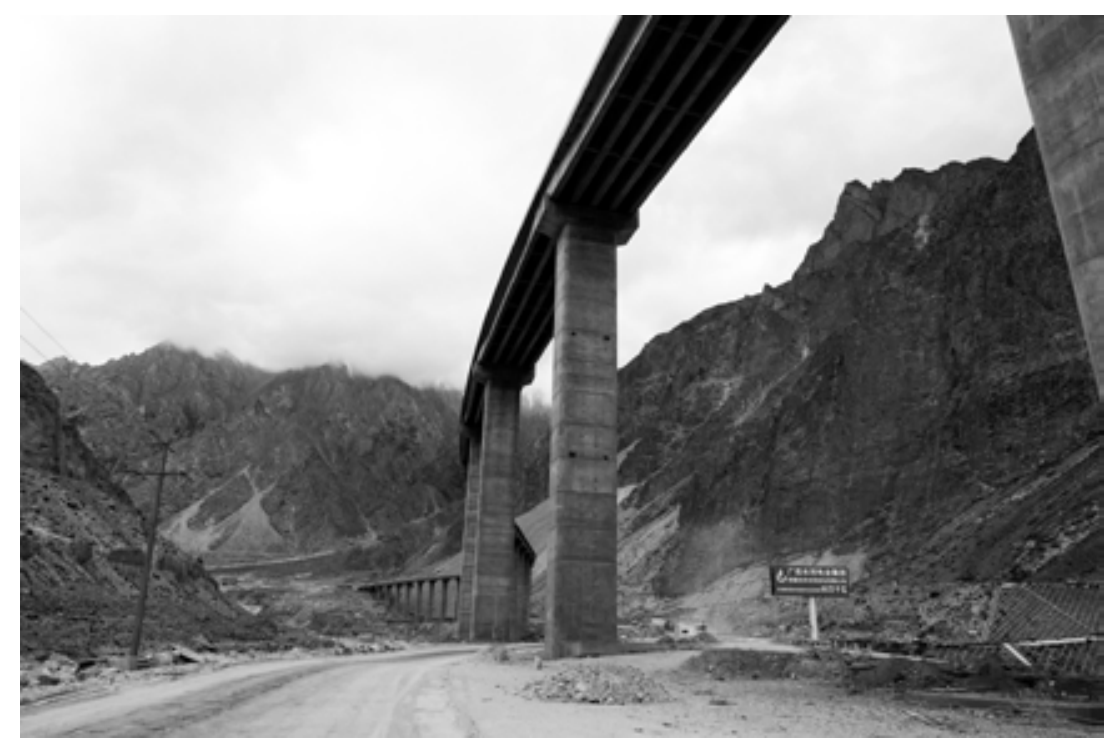

Figure 15: Suspension bridges on the new KKH in the Gez Canyon (picture by the author, 2016) 



\section{Control}

"Development is the foundation of security, and security the precondition for development" —Xi Jinping, May 21, 2014

"Routes may be seen most abstractly as a form of regulation" — Mahnaz Ispahani (1989:2).

In February 2013, I met Ali - the dry fruit trader from Nagar that I introduced in the first interlude - while we both were in Rawalpindi, Pakistan, on rather different missions. He had only recently returned from a month-long stay in Xinjiang, during which he was trying to find interested buyers for a cargo of Afghan walnuts. Now, he was in Rawalpindi securing the shipment, and was considering a quick trip to Peshawar to meet the main supplier in person. I, on the other hand, was spending two months conducting interviews with the Uyghur community of Rawalpindi - the largest in Pakistan with over 2000 members. Some Pakistani Uyghurs - or Kashgari, as they were generally known in Pakistan - were involved in trading businesses with China, and thus owned shops in the so-called China market. For Ali, the China market was a mandatory stop during his visits to Rawalpindi, as traders and logistics companies dealing with China were generally based in this area. The name itself - China market - leads to little speculation. This cluster of busy alleys and malls around Gordon College Road, close to downtown Rawalpindi, was the go-to place for anyone interested in the China business. Street-front shops displayed a vast array of made-in-China goods, imported either via the $\mathrm{KKH}$ or via Karachi and the sea route, while many of the higher floors were occupied by small offices of logistics companies. The names of the malls make the China Market rather unique: "China town", "China shopping center", "China store", "New China market”, "Beijing shopping center", "Uromqi Plaza”, and so on. Activities around Gordon College Road were always frenetic. Cars and motorbikes would drive dangerously through the crowds, while young boys carried trays with half a dozen chai cups. Heated conversations among traders, in several languages, could be heard while costumers lined up at a restaurant famous for its pulau. On the sidewalk, boxes of goods were continuously loaded and unloaded to and from trucks, cars, and rickshaws.

Ali and I decided to meet at the "China Restaurant" beside the Beijing Shopping Center. While the name might inspire sweet and sour chicken and 
Sichuanese hot pot, the "China Restaurant" was, in fact, the only Uyghur restaurant in the area. The restaurant was located on a rooftop, offering a beautiful view of Gordon College Road and the nearby neighbourhood. Owned by a family of Kashgari who moved to Pakistan in the 1980 os and that used to be in the clothing business, the restaurant had become an important meeting point for the Uyghur community of the China market. Ali and I sat down and ordered two portions of laghmen and a few kewabs. After some catching up regarding my research and his business, our conversation moved to the current situation in Xinjiang. Ali told me that in Kashgar and Urumqi he exclusively dealt with Uyghur traders. While he was free to travel to Xinjiang, however, it was more difficult for his Uyghur partners to obtain a passport and a Pakistani visa. He showed me a letter of invitation that he had written for one of them to visit Pakistan, with which Ali hoped his partner could obtain a passport. Things, he pointed out, were not easy for Uyghurs in Xinjiang. Soon after, however, as we discussed how security measures have become stricter at the Khunjerab Pass, Ali elaborated a different view. As he put it: "China is a free country, you can pray there. There are mosques everywhere in China. Uyghurs should stop creating problems. They live in a developed country, and they complain, they riot. It's not good."

This conversation conveniently sums up a particular contradiction that lies at the heart of how many Pakistani traders view Xinjiang Uyghurs. On the one hand, Uyghurs are fellow Muslims living in a non-Muslim state. While Ali pointed out that Uyghurs are free to pray, Pakistani traders (and Ali himself, on different occasions) often recognised that there are severe restrictions to Uyghurs' religious lives. On the other hand, I have heard Pakistani traders blaming Uyghurs countless times for the dire security situation in the region - something that directly affects their business interests. "They should thank the Chinese [government]," one went as far as saying, "instead all they can do is rioting."

Such multiple and mutually incongruent views of the Uyghurs seem to also be mirrored by China's policies in Xinjiang. On the one hand, development initiatives, from the xibu da kaifa to the Belt and Road are promoted according to the objectives to foster cross-border ties and generate economic opportunities for local ethnic minorities. On the other hand, regimes of control and securitisation concurrently implemented are designed to target specific groups, resulting, as the previous chapters already documented, in increased dependency, economic marginalisation, and social exclusion. Part Three addresses the particular connection between infrastructure development and the disciplinary measures that are put in place for the 
management of ethnic subjects, focusing in particular on the consequences on cross-border trade. While as I have argued, curational interventions are particular relations of power, here I ask what these relations tells us about power in China more broadly, and what their impact is on cross-border relations. In so doing, I address the contradiction between the promises of speed and development - which I articulate through the figure of the corridor - embedded in many infrastructural projects such as the renewal and expansion of the $\mathrm{KKH}$, and the emergent technologies of surveillance and control that seem to curb such promises.

In this chapter, I show that China's focus on security pre-dates Chen Quanguo's term as Party Secretary of Xinjiang, and rather defınes China's approach to its western regions more broadly. In order to do so, I begin with my research among the Uyghur community of Pakistan, before addressing the impact of Xinjiang's recent securitisation drive on cross-border trade. I then theorise this particular modality of power in the Interlude, moving from the notion of curation as well as the work of Deleuze and Guattari, and I describe its particular spatialisation with the image of the corridor.

\section{The Uyghurs of Pakistan}

On Gordon College Road, in Rawalpindi, only a five-minute walk from the restaurant where I had lunch with Ali, is the Khotan House. Together with the nearby Kashgar House, the Khotan House had become a major landmark in the history of the Kashgari community, since the opening of the Karakoram Highway in the mid-1980s. ${ }^{1}$ Both houses were donated

1 I refer to the Uyghurs of Pakistan as "Kashgaris". As I have discussed elsewhere (Rippa $2014 \mathrm{~b}$ ), not all of them refer to themselves as Kashgaris. Some use the word "Turki", others "Uyghurs", others "ex-Chinese" or, even, "Chinese." In this chapter, I refer to them, however, as Kashgaris, partly because it is the most used, and partly because the other ethnonyms carry a specific political meaning. "Turki", for instance, is generally connected with separatist and pan-turkic movements in Xinjiang, and the expressions "Turkestan" and "East-Turkestan" have been banned by the PRC. Echoes of this have reached Pakistan as well. In a Kashgari neighbourhood in Westridge, Rawalpindi, the local mosque used to be called "Turkestani", in their honour, until the local authorities, under pressure from the Chinese government, decided to change the name. The Kashgaris, then, are not only well aware of how politically charged those expressions are, but also sensitive to the influence Chinese authorities seem to have over the local, Pakistani government. Both the expressions "ex-Chinese" and "Chinese", on the other hand, seem to be a recent development connected with the institution, in Pakistan, of an Overseas Chinese Association. As it will become clear throughout the chapter, the Overseas 
to the Kashgari community by wealthy Uyghurs residing in Saudi Arabia, and soon became important transit points for Uyghur pilgrims directed to Mecca. Xinjiang Uyghurs would cross the Khunjerab Pass into Pakistan, and with the help of the Kashgari they would apply for Saudi visas and travel permissions. In these years, the Khotan House and Kashgar House used to serve as hostels in which Uyghur pilgrims could stay for free. Oftentimes, I was told, pilgrims were so numerous that many had to sleep on the bare floor in the courtyard - yet none of them were ever charged a single Rupee for staying there.

Before the opening of the Karakoram Highway, connections between Xinjiang Uyghurs and Pakistani Kashgari were much more tenuous. The history of the community can shed some light on this particular relation. As Abdulaziz, a Kashgari trader from Gilgit, told me while sitting in his shop where he sold made-in-China blankets and cushions, "There are four kinds of us [Kashgaris]: those who are originally Pathan [Pashtun], those who are originally from Baltistan and those who are originally from [Indian] Kashmir. And there are those [...] who are 100 per cent Uyghurs." However, the composition of the Kashgari community, I would discover, was even more complex than that. In the course of my research, I also heard stories of families who lied about their South Asian origins and still managed to enter Pakistan, as well as stories of Kashgari families of mixed Uyghur-Afghan background who ended up in Pakistan following the Soviet invasion of Afghanistan.

As I have described elsewhere (Rippa 2014b), the earlier Kashgari migrants I interviewed moved to Pakistan just before the partition of the subcontinent (1947) and the foundation of the People's Republic of China (1949). Many simply left Xinjiang for the hajj, or on business, and could not go back because the border was sealed, while others decided to move to Pakistan for their faith or for fear of persecution from the communists. I was, for instance, told that in 1948-9 about 500 people moved to Pakistan from Yarkand, apparently afraid of the People's Liberation Army's advance in Xinjiang. Some of them were rich families of traders with an established network of contacts in the region, others were farmers with little or no experience of the world outside of their native villages. For exactly these reasons, many moved in the years following the establishment of the PRC, when the new government did not thoroughly control Xinjiang's border and crossing was 
still relatively easy. Frequently mentioned in the course of my interviews was an uprising that took place in Khotan in 1954 (Dillon 2004: 54), after which many Uyghurs involved decided to leave Xinjiang fearing repercussions for them and their families (see also Rahman 2005). ${ }^{2}$

Most Kashgaris, moreover, seem to have moved to Pakistan during the eleven years of Ayub Khan's presidency, between 1958 and 1969. Ayub Khan, the second president of Pakistan, facilitated their transfer to Pakistan, a movement that many considered a return rather than a migration. As Abdulaziz pointed out, many Kashgaris have South Asian origins, as before the 1940 s it was quite common for Kashmiri or Pashtun traders to marry Uyghur women and move to south Xinjiang (cf. Warikoo 1996; Rizvi 1996, 1999; Thampi 2010). In most cases, the fact that those migrants carried a British passport - or other documents proving their family's South Asian lineage - allowed them to move back to Pakistan during Ayub Khan's government. A few elderly Kashgaris I interviewed in Rawalpindi still remembered their journey through the Karakoram, each giving me similar accounts not only of the long and tiring route, but also of the reasons why they decided to leave Xinjiang: their family's properties nationalised by the Maoist state, the famine brought by the failure of the Great Leap Forward, restrictions to their religious practices. They were all fleeing a communist state for a Muslim country and, according to Ayub Khan's policy, they were immediately given Pakistani citizenship and 500 Rupees each upon their arrival.

The opening of the Karakoram Highway in the early 1980 s was a major turning point for the Kashgari community. For many, it represented the first opportunity in over three decades to travel to their homeland. ${ }^{3}$ Most chose to take their families with them on the journey. Furthermore, as the Highway opened up new possibilities for mobility across the Karakoram, many Xinjiang Uyghurs took advantage of the political relaxation in the PRC and travelled to Pakistan for different purposes. Although only a few

2 According to Chinese sources, in $195^{2}$ around 3000 Afghan and Pakistani nationals living in Xinjiang voluntarily became Chinese citizen so that by 1953 there were virtually no Pakistani citizens living in Xinjiang. According to the same account, in the following years, many of these people demanded to withdraw from their newly acquired Chinese nationality and applied for a return to Pakistan (Li 2013: 59). While this information is consistent with my own findings with regard to the time many Uyghurs moved to Pakistan, I could not verify whether any of those who moved in the 1960 s had previously received Chinese citizenship. The Chinese article in which this information appears, moreover, is characterised by a highly propagandistic tone and should be taken with a fair degree of scepticism. In any case, the issue is unlikely to be solved until scholars are granted access to official documents in both Xinjiang and Pakistan.

3 Chinese sources record 1473 visits by Pakistani Uyghurs to Xinjiang between 1980 and 1987 , at around the time of the opening of the $\mathrm{KKH}(\mathrm{Li} \mathrm{2013}: 60)$. 
of such travellers have settled in Pakistan, they have generally interacted with the Kashgaris and have had a significant impact on this community. In particular, as with much of the history of interactions between Central and South Asia, the opening of the KKH saw traders and pilgrims once again becoming the main force of cross-border mobility in the area. In the aftermath of the Cultural Revolution and, particularly, of Mao's death (1976), the Chinese Communist Party moved towards more tolerant policies in an attempt to regain support among the non-Han people of Xinjiang. Together with a return to a non-assimilationist policy, the early 1980 s marked a period of relative religious and cultural freedom for the Uyghurs. As a consequence, thousands of mosques and madrassas were reopened or constructed, and many took advantage of this situation to conduct the hajj pilgrimage, which had resumed in 1979 after fifteen years of interruption (Shichor 2005: 122; Waite 2006: 254-5). Pakistan then became a major transit point for Uyghur pilgrims as it had in the 1930 s. In 1985 , about 1200 pilgrims crossed into Pakistan in order to reach Saudi Arabia for the hajj. As in the past, they also brought various (Chinese) goods with them, and thus through this informal, individual form of trade covered part of their costs (Kreutzmann 1991: 725).

Once in Pakistan, those pilgrims usually had to wait a few weeks for their Saudi visas to be processed in Islamabad, and thus the local Kashgari community developed an important network of support. Haider (2005), in an article on the Karakoram Highway partly based on fieldwork among Pakistani traders in Xinjiang, claims that "most of the Uighur settlements that can be found in Pakistan today were established in the 1980s as transit points on the way to Mecca" (525). According to my own interviews in Pakistan, most Uyghur pilgrims ended up staying either in Kashgari neighbourhoods, or in specific "houses" set up with the help of the Kashgari community. The pilgrims, in other words, were helped and supported by an established network of Kashgaris in settlements that existed since well before the opening of the KKH.

Particularly significant in this regard were the Khotan House and Kashgar House. Opened in 1986, Khotan House is a three-floor building with a few dozen rooms overlooking a small courtyard. At the time of my visit in 2013, each room was equipped with two bunk beds and a small table, while half of the courtyard was occupied by a prayer hall covered with a few small rugs. The only piece of decoration was an old picture showing General Zia-ul-Haq and the Chinese consul welcoming a group of Uyghur pilgrims. Already then, however, both the Khotan and Kashgar house remained empty of pilgrims. In 2006, the Chinese and Saudi governments signed an agreement that allowed pilgrims to fly directly from Beijing, and thereafter most Uyghurs from Xinjiang stopped 
going to Pakistan on their way to the hajj. Largely as a result of this change, Kashgar House and Khotan House closed after 20 years, and the buildings are now used by Kashgari traders as warehouses. As the next section describes, this was only one of several measures implemented after $9 / 11$ that would radically impact the quantity and quality of cross-Karakoram exchanges - and the internal politics of the Kashgari community more specifically.

\section{The making of an overseas ethnic minority}

Since the Kashgaris settled in Pakistan in the second half of the 2oth century, most have had virtually nothing to do with the Chinese government. Many obtained Pakistani citizenship as they arrived in their new country, and did not seek any relation with PRC authorities. During the course of my interviews, I was repeatedly told that, until recently, the Uyghur community of Pakistan seemed of little or no concern to China. It was only in 1988 that the Chinese government sent its first Uyghur official to its Islamabad embassy, with the specific purpose of dealing "with affairs related to Uighur expatriates" (Rahman 2005: 1). ${ }^{4}$ Most Kashgaris I interviewed, moreover, agreed that Beijing began to actively interact with their community only after the 9/11 attacks on the United States, when Pakistan suddenly found itself once again deeply involved with a war in nearby Afghanistan, and the Kashgaris became one of the main concerns in China's own "War on Terror". China's interests in the Kashgaris became particularly evident in the months that preceded the 2008 Beijing Olympics, when rumours of Pakistan-based Uyghur terrorists ready to target the Games were rampant. ${ }^{5}$

In this context, Pakistan's strategic importance for China increased significantly (Yang and Siddiqi 2011; Small 2015); yet, at the same time, the instability of the country and China's concern with the situation in Xinjiang redefined China's policies towards its "all weather" ally. Duchâtel (2011), for instance, individuates two main adjustments: sustaining a pro-China "United Front," and reassessing Pakistan's strategic value. If the second "adjustment" is of little concern here, the pro-China "United Front" consists

4 This decision did not end well for the Chinese authorities, as the young Uyghur diplomat left his post after only thirteen months, going into hiding as an Afghan refugee in Peshawar and eventually obtaining asylum in Switzerland (Rahman 2005).

5 In 2008, several bombs were detonated on buses in Urumqi and Kunming, with the Turkestan Islamic Party (TIP) claiming responsibility, while in March 2008 a Uyghur woman travelling on a Pakistani passport was stopped from lighting a container filled with petrol on a flight from Urumqi to Beijing. For an analysis of those incidents see Pantucci and Schwarck (2014: 10). 
essentially of cultivating relations with a wide range of actors, from civilian parties to the military, to religious groups and important members of civil society. This is generally accomplished through the Chinese embassy in Islamabad, and builds upon the principle of "neutrality," which means that when an internal conflict emerges China refrains from taking sides and thus avoids making enemies (Duchâtel 2011: 551-3). In other words, it consists of a network of relationships cultivated through time and skilful diplomacy that the Chinese government can use in times of need. As part of this effort, China has since the early 2000 s sought to influence the Uyghur community of Pakistan through the institution of the "Overseas Chinese Association".

Virtually all the Kashgaris I talked with in Pakistan were involved with the activities of the Overseas Chinese Association, which many, particularly in Rawalpindi, called "ex- Chinese Association." ${ }^{6}$ The "Association" does not have an office, but it has two presidents and two chairmen, for Gilgit and Rawalpindi, respectively, who manage the money provided by the Chinese embassy and distribute it to the community. ${ }^{7}$ When I interviewed him in February 2013, Sultan Khan, chairman of the Association for Gilgit-Baltistan, told me that it was the "Chinese High Commission in Pakistan" which asked them to form "an association of ex-Chinese." The embassy, Sultan Khan explained, wanted to know the strength of the community so that they could economically support it. I was told, in particular, that between 2003 and 2013 the Association had received about sixteen million Rupees from the Chinese embassy. Sultan Khan also confirmed that in 2013 alone the Chinese High Commission in Pakistan released the amount of four million Rupees, which in Gilgit was distributed in the following way: 5,00o for each student and 10,000 each to about 30 Kashgari widows. Although there is not a significant community of Kashgaris living outside of Rawalpindi and Gilgit, various members of the Association told me that they were in contact with families in Lahore, Karachi, Peshawar, and even Chitral. I was once shown a list with the names of about two dozen Kashgari children from Chitral, who were also receiving some financial help for their school fees.

6 The Association is known in Chinese as huaren xiehui, or "Overseas Chinese Association." Pakistan is also home to a small diaspora of Han and Hakka groups from Eastern China (Lin 2017). They are not, however, involved with the Overseas Chinese Association but mostly involved with another Association that was formed at around the same time, the so-called "China-Pakistan Overseas Chinese Association." For a discussion of the Han diaspora in Pakistan see Lin (2017). 7 The founder of the Association was Raza Khan, the most successful businessman within the Kashgari community and owner of a steel mill in Rawalpindi. Raza Khan, whom I only briefly talked to on the phone, passed away at the time of my research in Pakistan. For more information see Rippa (2014b). 
While the creation of the Association can be understood within the framework of China's attempts to secure Xinjiang's borderlands and the ongoing expansion of its diplomatic influence abroad, it also needs to be addressed within the wider context of the PRC's relations with its overseas communities. Traditionally, the overseas Chinese (generally huaqiao or huaren $)^{8}$ have been seen as China's "fifth column," particularly in Southeast Asia where their number and economic influence is more significant. ${ }^{9}$ In 1978, the "Overseas Chinese Affairs Office" (qiaoban) was set up under the State Council, stressing the importance of Overseas Chinese affairs for the PRC's national interest. With it, as it has been pointed out, the Chinese government implicitly claims that the Overseas Chinese belong to China, thus legitimising "the work aimed at enhancing the symbolic affiliation and material contribution of the overseas Chinese to their homeland" (Barabantseva 2005: 4). To this end, a significant effort was made toward the creation of organisations for Chinese migrants in their country of residence in order to assist and promote the unification of those communities (Zhuang 1997; Cheng 1999; Barabantseva 2005; Nyíri 2002). ${ }^{10}$

If the establishment of the Overseas Chinese Association in Pakistan perhaps fits the aims of the Overseas Chinese Affairs Office's project, it also

8 "There is a certain degree of confusion in the West over how the Chinese terms huaqiao, huaren, and huayi should be translated into English. While there are important differences in the status of these groups and their relations to China - huaqiao denotes citizens of China living abroad, huaren and huayi refer to foreign nationals of Chinese descent - it seems that in the PRC's policy-making realm these distinctions are rarely drawn. In fact, most of the Chinese literature uses the generic term of huaqiao huaren signifying that both groups fall within the scope of the overseas Chinese policies of the PRC's government. Therefore, as used in this article, overseas Chinese is equivalent to the Chinese term huaqiao huaren and loosely refers to the Chinese people outside the PRC" (Barabantseva 2005: 1).

9 Particularly since the reform period, the Chinese diaspora has played a major role in terms of investment and know-how for the development of the mainland. There is no shortage of scholarship on the economic success of Chinese diasporic communities (cf. Seagrave 1995; Hodder 1996; Tagliacozzo and Chang 2011; Nyíri 1999).

10 Barabantseva (2005) refers to a programme called "Developing Motherland and BenefitingAssisting Overseas Chinese" initiated 2002 by the Overseas Chinese Affairs Office. "This plan" she argues, "has a two-fold strategy. Firstly, it seeks to promote the interaction between old overseas Chinese communities, and new Chinese migrants. The second component of the plan involves work on enhancing connections between overseas Chinese communities and China. This plan is one example of a series of strategies employed by the Chinese nation-state to attach the overseas Chinese to the modernisation project in China. Another side of these strategies is to export the PRC's ideological presence in the Chinese communities abroad" (Barabantseva 2005: 16). As part of the latter strategy, as Nyíri (1999) pointed out, the most recent Chinese overseas organisations have been either set up through PRC direct involvement, or are strongly oriented towards it. 
seems at the same time very distinct from them. In particular, unlike the dynamic described by Barabantseva, in the case of the Uyghur community of Pakistan there is not any apparent economic interest on the part of the Chinese government, and nothing to gain in terms of the "modernisation project in China." Furthermore, the fact that the Uyghurs are a minority in China adds another layer of complexity. In fact, the PRC's policy toward the overseas Chinese is "tailored" for the Han (Barabantseva 2005: 29) despite recent attempts by Chinese scholars to highlight the multi-national nature of the Chinese communities abroad, claiming their identities remains a "taboo zone" for the Chinese government. Barabantseva thus argues that although "these groups are not completely absent from the vocabulary of the PRC's officialdom," China seems to silently recognise the fact that "it does not have enough legitimacy to seek the loyalty of the Chinese ethnic minorities overseas" (Barabantseva 2005: 31).

The case of the Overseas Chinese Association in Pakistan seems to represent an exception. Although the language is not always clear, and members of the association seem, at times, to be ambiguous about it, the goals of the Association are mostly political. Like other (Han) overseas communities, in the case of the Uyghurs of Pakistan, the Chinese government seems to make a considerable effort in winning the loyalty of this community, aligning it to its nationalist agenda. In order to do so, the Pakistani Overseas Chinese Association is not directly connected to Beijing and the central government, but rather to the Xinjiang government. Here, the main actor is the "Xinjiang Overseas Exchange Association" (Xinjiang haiwai jiaoliu xiehui), which was set up in 1992 in order to create a link between the "Overseas Chinese from Xinjiang" (Xinjiang huaqiao huaren) living in countries like Kazakhstan, Pakistan, Kyrgyzstan, Egypt, Saudi Arabia, Australia, and Canada (China News 2013). In 2013, the "Xinjiang Overseas Exchange Association” held its second General Conference, in Urumqi, while a few years before it briefly made the (Chinese) news for donating 200,000 RMB to the Pakistani community (Sina 2008; Xinhua 2008). As part of the Association's attempt to draw the overseas Xinjiang groups closer to the homeland, I was told in Pakistan that annual visits to Xinjiang were organised for various members of the community. In one case, in 2012, a small delegation was invited to Beijing as part of the "Delegation of Overseas Chinese minorities from Xinjiang" (Xinjiang shaoshu minzu huaren huaqiao kaocha tuan). In a picture I was shown in a Kashgari shop in Gilgit, a group of about 30 people were gathered in one of Beijing's largest Xinjiang restaurants, were they held a conference followed by a traditional Uyghur meal and dances. 
China's attempt to redefine the Kashgari as an overseas community seems largely based on geopolitical and security concerns (see also Small 2015). ${ }^{11}$ As such, it comes as a little surprise that the Association's first task was that of obtaining a comprehensive database of the location, composition, and socio-economic conditions of all Uyghur families in Pakistan. In the process, Chinese authorities in Islamabad have been extremely successful in co-opting some of the Kashgari elites, particularly those families involved in cross-border trade. Over the course of my research among the Kashgari in Pakistan, I became particularly acquainted with Sultan Khan, the chairman of the Association for Gilgit-Baltistan, and his family. Sultan Khan saw the Kashgaris as an in-between community, with its roots as much in China as in Pakistan. As he once put it to me, "our fathers are from Pakistan and our mothers from China, we belong to both countries and we represent an important bridge between them." In the 1990s, for instance, he stressed that many Kashgaris used to work as interpreters and facilitators for the Uyghur pilgrims coming from Xinjiang. Others, like Sultan Khan himself, were doing business between the two countries. In the spirit of what Marsden, Ibañez-Tirado and Henig call "everyday diplomacy" (2016), Sultan Khan held his activities as part of the Association in high regards. "We are an important messenger between China and Pakistan," he explained once while sitting in the back of one of his Swiss watch shops in Rawalpindi. With reference to these criticising China and its treatments of the Uyghurs, he further added that "the Chinese government is working for the public welfare and is giving religious freedom. In my view the policy of the Chinese government is very good particularly for the Uyghur people." In Xinjiang, he went on to explain, people receive unemployment benefits, and they are given land for free. "Those who say that Muslims are being suppressed in China are listening to some wrong propaganda. There is religious freedom in China, it all depends upon the individual whether he or she wants to go to a bar, a mosque or to church."

\section{Move north, young man}

In June 2013, during a few weeks of research among the Kashgaris of Gilgit, I met the man in charge of distributing school fees to Kashgari children on

11 Pakistan, in this regard, is not an exception. China has been increasingly monitored and engaged Uyghur communities abroad, from Central Asia to Turkey and Egypt (cf. Roberts 2004; Vanderklippe 2017). 
behalf of the Association, Akbarjan. Over several cups of tea in his shop in Gilgit's main bazaar, Akbarjan told me his story, and how he came to work for the Association. Akbarjan had an honest smile and spoke English slowly and thoughtfully. He told me that his father was born in Khotan, and moved to Pakistan in 1958, along with other Uyghur families. His family used to run a silk business in Khotan, purchasing and selling silk between Xinjiang and British India. It was only because his grandfather was originally from Peshawar, and thus held British documents, that Akbarjan's father was able to migrate to Pakistan in 1958. Akbarjan himself used to go to Xinjiang quite often after the Karakoram Highway opened in the early 1980s, "on business." Yet, since a massive landslide hit Attabad and blocked the road in 2010, trade has become unprofitable, and Akbarjan had been mostly staying in Gilgit. "Once the tunnel [across the Attabad lake] is finished," he told me, "I will go back to China, do some business." What he told me next was even more interesting. As a member of the Overseas Chinese Association he had very good relations with Chinese officials in Islamabad. While some Kashgari families were known for taking advantage of it, he claimed that the money provided by the Association was doing a lot of good. "After the association was established, Kashgari people are much more educated and can find better jobs here in Pakistan." In business, too, China has promised help. He elaborated:

The Chinese government offered us [the Kashgari in Gilgit] to move back to China saying that they will support our business and the education of our children. [...] You know, recently the Chinese government built a big market in Kashgar. They offered us to go, saying that we can do business there free of any cost.

Only two weeks after this conversation, I was strolling through the "big market" Akbarjan was referring to, in Kashgar. I had returned to Xinjiang in order to join the Ninth Kashgar Central \& South Asia Commodity Fair - the biggest trade fair in town, to which over a hundred Pakistani traders were invited. As I described in the first chapter, the main venue of the fair was the impressive Kashgar International Convention and Exhibition Centre. A second, smaller venue, was at the Guangzhou new City - a 1.5 million square metre "urban centre" located in the south-western outskirts of Kashgar, along the Karakoram Highway, that had just been inaugurated. For the occasion of the fair, the Guangzhou New City was quite full. An entire floor, the fourth, was occupied by at least three dozen Pakistani stands, with traders from Gilgit-Baltistan, Punjab, and Khyber Pakhtunkhwa selling their goods. 
For me, it was a chance to catch up with a number of friends that I had not seen in months and check how business was going for Pakistani traders in Xinjiang. Karim, the trader from Gilgit-Baltistan whose family ran three shops in Kashgar and Tashkurgan also had a little stand at the Guangzhou New City. I asked him about Akbarjan's story that the Chinese government was offering business incentives in Kashgar for Pakistani Uyghurs. He confirmed that the story was true, and that it was not only about Pakistani Uyghurs, but Pakistani traders in general. "If I want," Karim told me then, "I could move my shop here, to the Guangzhou New City. They [the Kashgar government] are giving office and retail space for free to us, if we want to, we don't have any rent to pay."

Karim was not interested in the offer - his family had just opened a third shop in Xinjiang, right in the Kashgar's city centre where he was hoping to cash in from the growing number of Han Chinese tourists. Others, however, did take advantage of the Kashgar government's offer, and over the next two years I heard several rumours about Pakistani traders in the Guangzhou New City. I was able to confirm these rumours only three years later, in the summer of 2016, when I returned to Xinjiang for the first time after the end of my doctoral research. In the meantime, a lot had happened. The China-Pakistan Economic Corridor was making headlines, and China had committed the stunning figure of US $\$ 62$ billion to it. The China Road and Bridge Corporation had completed the tunnels around the Attabad Lake, and the Karakoram Highway was in very good conditions all the way to Gilgit. Not all, however, was going so well.

After spending a few days in Kashgar, in August 2016, I went to Tashkurgan. There, together with some old friends, I met a Hunza trader who had tried his luck at the Guangzhou New City. Like a dozen other traders from Gilgit-Baltistan, Hafiz had a small shop in Tashkurgan in which he sold gemstones, brass vases, and other handicrafts imported from Pakistan. Hafiz co-owned the shop together with two other partners, who took turns going back and forth across the Khunjerab Pass. While Hafiz's shop in Tashkurgan opened only in 2015, he told me that he had been doing business in Xinjiang since 2013. Back then, he opened a shop at the Guangzhou New City. Like him, a few other Pakistani traders opened small businesses there, all rent and tax-free. Things, however, did not go particularly well. As he put it to me: "you see, you can have all the space in the world, no rent, no taxes. But if there's no people, no customers, you still don't make any money." The Guangzhou New City, far from the city centre, never managed to attract any customers. Pakistani traders who opened businesses there all left, after a year or two. As I could see 
for myself on the way back from Tashkurgan, the place laid virtually abandoned. ${ }^{12}$

To be sure, Kashgari traders are today strikingly missing from the Guangzhou New City and similar projects across Kashgar. None of the Kashgari seemed to have taken advantage of the offer that Chinese authorities in Pakistan had made to members of the community, as per Akbarjan's explanation. Why is that? Why, despite the difficult financial situation in which many Kashgari families are, had nobody been eager to return to Xinjiang? The following section, discussing the history of the Kashgari's involvement in cross-border trade, as well as some of the un-expected outcomes of China's recent engagement with the community, will shed some light on this question. In doing so, it will also introduce the issue of the recent securitization of Xinjiang. As many analysts, journalists, and human rights groups have observed the level of securitisation is Xinjiang has reached since 2017 unprecedented scope. Rather than an exception, however, in this Chapter I show that what is currently taking place in Kashgar is the logical consequence of a particular modality of development that privileges control over economic growth.

\section{China's wars on terror}

According to Sultan Khan, the first time China invited Kashgari traders to visit Xinjiang and "do business there" was shortly after the opening of the KKH, in the early 1980 . This move needs to be understood as part of a larger strategy, as since the beginning of the reform period the Chinese government has encouraged minorities to develop trade relations with neighbouring countries (Haider 2005: 525). Deng Xiaoping notably viewed this as a process that may help the minorities' modernisation, as well as a way to develop more friendly relations with the neighbouring Muslim countries (Dreyer 1993: 377). Many Uyghurs in Xinjiang took advantage of the new policies and re-established lucrative trade on the routes connecting Xinjiang with its neighbourhoods in the north and in the west (Roberts 2004: 218-225; Millward 2007: 288-93). Others - a minority when compared

12 Miller (2017: 71) quotes a local estimate that 150 Pakistani traders moved into the Guangzhou New City. By my own estimates, this figure is far too generous. According to my own contacts in Xinjiang, no more than two dozen shops were opened by Pakistani traders in the Guangzhou New City. While some of the shops changed hands a few times between 2013 and 2016, the figure of 150 traders involved in these initiatives seems unlikely. 
to those who went to post-Soviet Central Asia - went to Pakistan. Yet, at this time, as my interviews among Uyghurs in both Pakistan and Xinjiang attest, an important part of the Xinjiang-Pakistan trade volume rested in the hands of the Kashgaris. Making skilful use of their kinship ties with Xinjiang Uyghurs, as well as of their linguistic abilities and knowledge of Pakistan, the Kashgaris found themselves well equipped for the new opportunities presented by the opening of a road connection with China.

Similarly to what happens today, in the 1980 s the bulk of the trade consisted of Chinese consumer goods, crockery, shoes and garments produced in Eastern China and often brought to the Xinjiang bazaars by itinerant Uyghur traders. Furthermore, of particular interest for many Kashgari traders I interviewed was silk. In Rawalpindi's China Market, a few silk shops are still owned by Kashgaris, but I was regularly told that due to the depreciation of the Pakistani Rupee and the growing number of Pashtun traders, this business was not as profitable as it used to be. In fact, since the late 1990s, Uyghurs and Kashgaris both lost their respective advantages in the Karakoram Highway trade, and were soon replaced by Han Chinese companies and other Pakistani traders. Today, only a minority of Kashgaris are still involved with cross-border trade, while only a handful of Uyghurs from Xinjiang still manage to visit Pakistan regularly for business purposes.

A number of factors contributed to the exclusion of most Kashgari from the profits of cross-border trade. As I pointed out earlier in this Chapter, 9/11 and China's participation in the US-led "war on terror" led to increasing concerns among authorities in Beijing and Urumqi about a Uyghur presence in Pakistan. In November 2001, in particular, the PRC government released a document entitled 'Terrorist Activities Perpetrated by 'Eastern Turkistan' Organizations and their Ties with Osama bin Laden and the Taliban" (Permanent Mission of the PRC to the UN 2001). The document describes the existence of an international network of Uyghur terrorists posing an urgent threat to China. Uyghur human rights groups, the document claimed, were also part of such a network funded by Osama bin Laden and Al-Qaida. Shortly after the appearance of this document, the PRC issued a more detailed "White Paper" on the terrorist activities Uyghur terrorist groups, entitled “"East Turkistan" Terrorist Forces Cannot Get Away with Impunity" (People's Daily 2002). Eventually, despite the lack of evidence provided to support such claims, China's efforts convinced the United Nations and the United States to officially recognise the existence of a militant Uyghur group, the Eastern Turkistan Islamic Movement (ETIM) - which, until then, was unknown to most Xinjiang experts and residents of the region. As per China's version, however, the East Turkestan Islamic Movement was not only a major threat 
to peace stability, but it was also operating out of bases in the north of Pakistan, in the "lawless" areas which border Afghanistan, enjoying the support of many Islamist groups in the region..$^{13}$ In fact, as Sean Roberts has compellingly shown, most of the information we currently have regarding Uyghur militant organisations abroad is based "exclusively on biased Chinese and Central Asian intelligence" (Roberts 2012: 3), thus leaving ample room for scepticism. Nevertheless, as he further argues, the official recognition of a Uyghur threat "provided the justification for the production of a long chain of knowledge about ETIM produced by think-tank experts, policy analysts, security experts, and academics" (Roberts 2012, 3). Most importantly, it also led to the implementation of specific security policies within Xinjiang, as well as Pakistan and among other Uyghur communities outside of China.

The creation of the Overseas Chinese Association in Pakistan in 2003 must be understood within this broader approach to security. Because of its creation, business relations have become more politicised, and the Kashgari community fragmented according to different views over Chinese influence. A Kashgari man whose family moved from Yarkand in $195^{2}$ and who preferred to stay anonymous, told me his opinion - which I have since then found to be shared by many others - in the following words. "The Chinese government isn't really doing anything for us," he whispered as we chatted in a small teahouse in the centre of Gilgit, "they give money to some people, but then these people use the money for themselves and the others don't get anything." The Association, in fact, operates with little transparency. No one was either able or willing to tell me how this money was distributed, or based on which criteria some people received scholarships

13 The Soviet war in Afghanistan, when China joined the anti-Russian coalition, was another factor that seemingly contributed to the movement of Xinjiang's Uyghurs to, and through, Pakistan. As reported by Fuller and Lipman (2004), it has been estimated by Chinese sources that "as many as 10,000 Uyghurs had travelled to Pakistan for religious schooling and "military training"” (342). What the Chinese government did not mention is that during the time of the Soviet occupation in Afghanistan, Beijing provided over US\$ 400 million in military aid to the mujāhidin in the form of arms and advisors, all flowing into Afghanistan through the established network of the refugee camps in Peshawar, Pakistan (Cooley 2002: 6o). Moreover, in 1985 , training camps were opened near Kashgar and Khotan, where militants learned the use of "Chinese weapons, explosives and PLA [People's Liberation Army] combat tactics" (Cooley 2002: 59). Other analysts (Rashid 2002: 204, Christoffersen 2007:52), have highlighted the presence of Uyghur militants in Pakistan since the 1980s, often adding that many were enrolled as students in local madrassas. Unfortunately, we do not seem to have enough information to either sustain or dismiss those claims, particularly when it comes to the current capability of those groups, and the assertive language of Rashid and others has thus been criticised by several Xinjiang experts (Bovingdon 2010: 135-6). For a thoughtful critique of the existing literature on Uyghur terrorist groups see Roberts (2012). 
or benefits. More importantly, nobody was entirely clear about what the political motivations were behind China's efforts to engage the Kashgari community.

At the time of my research, the Association's most severe critic was Umer, who told me his story over the course of several meetings at his house in Rawalpindi. Umer's family was originally from Kashgar and moved to Pakistan in 1948. Born in Rawalpindi, he worked in Saudi Arabia with his brother for a few years, as many Pakistani did in the 1970 and 1980 os. When he returned to Pakistan, he was in charge of Khotan House and Kashgar House between 1986 and 2006. In 2008, Umer and his brother, together with four other people, founded the Umer Uyghur Trust with the aim of teaching Uyghur language and culture to the youngest generations of Kashgaris in Rawalpindi. Now a hefty man of mild manners in his mid-5os, Umer talked with confidence as he offered me tea and sweets. "Education," Umer said, "is the basic right of every person. We just want to teach our culture and our language to our children." With this purpose, Umer opened a small school near his house, in the Westridge neighbourhood of Rawalpindi where most Kashgaris live. Soon after the school was opened, he received several visits from different "Pakistani agencies" pressuring him to close it, as, according to them, it was endangering the good relations between China and Pakistan. He told me that the agencies made him an offer in lieu of the Chinese embassy, that he would be given "financial aid" and benefits if he stopped his activities. He did not. Eventually, Umer claimed, under Chinese pressure a group of (Pakistani) men from some (Pakistani) agency came to the school and destroyed everything, while his name and that of his brother were put on the Exit Control List, thus preventing them from leaving the country (Radio Free Asia 2010, 2011; NBC News 2010).

At the time Umer's school was forced to close, a new "Montessori school" opened in the neighbourhood - only a five-minute walk from Umer's house. The principal of the school - a Punjabi man with little interest in political feuds within the community of Kashgaris - told me that he was first contacted by the Overseas Chinese Association in 2010. They were interested, he told me, in opening a school in the area for the children of the Kashgari families. They eventually found a way to collaborate, and with the financial assistance of the Association the school moved into a new, four-floor building. The Chinese ambassador visited the school on more than one occasion, and donated sixteen computers and books for the school's library. At the time we spoke, the principal told me that about 150 "Ex-Chinese" children - as he called the Kashgaris - were currently enrolled in the school, all their fees and expenses paid by the Association. "We also have a plan to teach 
their language [Uyghur]," he told me, "but the Association is in charge of that and I honestly don't know [when we will begin]." A few years later - as of late 2019, that is - Uyghur is still not taught at the Montessori school in Rawalpindi. The school nevertheless became a symbol of China-Pakistan friendship. Around the new building several posters displayed the Pakistani and Chinese flags one beside the other, and in the principal's office I noticed several pictures taken when the works on the new section of the school began. They showed the principal shaking hands with the former Chinese ambassador Liu Jian, with prominent member of the Kashgari community in the background. On one occasion the principal took me on a little tour of the various classes, where he asked the small pupils "Who is an ex-Chinese?," to which a group of kids responded by raising their hands, telling me their names and confirming that they were, in fact, "ex-Chinese."

For some of the Kashgaris living in Westridge, however, the school was not only a symbol of friendship. As I was told by a few elder members of the community, through the school the Chinese were simply trying to "bribe" the Kashgaris, so that they would not think about the various injustices the CCP was committing in Xinjiang. Umer, obviously, was particularly critical of the new school - but his attacks were reserved for the Association more broadly. According to him, the Chinese embassy was "using" the Association. But why would Pakistani Uyghurs get along with it, I asked. Umer named some of the leaders of the Association, pointing out that they were businessmen "with lots of contacts with Chinese companies." Like Sultan Khan, they had much to gain from friendly ties with Chinese authorities.

Umer had a point. Businessmen such as Sultan Khan have profited handsomely from their proximity to the Chinese embassy. Not only have their businesses have expanded, but they have successfully managed to send their children to some of China's top universities under generous China-funded scholarship programmes. Sultan Khan's two eldest sons both studied in Shanghai, while his youngest son was in 2013 finishing up a Master's degree in a prestigious university in Beijing. Sultan Khan's brother, another wealthy member of the Kashgari community, had two sons in China, studying at Chinese universities through scholarships provided by the Association. As one of them, Salman, put it when I met him in his dorm room at Tsinghua University, in Beijing:

The scholarship has no name [...] it's just the government that gives it. And it's for Xinjiang people from all over the world. This year, at Minzu university, there are students from Pakistan, Kazakhstan, Kyrgyzstan, Uzbekistan, Turkey, Australia, Saudi Arabia. All of them Xinjiang people. 
[...] First, I also studied at Minzu University, on a scholarship as well. When I went back to Pakistan [after my BA] my father applied for me to go to Tsinghua University. The people at the [Chinese] embassy and his friends [in Beijing] helped him so that I could have a scholarship in Tsinghua. I'm the first from Pakistan to get a degree at Tsinghua. I'm the first and my cousin is the second, he is getting ready.

Salman's dorm was close to the north-east gate of Tsinghua University. At the time I met him he was sharing it with a Mongolian student. A very tidy room, the only decoration was made up of a few pictures hanging on the wall. An alpine landscape. Dunes in the desert. Salman and a few friends in a Beijing club particularly popular among foreign students. In one corner of his room Salman kept a small stove, where he would "cook Pakistani biryani every week." A small desk with a computer and a small pile of books, beside Salman's own bed, completed the room. "You see," he continued, "the Association was made by Chinese officials - but they made it for the Uyghur community [of Pakistan]." I asked him what the Association was supposed to do. "They give us some funds and with those funds my dad is supposed to make some schools or community work, or when [Kashgari] people need to travel to China they go through a process with my father and they can get very easily a visa. Or if there is some problem [with Chinese people] in Pakistan [...] my dad helps the embassy." Terrorism, Salman pointed out, was one such problem. Echoing PRC language on the subject, he mentioned "a few, very few" Uyghur terrorists in Pakistan. "Most of us are peaceful, we are not extremists," he contended, "and the Association is trying to help the [Chinese] embassy find the terrorists."

As it emerged from this brief exchange, and as many Kashgari pointed out during several conversations in Pakistan, the leaders of the Association had the power not only to distribute subsidies and scholarships, but also to facilitate one's application for a Chinese visa. Proximity to the Association thus became paramount to the Kashgari's ability to travel, and therefore conduct business, in Xinjiang. For Umer, conversely, his opposition to the Association led to his - and his family's - inability to travel, and thus to the end of his business dealings with China. In general, with the exception of a few wealthy traders, such as Sultan Khan and his brother, most Kashgari have over the past decade abandoned their cross-border businesses. The main reason, many pointed out, was the increasingly difficult economic situation in Pakistan, with the devaluation of the Rupees and the growing cost of RMB. Secondly, many former traders complained about the difficulties in obtaining a visa for China. As Abdulaziz told me once while chatting in his Gilgit shop: "they 
[the Chinese] say that we are always welcome, but then when we go to China they treat us as terrorists." In this regard, most of my interviewees agreed that the creation of the Association has not changed this situation - benefitting those in power, but with little impact on other Kashgari.

The effects of securitization on most Kashgaris' business was well visible at the China Market, in Rawalpindi. After several visits and interviews with various businessmen there, I was able to conclude that not only was the overwhelming majority of the goods was imported via Karachi, but also that Kashgari represented only a minority of the "China traders" there. Most traders, in fact, were either Pashtun, Punjabi, and to a lesser degree from Gilgit-Baltistan. Ali, as we talked over a number of meetings around the China Market, recognised that not many Kashgari were in the business anymore. He did not know why, particularly as he seemed pretty content with his business. 2013 was promising to be a good year. He was hoping to ship two full containers of walnuts to Kashgar - he had already bargained a good price, found interested buyers in Kashgar, and was ready to collect the walnuts once the Khunjerab Pass would open, in May. Unfortunately for Ali, and many like him, such expectations would not fully materialise. Security measures in Xinjiang increased over 2013 and 2014, making it more complicated for small-scale traders to find reliable Uyghur partners and get their goods through customs. Furthermore, over a decade after joining the US's war on terror, China launched in 2014 a "people's war on terror" in Xinjiang. The objective, as Xi Jinping explained, was to erect a "Great Wall of Steel" around Xinjiang, to ensure stability and peace.

As in the early 200os, increased security impacted cross-border trade in particular ways. This time, however, it was not only the Kashgaris who were affected. The next section, after describing some of the security measures introduced in 2017, focuses on the $\mathrm{KKH}$ as a unique point of entry from which to look at how control was given primacy over trade, immobility over mobility, security over development. In so doing, I return to Karim and Ali, before addressing the particular configuration of power displayed at China's borderlands.

\section{Driving (slowly) through the core hub}

Already one of the most heavily policed places on earth, Xinjiang's security spendings increased 10-fold in the years since 2009, totalling more than $5^{8}$ billion RMB in 2017 (The Strait Times 2018). The most recent increase - of almost 100 per cent between 2016 and 2017 - coincided with the first year 
of Chen Quanguo as Party Secretary of the XUAR. Before being named to this new position, Chen Quanguo had gained a reputation for his work in the TAR, which he governed through a combination of intense securitization and penetrating social control mechanisms (Zenz and Leibold 2017). While initially implementing similar policies in Xinjiang, such as launching massive police recruitment, Chen soon introduced drastic measures that had not been part of his tenure in the TAR. What has received most media attention since mid-2017 is, in particular, the opening of "re-education" camps throughout Xinjiang, in which over a million Uyghurs are estimated to have been held (Zenz 2018; Humans Rights Watch 2018). Other measures include the construction of tight network of "convenience police stations," the installation of cameras on lampposts and at all main roads and intersections, and the upgrading of facilities at roadside checkpoints across the region. ${ }^{14}$

In Kashgar, the surveillance landscape had changed dramatically between my visit in the summer of 2016 and in August 2017. In the course of that year, as the few friends I managed to meet and talk to described, convenience police stations were built at all major intersections. Cameras dotted most corners, and high fences and barbered wire secured the perimeter of all public offices, schools, and even kindergartens (Figure 16). All main entrances to the newly finished "old town" were by then equipped with a body scanner manned by at least two police officers. Uyghur men, women, and children had their bodies and possessions thoroughly checked, their ID cards electronically read, while Han Chinese tourists and the occasional westerner were led through without hassle. Business owners were forced to hold regular drills, during which they would parade the neighbourhood marching with sticks and military helmets. Virtually all shops and restaurants had metal gates. To order a polo (Uyghur lamb pilaf), one now had to ring a bell.

14 As briefly discussed in the previous chapter, to complement the dystopian panorama of digital surveillance, several programmes of human surveillance have been introduced in the region. One such programme, called "becoming kin," assigns a (mostly Han) official to a local family as an adoptive family member. The cadre is expected to regularly visit the host family and provide regular reports. Such reports are also regularly compiled as part of the fanghuiju system, in which a small team visits houses on a regular basis to assess and report the socio-economic and well as ideological status of Uyghur families. As the Global Times wrote in November 2018, in response to mounting interests on the subject from international news outlets, "some 1.1 million civil servants have paired up with more than 1.69 million ethnic minority citizens," while "various administrative departments [...] have made over 49 million visits to local residents. The number of activities themed "ethnics unite as a family," held by these departments, reached more than 11 million" (Global Times 2018). Combining big data resulting from digital surveillance with the work of fanghuiju and forced homestays, the Party has established a ranking system according to which Uyghurs are classified. Being labelled "untrustworthy" can lead to a camp (Zenz 2018). 


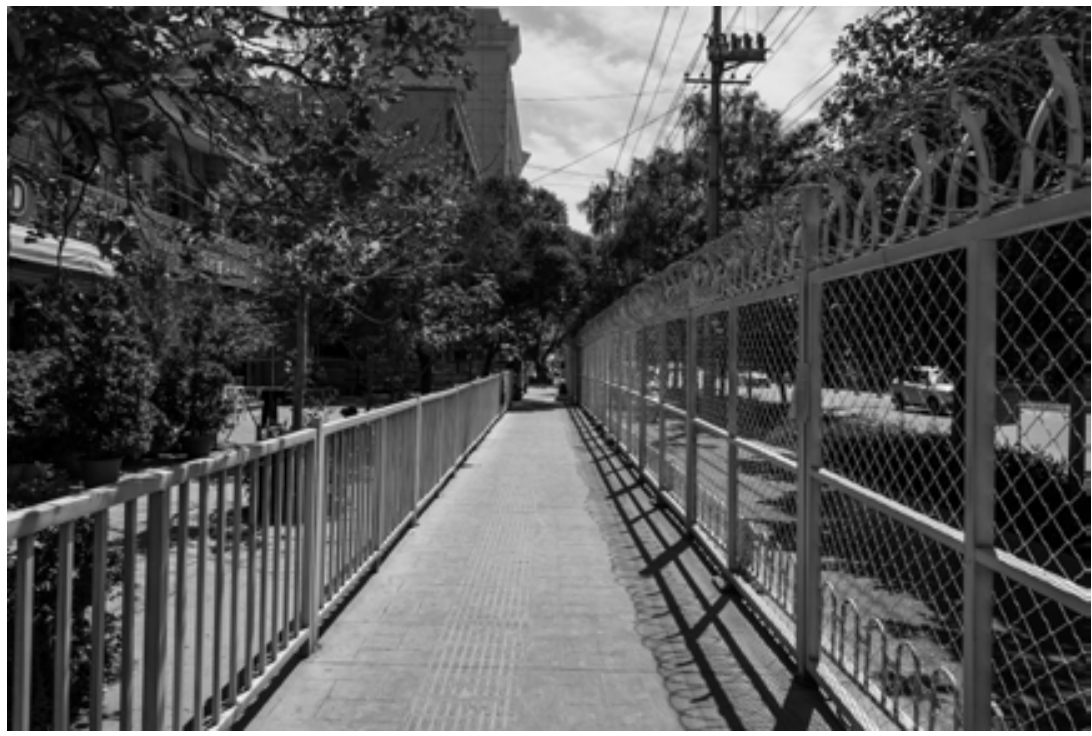

Figure 16: Fences along a road in Kashgar (picture by the author, 2017)

It is important to notice that in Xinjiang, the establishment of a surveillance network occurred simultaneously with two major developments. First, the renewal of Kashgar's old town according to an aesthetic model that is now being replicated throughout smaller cities in south Xinjiang. Yarkand's city centre, for instance, as I could witness during a brief visit in 2017, went through a similar project of renovation. The same happened in Aksu (Kobi 2016). Secondly, securitisation in Xinjiang coincided with its definition, in the official parlance, as a "core hub" within Xi Jinping's Belt and Road Initiative. While the rhetoric behind the project frequently refers to people-to-people interaction and increased mobilities, Xinjiang is captured in a thick net of checkpoints, prison camps, and police stations. To understand how this impacted cross-border ties, I now move to an analysis of how security changed the ways in which people travel along the KKH.

At the time of my first trip from Kashgar to Tashkurgan and the Khunjerab Pass, in 2009, the Karakoram Highway on the Chinese side had only recently been remade. ${ }^{15}$ A single-lane line of dark tarmac connected the busy, dusty

15 In Kashgar the Karakoram Highway is rarely addressed with this name (or its Chinese equivalent, kalakunlun gonglu). The KKH in China is generally known as the "China- Pakistan Friendship Highway" (zhongba youyi gonglu), a formula which is generally reduced to "ChinaPakistan Highway" (zhongba gonglu) or, less frequently, "Friendship Highway" (youyigonglu). The Chinese side of the Highway, moreover, is part of the almost $2000 \mathrm{~km}$ long China National Highway 314 (known as G314 or guodao 314), which runs from Urumqi to the Khunjerab Pass 
outskirts of Kashgar to the snowy and imposing heights of the Karakoram range. While in a few sections the road was already showing signs of decay, particularly around the Gez canyon where small landslides are rather frequent, the composition of the road was rather uniform. The drive, as I recall it, went smoothly. While the old public bus struggled on some of the steeper sections, and trucks would occasionally slow us down, the trip from Kashgar to Tashkurgan was completed in less than eight hours - including an hour-long breakfast break in Opal and the permanent checkpoint in Gez which took at least some 30 minutes.

In the years that followed, I travelled along the same road more than a dozen times, back and forth between Kashgar and Tashkurgan. The road, renovated in 2008, went through another round of widening in 2012-13. At the time of my doctoral fieldwork, several sections of the road remained under construction, and cars were redirected onto improvised, unpaved sections of the road that could last several kilometres. Still, drivers would take such setbacks with optimism. "With the new road," I was often told, "we will drive to Kashgar in four hours and will be back to go back and forth on the same day." By the end of my fieldwork, in the summer of 2013, the new road had been completed. A Tajik driver in Tashkurgan, with whom I had become acquainted months before, boasted that now he could, indeed, drive me to Kashgar in less than four hours. In the end, the trip took four and a half hours, though to his credit, if it hadn't been for the Gez checkpoint and a new permanent checkpoint that had been recently established outside of Tashkurgan, we probably would have made it within his estimate.

On my next trip to the region, in the summer of 2016, I was surprised to see the KKH going through yet another round of renovations. This time, more ambitiously, the most challenging section of the road leading up the Gez canyon was to be made into a series of suspended bridges cutting through the valley (Figure 15). While still a construction site, the two-way highway looked rather impressive, as did its embodied promises of speed and development. The road, however, was already dotted with more checkpoints than I had ever experienced (Figure 17). The first one, by the Guangzhou New City, was a rather impressive building. An English-speaking official, singling me out, made sure to tell me not to take pictures of anybody engaging in religious activities. To my request for explanations, she simply replied that I was not supposed to "disturb the locals." Two more checkpoints had also

- and it is occasionally referred to as guodao by drivers and local officials alike. For the sake of simplicity and uniformity, however, in this book I refer to the road as KKH regardless of whether I am talking about the Pakistani or Chinese side. 


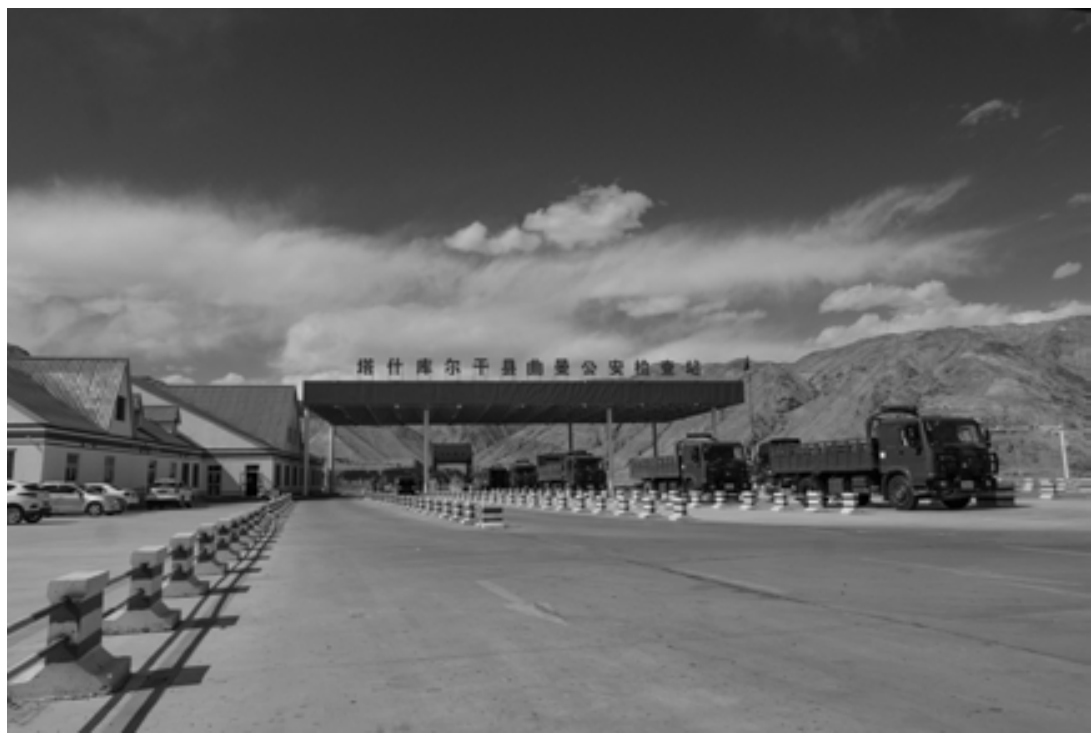

Figure 17: A new permanent checkpoint along the KKH near Tashkurgan (picture by the author, 2017)

been established between the Kashgar New City and the Gez canyon, where the oldest permanent checkpoint was going through some renovations. All the various checkpoints were particularly tedious on the way back to Kashgar, when it took me the entire day to reach the city. The reason I was given for those increased security measures is the simultaneity of the G2o meeting in Hangzhou and the upcoming Eid Qurban festivities. Everybody, it seemed, was on high alert.

In the summer of 2017 , I travelled up the Karakoram Highway once again. I had heard that the new road had already been finished, and I was curious to see how fast we would reach Tashkurgan this time. Upon leaving Kashgar it became already clear that the KKH had finally become a proper highway. What I had not foreseen, however, were speed trap cameras placed every few hundred metres along the road. Our driver, a Uyghur man in his $50 \mathrm{~s}$ whom I had never met before, but who had been recommended by a friend, seemed very wary of them. While the speed limit for cars was $60 \mathrm{~km} / \mathrm{h}$ (and $40 \mathrm{~km} / \mathrm{h}$ for trucks), he would rarely drive over $50 \mathrm{~km} / \mathrm{h}$. When I asked him if he could drive faster, he told me that his vehicle was monitored through the satellite - pointing to a small beeping device on the dashboard. This, he told me, was mandatory for all tourist vehicles. It soon became clear that our driver not only would not drive at more than $50 \mathrm{~km} / \mathrm{h}$, but that he would also avoid stopping at any place that was not considered appropriate for tourists. In fact, when I asked him to stop at the village of Balankul, a 
new village that I had visited the year before, the tracking device started beeping as soon as we left the main Highway. Visibly scared, the driver turned around telling me that we were not allowed to visit that specific place. No further explanation was given. On the way back, as we drove through the Gez checkpoint our driver received a phone call. The local police representative on the other end of the line was informing him that, according to a new regulation, all passenger cars travelling to Kashgar could not exceed $40 \mathrm{~km} / \mathrm{h}$. He promptly complied, without showing any sign of annoyance. At the end, the trip to Tashkurgan took longer than it did in 2009, or at any given time during my doctoral fieldwork in 2012-13. Dreams of fast connections had indeed not materialised along the KKH.

Speed trap cameras, car-tracking devices, and imposing checkpoints are only three example of the massive surveillance technology apparatus that began appearing in southern Xinjiang in 2016. Such measures had an effect on both Uyghurs and Pakistani traders. Many complained to me about new, stricter visa regulations. Other recounted daily visits by local police officers, who installed security cameras inside their shops and would interrogate them about each and every customer who paid them a visit. Higher import tariffs were also a major concern, to the extent that very few things were brought in from Pakistan at that particular moment. In general, all Pakistani traders I talked to lamented that the number of checkpoints, the burden on mobilities that new regulations brought upon themselves and their business partners, and the low number of tourists visiting southern Xinjiang were detrimental to their businesses.

Sometimes, stories would get personal. Karim, for instance, as we were having dinner in Tashkurgan in August 2017 told me of Nisagul - a Uyghur woman who he had employed in his Kashgar shop for the past few years. I remembered meeting her a few times. Nisagul's husband, Karim told me, was recently put in jail and sentenced to seventeen years. No reason was given, yet Karim had no doubts: "they put him there because he was in contact with us, with people from Pakistan, because his wife works for us. Now this is enough: if a Uyghur talks to us, they put him in jail." Karim was not exaggerating. In the months to come the world was to become aware of the systematic imprisonment of Uyghurs. Entertaining any kind of relation with a foreigner, especially if from a Muslim country, was a major reason for imprisonment. "It all changed in April [2017]," Karim pointed out. "I was in Pakistan for the winter, and when I came back everything was different." As we talked, he did not see any reason for optimism. "Things now change every day, there is always something new. In Kashgar it used to be easy and possible to visit people in their houses. Uyghurs would invite me over; 
this does not happen anymore. Nobody wants to talk to us." Business, too, was not going very well. Since the Khunjerab Pass opened in May, customs operations had moved from Tashkurgan to the Khunjerab Pass. On the Chinese side, Karim described a new facility, only a few hundred metres from the border, equipped with state-of-the-art scans and $\mathrm{x}$-rays machines. "Controls are extremely thorough, last time I came it took six hours to get through," Karim told me. At 4,6oo metres, I found myself saying, this is not just absurd - it is reckless. Karim nodded, and told me that recently Pakistani traders went on strike. The bone of contention, apparently, was the treatment reserved to them at the China border. In protest, they stopped coming to China for a week, until they were given some reassurances. Still, he went on, "all luggage taken on buses now goes through customs. We are not allowed a small amount of goods for free as it used to be." This, as I recounted in Chapter 1, had happened before. Now, however, the situation was so dire that Karim thought it was unlikely, after all, to return to normal any time soon.

As we met for breakfast the following day, Karim and I talked about the future. "I might need to find another business," he told me. "Last summer I went to Guilin and Guangzhou, these are good places," he reasoned. "I'm looking for partners there, maybe next time we'll meet it will not be in Tashkurgan." Like Karim, a few other Pakistani friends with over a decade of experience in the Xinjiang trade were ready to pack their bags and find new business venues. Xinjiang, they all told me, was not a good place for business anymore.

Such assessment of Kashgar as a "bad" place for business produce a stark contrast with the Belt and Road rhetoric that, since the launch of the Initiative in 2013, has incessantly grown. Xinjiang, a "core hub" of the Silk Road Economic Belt, features prominently it the Belt and Road imaginary showcased in maps and renderings of future projects. Southern Xinjiang is dotted now with propaganda posters referring to the Belt and Road Initiative - often in surprising ways. In 2017, In Tashkurgan, for instance, yi daiyi lu appeared on a large poster promoting a poverty alleviation programme. Along the KKH, between Tashkurgan and Kashgar, on the other hand, large red posters with yellow Chinese characters and Uyghur script promoted the plans for transnational connectivity in the area. "One county neighbours three countries, two entrances leading to two Asias (yi xian lin san guo, liang kou tong liangya)," read one, referring to Tashkurgan county's strategic location at the convergence of China, Pakistan, and Tajikistan and to the two routes to the Khunjerab and Kulma passes into South and Central Asia (Figure 18). "Build the China-Pakistan international logistics complex, 


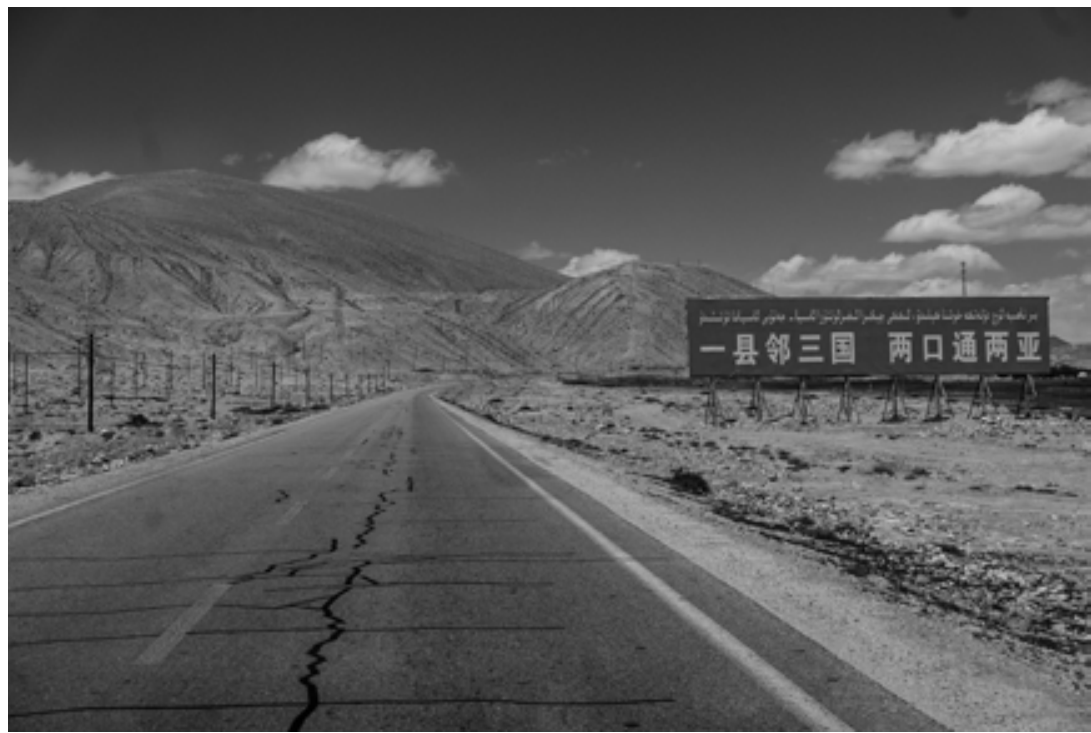

Figure 18: Sign along the KKH near Tashkurgan saying "One county neighbours three countries, two entrances leading to two Asia" (picture by the author, 2017)

create the China-Pakistan Economic Corridor nodal city (jiangshe Zhongba guoji wuliu zongheti, dazao Zhongba jingji zoulang jiedian chengshi)" read another, referring to Tashkurgan's role as the gateway to Pakistan in the CPEC imaginary.

If one looks at the recent history of cross-border trade along the $\mathrm{KKH}$, however, it is hardly surprising that security is given primacy over the free circulation of people and goods. Already at the time of my doctoral fieldwork, in 2012-13, the Khunjerab Pass was regularly closed for a few days around major Chinese political events, such as national-level Party meetings, and even holidays. In 2013, for instance, the border remained closed between 28 September and 7 October, ahead of celebrations for China's National Day, in an attempt "to guard the country against anti-state elements involved in subversive activities in the Xinjiang autonomous region" (The Express Tribune 2013). As Haider had pointed out already in 2005, "Beijing's primary concern has been how it facilitates the spread of Islamic ideology into Xinjiang and the movement of radical Uighur militants," as well as the KKH's role in the drug trade that led to high HIV/AIDS rates in Xinjiang - factors that led to the closure of the Highway for brief periods (Haider 2005: 523). Therefore, despite the "Silk Road" rhetoric often employed by Pakistani and Chinese authorities alike (Haines 2012), the Karakoram Highway remains, at least on the Chinese side, a very ambiguous infrastructure, in which security is 
given primacy over trade, immobility over mobility, and regulations over exchanges. While larger roads and SEZs are built at an unprecedented pace, it is the "hidden mobilities" (Van Assche and Hornidge 2014) of transnational connectivities and the forces of proximity that I have outlined that remain the main target of China's attention. The quest for frictionless corridors seems to pass through their elimination.

\section{Conclusion}

"Why don't you move to Xinjiang?" I once asked Sultan Khan, as we were talking about the offer of rent-free shops and offices that the Chinese embassy made to a number of Kashgari. "You see," he replied, diplomatically, "China is a good friend." He paused for a moment. "But Pakistan is home for us. Even if it's not [as] developed [as China], here we can practice our religion." That last remark was something that I had heard repeatedly while in Pakistan, from Kashgari and "China traders" alike. "China is not a Muslim country," I was once lectured by an old Kashgari man while sitting at his house in Rawalpindi. "But there is freedom of religion," added the man's nephew, a software engineer in his early 30 s who had been to China only once. The old man nodded, then added: "yes, but it's not like here."

This ambiguity towards China has become a defining feature of the Kashgaris' lives. To be sure, China's direct intervention into the lives of the Kashgaris has produced a significant divide not only within the community, but within individuals themselves. While, on the one hand, the opening of the KKH and the flow of Uyghur pilgrims into Pakistan produced a new awareness and a re-definition of a specific Kashgari identity, the 9/11 attacks, Beijing's own war on terror, and the creation of the Overseas Chinese Association led to a widening political divide within the community. As one young Kashgari summed it up: "Now it feels like there are two separate communities [of Kashgaris], [...] before the community was united, but without any awareness about our culture. Now - on the other hand - we know we are different from the Pakistani, we have this awareness."

In 2018, as news of China's prison camps in Xinjiang began to make headlines around the world, Pakistan and the Kashgari community made a few appearances. First, as reported by several outlets, a number of traders from Gilgit-Baltistan raised official complains with local authorities about the fate of their Uyghur wives in Kashgar (Barker 2018). According to them, at least 50 women married to Pakistani men were in detention, their children stripped away from them and unable to reunite with their Pakistani father. 
As I read such reports, Karim's words came to mind - "if a Uyghur talks to us, they put him in jail." Only a few weeks later, the South China Morning Post (Elmer 2018, see also Aamir 2018) reported of a meeting between Chinese diplomats and a group of "Uygur Chinese people" at the PRC embassy in Islamabad. The meeting was set up by Chinese authorities to provide details about the situation in Xinjiang. Deemed as "the most high-profile evidence of Beijing stepping up its new narrative outside China," the meeting featured consul general Shen Zicheng, who reportedly said that "the Uygur Chinese citizens in Pakistan had a role to play in promoting friendly relations between the two countries, and supporting the work in Xinjiang." In the picture of the meeting that accompanied the story I could recognise Sultan Khan's brother, and two other prominent members of the Association.

If the Kashgari's attitude towards China can be defined as ambiguous and fragmented, that of Chinese state representatives towards Pakistan is just as puzzling. Take, for instance, the following examples. On 15 October 2013, during an official visit to Urumqi, the Chinese Defence Minister "called for a strengthened border and national defence in northwest China's Xinjiang," and "asked military units to further consolidate border defence and cast 'a wall of copper and steel' in the frontier" (Xinhua 2013). The same day, the Chinese ambassador in Pakistan during a visit to Gulmit, in the upper Hunza region, "emphasized the importance of developing communities in the border region, terming it to be in the interest of both the Chinese and Pakistani governments" (Pamir Times 2013a). The day before, during a gathering in Karimabad, the ambassador also remarked that "the development of the Xinjiang autonomous region will have positive impact on the socio-economic uplift of the Hunza Valley in particular and Gilgit-Baltsitan, in general" (Pamir Times 2013b). Reading through such contrasting news only a month after returning from a year of field research in the region, I remember my puzzlement at the meaning of it all. Was the ambiguity the result of poor communications between different segments of the government, or was it a skilful tactic to attract investments and claim inclusiveness, yet continue undertaking repressive policies towards ethnic minorities in the borderlands?

What is certain is that these different statements show the mix of confidence and concern with which the Chinese government is looking at its westernmost borders. On the one hand, borders have to be strictly controlled, preventing any destabilising factor from entering the XUAR. ${ }^{16}$ On the other,

16 There is very little access and information about the People's Liberation Army border patrol in the area. A recent AsiaOne report, however, shed some light on the daily routine of Chinese soldiers along Xinjiang's border with Pakistan and Afghanistan (AsiaOne 2014). 
Chinese officials in Beijing and Islamabad stress friendly collaborations with authorities and communities on the other side of the border. The promoters of such approach seem to promise that the pacification of Xinjiang can only be achieved not only through the securitisation of the province (Becquelin 2004; Dreyer 2000; Tian 2004; Wiemer 2004), but also, and perhaps most importantly, through the development of nearby regions. ${ }^{17}$ Yet development along China's borderlands, as this chapter has shown, is as much a tool of control as it is one of improvement. Most specifically, the focus on control that underlies the CCP's Xinjiang policies have become detrimental to the kind of economic ties that development initiatives such as the BRI are supposed to foster. Furthermore, as the case of the Kashgari community demonstrated, security is given primacy over people-to-people ties and the inclusiveness that the BRI rhetoric embraces. Rather than embodying the spirit of cross-border relations, or the "bridge" that Sultan Khan depicted, Uyghurs and Kashgari are the ultimate targets of surveillance measures that curb their mobility and economic activities.

To understand how such relations are spatialised I resort to the image of the corridor.

17 Some analysts have expressed similar views. As Laruelle and Peyrouse put it in their work on China and Central Asia: "The Karakoram Highway between the Pakistani port of Gwadar and Chinese Xinjiang does not at all modify trans-Eurasian commerce, since the flows remain minimal, but it facilitates access to the products of remote Pakistani mountain regions. The pattern of development is similar for the Sino-Tajik trade, as well as some border connections between Central Asia and Xinjiang. The aim is not to influence large international trade flows, which would be unrealistic, but to provide isolated populations with tools for development" (2012: 62). 


\section{Interlude - corridor}

3 November 2018. It's early morning in Boulder, Colorado, as I received a message from Ali. "Hi, how are you friend?" he asked, via Facebook Messenger. "Hi, I'm good," I quickly replied, then continued. "I recently moved to the USA, I'm not sure if I told you already. How are you?" I expected him to be in Pakistan, possibly in Gilgit. Since we last met, in 2013, we have remained in touch, sending each other regular messages via either Facebook Messenger, Skype, or WeChat. In 2015, he told me, he had given up trading and started a small business in Gilgit. Chinese import tariffs for Afghan dry fruit had become too high to make his business profitable. I found it ironic that his decision to stop trading coincided with the opening of the tunnels around the $\mathrm{KKH}$, and with the rhetoric surrounding CPEC and the BRI reaching its climax. His was not the only story of this kind I was hearing at around that time. Other small-scale Pakistani traders - in dry fruit as well as other items - had stopped travelling to Kashgar, frustrated either by growing tariffs, the treatment of border guards, and the securitisation of the region. I checked in with him the following year, in November 2016, as I was reading about the first official CPEC convoy to Gwadar: when, amidst much fanfare, over 100 containers carrying Chinese goods were escorted by armed police all the way from Sost to the Indian Ocean (Zafar 2016). Ali, he told me then, did not yet see a reason to restore his old business - "the conditions," he simply put it, "are not good." In November 2018, as I was working on some much-needed morning coffee, I was thus very surprised to see Ali's reply to my question. "I am in Kashi [Kashgar]" - he wrote, then asked: "So you are not in China?" I was not, but I was interested in hearing about what he was doing there. Apparently, while Chinese import tariffs were still very high, in 2018 Chinese dry fruit was cheaper than in Pakistan, and Pakistani import tariffs were low. Ali's business had changed direction: he was now buying in China, and selling in Pakistan. Almonds were still too expensive (20 RMB $/ \mathrm{kg}$ ), but walnuts were cheap. At $11.8 \mathrm{RMB} / \mathrm{kg}$, they made for a sure deal in Rawalpindi. Ali, who was going back to Pakistan the following day, was planning on selling the whole cargo within a week, and then perhaps make another trip to Kashgar before the seasonal closure of the Khunjerab Pass in December. "Money is good," he told me. Yet, as we chatted about his business, I could not help but thinking about the ongoing situation in Xinjiang, trying to picture him busily travelling from one market to the other while dealing with endless checkpoints. Reports 
on Xinjiang's prison camps were by then featured almost daily on major newspapers outside of China. Reports on the missing wives of Pakistani traders had recently appeared in Pakistani newspapers. Only a few days after our conversation, a new UN panel would examine evidences of China's human rights abuses in the region. When I asked how Kashgar was, his reply was the following:

Kashgar is not good, everywhere we face strong security. At the entrance of hotels and markets everybody is scanned, and only then is allowed to enter. All [Uyghur] traders who trade with us are arrested and put in jail. No Uyghur person is receiving our phone call. If we call them they will be arrested and investigated.

Building upon Foucault's notion of discipline, in a short essay, Postscript on the Societies of Control, Gilles Deleuze (1992) outlines a new theory of power. In particular, Deleuze shows how we are moving away from what Foucault articulated as disciplinary societies toward a society of control. Societies of control, according to Deleuze, are no longer characterised by sites of enclosure, such as schools and factories, hospitals and prisons. It is to such spaces that Foucault dedicated much of its intellectual project to, particularly looking at the ways in which they function as particular regime of discipline. Deleuze, on the other hand, argues that contemporary societies are rather defined by control, which, in contrast to discipline, operates as a modulation. Spaces of enclosure are no longer relevant. We can work from home, pursue an online education, and so on. In such new societies, freedom has seemingly increased, yet control has expanded in significant other ways - from algorithms to regimes of self-control that are central to "independent" work. At the same time, surveillance is normalised: we know our online activities are monitored, for instance, but we should not pay too much attention to it.

Curation, as a particular modality of power, can be seen as bridging the gap between disciplinary societies and societies of control. While Chinese development efforts in its borderlands enforce enclosure with a disciplinary aim, as emerges from the case of Kashgar's old town, they also aim at transforming the overall environment thus enabling constant monitoring. As new villages, cameras, checkpoints, police stations and IT technologies provide the infrastructural basis for China's surveillance efforts in Xinjiang and elsewhere, a "serpent of control" (Hankins 2014) is inevitably nestled in ethnic minority subjects' self-monitoring and self-censoring attitudes. 
To build on this discussion, it is now important to focus on how such forms of control are spatialised. To do so, I resort to the image of the corridor with the aim to capture the intertwined nature of discipline and control that is shaping the Chinese borderlands today. I conceptualise the corridor as a space that is discursively and materially produced with the aim of enabling the movement of people, goods, and capital, but that is also productive of a particular kind of channelled control. Along many of China's borders new and imagined corridors often follow old pathways (Saxer 2016) carved through difficult terrains. Yet, corridors, unlike pathways, are exclusive - they remove, block and leave out what is outside of them with the aim of channelizing movement and increase speed. A pathway is, on the contrary, inclusive: it brings in, through its hinterland, as I shall argue shortly. A corridor implies linearity: it connects two or more places. A pathway, on the other hand, is rhizomatic (Deleuze and Guattari 1987; Rippa 2015b): it has no clear beginning or end, and it expands and shrinks through its hinterlands. A corridor is highly visible, a pathway can be elusive. As such, corridors are technologies not only of connection, but also of containment. To echo Elizabeth Dunn's (forthcoming) characterisation of the tunnel, corridors, too, serve the state purpose of controlling "volumetric space by flattening it." As such, through corridors the state can "monitor" movement and "filter" who is allowed to move across and who is not - often through the installation of particular chokepoints (Carse, Cons, and Middleton 2018). Accordingly, on the one hand, I conceptualise corridors as particular technologies of enclosure. On the other hand, through them, control over particular forms of mobilities become normalised. Let me analyse these two aspects in more details.

Etymologically, the word "corridor" comes from the Latin currere: to run. In 16th-century French, the word corridor was used to indicate the outer edge of a fortification, a hallway protected by a parapet in military forts or installations. Similar to infrastructure and logistics, as discussed in Chapter 1, the word corridor goes back to French military vocabulary of the 16th-18th centuries. Today, as a major feature of BRI endeavours, corridors are envisioned to connect China's landlocked regions with the ocean in Gwadar, Bangladesh, Burma, but also to Singapore and Vietnam. Goods and people are expected to move along them at great speed, across formerly remote and reportedly inaccessible terrain. The etymology of the word itself seems to reveal corridor's disposition to privilege speed by neglecting local frictions. It also implies the creation of a fenced-off thoroughfare connecting specific nodes, while excluding everything else - or what could be understood as a technology of enclosure. As such, corridors are detrimental to what anthropologist Martin Saxer has called "hinterlands": 
particular economies that, in seemingly remote regions, are centred around particular pathways of exchange. The Himalayas are, Saxer argues, full of such pathway-hinterlands connections. There,

Pathways create their own 'hinterlands' and thereby structure Himalayan borderlands. 'Hinterlands' often orient themselves rather towards a pathway than a larger urban center of a state. In a certain sense, the nodes that form along major pathways become centers themselves, and a center-periphery dynamic between these nodes and the hinterlands is again at play here, although on a smaller scale (Saxer 2016: 113). ${ }^{1}$

These hinterlands, it might be argued, profit from the particular "friction of terrain" (Scott 2009), through which pathways are carved out. This friction, which according to Scott guaranteed safety and distance from the state for upland communities, was also an opportunity for highland communities to prosper from long-distance trade in which they were not directly involved. Along Himalayan trading routes, for instance, animals' need for fodder and traders' need for food and rest, created numerous pathway economies centred around specific nodes. Today's economic corridors, such as the CPEC, have been drawn following some old trading routes - at least in part. While pointing to the relative resilience of pathways, economic corridors also reflect a very different approach to terrain and hinterlands. By trying to do away with the "friction of terrain" both discursively and through the implementation of major transport infrastructure, a significant element that differentiates modern corridors from pathways is that they shrink hinterlands rather than create them.

Strictly intertwined with this first aspect of the corridor as a technology of enclosure is the normalisation of control that it underpins. The example of travelling along the $\mathrm{KKH}$ described in the previous chapter is emblematic. As promises of flawless and speedy transnational exchange embedded by CPEC were hyped by both Chinese and Pakistani officials, a thick network of speed-trap cameras limited the pace of travel to $40 \mathrm{~km} / \mathrm{h}$ on a broad and smooth four-lane highway. The impact goes beyond a few extra hours on the road. Speed limitations and the constant police monitoring through phone calls and GPS tracking represent an act of violence, an exercise of disciplinary power aiming at creating normative subjects. As such, cameras and car-tracking devices do not even need to work in order to be effective.

1 For a discussion of Saxer's notion of pathways in the context of today's BRI Economic Corridors see Rippa (2020). 
More broadly, with the implementation of CPEC, chokepoints in the form of "inspection stations (jincha zhan)" have become the norm, tariffs favour Chinese exports over imports, and only some people are allowed to "freely" move along it. Dreams of frictionless corridors are not for everyone. The image of the corridor, intended both as its discursive articulation as well as its material implementation, "purified" (Latour 1993) the messiness and illegibility of proximity. Placed on the level of "the market," set aside from local encounters, the term "corridor" is used to designate frictionless connections represented by broad and smooth arrows on maps and investments brochures. Through its material implementation, however, mobilities along the KKH have become selective. For many Kashgari, for instance, the upgrading of the road did not coincide with more opportunities to visit their relatives in Xinjiang and conduct business in the region. As in the case of Umer, strained relations with the Chinese Overseas Association meant, rather, forced immobility. Corridors, then, while embedded in promises of connectivity and development, often bring about particular modulations of power that are inherently asymmetrical and exclusive.

3 November 2018. After Ali told me about Kashgar - the checkpoints, the prisons, Uyghur traders avoiding his phone calls - I wondered how he could possibly conduct his business. During my time in Kashgar, I spent several days with him, sitting in restaurants with some of his partners, checking the local dry fruit bazaars, talking about prices, and calling dealers in Rawalpindi and Peshawar. His business, as I came to know it, was deeply embedded in a network of close relationships for which personal contact and the trust resulting from years of deals was fundamental. As we exchanged messages in 2018, while he was in Kashgar, the situation was different. "Now I have to go to the wholesale market - it's new, $4 \mathrm{~km}$ from the Seman hotel." I had never been to that place, I wondered how it must look like. I pictured another fruit wholesale market I visited in Tengchong, that opened only in 2016. Ready-made, 2 -floor buildings with blue tin-roofs. In each building the second floor would function as a deposit, while the first floor as office space, kitchen, playground for kids, and parking for cars and motorbikes. Traders would come by taxi, or on their own e-bike. They would check the merchandise, discuss a price, perhaps place an order. Nearby, boxes full of bananas were uploaded on an electric cart. I asked Ali what was different from the bazaars he used to work in. "They only accept cash payment here, no money transfer or bank transfer. We have to pay cash when we place the order." 
Trust, in Ali's business, no longer appears to be crucial. The exchanges he is now taking part in, based on immediate cash payments, are of a different nature. He does not entertain any personal relation with the dealers - "95 per cent Uyghur," he says - who work out of the newly opened wholesale market in dry fruit. The forces of proximity are not relevant as before. His experience still plays a role - his knowledge of the language, the product, as well of dealers in Pakistan. The social relations that used to define his business, however, have largely been cut off.

The experiences of traders along the Karakoram Highway reflect the changes implicit in the re-configuration of space conjured up by the image of the corridor. With the development of transport infrastructure and the scaling up of the security and surveillance apparatuses, Pakistani traders have struggled to keep their businesses afloat. Social relations carefully built over years of engagement, particularly with their Uyghur counterparts, have been eroded by the pervasiveness of security measures. For the same reasons, their ability to move has been curbed, while the stricter implementations of new regulations at the border have complicated the movement of goods. At the same time, spaces designed by state authorities for the development of new trading practices, such as the Guangzhou New City, have so far largely failed to provide the same opportunities that Pakistani traders used to enjoy. What we see here are the limits of a particular vision of transnational connectivity which ignores - or purposely tries to eliminate - previous forms of exchange.

As particular modes of transport become dominant, the old business of proximity needs to find new venues. It is, however, important to highlight that these two forms of mobility and the particular spaces that they attempt to create are not mutually exclusive. Proximity still plays a role. Even the smoothest highway does not eliminate local encounters. Traders in Pakistan and Xinjiang are still navigating through customs facilities, bazaars and warehouses in which language skills and personal relations affect the success of particular transactions. Corridors, then, do not fully eliminate the importance of proximity. From an ethnographic perspective, corridors are, in this sense, "multiply imagined and enacted" (Murton and Lord 2020): they are far from being stable and frictionless (Carse 2014; Barry 2013). And yet, the corridor as a "dream zone" (Cross 2014) continues to drive the political agendas of elites in China and elsewhere, producing significant consequences on the ground. This section, and this book more broadly, represents an attempt to investigate what happens when dreams and reality meet, when the corridor as it is drawn by policymakers in Beijing and Islamabad is lived through daily crossings of the Khunjerab Pass. 
In doing so, it is important to note that the interests of the state and those of traders are not always on opposite ends of the spectrum. Corridors and proximity are not mutually exclusive. Thus, in the case that I describe in the following chapter, that of Houqiao and the Bangladesh-China-India-Myanmar Economic Corridor, the state is complicit in the forms of transnational connectivity that do not necessarily adhere to the principles expressed by the regulations that the state is supposed to uphold. The new re-configuration of space introduced with the development of this economic corridor, and in particular of a border trade zone, however, in this case also contributes to particular forms of exclusion and marginalisation.

It is time now for one final change of scenery. 



\section{$6 \quad$ (Il)Licitness}

“The common Yunnanese proverb qiong zouyifang ji zou chang 窮走夷方急走廠 best describes the situation: when one needed money, one joined the caravan trade and went to areas occupied by "barbarians" (other ethnic groups), or alternatively tried one's luck in jade or other mineral mines in Burma. Those who were hesitant to take up such ventures were considered timid and often teased by fellow Yunnanese" — Wen-Chin Chang (2011: 460).

"In our experience, the quality of roads bears direct correlation to the speed of development"

- Chinese Vice President Li Yuanchao at the opening ceremony of the third China-South Asia Expo in Kunming, June 12, 2015.

The music is insistent, epic. The scene begins with drone footages of a prosperous, modern city. The camera pans across golden skyscrapers and multi-lane highways. "It is Shenzhen," the voiceover informs the viewer. "Thirty years ago," the voice goes on, "Shenzhen was a little fishing village. Today, Shenzhen has become China's most successful Special Economic Zone, with GDP surpassing 1.5 trillion RMB." Shenzhen, the video underlines, showcases the success of thirty years of Chinese economic reforms, and speaks to the recovered wealth of the Chinese people. But this is not the end of the story. "New global challenges (tiaozhan) have led CCP General Secretary Xi Jinping to launch a new initiative: the Belt and Road." Moving from images of Shenzhen to images of Xi Jinping and Li Keqiang, the video finally opens up to Houqiao's new, massive border gate - its towering marble-like colour and neat features offering a stark contrast with the surrounding forest (Figure 19). It seems to reflect an image of order in the midst of a hilly, remote, perhaps unruly frontier. We are in Tengchong county, at the China-Burma border, where a new Border Trade Zone is taking shape. Thanks to the BRI and the BCIM, the video insists, Houqiao is set to become another Shenzhen along China's borders - a node of development along the country's peripheries. ${ }^{1}$

The video I just described is featured on the website of the Hong Yi Da company, the firm in charge of the construction and development of the Houqiao International Trade City - a major component of what local authorities 


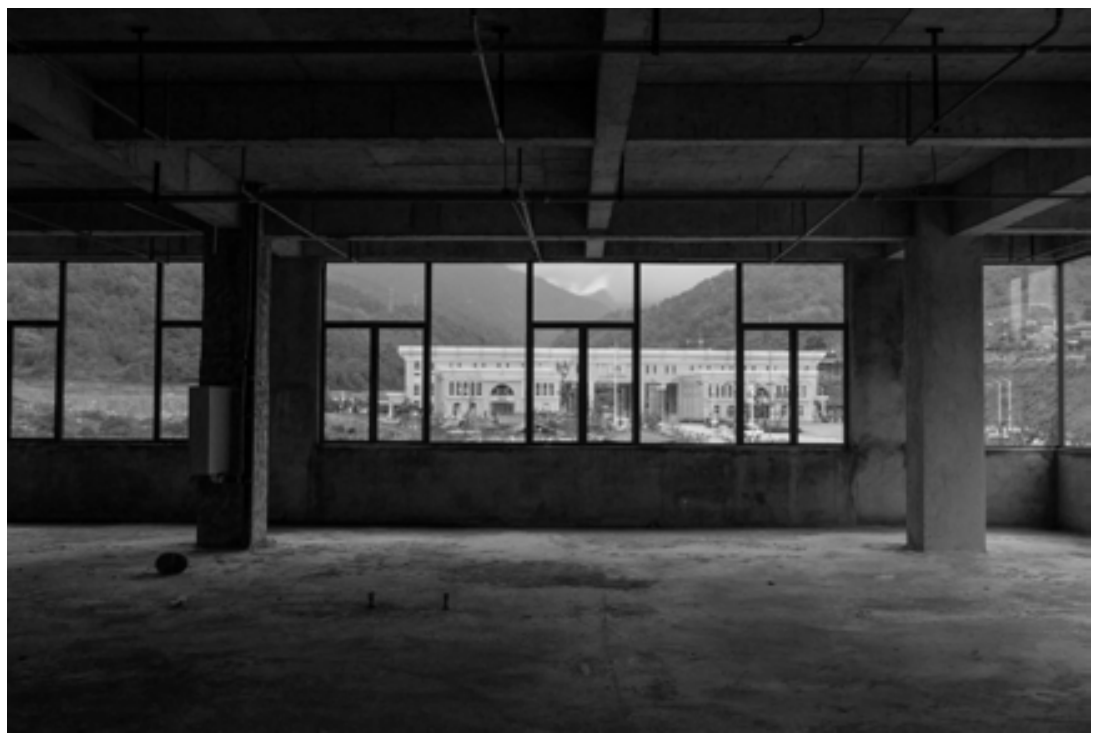

Figure 19: The Houqiao border gate as seen from inside the new International Trade City (picture by the author, 2016)

promote at the new Border Trade Zone that will rival Ruili as China's main gateway to Burma. The video provides, in a nutshell, a wonderful example of Chinese Public Relations efforts in the age of the BRI. ${ }^{2}$ In particular, it encapsulates some of the motives that have become ubiquitous across a number of development projects along China's borderlands. The trope of "the next Shenzhen," but also the idea that global trade is key to prosperity. In so doing, it also reiterates something fundamentally incorrect: that the Belt and Road initiative somehow invented modern Asian connectivity. And that it was China, and Xi Jinping in particular, who draw the ambitious vision of a continent criss-crossed by economic corridors and speckled with Special Economic Zones.

This motive is particularly evident if we look at some of Xi Jinping's speeches on the topic over the past few years. From his speech in 2013 at Kazakhstan's Nazarbayev's University, in which he launched the idea of the Silk Road Economic Belt, to his speech at the Indonesian Parliament, during the same year, in which he defined the 21st-century Maritime Silk Road, to the opening of the Belt and Road Forum, the pattern is similar. First, Xi would refer to historical ties between China and its neighbouring countries, citing Chinese envoy Zhang Qian to Central Asia, and Zheng He's missions to the 
"Western Seas." This history of friendship, Xi elaborated, needs to be revived today in the spirit of the old Silk Road: peace and cooperation, openness and inclusiveness, mutual learning, and mutual benefit. In Xi's vision, this is what the Belt and Road is set to do. However, between the Han dynasty and Xi Jinping's China, a number of development projects took shape across the region, many of which quite recent. Japan, for instance, funded several infrastructure projects in India and Southeast Asia. In the region, a number of sub-regional projects emerged in the 1990s in the form of growth triangles (Ong 2000: 66) and economic quadrangles (Walker 1999). In Central Asia, where China plays today an increasingly important role (cf. Laruelle and Peyrouse 2012), the Central Asia Regional Economic Cooperation Program (CAREC), established in 1997 by the Asian Development Bank, had its own economic corridors. More examples - such as the United States' own "Silk Road" project following the Afghan war - could be mentioned. As the first part of this chapter will show, moreover, the Belt and Road Initiative appears to replicate many of the discursive frameworks created as part of these projects, such as the idea of economic corridors as development tools.

This chapter moves from this particular discussion by returning to the case of cross-border trade in Tengchong. More specifically, I show what happened in Tengchong after the end of the timber trade, in the mid-201os, when a new transnational geography dominated by the Bangladesh-China-India-Myanmar (BCIM) Economic Corridor was imposed upon the existent timber-driven infrastructure of border crossings that I have analysed in the second chapter. My purpose is twofold. First, through a discussion over the persistence of illegal trade in Tengchong and the local government's participation in such transactions I will show how the two forms of connectivity that I have outlined in the first part of the book - one informed by long-term localised exchanges and one inspired by contemporary state-led visions of transnational trade - while incompatible at the level of ideology, are in fact deeply intertwined at the level of practice. Secondly, I show how the corridor-isation of trade does not necessarily imply the end of illicit practices. Rather, as I discuss through the case of Burmese amber, it institutionalises them while fostering the marginalisation of small-scale traders. In so doing, I go back to my discussion of proximity and show how closeness to the state remains a powerful asset for traders in the age of the BRI.

In order to do so, the chapter is organised as follows. First, I discuss some of the literature on legality and licitness that underpins my argument in this chapter. Secondly, I place the development of the BCIM corridor within the broader history of economic corridors as devices of economic growth and development. In it, I show that the BCIM has its roots in the 
1999 Kunming Initiative, and thus predates the launch of the Belt and Road Initiative by over a decade. Thirdly, I move to an analysis of how the promises embedded in the BCIM project take shape in Houqiao through the development of a border trade zone. I show how personal connection and government support are fundamental to the success of seemingly "private" initiatives. In the remaining part of the chapter, I show what are effects of the corridor-isation of trade on local businesses, particularly those who used to be involved with timber. I use the case of Burmese amber - whose imports boomed at around the time when timber imports stopped - to show how government officials are intimately involved in the persistence of illicit traffics across the Tengchong borderlands. Lastly, I discuss the notions of legality and licitness to highlight their co-constructed nature along China's borderlands.

\section{Licit, illicit}

Inquiries into illicit economies have often looked at borderlands as prominent spaces of lawlessness and shadowy exchanges (Galemba 2013; Bruns and Miggelbrink 2012; Abraham and Van Schendel 2005; Chouvy 2013). Far removed from the centres of power, borders seem to carry the burden of remoteness that allows for such unlawful economies to prosper. Borders, even when strictly enforced, seem to remain ultimately unmanageable and uncontrollable. Borders, moreover, are often characterised by marked economic differentials which, in turn, afford those involved in both licit and illicit trade countless opportunities (Saxer 2009, 2016a; Alff 2016b). One of the main contributions that anthropologists have made to this body of literature in recent years lies in the realisation that, however illicit or illegal such economies might be defined, they can be extremely formalised, often operating along kinship networks (Steenberg 2014; Van Spengen 2000) and ethnic identities (Eilenberg and Wadley 20o9; Schoenberger and Turner 2008) that span across national boundaries. As Nordstrom (2010) reminds us, "shadow networks" are not just often formalised through specific hierarchies, but also follow specific rules of conduct. This clearly brings into question the idea that shadow exchanges are primarily motivated by the desire to escape regulation - in most cases dictated by nation states. Anthropologists and other social scientists, moreover, have invited scholars to look beyond the state in the analysis of such practices (Abraham and Van Schendel 2005; Gootenberg 2005), showing how the state is often directly involved with such traffic on different levels and scales (To, Mahanty, and Dressler 2014). 
Within this context, the Tengchong case discussed in this Chapter is interesting for at least two reasons. First, it shows how the state is complicit in the creation and maintenance of these (shadow) networks. In both the cases of Burmese timber (analysed in Chapter 2) and amber (discussed below), Chinese authorities in Tengchong were aware from the very beginning of the illicit aspect of the trade. Yet, understanding the potentiality for the further development of the trade and its positive impact on the overall economy of Tengchong, they consciously decided not to intervene - a situation that clearly contradicts views of the shadow economy as harmful to the formal economy and mostly due to weak regulatory institutions (Schneider and Enste 2002). Thus, following Abraham and Van Schendel's (2005) distinction, the trades in timber and amber might have been illegal from the perspective of the law, but were certainly considered licit by those involved - state officials included. In fact, local authorities' push for cross-border infrastructural development and increased ties with nearby Kachin State impacted positively the development of both the timber and the amber trade, rather than jeopardise them. ${ }^{3}$

Secondly, the Tengchong case shows how an illegal market comes to be regulated in China. Against simplistic views of the state as the sole maker of rules, the amber case that I will discuss in this chapter highlights the contextual nature of processes of regulation, involving not only government officials but also private entrepreneurs. Going back to Nordstrom's point, this case is particularly interesting, as the call for official recognition and regulation emerged initially from the traders themselves - the same ones who, for a number of years, enjoyed the benefits of an unregulated flow of amber. Not unlike the timber trade, in which traders first invested into roads to the border that later allowed for the consolidation of state presence there, with amber it emerges clearly how the interest of private businesses and public officials intersect. If we then follow Baud and Van Schendel's (1997) urging to adopt a view from the peripheries to look at borderland communities and cross-border exchanges, the Tengchong case adds another layer of complexity to the ongoing debate on state and market in China. As Osburg (2013) argued, not only do Chinese entrepreneurs work deliberately to enmesh business activities into powerful political and social relations, but

3 In a similar vein, Eilenberg (2014) shows in the case of the Kalimantan how increased state presence does not necessarily imply the end of illicit economies, in this case Malaysian logging companies, but rather can shield and protect them. Kevin Woods makes a similar point in the case of northern Burma, arguing that illicit economies flourish not because these remote frontiers are ungoverned and anarchic spaces, but rather because they are embedded in "ordering" processes where both state and non-state actors play important roles (Woods 2016). 
they also - through those very relations - play an active role in shaping the overall regulatory framework. Furthermore, it is not only states that have the need to perform a double act through which they "pursue their neoliberal dream of a borderless economy and at the same time barricade their borders" (Abraham and Van Schendel 2005: 23). Traders, often the same figures who benefited from the lack of regulations in the first place, are also actively involved in the "barricading" of borders within a new markedly neoliberal border regime. As this chapter describes, in fact, traders involved in the "illegal" import of Burmese amber - and timber in previous years - came to see the state as an asset, rather than as a threat, and actively worked to bring it into the picture through the institution of the Tengchong Amber Association. Building on the quoted literature on cross-border exchanges, this example further complicates the simplistic notion that contrasts illicit markets and the regulatory efforts of the state.

In such complexity, how does one draw the lines of legality and licitness? It is certainly difficult to draw categories to describe and discuss a situation in which the (Chinese) state regulates and at the same time provides the means for the illegal exploitation of timber products, or the imports of amber, and where the illicit trade in a particular commodity dictates the geography of national bordering as I have remarked in Chapter 2. One would be tempted to ascribe this exceptionality to a particular moment in time, a combination of causes that made possible for exceptional measures and responses to take place: ceasefire capitalism, war economy, China's open up and reform era, large funds available as part of the xibu da kaifa first and the Belt and Road Initiative later. Yet, a focus on exceptionality can obscure some of the contradictions that lie at the heart of the way we categorise, discuss, and understand, issues of legality and illegality, licitness and illicitness, and even morality and immorality.

The problem, in other words, might be that we tend to identify illegal trafficking or immoral behaviour as exceptional in the first place. In anthropology, on the other hand, recent inquiries into the workings of corruption have shown it to be integral to business transaction - or what Chabal and Daloz call an "instrument of disorder" (1999). What, then, if we were to take corruption - or illegality more broadly - as an obvious fact of life? As Christopher Gregory points out in a recent preface to his classic study Gifts and Commodities: "How different would political economy, economic anthropology, and cultural economy look if we all made such an assumption?" (2015: 1). The questions we would be dealing with, would be rather different. Not: what sort of socio-economic system allows for the existence of corrupt behaviour? But instead: How do specific practices of 
illegality inform the ways in which capital is accumulated? In the case described in this chapter, I follow this advice and show how the state is embedded in such practices and how the corridor-isation of trade did not put an end to illegal cross-border practices - but rather institutionalised them. To tell this story, let us begin with a discussion of the economic corridor.

\section{A brief history of the economic corridor}

The protagonist of this chapter is the Bangladesh-China-India-Myanmar Economic Corridor. The project has its roots in the so-called Kunming Initiative in 1999, when the idea of a network of infrastructure tying together the four countries, and with them, South, Southeast, and East Asia emerged. In the last few years, the project has become retroactively enrolled in official BRI discourse by virtue of being part of the "six major land transport corridors" that seek to "follow the ancient Silk Roads" via a series of economic corridors (Liu and Dunford, 2016: 336). What interests me here, beside tracing the history of the BCIM, is also to stress how economic corridors became such a prominent part of the BRI rhetoric - to understand what they are, how have they come to be envisioned as particular instruments of development, and what they are expected to achieve. To do so I must begin not in Beijing, Kunming, or Tengchong, but rather with prominent international donors which have shaped much of the discourse around economic corridors and development more generally.

In a similar vein to Xi Jinping's BRI speeches, the literature on development often stresses the fact that economic corridors have a long history with its roots in the Silk Road and other trans-regional trading routes ${ }^{4}$. As one Asian Development Bank (ADB) report put it, "Economic corridors connect

4 Take, for instance, the following extract: "Transport corridors have been around for a long time. Trans-Saharan trade routes across the Wadi Hammamat can be traced back to at least $4000 B C$ from the Nile to the Red Sea. Around $200 B C$, Hammamat became an important part of the Silk Route (Silk Road). The Silk Route was a network of trade and cultural transmission routes that were central to cultural interaction through regions of the Asian continent connecting the West to the East by linking traders, merchants, nomads and urban dwellers from China and India to the Mediterranean Sea. Extending some four thousand miles, the Silk Road derived its name from the lucrative trade in Chinese silk. Trade on the Silk Road was significant in the development of the civilisations of China, the Indian sub-continent, Persia, Europe and Arabia, opening up long-distance political, economic and social interaction between civilisations. Although silk was the main trade item from China, many other goods were traded in both directions along the route, religions were expanded and technologies transferred and developed. The transport route evolved into a development corridor" (Hope and Cox 2015). 
economic agents along a defined geography" by providing "important connections between economic nodes or hubs that are usually centered in urban landscapes" (Brunner 2013). Moreover, economic corridors "do not stand alone, as their role in regional economic development can be comprehended only in terms of the network effects that they induce." Economic corridors are, in other words, embedded and integrated into specific networks with peculiar characteristics and their impact varies significantly across different regions. In another ADB report Srivastava (2011), for instance, posits that "Corridor development does not create economic strength so much as it channels, focuses, and amplifies the potential for economic growth." Accordingly, in order to be successful, a corridor needs not only to link two or more nodes, but particular nodes with potential for growth in between. Corridors, then, whilst having been around for a long time, still seem to require some form of "management" (Kunaka and Carruthers 2014; Arnold, Ollivier and Arvis 2007). In their multiple forms - a topology of corridors would identify trade corridors, freight corridors, industrial corridors, among others - corridors seem to be ambiguous creatures. They emerge naturally - they have always been there! - yet need investments, cooperation, and strategic partnerships in order to succeed.

As development tools, however, the history of economic corridors is a rather short one. The concept itself gained popularity only in the 199os due to the Asian Development Bank (ABD), most notably through its launch of the Greater Mekong Subregion (GMS). The GMS, an imagined geography of regional cooperation centred around the Mekong River, focused on a set of economic corridors connecting Burma, Thailand, Laos, Cambodia, Vietnam, as well as southern Yunnan and Guangxi. The corridors were initially envisioned as road networks which would encourage mobility, integration, cross-border trade, and thus foster economic development in the region. Yet. according to the ABD an "economic corridor is not simply a connection between points A and B" (ADB 2016), rather, transport infrastructure is only the first step towards the implementation of an economic corridor. Economic corridors were thus envisioned to link centres of production with centres of demand, such as major urban settlements. Furthermore, they were set to involve the crafting of laws and regulations - or "soft" infrastructures - in order to encourage business, access to markets, and development in a comprehensive and transparent manner.

While the GMS largely failed to deliver on the terms its proponents set out (cf. Shi 2009; Lyttleton 2009; Dwyer and Vongvisouk 2019), by the early $2010 \mathrm{~s}$ economic corridors had become a mainstream development tool and were soon to be incorporated as major features of the Belt and Road Initiative. 
Speaking at the opening of the Belt and Road forum in Beijing, in May 2017, Xi Jinping referred to economic corridors as underpinning "a multi-dimensional infrastructure network [...] featuring land-sea-air transportation routes and information expressway and supported by major railway, port and pipeline projects." Economic corridors should, according to Xi's words, contribute to the BRI's overall goal of "opening up," and in so doing "establish a fair, equitable and transparent system of international trade" (Xinhua 2017). In Xi's vision, then, economic corridors seem to be defined by the same logic underpinning ABD and the World Bank's approaches to the region: as "bundles" of transport infrastructures facilitating interactions and connections between large centres of activity. ${ }^{5}$ More than simple infrastructure systems, economic corridors as engines of development are also expected to boost transparency, fairness, as well as "rules and standards."

The BRI, as Xi Jinping remarked in the course of the same speech, is in fact centred around six main corridors. These are: the China-Mongolia-Russia Economic Corridor, the New Eurasian Land Bridge, the China-Central Asia-Western Asia Corridor, the China-Indochina Peninsula, the China-Pakistan Economic Corridor and the Bangladesh-China-India-Myanmar Economic Corridor. ${ }^{6}$ Remarkably, none of these projects is original to the BRI, but rather builds upon years of bilateral and multi-lateral relations and growing economic and political ties between China and its neighbours (Saxer and Zhang 2016).

As a key example, the BCIM has its roots in a conference on Regional Economic Cooperation and Development among China, India, Burma and Bangladesh organised by the Yunnan Academy of Social Sciences in Kunming in August 1999. The conference, attended by 134 delegates from the four countries, led to the establishment of a Forum for Regional Economic Cooperation through which officials could gain assistance from international organisations and institutions and work together towards their common goals. For China, as described in Chapter 2, these were the promotion of trans-border infrastructure to access markets and resources. ${ }^{7}$ In the final report of the conference, the word economic corridor was not mentioned,

5 A World Bank paper defines BRI corridors as "coordinated bundles of transport and logistics infrastructures and services that facilitate interaction between major centers of economic activity." (Derudder, Liu and Kunaka 2018). This definition echoes the one provided by the ABD and quoted above.

6 for a detailed description of the six projects see Derudder, Liu and Kunaka (2018).

7 Che Zhimin, whose work had been discussed in Chapter 2 in connection to the promotion of Yunnan as a major land bridge towards Southeast Asia, was involved in this early phase. For a summary of the history of the BCIM, see Uberoi (2013). 
yet among the topics of discussion were "the construction of communication channels and networks among China, India, Bangladesh and Burma (including the opening and reconstructing roads, air lines, water routes and railways)." ${ }^{8}$ As economic corridors became mainstream development tools in the course of the 2000 , the Kunming Initiative developed into the less-partisan denomination of the annual BCIM Forum, from which the idea of the BCIM economic corridor emerged.

Two decades and over a dozen high-profile meetings on, the BCIM has yet to produce most of its intended objectives. The four countries are still largely under-connected, and a viable direct link between China and India through northern Burma remains hindered by the of renewal conflict between the Burmese army and the KIA since 2011. There is, however, at least one place in which BCIM dreams and promises have taken concrete shape, driving both financial speculations as well as concrete infrastructure. To understand how such grand schemes materialise on the ground, it is now time to pay a visit to Houqiao, in Tengchong county, at the point where the BCIM crosses the China-Burma border.

\section{Sitting on the bridge(head)}

Strategically placed at $64 \mathrm{~km}$ from Tengchong, and only $140 \mathrm{~km}$ from Myitkyina, the capital of Burma's Kachin State, Houqiao has in recent years been chosen as the main port of entry for the county. Plans for its development are strictly connected with the history of the Stilwell (or Ledo) Road, and dreams of future connectivity reflected in the Bangladesh-China-India-Myanmar Economic Corridor. History, in Tengchong, has not been forgotten. On the contrary, as anthropologist Zhou Yongming has compellingly shown, history is used by local authorities in order to make active claims over future visions of transnational connectivity. He puts it in pugilistic terms, with Tengchong trying to "box out" rival counties or municipalities in order to attract funding and investments from the central and provincial government. Instead of fists, history is selectively used to strengthen the argument in favour of Tengchong as a 21st-trade hub (Zhou 2013). ${ }^{9}$ The vision local authorities are pushing

8 The report is available at: http://www.ibiblio.org/obl/reg.burma/archives/1999o8/msgoog46. html (accessed May 2019).

9 On the ways in which Yunnan has been in recent years re-imagined and re-branded as a major hub for regional connections see also Summers (2012); Su (2013); Rippa (2017, 2020); Sigley (2016). 
forward is, in many regards, similar to the Tashkurgan case discussed in the first Chapter. The reasoning goes as follow: strategic location, proximity to the border, long-lasting trading ties with Burma, the possibility to access a resource-rich market - these are all characteristics that prove, and therefore ensure, that Tengchong can be once again a major "bridgehead (qiaotoubao)" in cross-border exchange.

In Houqiao, in early 2016, these ambitions took the shape of a major construction site by the impressive border gate. Across it, as a small group of Chinese tourists was busy taking pictures, empty trucks were waiting to cross into Burma in a long line, heading for Chinese-owned banana plantations. They would return full within a day or two. The construction site covered an area of 143,000 square metres and the three-storey building was set to become the new Houqiao International Trade City, part of the Houqiao Border Economic Cooperation Zone and International Trade City (Houqiao bianjing jingji hezuo qu kou'an guoji shangmao cheng) - or what is locally known as the Border Trade Zone. On the other side of the road from the main construction site a small building hosted the offices of the company in charge of its construction: the Hong Yi Da trading company. By the main entrance, two large posters showed the vision behind the project. In the one at the bottom the four countries of China, Burma, India and Bangladesh were brought together by four forearms, one emerging from each country, forming a square of sorts. The large caption read: "Houqiao Border Crossing - the centre of the Bangladesh-China-India-Myanmar golden corridor." The other poster showed a rendering of the new "Houqiao International Trade City," with the contact information of the Hong Yi Da company in both Mandarin and Burmese.

The office of the Hong Yi Da company in Houqiao was not nearly as impressive. A large redwood table with some investment brochures, two smaller tables on the side, and a couple of posters with maps of the area and BCIM routes is all there was to it. The only person inside was $\mathrm{Mr} \mathrm{Yu}$, sitting at one of the small tables in front of his laptop, a small electric heater on his side. He got up as I walked in, and greeted me with a smile. Over the following two years, I visited him in this office several times. He never seemed to be busy, and I had never met anybody else in the office. During each visit, I would be served local Wulong tea in small paper cups he kept refilling with hot water, the green leaves laying at the bottom of the cup. Over such meetings we would smoke endless cigarettes, alternatively handing one out of our own box to one another as we talked about the Hong Yi Da company, the Houqiao International Trade City, the future plans for the BCIM, and about how $\mathrm{MrYu}$, then in his mid-2os, ended up working here. 
His story is not uncommon across the Chinese borderlands. Born and raised in Tengchong, Mr Yu went to college in Kunming - a phase of his life he often talked about: the big city, daily life in the large dormitories, early morning exercises, and afternoons spent sleeping in the library. Once graduated, he was faced with the choice of moving back home, or pursuing a career in Kunming or elsewhere. Many of his friends remained in Yunnan, yet some headed off to the coastal cities and are now back only once a year for New Year. "That was never for me," Mr Yu told me once, "I like it here, in Yunnan." Mr Yu, however, was not necessarily looking for a job in Tengchong when an opportunity with Hong Yi Da came up. A new, ambitious company was hiring in Tengchong county, promising a decent pay and an international working environment. As he explained, the company had already put RMB 320 million (US\$ 50 million) in the construction of the International Trade City and the development of the Houqiao Border Special Economic Zone. According to the company's vision, Houqiao was set to become the largest import/export trading centre in Western Yunnan relying on innovative logistics system and business models. At the time I first spoke to $\mathrm{Mr} \mathrm{Yu}$, the project envisioned the construction of six areas with different purposes: an integrated commercial city, a logistics district, a central plaza, a wholesale market, a recreational and tourist area, and public fitness facilities. Additionally, the company was also in the process of developing a nearby Lisu village into a tourist attraction. Mr Yu once told me that growing up in Tengchong he had often heard stories about Houqiao and about Burma. The idea of being part of such an ambitious, transnational project excited him - and that is how he decided to take the job.

The small office in Houqiao hardly fit such ambitious vision. Mr Yu, however, remained hopeful and optimistic. With enthusiasm, he walked me through the Houqiao International Trade City brochure, and illustrated the plans for the development of the area. Houqiao, he explained, was upgraded to a national-level border crossing (guojiayilei kou'an) in 2000. Yet, in practice, he told me, the change was not implemented until 2004. Nevertheless, its location made it China's major gateway for trade with India. While $\mathrm{Mr} \mathrm{Yu}$ admitted that distance was a negative factor, and he was well aware that north-east India was certainly not the most developed part of the country, potentials, according to him, outweighed the risks by a significant margin. "You see," he told me earnestly once, "there is a potential market of over one billion people that we can serve through here, western China, Southeast Asia, South Asia - it's huge!"

Despite the promises of development and connectivity that it carries, the history of Houqiao as a major gateway for China-Burma trade is a fairly 
recent one. As shown in Chapter 2, until the late 2000 s a significant volume of trade was in fact going through smaller border crossings further north along the border. In particular Diantan, as well as the smaller and most remote border crossing of Zizhi, became major entryways for Burmese timber throughout the 1990 and 200os. In Chapter 2, I discussed the ways in which the timber trade affected the geography of border crossings and border infrastructure in Tengchong, pointing out how an illicit economy led to the consolidation of state presence at the borderlands. In this Chapter, on the other hand, I describe what happened in Tengchong since the end of the timber trade, in the mid-2010s, counterposing the situation in Diantan and Zizhi to the increasing importance of Houqiao. In particular, I will show how the visions expressed by Mr Yu in Houqiao, while pointing to a particular image of development, trade, and global exchanges, grounded in legality and transparency, also hides some of the fundamental dynamics that have shaped and still shape the lives and fortune of Tengchong's trading families. First, however, let us discuss what happened in Tengchong in recent years, and why.

\section{Life after timber: Illicit no more?}

After showing me the border marker that he kept in the Tengchong Translators Association's backyard, Chairman Zhou told me that Burma did not have any forest left. This reminded me of a passage from Archibald Rose's description of the China-Burma frontier in his 1912 report. Rose noted that there was "a physical reality about the frontier" impressing the travellers crossing that particular boundary:

On the one side lies Burma, green and forest-clad as far as the eye can reach, the hills raising their wooded summits from a sea of white and billowing mists, whilst on the other side China stretches away to the sunrise, with hills that are bare of trees, rugged and weather-worn, with every crevice standing clear in the still sparkling air of the winter morning (Rose 1912: 197).

As Chairman Zhou's words made clear, by the late 200os, the outlook of the China-Burma border had turned. Thanks to Chinese loggers, where there once were trees, now lies a maze of logging roads and bare hills. On the Chinese side, on the other hand, the hills are covered by thick vegetation - the result of the Sloping Land Conversion Programme and Yunnan's 
ban on logging. Yet, according to Chinese and Burmese business people in Tengchong, the situation of Burma's forests was bound to turn once again.

Since 2015/2016, as I could witness myself, very little timber has been coming into Tengchong county. Both Chairman Zhou and Mr Zhang, as well as several other Tengchong officials I interviewed, ascribed the end of the timber trade to a change of policy in Beijing. Facing Burma's discontent over the trade and increasing international scrutiny, I was repeatedly told, China decided to put an end to the illegal export of Burmese timber to instead establish good relation with the newly elected government in Naypyidaw for the development of large-scale cross-border infrastructure and agribusiness concessions within the country. ${ }^{10}$

In general, what emerged from my interviews in Tengchong is that the decision to put an end to the illegal import of timber from Burma did not come from the local government in Tengchong or from the provincial government in Kunming, but rather from Beijing. At such, it can be seen as an integral part of broader foreign policy changes towards Burma that have taken place in recent years. The major driver of such changes can be identified as a more "assertive" Chinese approach aiming at protecting its own interests in Burma, fearing Naypyidaw's growing ties with the United States since the beginning of political reforms in 2011 (cf. Han 2017). According to this model, Beijing is seemingly applying a carrot-and-stick policy in which investment in infrastructure projects that would deepen China's influence in Burma are held against Beijing's ability to interfere in Burma's civil war through its connections with rebel armies along the Yunnan borders. By enforcing a ban on timber imports, and de facto halting Chinese logging operations in northern Burma, Beijing is making a strategic concession - one that does not represent a big sacrifice, but that nonetheless displays China's willingness to conduct its business in Burma in a fair and transparent manner.

In this regard, the fact that a major BRI corridor is set to transit through Tengchong is likely to have played a role in the strict enforcement of the ban in the area. In 2016 and 2017, throughout a number of visits to major points of entry for Burmese timber such as Diantan, Zizhi, and Pianma (in the Nujiang Lisu Autonomous Prefecture, only a few kilometres from the northern limits of Tengchong county), I could confirm that very little timber had entered China in this phase. Zizhi and Diantan, which were next to totally dependent on the timber trade, have become semi-deserted. In Zizhi, what used to be a busy trading hub with restaurants, hotels, KTVs 
and massage parlours, it had become difficult to find a place open for lunch. ${ }^{11}$ During a visit in 2016, the only open businesses were a few sawmills working on long-built reserves of timber. As the manager of one such place told me, their days were numbered, the future was bleak. Timber traders in the area confirmed that it was a Chinese decision to put a stop to the trade. "The Burmese," one such traders told me in Zizhi, "would love to do business with us. They make money with timber, but the [Chinese] government (zhengfu) doesn't let us."

The trader, whom I shall call Mr Wang, was one of many Sichuanese migrants who had come to the Yunnan-Burma borderlands in the early $2000 \mathrm{~s}$ to work in the timber trade. As he proudly pointed out, he had been "all along the border, in all places where there is timber," before eventually settling down in Zizhi where he purchased a lot of land and opened his own sawmill. As we talked, he walked me through the main showroom, a large open space where he kept some of its best products - mostly large tables carved out of rare tropical redwood. "The tables," he told me, "we usually carve here, but we also send raw timber to Fujian and other places where they make high-quality furniture." He seemed very proud of what he had built, and did not seem too concerned about the uncertain future that his business was going to face with the end of timber imports. I asked him what he thought about it. "Obviously I am not happy with it," he said. Yet, after a moment of silence, he added: "but we knew it was not going to last forever - there is almost no timber left in Burma anyway." As his wife served us some dinner - a couple of dishes of fried vegetables and a Yunnan favourite, minced pork with spicy pickled greens - Mr Wang opened a bottle of liquor. We toasted to our friendship and to his business, then talked more about the timber trade. Like many of his fellow traders, Mr Wang was very aware of the destructive impact of his business on Burmese forests. Yet he, unlike many other traders I had spoken to over the years, did not try to justify it by mentioning Burma's "backwardness," or the conflicts that were still breaking the country apart. "Our business," he pointed out, "was good for China." He continued: "who do you think made more money? We did, our government did. The local Party leaders, everybody." I could sense some uneasiness in his voice. "And what changed now?," I asked. "Policies changed, in Beijing," he replied without hesitation, "it's because of the anti-corruption campaign, the Belt and Road Initiative, they don't care about us now.”

11 There are ongoing plans for the re-development of cross-border facilities in Zizhi to foster the development of the area (Ming 2016: 44). What is interesting here is how development is identified as consequence of state investment, whereas timber - what brought fortune and infrastructure to Zizhi in the first place - does not figure. 
Houqiao is a good place from which to observe how a new discourse over legality, in combination with BRI-led development, is affecting cross-border interactions. Here, as trucks line up every day in front of Mr Yu's little office, waiting to clear customs and enter Burma, the timber trade is clearly a thing of the past - something that nobody seems to be particularly proud of. Yu spelled it out clearly. "You see," he said once, "the timber business was not a good business. A lot of forests were destroyed, people made a lot of money, but it was not good." Mr Zhang, back in Tengchong, held similar views. As we sat down for dinner at his house, facing the ancestors' altar in the central room (tangwu), he gave me his view on the end of the timber trade. "I used to work in Diantan, you know, I saw so much timber coming in, so much you cannot even imagine. But it was all unregulated. We would go in, and log an entire mountain. That's not good, you need regulations (guiding)." To the immorality of the timber trade, Tengchong officials and traders alike tend to counterpose today's approach. Thus Mr Yu, from his Houqiao office, did not shy away from an analysis of what has changed, and of what is to come:

This [the Houqiao Trade City] is not about imports. The timber trade is over. The companies investing here are all exporting - construction materials, agricultural products, utensils and electronics. This is what we focus on. [...] In order to succeed, this business needs good relations between China and Burma, China and India. The timber trade was bad for these relations, that's why it's now illegal (weifa).

Scratching the shiny surface of official speeches and company brochures, however, a more complicated situation emerges. It is an open secret among Tengchong's well-to-dos that the Houqiao Trade City is the result of locallevel Party policies and favours. ${ }^{12}$ Initially, the story goes, the Hong Yi Da company was contracted to build the Trade City, which would have then been run by the Baoshan city government. ${ }^{13}$ The company itself is run by a businessman originally from Qujing, a city in eastern Yunnan from where the current major of Baoshan was transferred from - leading to speculations over the major's personal stake in the project. Nevertheless, the Baoshan government was rumoured to have soon run out of money. Unable to pay for the construction, which had been in the meantime almost completed,

12 The following story was confirmed in a long conversation with one of the members of the Management committee of the Houqiao Border Trade Zone.

13 Baoshan is the prefecture-level city with jurisdiction over Tengchong county. 
the government negotiated the transfer of ownership of the Trade City to the Hong Yi Da company, which agreed to take over as the offer included preferential policies over taxes. Mr Zhang, knowing more than he could - or would - let on, told me in 2017 that the bargain did not quite pay off for the Hong Yi Da management. The Trade City was about to open, but most of the space up for lease was still empty. "Nobody wants to go and do business in Houqiao when you can do the same business here in Tengchong, we also have a Special Economic Zone. That's why the Hong Yi Da made such good website with all the reference to the Belt and Road Initiative. They hope they can sell some space, but they can't." I pointed out that despite everything the company was still running, the Trade City was almost finished, and more projects were popping up in Houqiao. Mr Zhang nodded, then exclaimed: "but of course!" He continued: "you see, this is Belt and Road now, the government needs to invest in it even if they have no money. They [Hong Yi Da] still get money from Baoshan."

What to make of a situation in which, on the one hand, the trade in timber that was for years not only tolerated, but also encouraged by Tengchong authorities, is now vehemently condemned as immoral and shameful, while new Belt and Road deals seem to be embedded in shadowy dynamics despite emphatic calls for transparency and accountability. One might be tempted to dismiss Tengchong officials' rhetoric as simply hypocritical, or to altogether question their integrity and honesty. On the other hand, a growing literature in the social sciences have pointed out that distinctions between what is legal and what is illegal, licit and illicit, and even moral and immoral, are inherently fluid and unstable. In the next section, I build upon this literature and touch upon the case of the amber business which has boomed at around the same time that the trade in timber was being shut down. By addressing Tengchong's officials and business community's different approaches to the two commodities, I show how legality and illegality are intimately bound with each other at the level of practice, while remaining powerfully - and conveniently - separated at the level of official discourse.

\section{From timber to amber}

In their introduction to Illicit flows and criminal things, Abraham and Van Schendel point to the fluid interface between what is considered illegal and illicit in the context of national borders. In particular, they identify the borderlands as particular spaces where activities that are legally banned but 
socially accepted take place. They term such activities "licit" and counterpose them to what states consider to be legitimate - what they refer to as "legal." In the borderlands, they argue, there are many instances in which the transnational movement of particular people and goods is considered illegal, as it defies the rules of the state(s). Such movement, however, can be seen as acceptable, and therefore sanctioned and protected, by those who actively participate in such transactions and that consider the trade to be a licit one. Recent works on everyday life at the borderlands of China and Southeast Asia have indeed showed the fluidity of such categories in the context of cross-border exchanges. ${ }^{14}$ Particular emphasis had been put on the role of the state in such processes, showing how local traders are able to negotiate and collaborate with it even in the context of "illegal" transactions. Here, I explicitly build on Van Schendel's (2005) argument about the fluid interface between illegality and illicitness in the borderlands to explore how what is considered "licit" and "illicit" changes in conjunction to state-driven discursive and policy shifts. In Tengchong, this shift took place at around the mid-2010s.

As timber imports faced closure, the mid-2010s witnessed the explosion of another form of cross-border trade, this time in Burmese amber (Figure 20). As I have discussed elsewhere in detail (Rippa and Yang 2017), ${ }^{5}$ Burmese amber - also known as Burmite - has been a renowned trading item for Tengchong families since at least the Ming dynasty. The main amber mines are located in northern Kachin State, close to the town of Danai through which the Stilwell Road used to run and now a contested piece of territory between the KIO/A and the Burmese army. Due to a number of factors, from political instability in the region to the prominence of trade in jade and timber as well as lack of demand, the trade in amber did not play an important role in the local economy until recently. Starting in the late 2000s, a few Tengchong traders began to import more Burmese amber, slowly building up a market for it. Less than a decade later, Tengchong had become China's amber capital, overseeing a trade that in 2015 included around 100 tons of amber being imported into Tengchong county, according to local estimate.

Despite the size of the business the bulk of the amber trade occurs outside of the regulatory regime, as amber rarely, if ever, goes through either Chinese or Burmese customs at the border. As a Tengchong amber trader put it: "If

14 See for instance Walker (1999); Kusakabe (2009); Sturgeon (2005); Schoenberger and Turner (2008); Hinton (1998, 2000: 22-23); Ford, Lyons and Van Schendel (2012); Nyíri and Tan (2016).

15 This section is largely based on this article. 


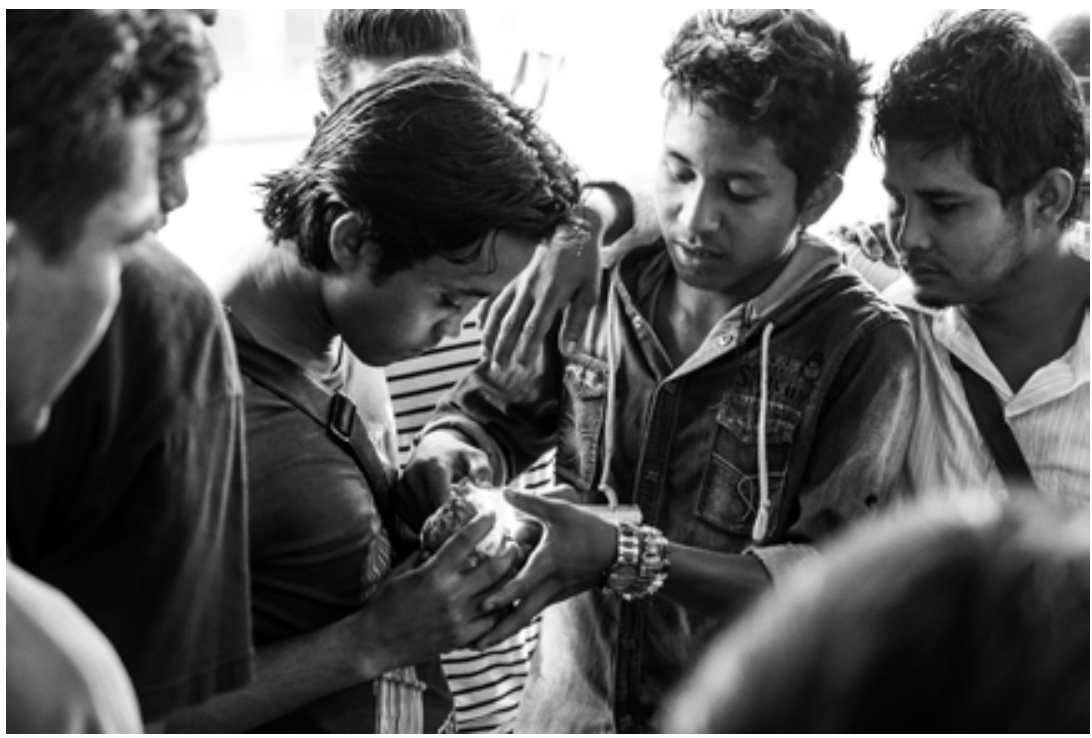

Figure 20: Amber dealers in Myitkyina, Kachin State (picture by the author, 2015)

amber were to go through customs it would not be profitable. We sell amber by the gram. I heard that customs tax is around $40 \mathrm{RMB} / \mathrm{gram}$, more than the price of a gram of most amber you find in Tengchong!" Furthermore, given the success of the trade, the Tengchong government recently listed amber as one of the city's main eight industries, and put its management under the responsibility of the Tengchong Cultural Industry Office. Authorities in Tengchong are well aware that Burmese amber reaches Tengchong via illicit channels, without going through customs at Houqiao or any other port of entry. The trade, however, has largely been tolerated, although stories of amber being seized along the Houqiao-Tengchong route circulate in the main gemstone market in Tengchong. The same trader put it in the following way: "Customs officials can confiscate [amber], they carry out inspections and can also set up mobile check-points. But it doesn't happen very often. [...] The majority of the vehicles carrying amber make it to Tengchong, more than go per cent; very few are seized." According to many traders, moreover, seized amber can be easily bought back from corrupt customs officials, and thus ends up at the Tengchong market anyway. Once there, I was repeatedly told, the amber is considered legal, and nobody can seize it. All the risks, then, are limited to the few kilometres between Houqiao and Tengchong.

This does not mean, however, that there are no attempts, in Tengchong, to regulate the amber market. Quite significantly, however, it was not local officials but the amber dealers themselves who initially pushed for a more 
regulated market and increased collaboration with authorities. Those efforts culminated with the creation of the Tengchong Amber Association (Tengchong shi hupo xiehui) in January 2016, at a meeting in a five-star hotel in Tengchong. ${ }^{16}$ It was the apparent ambiguity between the illicit means through which amber was brought into China, and the legal ways through which it was traded once in Tengchong, that represented one of the main reasons behind the traders' effort to set up the Tengchong Amber Association. Virtually all of the traders I talked to were hopeful that through the Association, amber traders and government officials would come to an agreement over the taxation of amber that would be favourable for business, and ensure that no further seizures would occur and more investments would be made - and most importantly, that the government would represent their interests to the Association's counterpart(s) in Burma. In the language of much economic discourse in today's China, traders in Tengchong were thus hoping for a mutually beneficial (gongying) outcome.

The report of the first meeting of the Association contained a first draft of the Association's constitution, an outline of the voting system for the members, and a list of its current members. The document established the Association as a non-profit entity, whose purpose was to foster unity (tuanjie), communication (jiaoliu), trust (chengxin), and development (fazhan) between the government and members of the Association, thus acting as an intermediary between officials and traders. Accordingly, the Association was in charge of delivering and discussing new government policies with the members, keeping the price of amber stable, ensuring the absence of fake amber from the market (as part of the Association's regulations, if a member sells fake amber he or she would have to compensate the cheated costumers for ten times the price spent), representing the members' interests at the government level, mediating disputes among members, and guaranteeing the fairness of the trade (gongping jiaoyi). Members, on the other hand, must subscribe to the Association's rules and pay membership fees according to their rank.

Despite its only recent appearance and the vagueness of certain critical points, none of the traders I interviewed in Tengchong underestimated the impact that the Association would have on the amber trade. The general impression among those involved with the Association was that, with time, traders and the government would reach an agreement based on the following two pillars: a low customs tax on amber which traders would

16 For an overview of small- and medium-sized associations in China see Weyerhaeuser, Wen and Kharl (2006). 
commit to paying in exchange for government support and investments. No one, however, ventured into providing more details, insisting that the actual content of the accord was to be worked out within the Association over the following months and years. The overall impression, moreover, was that for Tengchong traders the Association was less about regulating the imports of amber in order to avoid its seizure by border patrol forces, and more about providing them with a way to shape how government policies regarding amber were drafted and carried out. To be sure, traders were confident that having the government on their side would be of significant help in cases of conflicts with their Burmese counterparts or Burmese authorities. The creation of the Association was then a way, for traders, to bring the state in, but also to ensure that the amber trade would be dealt with according to their own interests.

Thus far, the creation of the Association does not seem to have had any significant impact on the way amber is brought into Tengchong. For the most part, the actual import of amber through Houqiao remains in the hands of individuals or small groups of Burmese dealers who generally take all of the risks. Many Tengchong traders pointed out to that there is so much amber coming into Tengchong via these channels, that they generally only have to sit tight and wait for somebody with a good deal to walk through their doors. Paired with the mining operations in Kachin State, which remain in Burmese hands, the case of the amber trade in Tengchong thus seems to resemble what Anna Tsing (2015) has called "supply chain capitalism." Miners around Danai and small-scale Burmese dealers bringing amber to Tengchong, in other words, whilst being an integral part of this specific supply chain, remain largely outside of any form of capitalist accumulation. Tengchong-based traders, on the other hand, work from within a system of accumulation bounded by state regulations they themselves collaborate in creating. As Tsing asserted, there is salvage accumulation on the one hand - illegal, risky, and unrepresented - and capitalist accumulation on the other - in which the state and traders come together to define the market for a particular commodity (Tsing 2005; 2015).

The Tengchong Amber Association, moreover, seems to have been created with the implicit goal of promoting the interests of a specific group of Tengchong amber traders: the wealthiest ones. Each member of the Association is required to pay a fee in order to be part of it. While the fee for a regular membership is not high, the president of the Association (currently Yang Chenguang, a major trader from Fujian) paid 200,000 RMB (US\$29,000), and the vice-President (Lin Shengyao, a local businessman) 100,000 RMB (US\$ 14,500 ) for the first year. When asked about why someone would pay such 
a high fee for these positions, the answer was "fame and wealth (mingli)," particularly the chance to establish closer ties with the government.

As mentioned above, there is a growing literature on small-scale cross-border trade in the Chinese context that shows how the state is embedded in flourishing illicit economies (cf. Ngo and Hung 2019). Building upon this literature this Chapter has underlined the coexistence of such processes with the establishment and development of large-scale cross-border infrastructure as part of the BRI. While much of the rhetoric behind such projects stresses transparency and inclusiveness, then, they are ultimately tied into pre-existing networks that blur commonly established lines between what is considered legal and illegal, licit and illicit. This is not to say, however, that the super-imposition of Belt and Road transnational connectivity projects has not affected local forms of trade. To the contrary, while illicit practices are institutionalised, some benefit from such investments while others excluded from them. In this context the creation of the Tengchong Amber Association reflects a larger trend as part of which large-scale traders take advantage of close ties with the local government, while small to mid-size trading enterprises suffer as their interests remain unrepresented. Burmese dealers, despite their fundamental role in the amber supply chain, are ultimately replaceable and thus stand at the lowest end of the spectrum, and are not even allowed to join the Association. To put it differently, the corridor-isation of the border regime at the China-Burma borderlands operates unevenly across different groups of traders. As a result, some have been further marginalised, while others have been included in the regulating process while, at the same time, profiting from the illicit practices they are supposedly regulating. Contrary to repeated claims of open borders and free markets so embedded within the BRI vision, what the case of the Tengchong Amber Association shows is that proximity to the state seems to be, still, the main guarantee of success in China's borderlands.

\section{Conclusion}

Today, in Tengchong, the trade in timber is seen with a sense of shame by local officials and traders alike. Deemed immoral, it is something most people particularly those who used to be involved with it - prefer not to talk about. In its place, what is promoted is a different kind of connectivity. Not one based on informality, shadowy exchanges, and lawless frontier-like imaginaries. Instead, the projected modernity of spaces like the new Houqiao Border Trade Zone displays transparency, accountability, and mutual respect. Yet, as this chapter has shown, while these two visions of connectivity might be incompatible at 
the level of ideology, they are deeply intertwined at the level of practices. As such, as the case of the Tengchong Amber Association exemplifies, a degree of illegality remains institutionalised even in the Belt and Road era.

In this chapter, by looking at borderlands as historical processes, rather than as taken-for-granted realities, I have described how legality and illegality can make one another. As Chapter 2 argued, the illegal trade in timber in Tengchong county brought about one of the most visible symbols of the state's lawful national sovereignty: immigration and customs facilities in two of the county's most remote border towns. The "legality" of such facilities, however, facilitated the unlawful exploitation of Burmese forests for almost two decades. Today, the legality of the Tengchong Amber Association oversees what remains, essentially, an illegal trade. As part of this process of formalisation, moreover, small-scale and Burmese traders have been excluded, further increasing their risks and lowering their potential gains.

To generalise, as cross-border trade is channelled through a smaller number of border crossings for political and economic reasons (Harris 2017), customs inspections and security checks are expected to become more severe, but also fairer and more transparent (Alff 2016b; 2016c) ${ }^{17}$ When observed on the ground, however, these same regulations produce an uneven impact across different groups. The corridor-isation of trade brought about

17 One study in particular is worth mentioning here, that of Economic Quadrangle at the borderlands of Laos, Thailand, China and Burma which Andrew Walker addresses in his monograph The Legend of the Golden Boat (1999). Offering a detailed regional history of trade in the borderlands of north-western Laos, spanning from the eighteenth century to the present day, Walker shows that this seemingly peripheral hinterland was, in fact, a dynamic commercial crossroads. He then describes recent attempts to "liberalise" these borderlands taking place since 1986, and materialised in particular in the Economic Quadrangle of Thailand, China, Laos, and Burma. Not unlike contemporary dreams of transnational connectivity in Houqiao, the vision behind the Economic Quadrangle was one of rapid growth fuelled by infrastructural development, trade liberalisation, tourism schemes, and foreign investment. Here is Walker's most compelling argument: "as trading and transport conditions become more liberalised, opportunities and incentives for regulation flourish" (1999:5). This, Walker shows, is the paradox of liberalisation: what is usually taken to mean free trade and deregulation leads, in fact, to more opportunities for local officials, traders and entrepreneurs to profit from the remunerative rights to trade regulations. Geometrical simplifications such as economic quadrangles, triangles, and economic corridors seem to produce more, not fewer state regulations. And, in turn, more, not less, state presence. What is interesting about this argument is that, in both the cases of CPEC and BCIM trade in Tashkurgan and Houqiao, the struggles of local small-scale traders in recent years seem to follow this very pattern. New regulation, in both regions, have favoured large companies and contributed to the marginalisation of local actors. As the first part of this book pointed out, by stressing a particular form of transnational connectivity - reflected by economic corridors and large-scale projects - another form of connectivity, more local and embedded in the physical and cultural landscapes of the Chinese borderlands, is virtually erased. 
by Xi Jinping's new vision for transnational connectivity, in other words, brought about more security (Chapter 5 ) and the institutionalisation of illicitness. The results, far from the official rhetoric, are producing exclusion and marginalisation for many small-scale actors which have been involved in cross-border trade for decades. The BRI, in this regard, might as well signify the end of proximity. 


\section{Coda}

February 2013. Houses tell a lot about the people who live in them. They are a canvas upon which past lives, stories, and memories find a way into the present. They tell of someone's aspirations and fears, of one's loves and dreams. Such were my thoughts as I walked into the house of Brigadier Khan, in a quiet residential area in the outskirts of Islamabad. The walls were covered with a number of family photographs. I saw the young brigadier on the day of his marriage - "many years ago," as he pointed out. Other pictures were showing his four daughters with their respective husbands and children, and one large image showed the whole family together. All of the brigadier's daughters were living in different places now: Vancouver, Manchester, Karachi. The fourth one, I can't recall. As the Brigadier pointed out, proudly, "it all started from me, and now they are all over the world with their families".

In February 2013, at the time I interviewed him in his house in Islamabad, Brigadier Khan was 82 years old. Tall and skinny, his long fingers moved quickly as he generously talked to me about his life for over two hours, while sipping sweet chai and eating cookies and dry fruit. He enjoyed his time in the army - and he certainly enjoyed recalling the old days. The reason I was interviewing Brigadier Khan was because he had been responsible of the construction of "over 400 miles" of the $\mathrm{KKH}$, in the 196os and 1970s, when he was a commander of the Corps of Engineers of the Pakistani army.

I had come to know Brigadier Khan through another prominent member of the Corps of Engineers, Brigadier (retired) Mumtaz Khalid. Brigadier Khalid was the author of a two-volume history of the construction of the KKH $(2006 ; 2009)$, which I had carefully read and discussed with him over meetings at his house in Rawalpindi. Yet when my questions lingered around the relationships between Pakistani engineers and their Chinese counterparts, he suggested I get in touch with Brigadier Khan. He, Mumtaz Khalid told me, was working closely with the Chinese, and travelled extensively to Xinjiang and Beijing to discuss cooperations and protocols with Chinese officers. He had even met Zhou Enlai once, I was told.

Brigadier Khan, as I arrived at his house, invited me to sit in a large living room, surrounded by sofa, with a big window pointing toward the small garden beside the street. As I walked in, I couldn't avoid noticing the huge carpet that was covering most of the room's space, a beautiful 
Bijar specimen with an impressive central floral medallion design and a beautiful floral border. Beside it, I noticed a much smaller carpet, of Caucasian design, with three medallions of rather odd pink colour. I immediately complimented the Brigadier on the carpets, hoping that he would tell me more about the small Caucasian one, which I found particularly interesting. As I suspected, the Brigadier told me that he had bought it in Xinjiang, "in Khotan to be precise," in the course of a visit to the XUAR in the 1980s. Another object, in the living room, was representative of the Brigadier's past Chinese experiences. It was a Chinese cinnabar lacquer plate depicting a view of the Great wall.

"I used to work in close contact with the Chinese, we used to have discussions and meetings about all sort of problems," Brigadier Khan recalled. "We used to meet the Chinese in Hunza, they worked there," he continued, but "the main headquarter was in Gilgit. They [the Chinese] used to come there, commander and director general. They had very good engineers, very outstanding. They also had all the security personnel, the army, and also a group of interpreters, Urdu and English interpreters." Yet, while Pakistani and Chinese engineers and officials held regular meetings to discuss all matters related to the road's planning and execution, equipment, and labour, Chinese workers employed in Pakistan kept to their own camps and interactions with locals were minimal. As Brigadier Khan put it: "many [Chinese] students also came and work on the road. But they were all kept in the north. They were devoted communists, Mao Zedong was alive, and I think most people were not allowed to talk to us."

Most Chinese workers were members of the Xinjiang Production and Construction Corps. They had military training and were used to the hardship of an alien terrain and cultural space. They also knew how to keep by themselves. Nevertheless, the distance at which they were kept from entering in any contact with any local chafes with the language of friendship and brotherhood often employed by authorities to define the China-Pakistan relation. Instead of being encouraged, "people-to-people exchanges" - as the same rhetoric often phrases it $^{1}$ - were prevented. As Brigadier Khan observed, ideology - specifically, Maoism - played a part in hindering such relations from taking place and developing. Security concerns also played a role. As Chinese accounts of the lives and experiences of construction workers on the Pakistani side of the $\mathrm{KKH}$ reveal, contacts were for the most part limited to the few Pakistani

1 See, for instance, the official Pakistani government website of the China-Pakistan Economic Corridor: http://cpec.gov.pk/project-details/61 (accessed May 2019). 
soldiers who were helping their Chinese counterparts to guarantee the safety of Chinese workers (Li Menghe 2017).

While the dominant ideology of the time has hardly survived four decades of modernisation, along today's KKH some of the same problems remain. As I could observe in Karimabad, Hunza Valley, where most Chinese workers employed in the construction of the tunnels around the Attabad lake were residing in 2013, contacts with locals were kept to a minimum. I was often told that Chinese workers were "not allowed" to talk to locals, to eat at local restaurants, and to leave their camps and workplace without an armed escort. Since 2013, moreover, the issue of the security of Chinese workers in Pakistan had become an element of paramount importance in the relations between the two countries. Pakistan has repeatedly stressed that it will do its best to protect Chinese workers, while China had begun employing its own security contractors to protect its interests in the country. The result, much like in the early days of the construction of the $\mathrm{KKH}$, is that relations between Chinese workers and Pakistani are limited to the workplace.

A corridor can take many different shapes. In its quest for producing frictionless connections, it is always incongruous. Local frictions cannot be fully eliminated, and the forces of proximity are playing an important part even in the Belt and Road era. A corridor, in other words, is always aspirational - yet in its material encroachment it produces concrete consequences. In projecting ideas of connectivities, it prevents contiguities. In producing connections, it erases existing relations. In its attempts to bring together, it separates.

Such is the story of the China-Pakistan Economic Corridor. Such is the future the Belt and Road Initiative is set to shape. 



\section{Conclusion}

In the summer of 2016, during a two-week visit to Xinjiang, I travelled up the Karakoram Highway from Kashgar to Tashkurgan in the company of two colleagues. Not long after the Gez canyon checkpoint, upon reaching the high plateau that would lead us to Karakul Lake, we made a short detour to visit a new village to which a few hundred Kyrgyz have been recently resettled. The outline of the village followed a familiar pattern, with concrete houses built in orderly fashion along straight roads, each separated by a concrete wall enclosing a small garden. To the southernmost edge of the village a few buildings were meant for livestock, which families were prohibited from keeping in their own yard for "hygienic" reasons. Not unlike the new villages in the Dulong Valley described in Chapter 3, the Kyrgyz village in Xinjiang also featured Party offices, a building for communal activities with a basketball court, and a school. At the time of our visit the village was mostly unoccupied. Young men and women, as well as the livestock, were camped at higher altitudes, in the summer pastures, and would not come back until the change of the season. Driving through the village's empty street we could not help but feel a distinct sense of desolation.

Nevertheless, we decided to take a short walk around to talk with some of the few elders who had remained in the village, and to snap a few pictures. As we reached the school, we observed a number of murals that had been painted on the school wall, not unlike most schools China. What was rather different in this case were the subjects, focusing mostly on praising ethnic unity and crushing the "three evils" of terrorism, separatism, and religious extremism. In one mural, a fist displaying the national emblem of the PRC crushed three "terrorists," depicted with beards, white turban, and carrying knives and explosives. "This is how we respond to extremists," the handwriting said, in both Chinese and Kyrgyz. On a nearby wall a group of CCP officials, Kyrgyz herders and SWAT policemen were fighting armed terrorists with pitchforks and guns. Yet, what caught my attention was another mural, depicting yet another violent scene (Figure 21). An axe, carrying the national emblem of the People's Republic of China, had fallen on what was set to represent a group of terrorists. Two, carrying sword and spears were beheaded, leaving traces of red blood. A third was depicted as a snake, cut in half. A fourth, a man dressed in blue was cut by the axe at his knees, while lying face down. This man was not carrying weapons, but a flag. A green flag, with a white crescent and star in the top-right corner. The flag, a clear reference to Islam, was not close to that of any terrorist 


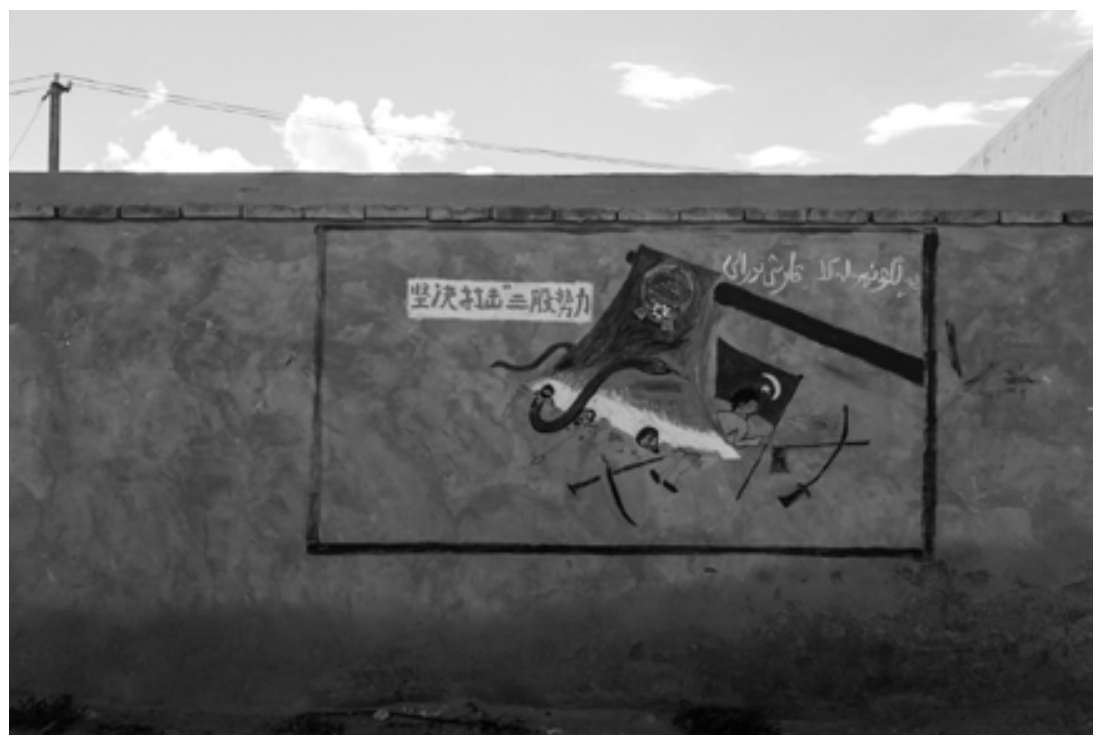

Figure 21: Mural in Kyrgyz village along the KKH. The text, in Chinese and Kyrgyz reads, "Firmly strike the 'three evils'" (picture by the author, 2016)

group we could think of. What it resembled, however, was the flag of the Islamic Republic of Pakistan - the only noticeable differences the fact that the crescent was facing downwards, instead of upwards, and the absence of the white stripe on the left.

Upon reaching Tashkurgan, only a few hours later, we were welcomed by another flag - or more specifically, by two flags placed alongside one another. This time, the flag of Pakistan was depicted correctly, on a large poster at Tashkurgan's main intersection along the KKH (Figure 22). The flag of the Islamic Republic was placed beside that of the PRC, above a sentence written in large Chinese characters as well as in the following English translation: "Warmly celebrate the 65 anniversary of the diplomatic ties establishment of China and Pakistan!"

This vignette encapsulates some of the key themes that I have discussed in this book. On the one hand, China's anti-terrorism and security paranoia is reflected in the Kyrgyz village's murals. In it, what looked like a Pakistani flag resonates with many Han Chinese's views of Pakistan. An ally, certainly, but also an underdeveloped and dangerous (weixian) country - and one in which terrorists are rumoured to thrive. On the other hand, the large poster in Tashkurgan speaks to the CCP's official line towards its "iron brother" - a key strategic and economic partner, to which China has promised a plethora of infrastructure and development projects as part of the CPEC. This poster 


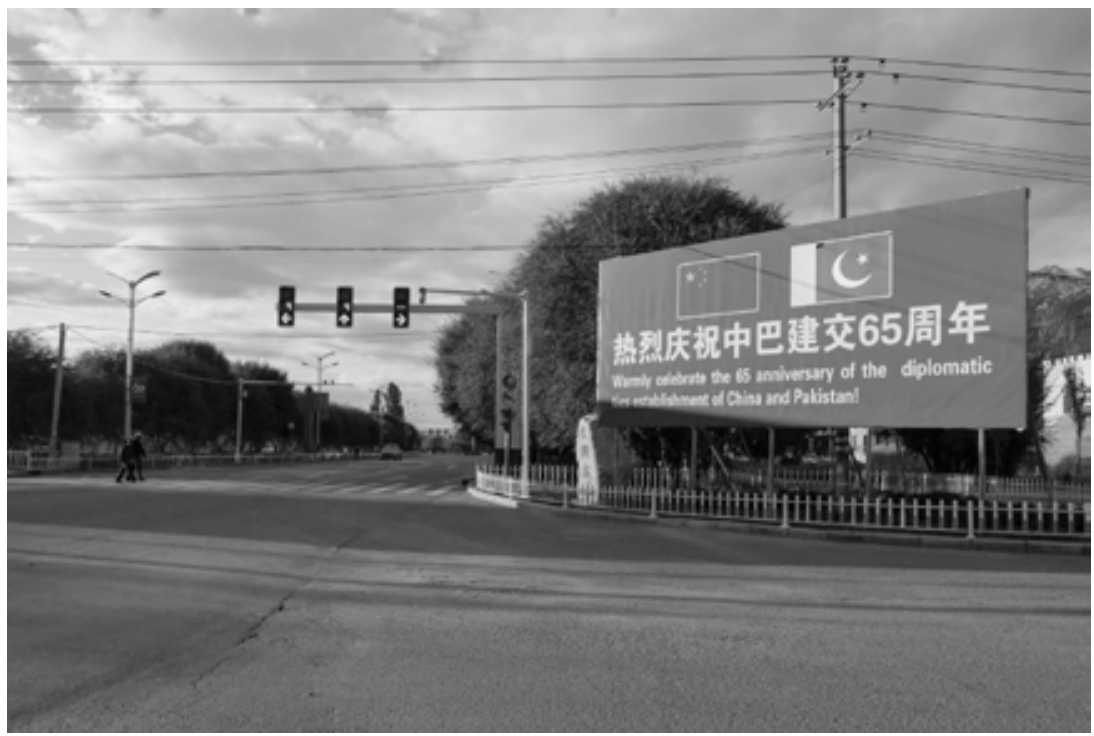

Figure 22: Celebratory sign along the KKH in Tashkurgan (picture by the author, 2016)

also reveals something else, particularly through what is missing. Written in Chinese and English, it does not present any local language - Uyghur, Kyrgyz, Wakhi, or even Urdu. Implicitly, then, it seems to point to the "high-level" relations that are at stake - one that, clearly, does not reflect entirely at the local level.

In what follows, as a conclusion to the book and a sobering appendix to much of the discussions and expectations surrounding the BRI, I suggest that such ambiguities represent China's main obstacle in the development of its transnational project and will ultimately hamper its ambitions. By doing so, I reflect upon what a view from the borderlands can tell us about the Chinese state and the future of China. Lastly, I return to the notions of proximity, curation, and corridor, which I have discussed throughout this book, in order to show how they can be employed as points of departure for understanding some of the dynamics cross-cutting not just the borderlands, but China as a whole.

\section{From the margins to the centre: Development, Security, and the BRI}

The concept of "community of shared destiny (mingyun gongtongti)" has gained popularity in Chinese foreign policy in recent few years. Xi Jinping first elaborated on this concept in the course of a 2013 keynote address to the "Conference 
on Diplomatic Work with Neighbouring Countries,"1 shortly after his launch of the BRI between Kazakhstan and Indonesia. At its core, the idea is neither new, nor particularly well-elaborated, vaguely referring to the need to develop good relations with neighbouring countries thus ensuring peace and stability. Xi pledged to cooperate with neighbours on the basis of friendship, reciprocity, and inclusiveness. That way, he added, neighbouring countries "can benefit from China's development and China can benefit and gain support from theirs" (Xi 2014b: 327). This particular approach, Xi stressed, has a strategic component too: to safeguard peace and stability in the region. ${ }^{2}$ Only a few months later, at the Summit of the Conference on Interaction and Confidence-Building Measures in Asia (CICA) in Shanghai, Xi Jinping presented another major foreign policy framework of his administration: the New Asian Security Concept. Employing a similar vocabulary to Xi's Belt and Road speeches, the New Asian Security Concept was defined as a "common, comprehensive, cooperative and sustainable" (Xi 2014a) security framework, ultimately revolving around the three main pillars of development, cooperation, and inclusiveness.

When taken together, as they rarely are, these two approaches to China's foreign policy seem to reflect the CCP's approach to the governance of the country's peripheries. As discussed in this book, this revolves around the two pillars of development and security. One, in Xi Jinping's China, cannot exist without the other. Or, as Xi himself put it in the same speech in Shanghai: "Development is the foundation of security, and security the precondition for development."

Let us focus on this particular correlation in the context of the Belt and Road Initiative. In a recent article, Shahar Hameiri, Lee Jones, and Yizheng Zou (2018) look at the case of China-Burma relations to argue that not only security did not follow decades of Chinese economic engagement in its neighbouring country, but that the opposite outcome has occurred. As they summarise:

On the Myanmar side, Chinese economic engagements have been associated with increased organised crime, environmental degradation, land

1 The main points of the speech are included in Xi (2014b: 325). On the community of shared destiny see Rigby and Taylor (2014).

2 Xi's remarks seem to be at odds with his administration's assertive attitude towards many of China's neighbours, particularly in the context of ongoing territorial dispute in the South China Sea. As two observers pointed out, "it is difficult to recall a period, in recent history at least, where there has been such a substantial gap between Beijing's public rhetoric and what it has been doing in practice, with the result that it has alienated, alarmed and infuriated many of its neighbours" (Rigby and Taylor 2014). 
grabs, and escalating socio- political conflict. On the Chinese side, closer integration with Myanmar has intensified problems of smuggling, illegal gambling, narcotics trafficking, drug abuse, and HIV/AIDS. The SinoMyanmar borderlands thus exhibit a development-insecurity nexus (3).

They further identify two causes. First, as the critical literature on development has consistently shown, the liberal mantra of peaceful development is misleading: processes of capitalist accumulation are rather inherently violent and conflict prone. Secondly, Chinese engagements in Burma have been largely in the hands of businesses operating out of Yunnan, thus in conjunction with an agenda set not by the central government in Beijing. This fragmentation and decentralisation of power, they argue, led to an uncoordinated and incoherent approach that is generative of conflicts. In this book, particularly in Chapters 2 and 6, I have shown how locally-driven development initiative at the China-Burma borderlands collided with the agenda set by CCP leaders in Beijing - a conflict that eventually led to a change of policy around the mid-2010s and to a more centralised approach to foreign policy.

To be sure, BRI projects in Burma, Pakistan, and elsewhere have raised several controversies, doubts, and fears. As I showed in this book, such scepticism over China's promises of inclusiveness and win-win outcomes is well placed, yet for reasons that go beyond geopolitical anxieties. As I have discussed at length, by projecting a new, ambitious geography of transnational connectivity, the Belt and Road Initiative has ignored much of the pre-existing forms of mobility and exchange at the borderlands. As such, we can see the BRI as an ontogenetic project: it produces as imaginary of global connection that does not exist, never existed, and probably will never exist in such forms. In so doing, however, it jeopardises the viability of pre-existing networks and threatens the livelihoods of those dependent on them. Small-scale traders, in particular those who opened up many venues for China's outbound trade throughout the reform period, have not only lost their strategic advantage, but are struggling to keep their businesses afloat altogether. By increasing legibility and control, particularly in connection with security paranoia in Xinjiang, communities of local traders have been de facto excluded from profiting in any way from BRI investments.

This book shows that insecurity at China's borderlands is not only the outcome of the inherently violent nature of "peaceful" development and of the lack of coordination between peripheries and centre in China. The very discursive and material priorities at the core of Chinese investments abroad are likewise responsible for policy initiatives that disregard and 
jeopardise existing connections and forms of exchange. The example of Pakistani traders mentioned in Chapter 1 and Chapter 6 is emblematic, in this sense. For them, as I stressed, a certain level of unpredictability was "part of the business." Be it landslides, new regulations, or transportation issues, they could never guarantee a precise timeframe for the shipping of certain goods. On the other hand, new China-led infrastructure projects aim precisely at reducing such uncertainties, increasing speed and projecting an image of accountability. This tension, I argued, is not only the result of a different infrastructural or political landscape. Rather, it underlines differing notions of mobility. Notions that, embedded in small-scale traders' practices, cannot be measured. The other, represented by smooth arrows across maps of Eurasia, that focuses on A-to-B connections and removing local frictions. There is a fundamental element of incommensurability at the heart of this tension. This incommensurability points, as I have argued in the first part, to different, at times diverging notions of connectivity. What it also points to, as the rest of the book elaborated upon, is to the ways in which such plans impact local livelihoods, transnational mobilities, and the very construction of the state in such contexts.

Aihwa Ong and Li Zhang (2008) have argued that in contemporary China neoliberal policies coexist with socialist rule. In order to make sense of this apparent contradiction, they define this particular articulation of neoliberalism as "socialism from afar." The adoption of neoliberal reasoning, particularly evident in self-governing practices that are integral to neoliberalism as a technology of rule (Rose 1999), has thus allowed the Chinese state to maintain authoritarian rule "from a distance." To be sure, they view "China's selective embrace of neoliberal logic as a strategic calculation for creating self-governing subjects who will enrich and strengthen Chinese authoritarian rule" (Ong and Zhang 2008: 10). Thus, against totalising views that see neoliberalism and socialism in contradictory terms (Harvey 2005; Hardt and Negri 2000), the Chinese state exemplifies a particular configuration of power where different logics of ruling are at play (Ong and Collier 2005). This book, particularly in Chapters 3 and 4, presented a number of examples that spoke to this mix of self-governing and socialist governing that characterises contemporary China. Unlike Ong and Zhang's discussion, however, I have argued that this particular configuration is made possible not by distance, but by the sheer visibility and lumbering presence of the state in the borderlands. While promoting practices of self-management and self-control, in both Xinjiang and Yunnan the state showcases its presence in spectacular ways.

To be sure, one of the key arguments of this book has been that development, in the context of the Chinese borderlands, is always ideologically charged. In 
her work on Soviet architecture, anthropologist Caroline Humphrey (2005) reminds us that a seeming "straightforward" relation between ideology and infrastructure was, in fact, challenged by the everyday usage of particular spaces. She thus sees the material structure that, according to a Marxist perspective, should have generated a new society, more like a "prism" through which particular ideas and ideologies were continuously deflected and re-directed. The purpose of this book, on the other hand, was not to address the ways in which, for instance, new socialist villages in China can become sites of "deflection," or perhaps even of resistance to a particular ideological project. Rather, my intent was to address such project and to describe the Chinese state's approach to rural development in the borderlands as an ideologically driven effort. To highlight the political core of an intervention that is often framed in developmentalist - here read, economic - terms. The concept of curation conveyed this particular aspect of China's contemporary political-economic system. Through it, and through the discussion that I developed in the context of Dulong and Kashgar, it appears clear that it is impossible to understand China's contemporary development approaches outside of the socialist legacies that gave rise to it. Only moving from such backdrop can we fully understand the idiosyncrasies of China's global role and position.

On 17 January 2017, Xi Jinping spoke at the World Economic Forum in the alpine setting of Davos, Switzerland. Xi presented himself - and the People's Republic of China - as a champion of globalisation, a force that "powered global growth and facilitated movement of goods and capital, advances in science, technology and civilization, and interactions among people" (CGTN 2017). The speech, using many turns of phrases - from "win-win" to "inclusive development" - typical of BRI lingo, was delivered only a few days before Donald Trump's inauguration as the $45^{\text {th }}$ president of the United States. The timing of the two events signalled what many analyses have indicated as a historical turn of events: as Washington became more inward-looking, Beijing took over the helm of global economy. Compared to a conservative and nationalist majority in the United States, Xi's rhetoric of global development and Belt and Road connections seemed to conjure China up as the new global leader.

As part of this shift, and particularly due to the ambitiousness of the BRI, China's borderlands began to crop up in international news headline. Special Economic Zones under construction in seemingly remote places were covered by major news outlets, while the language of economic corridors spread well beyond the circle of experts to which it had been confined so far. Since the initiative was launched in 2013, China has hosted hundreds of BRI-themed conferences and workshop, while research papers and reportages on BRI 
projects seem to know no end. By late 2018, we were nevertheless told that Asia had already "[fallen] out of love" with the Initiative (Marlow and Li 2018).

Despite all of the attention that the BRI gathered, little has been said about those who actually live at the borderlands. The language of "win-win" outcomes and geopolitical considerations seem to have overshadowed the logic of local dynamics. Who, along China's borderlands, is left out of such projects? This is a question that has been rarely asked. This book, however, addressed precisely this paradox by focusing on how large-scale interventions ended up marginalising small-scale transnational traders and local ethnic minorities, but also diasporic groups outside of the PRC territorial boundaries. In particular, by showing the ideologically charged nature of such projects, this book attempted to place displays of global friendship and orientation such as Xi Jinping's Davos performance in perspective.

A view from the borderlands brings us back, then, to the very centre. To the ways in which the Chinese state is built and functions. But also, and most importantly, to how it is experienced and enacted at the level of everyday lives. The borderlands are not a space of exception, something that can be glossed over through the old cliché of "the emperor is far away." If anything, while representing the material edges of the state, they are also one of the places where state presence is more visible. They offer, then, a privileged perspective from which to observe and study it. Not from above, or below - but from the margins, much in the spirit of canonical anthropological tradition. In doing so, the notions of proximity, curation, and corridor that I developed throughout this book in the context of the Chinese borderlands, are also conceptually useful departing points for looking at China as a whole.

\section{Proximity, Curation, Corridor}

Over the course of my most recent visit to China, in the summer of 2019, I travelled to the Houqiao border crossing, over two years after my previous visit. To my surprise, the Houqiao International Trade City remained in the same, incomplete state, as I remembered it. On the ground floor, facing the road, two small stores sold basic items - drinks, snacks, cigarettes - to passing truck drivers and the occasional tourists, as well as to residents of the newly built Lisu village across the street. Beside them, two eateries and a pharmacy were all there was to it. The other floors of the Trade City remained unfinished, without windows, doors, and of course, businesses. Construction tools were still scattered around, as if workers were just taking a short break. Yet, it had been two years and there was no sign that construction would 
resume anytime soon. The office of the Hong Yi Da company was shut, with only a large banner hanging outside of it: "The project [the Trade City] is seeking partners or transfer of equity." Not a good sign, for what was initially branded as key project along the BCIM Economic Corridor.

Activity around the Trade City, however, had not stopped. If anything, the empty rooms of the Trade City functioned as an echo chamber carrying the message of infrastructure-led-development dear to both local officials and private developers. Across the street, between the Trade City and the new Lisu village, a hotel was under construction. A few hundred metres beyond the massive border gate, visible from the roof of the Trade City, another project was taking place. As part of the plan-cum-slogan "within the border, outside of customs (jingneiguanwai)," a new cluster of tax-free shopping malls and logistics centres appeared to be almost completed. $\mathrm{Mr}$ Yu had mentioned the project in the course of our conversations, yet during our last meeting construction had not yet begun. Now, I reasoned with the Sichuanese owner of one of the stores in the Trade City, it would soon be time to inaugurate it.

The owner of the store, a young man whom I had previously met when he first moved to Houqiao in 2016, had all the time in the world. "This port of entry," he pointed out, "gets busy only during banana season," when hundreds of trucks exit China heading for plantations in Kachin State, and return full. In the summer, however, between April and October, there is not much going on. "Still," he complained, "I am paying 4000 RMB per month in rent and have no customers!" He shook his head, but then told me that he was confident that things will get better soon. "This," he stressed, "is a Belt and Road corridor. Things must get better." His optimism aside little seemed to have happened in the past two years, and after a few more words on tourism and cross-border business in the area I decided to take a little stroll through the Lisu village across the street. There, what caught my attention was a three-sentence slogan that occupied the entire side wall of one of the village houses, facing the massive border gate. In large, red characters, the slogan read as follows:

Different ethnic groups unify and progress together (minzu tuanjie jinbu $)^{3}$

Border areas are prosperous and stable (bianjing fanrong wending)

The port of entry is open and dynamic (kou'an kaifang huoli)

3 This sentence could also be translated as "ethnic unity (minzu tuanjie) improves." Minzu tuanjie (generally translated as "ethnic unity" or "national unity") is a set phrase and was a popular slogan particularly in the $\mathrm{Hu}$ Jintao years. 
This terse slogan encapsulates some of the key threads that I have followed in the course of this book: the marked emphasis on cross-border trade as a source of prosperity, the role of ethnicity in processes of rural development, and the importance of maintaining security in border regions. In turn, I have analysed these processes through the notions of proximity, curation, and corridor - something to which I will now turn to, one last time.

The port of entry is open and dynamic. The first chapter of this book detailed a tension characteristic of many border areas in today's China. On the one hand, I described the persistence of cross-border connections that pre-date not only China's opening up and reform period, but the People's Republic of China itself. These connections can take the forms of particular trading practices, kinship relations, linguistic commonalities and shared cultural references. On the other hand, I discussed how the Chinese government's current emphasis on developing cross-border infrastructure and "people-to-people" ties not only ignore, but purposely try to do away with such forms of connectivity. The notion of proximity developed the former, while the image of the corridor captured the ways in which the latter is spatialised in today's China. Proximity, in particular, was defined as the continuously evolving socio-spatial configurations that underpin exchange practices, affording particular opportunities to specific groups. Through it, my aim was to capture histories and connections that would have otherwise remained hidden. Such were, for instance, Karim's ties with the Tajiks of Tashkurgan, as well as his regular efforts to ingratiate Chinese border officials. Or Ali's ability to learn Uyghur and strengthen business ties in Xinjiang through frequent visits and the establishment of relations of trust. As such, proximity is not necessarily specific to border areas. Since the beginning of China's reform period, and following a much older tradition, groups of itinerant traders have played a pivotal role in the ways in which goods are purchased, transported, and distributed across the country and beyond its borders. Such communities are often built around shared connections to a particular place and often reinforced through kinship ties. These are groups that, in other words, share a language, cultural references, and place of origin - business, for them, is but one element of a more complex relation. This, in a nutshell, is what I call proximity.

Different ethnic groups unify and progress together. Hiding in plain sight, under the "tight skin" of the Chinese nation, is a most common imperial legacy: indigenous groups that have been - more or less forcefully, more or less successfully - ushered into a modern project of nation-building. In today's China such groups are categorised as minzu, and their role and position vary greatly in different contexts. They all are, however, at the receiving end of Party instructions, generosity and violence. They are, as I 
put it, subjected to a specific form of care - yet one that is not necessarily defined by affection. Curation, rather, identifies the current condition of many ethnic groups in China, at the convergence of economic development, increased state control and monitoring, and the turn to heritage as both a source of opportunity and a defining aspect of minority identity. As with proximity, processes of curation are not limited to border areas, although the focus on "stability" here makes it more visible here than elsewhere. Curation as "healing" process can be a useful analytical category to address the struggles of minorities (not necessarily "ethnic") across increasingly uneven Chinese landscapes. Furthermore, curation as a "selective" process, that is, one that aims as "preserving", sheds light on the "active" role of heritage-making in both non-Han and Han areas.

Border areas are prosperous and stable. If Shohrat Zakir's interview with which I began this book brought to the fore the nexus of development and security that lies at the core of Xinjiang's system of prison camps, these six characters on the wall of a Lisu house in Houqiao stress its relevance across China. Prosperity (fanrong) and stability (wending) are but two faces of the same coin. In this book, the image of the corridor encapsulates this particular configuration of state-power in the Chinese borderlands. As such, it relates a number of contradictions. A corridor is both connective and divisive. It fosters movement by controlling it. It enhances speed by containing traffic. Across China, there is no shortage of examples of how the corridor-isation of trade and the economy is fostering both exclusion and inclusion. From the high-speed railway network system to the dramatic expansion of delivery services (kuaidi) and online retail, movement has been re-spatialised through a new set of "nodes" across particular logistics (wuliu) chains. The Belt and Road Initiative is, in this regard, an attempt at designing and capturing a similar form of development across Asia and beyond. In analysing this, the notion of corridor that I have developed can be a most useful tool.

To conclude, in today's China the borderlands continue to play a pivotal role. Yet not, as in the oft-quoted saying "the mountains are high and the emperor far away," as unruly peripheries in which central power struggles to maintain a hold. The borderlands, while maintaining their uniqueness, are as integrated into the CCP national project as they have ever been. More than that, they have become central to China's global efforts to develop a new world order - one pivoted around the People's Republic of China. The Xinjiang and Yunnan borderlands, then, are not just exceptional, marginal, out-of-the-way places. On the contrary, these borderlands offer a glimpse into the past, present and future of China. Of its relations with neighbouring countries. Of its evolving role across Asia and the world. 



\section{Bibliography}

Aamir, Adnan. 2018. "Beijing Engages with Pakistan's Uighurs in 'Charm Offensive'.” Nikkei Asian Review, 31 October, 2018: https://asia.nikkei.com/Politics/International-relations/ Beijing-engages-with-Pakistan-s-Uighurs-in-charm-offensive (accessed May 2019).

Abraham, I.; Van Schendel, W. 2005. "Introduction: The Making of Illicitness." In: W. Van Schendel and I. Abraham (eds.) Illicit Flows and Criminal Things: States, Border, and the Other Side of Globalization. Bloomington, IN: Indiana University Press, 1-37.

Agence France-Press (AFP). 2017. "Ghost Cities Haunt Stability Dream in China's Far West". $A F P$, September 4, 2017: https://www.scmp.com/news/china/economy/article/2109555/ ghost-cities-haunt-stability-dream-chinas-far-west (accessed May 2019).

Agnew, John. 1987. Place and Politics: The Geographical Mediation of State and Society. London and New York: Routledge.

Ahlers, A. L.; Schubert, G. 20o9. “'Building a New Socialist Countryside': Only a Political Slogan?” Journal of Current Chinese Affairs 38: 35-62.

Ahlers, A. L.; Schubert, G. 2013. 'Strategic Modelling: 'Building a New Socialist Countryside' in Three Chinese Counties.” China Quarterly 216: 831-849.

Al Jazeera News. 2018a. “Imran Khan's Speech in Full.” Al Jazeera News, 26 July 2018: https:// www.aljazeera.com/news/2018/o7/imran-khan-speech-full-180726124850706.html (accessed May 2019).

Al Jazeera News. 2018b. “Inside China's Internment Camps: Tear Gas, Tasers and Textbooks.” Al Jazeera News, 24 October 2018: https://www.aljazeera.com/news/2018/10/china-internmentcamps-tear-gas-tasers-textbooks-181024080527871.html (accessed May 2019).

Alff, H. 2016a. "Flowing Goods, Hardening Borders? China's Commercial Expansion into Kyrgyzstan Re-examined." Eurasian Geography and Economics 57 (3): 433-456.

Alff, Henryk. 2016b. "Trading on Change: Bazaars and Social Transformation in the Borderlands of Kazakhstan, Kyrgyzstan and Xinjiang." In Martin Saxer and Juan Zhang (eds.) The Art of Neighbouring: Making Relations Across China's Borders. Amsterdam: Amsterdam University Press, 95-119.

Alff, Henryk. 2016c. "Getting Stuck within Flows: Limited Interaction and Peripheralisation at the Kazakhstan-China Border." Central Asian Survey 35(3):369-86.

Alpermann, B. 2001. "The Post-Election Administration of Chinese villages." The China Journal 46: $45^{-67}$.

Anagnost, Ann. 1997. National Past-Times: Narratives, Representation, and Power in Modern China. Durham, NC: Duke University Press.

Anagnost, Ann. 2004. "The Corporeal Politics of Quality (suzhi)." Public Culture 16: 189-208.

Anagnost, Ann. 2013. "Introduction: Life-Making in Neoliberal Times." In: Ann Anagnost, Andrea Arai, and Hai Ren (eds). Global Futures in East Asia: Youth, Nation, and the New Economy in Uncertain Times. Palo Alto, CA: Stanford University Press.

Anand, N., Gupta, A., Appel, H. (eds.) 2018. The Promise of Infrastructure. Durham, NC and London: Duke University Press.

Anderson, Benedict. 1991. Imagined Communities: Reflections on the Origin and Spread of Nationalism (Revised and extended edn.). London: Verso

Anderson, John. 1876. Mandalay to Momien: A Narrative of the Two Expeditions to Western China of 1868 and 1975 under Colonel Edward B. Sladen and Colonel Horace Browne. London: Macmillian and Co. 
Arnold, J.; Ollivier, G.; Arvis, J. F. 2007. “Best Practices in Corridor Management.” Washington, DC: World Bank.

Asian Development Bank. 2016. "Review of Configuration of the Greater Mekong Subregion Economic Corridors.” Mandaluyong City, Philippines: Asian Development Bank: https:// www.adb.org/sites/default/files/institutional-document/214361/configuration-gms-corridors. pdf (accessed May 2019).

AsiaOne. 2014. "Chinese Troops on High Alert on Pamir Plateau." AsiaOne, 25 September 2014: http://news.asiaone.com/news/asia/chinese-troops-high-alert-pamir-plateau?page $=0 \% 2 \mathrm{Co}$ (accessed May 2019].

Atwill, David. 2005. The Chinese Sultanate: Islam, Ethnicity, and the Panthay Rebellion in Southwest China, 1856-1873. Stanford, CA: Stanford University Press.

Aviram, Ori. 2017. "Life on the Dulong River: Stepping towards the present." Go Kunming, 2 June 2017: https://www.gokunming.com/en/blog/item/3957/life-on-the-dulong-river-steppingtowards-the-present (accessed May 2019).

Bakken, B. 2000. The Exemplary Society: Human Improvement, Social Control, and the Dangers of Modernity in China. New York: Oxford University Press.

Barabantseva, E. 2005. "The Party-State's Transnational Outreach: Overseas Chinese Policies of the PRC's Central Government." Greater China Occasional Papers, No. 2. Available online: http://www.uni-tuebingen.de/uploads/media/2.pdf (accessed May 2019)

Barber, Elizabeth. 1999. The Mummies of Urumqi. New York and London: Norton and Company.

Barker, Memphis. 2018. "Chinese crackdown separates Pakistani husbands from Uighur wives." The Guardian, 15 March 2018: https://www.theguardian.com/world/2018/mar/15/chinesecrackdown-separates-pakistani-husbands-from-uighur-wives (accessed May 2019).

Barney, K. 2009. "Laos and the Making of a 'Relational' Resource Frontier." The Geography Journal 175(2): 146-159.

Barry, Andrew. 2013. Material Politics: Disputes along the Pipeline. Malden and Oxford: Wiley Blackwell.

Baud, Michiel; Van Schendel, Willem. 1997. "Toward a Comparative History of Borderlands." Journal of World History 8 (2): 211-42.

Becquelin, Nicolas. 2000. "Xinjiang in the Nineties." The China Journal 44: 65-90.

Becquelin, Nicolas. 2004. "Staged Development in Xinjiang." The China Quarterly 178: 358-378.

Bellér-Hann, Ildikó. 2013. “The Bulldozer State: Chinese Socialist Development in Xinjiang.” In: Madeleine Reeves, Johan Rasanayagam, and Judith Beyer (eds.) Ethnographies of the State in Central Asia: Performing Politics. Bloomington, IN: Indiana University Press, 173-197.

Bellocq, Maylis. 2006. "The Cultural Heritage Industry in the PRC: What Memories are being Passed on? A Case Study of Tongli, a Protected Township in Jiangsu Province." China Perspectives 67:22-32.

Bendix, Regina; Eggert, Aditya; Peselmann, Arnkia; Meßling, Sven (eds.). 2012. Heritage Regimes and the State. Gottingen Studies on Cultural Property, Vol. 6. Gottingen: Gottingen University Press.

Bernstein, T.P.; Lü, X. 2000. "Taxation without Representation: Peasants, the Central and the Local States in Reform China." The China Quarterly 163: 742-63.

Bhabha, Homi. 1990. Nation and Narration. New York: Routledge.

Billé, F. 2017. "Skinworlds: Borders, Haptics, Topologies." Environment and Planning D: Society and Space 36(1): 6o-77.

Blum, Susan; Jensen, Lionel. 2002. China OffCenter: Mapping the Margins of the Middle Kingdom. Honolulu: University of Hawai'i press.

Bovingdon, G. 2001. “The History of the History of Xinjiang.” Twentieth-Century China 26(2): 95-139. 
Bovingdon, Gardner. 2010. The Uyghurs: Strangers in Their Own Land. New York: Columbia University Press.

Bovingdon, G.; Tursun, N. 2004. “Contested Histories.” In S. F. Starr (ed.). Xinjiang: China's Muslim Borderland. Armonk: M. E. Sharpe, 353-74.

Brophy, David. 2018. “China's Uyghur Repression.” Jacobin, 31 May 2018: https://www.jacobinmag. com/2018/05/xinjiang-uyghur-china-repression-surveillance-islamophobia (accessed May 2019).

Brunner, Hans-Peter. 2013. "What is Economic Corridor Development and What Can It Achieve in Asia's Subregions?” ADB Working Paper Series on Regional Economic Integration: https://www. adb.org/sites/default/files/publication/100110/reiwp-117-economic-corridor-development. pdf (accessed May 2019).

Bruns, B.; Migglebrink, J. (eds.) 2012. Subverting Borders: Doing Research on Smuggling and Small-Scale Trade. Wiesbaden: VS Verlag.

Bulag, Uradyn. 2002. The Mongols at China's Edge: History and the Politics of National Unity. Lanham, MD: Rowman \& Littlefield Publishers.

Bunin, Gene A. 2018. "How the 'Happiest Muslims in the World' are Coping with their Happiness." Art of Life in Chinese Central Asia, 31 July 2018: https:// livingotherwise.com/2018/07/31/ happiest-muslims-world-coping-happiness/ (accessed May 2019).

Burrell, Kathy. 2008. "Materialising the Border: Spaces of Mobility and Material Culture in Migration from Post-Socialist Poland.” Mobilities 3(3): 353-373.

Byler, Darren. 2017. "Imagining Re-Engineers Muslims in Northwest China." Milestones: Commentary on the Islamic World, 20 April 2017: https://www. milestonesjournal.net/photoessays/2017/4/20/imagining-re-engineered-muslims-in-northwest-china (accessed May 2019).

Byler, Darren. 2018. “China's Government Has Ordered a Million Citizens to Occupy Uighur Homes. Here's What They Think They're Doing." China File, 24 October 2018: http://www. chinafile.com/reporting-opinion/postcard/million-citizens-occupy-uighur-homes-xinjiang (accessed May 2019).

Byler, Darren; Zolin, Nicola. 2017. “Uyghur Migrant Life in the City during the 'People's War.” Youth Circulations, 22 October 2017: http://www.youthcirculations.com/blog/2017/10/22/ uyghur-migrant-life-in-the-city-during-the-peoples-war (accessed May 2019).

Byler, Darren; Grose, Timothy. 2018. “China's Surveillance Laboratory.” Dissent Magazine, 31 October 2018: https://www.dissentmagazine.org/online_articles/chinas-surveillancelaboratory (accessed May 2019).

Calanca, Paola; Wildt, François. 20o6. "Les frontières: Quelques termes-clés” [Frontiers: Some key terms]. Extrême-Orient, Extrême-Occident 28: 17-56.

Callahan, William A. 2009. "The Cartography of National Humiliation and the Emergence of China's Geobody." Public Culture 21 (1): 141-73.

Callahan, William A. 2016. “China's 'Asia Dream': The Belt Road Initiative and the New Regional Order." Asian Journal of Contemporary Politics 1(3): 1-18.

Campbell, Ben. 2010. "Rhetorical Routes for Development: A Road Project in Nepal." Contemporary South Asia 18 (3): 267-79.

Cappelletti, Alessandra. 2014. "Social Change in Kashgar from a Cultural and Religious Oasis along the Silk Road to the 'Dubai of Central Asia'." In: S. Han and P. Santangelo (eds.) Proceedings of the Social Changes in China Academic Workshop. Ariccia, Italy: Aracne Publishers, 12-23.

Cappelletti, Alessandra. 2015. “Socio-Economic Disparities and the Development Gap in Xinjiang." In: Anna Hayes and Michael Clarke (eds.) Inside Xinjiang: Space, Place and Power in China's Muslim Far Northwest. London: Routledge, 151-182.

Carse, Ashley. 2014. Beyond the Big Ditch: Politics, Ecology, and Infrastructure at the Panama Canal. Cambridge, MA: MIT Press. 
Carse, Ashley. 2017. "Keyword: Infrastructure: How a Humble French Engineering Term Shaped the Modern World." In: Penny Harvey, Caspar Bruun Jensen and Atsuro Morita, (eds.) Infrastructure and Social Complexity: A Companion. London and New York: Routledge, 27-39.

Carse, Ashley; Cons, Jason; Middleton, Townsend. 2018. "Preface: Chokepoints." Limn 10.

Cartier, Carolyn. 2001. “'Zone Fever,' the Arable Land Debate, and Real Estate Speculation: China's Evolving Land Use Regime and Its Geographical Contradictions." Journal of Contemporary China 10(28): 445-69.

CGTN. 2017. "Full Text of Xi Jinping keynote at the World Economic Forum." CGTN, 17 January 2017: https://america.cgtn.com/2017/01/17/full-text-of-xi-jinping-keynote-at-the-worldeconomic-forum (accessed May 2019).

Chabal, Patrick; Daloz, Jean-Pascal. 1999. Africa Works: Disorder as Political Instrument. Bloomington and Indianapolis, IN: Indiana University Press.

Chalfin, Brenda. 2001. "Working the Border: Constructing Sovereignty in the Context of Liberalization." Political and Legal Anthropology Review 24(1): 129-148.

Chalfin, Brenda. 2010. Neoliberal Frontiers: An Ethnography of Sovereignty in West Africa. Chicago, IL: University of Chicago Press.

Chang, Wen-chin. 2009. "Venturing into 'Barbarous' Regions: Transborder Trade among Migrant Yunnanese between Thailand and Burma, 1960s-1980s." The Journal of Asian Studies 68 (2): $543-572$.

Chang, Wen-chin. 2011. "From a Shiji Episode to the Forbidden Jade Trade during the Socialist Regime in Burma." In: Eric Tagliacozzo and Wen-Chin Chang (eds.) Chinese Circulations: Capital, Commodities, and Networks in Southeast Asia. Durham, NC and London: Duke University Press, $455^{-478 .}$

Chang Wen-chin. 2014. Beyond Borders: Stories of Yunnanese Chinese. Ithaca, NY: Cornell University Press.

Chatterjee, Partha. 1986. Nationalist Thought and the Colonial World: A Derivative Discourse. London: Zed Books.

Che, Zhimin; Zhou, Naiguo (eds.) 1992. Yunnan duiwai tongdao ji kou'an (Yunnan's External Infrastructure Routes and Ports). Kunming: Yunnan People's Press.

Chen, Yangbin. 2016. "From Uncle Kurban to Brother Alim: the politics of Uyghur representations in Chinese state media." In: Anna Hayes and Michael Clarke (eds) Inside Xinjiang: Space, place and power in China's Muslim far Northwest. London and New York: Routledge, pp. 145-170.

Cheng, X. 1999. “Gaige kaifang yilai zhongguo zhengfu xuantai liuxuesheng de zhengce yange [The Evolution of Chinese Government's Policies on Selecting and Sending Students Abroad Since China's opening up]." Huaqiao huaren shi yanjiu [Overseas Chinese History Studies] 1: 37-44.

China News. 2013. "Xinjiang haiwai jiaoliu xiehui huanjie ji di er jie lishi dahui zhaokai (Xinjiang Overseas Exchange Association convenes for re-election and Second General Conference)." China News (Zhongguo xinwen wang), 19 August 2013: http://www.chinanews.com/ zgqj/2013/o8-19/5176811.shtml (accessed May 2019).

Chio, Jenny T. 2014. A Landscape of Trade: The Work of Tourism in Rural Ethnic China. Seattle, WA: University of Washington Press.

Chin, Tamara. 2013. "The Invention of the Silk Road, 1877." Critical Inquiry 40: 194-219.

Chouvy, Pierre-Arnaud (ed.) 2013. An Atlas of Trafficking in Southeast Asia: The Illegal Trade in Arms, Drugs, People, Counterfeit Goods and Natural Resources in Mainland Southeast Asia. London and New York: I. B. Tauris.

Christoffersen, G. 2007. "Islam and Ethnic Minorities in Central Asia: The Uyghurs.” In: Van Wie Davis and R. Azizian (eds.). Islam, Oil and Geopolitics: Central Asia After September 1. Lanham, MD: Rowman and Littlefield Publishers, 45-59. 
Clarke, Michael. 2007. "China's Internal Security Dilemma and the "Great Western Development": The Dynamics of Integration, Ethnic Nationalism and Terrorism in Xinjiang." Asian Studies Review $31(3): 323-342$.

Clarke, Michel; Smith, Douglas. 2016. China's Frontier Regions: Ethnicity, Economic Integration and Foreign Relations. London and New York: I.B. Tauris.

Cliff, T 2009, "Neo Oasis: The Xinjiang Bingtuan in the Twenty-first Century." Asian Studies Review 33(1): 83-106.

Cliff, T. 2013. "Peripheral Urbanism: Making History on China's Northwest Frontier." China Perspectives 3: 13-23.

Cliff, T 2016, Oil and Water: Being Han in Xinjiang. Chicago, IL: University of Chicago Press.

Comaroff, John; Comaroff, Jean. 20og. Ethnicity, Inc. Chicago, IL: Chicago University Press.

Conboy, Kenneth; Morrison, James. 2002. The CIA's Secret War in Tibet. Lawrence, KS: University Press of Kansas.

Cooley, J. 2002. Unholy Wars: Afghanistan, America and the International Terrorism. London: Pluto Press.

Cowen, Deborah. 2014. The Deadly Life of Logistics: Mapping Violence in Global Trade. Minneapolis, MN: University of Minnesota Press.

Cross, Jamie. 2014. Dream Zones: Anticipating Capitalism and Development in India. London: Pluto Press.

Crossman, Eileen. 2002 [1982]. Mountain Rain: The Biography of James O. Fraser. Bletchley: Authentic Media.

Dalakoglou D. 2012. “The Road from Capitalism to Capitalism': Infrastructures of (Post)Socialism in Albania." Mobilities 7(4): 571-86.

Dalakoglou, Dimitris; Harvey, Penny. 2012. "Roads and Anthropology: Ethnographic Perspectives on Space, Time and (Im) mobility." Mobilities 7 (4): 459-65.

Das, Veena; Poole, Deborah. 2004 (eds). Anthropology in the Margins of the State. Santa Fe, NM: School of American Research Press.

Dautcher, Jay. 2009. Down a Narrow Road: Identity and Masculinity in a Uyghur Community in Xinjiang China. Cambridge, MA: Harvard University Press.

De Angelis, M. 2004. "Separating the Doing and the Deed: Capital and the Continuous Character of Enclosures." Historical Materialism 12(2): 57-87.

Debarbieux, Bernard; Rudaz, Gilles. 2014. The Mountain: A Political History from the Enlightenment to the Present. Chicago, IL: The University of Chicago Press.

Deleuze, G. 1992. Postscript on the Societies of Control. October, Vol. 59:3-7.

Deleuze, G.; Guattari, F. 1987. A Thousand Plateaus: Capitalism and Schizophrenia. Minneapolis, $\mathrm{MN}$ and London: University of Minnesota Press.

Demenge, Jonathan P. 2013. "The Road to Lingshed: Manufactured Isolation and Experienced Mobility in Ladakh." Himalaya, the Journal of the Association for Nepal and Himalayan Studies 32 (1): Article 14.

Démurger, Sylvie. 2014. "Infrastructure in China." In: Shenggen Fan, Ravi Kanbur, Shang-jin Wei and Xiaobo Zhang (eds.) Oxford Companion to Economics of China. New York: Oxford University Press, $348-35^{2}$.

Derudder, Ben; Liu, Xingjian; Kunaka, Charles. 2018. "Connectivity Along Overland Corridors of the Belt and Road Initiative." Discussion Paper MTI Global Practice No. 6: http://documents. worldbank.org/curated/en/264651538637972468/pdf/130490-MTI-Discussion-Paper-6-Final. pdf (accessed May 2019).

Di Cosmo, Nicola. 1996. "Ancient Xinjiang Between Central Asia and China:The Nomadic Factor." Anthropology and Archaeology of Eurasia 34(4): 87-98. 
Dillon, M. (2004): Xinjiang: China's Muslim Far Northwest. London and New York: Routledge.

Dillon, Michael. 2014. Xinjiang and the Expansion of Chinese Communist Power: Kashgar in the Early Twentieth Century. London and New York: Routledge.

Donaldson, John A. 2009. "Why Do Similar Areas Adopt Different Developmental Strategies? A Study of Two Puzzling Chinese Provinces." Journal of Contemporary China 18(6o): 421-444. Donaldson, John A. 2011. Small Works: Poverty and Economic Development in Southwest China. Ithaca, NY: Cornell University Press.

Dong, Min; He, Jun. 2018. "Linking the Past to the Future: A Reality Check on Cross-Border Timber Trade from Myanmar (Burma) to China." Forest Policy and Economics 87:11-19.

Dreyer, J. 1993. China's Political System: Modernization and Tradition. New York: Paragon House.

Dreyer, J. 2000. “Ethnicity and Economic Development in Xinjiang." Inner Asia 2: 137-154.

Du, Fachun. 2012. "Ecological Resettlement of Tibetan Herders in the Sanjiangyuan: A Case Study in Madoi County of Qinghai." Nomadic Peoples 16(1): 116-133

Duara, Prasenjit. 1995. Rescuing History from the Nation: Questioning Narratives of Modern China. Chicago, IL: Chicago University Press.

Duchâtel, M. 2011. "The Terrorist Risk and China's Policy toward Pakistan: Strategic Reassurance and the 'United Front'." Journal of Contemporary China $20(71): 543-561$.

Duffield, M. 2001. Global Governance and the New Wars: The Merging of Development and Security. London: Zed Books.

Dunn, Elizabeth. Forthcoming. "Tunnel: Striating and Militarizing Subterranean Space in the Republic of Georgia.” In: Frack Billé (ed.). Voluminous States: Sovereignty, Materiality, and the Territorial Imagination. Durham, NC: Duke University Press.

Dwyer, M.; Vongvisouk, T. 2019. "The Long Land Grab: Market-Assisted Enclosure on the China-Lao Rubber Frontier." Territory, Politics, Governance 7(1): 96-114.

Eilenberg, Michael. 2014. "Frontier Constellations: Agrarian Expansion and Sovereignty on the Indonesian-Malaysian Border." The Journal of Peasant Studies 41(2): 157-182.

Eilenberg, Michael; Wadley, Reed. 20og. "Borderland Livelihood Strategies: The Socio-Economic Significance of Ethnicity in Cross-Border Labour Migration, West Kalimantan, Indonesia.” Asia Pacific Viewpoint 50(1): $5^{8-73}$.

Elmer, Keegan. 2018. "Xinjiang Camps: China Takes Its Defence of 'Re-education Centres' Overseas with Pakistan Meeting." South China Morning Post, 17 October 2018: https://www.scmp. com/news/china/diplomacy/article/2168932/xinjiang-camps-china-takes-its-defence-reeducation-centres (accessed May 2019).

Evans, Grant; Hutton, Christopher and Kuah Khun Eng (eds.). 20oo. Where China Meets Southeast Asia: Social \& Cultural Change in the Border Regions. White Lotus: Bangkok; Institute of Southeast Asian Studies: Singapore.

Fair, Christine. 2017. “Pakistan Can't Afford China's 'Friendship”'. Foreign Policy, 3July 2017: https:// foreignpolicy.com/2017/o7/o3/pakistan-cant-afford-chinas-friendship/ (accessed May 2019).

Fan, Hongwei. 2012. "The 1967 Anti-Chinese Riots in Burma and Sino-Burmese Relations." Journal of Southeast Asian Studies 43(2): 234-256.

Fan, M.; Li, Y.; Li, W. 2015. "Solving One Problem by Creating a Bigger One: The Consequences of Ecological Resettlement for Grassland Restoration and Poverty Alleviation in Northwestern China." Land Use Policy, 42: 124-130.

Farquhar, J. 2002. Appetites: Food and Sex in Postsocialist China. Durham, NC: Duke University Press. Farquhar, J. 2005. "Biopolitical Beijing: Pleasure, Sovereignty and Self-Cultivation in China's capital." Cultural Anthropology $20(3): 303^{-27}$.

Ferguson, James. 2015. Give a Man a Fish: Reflections on the New Politics of Distribution. Durham, NC and London: Duke University Press. 
Ferguson, James; Gupta, Akhil. 2002. "Spatializing States: Toward an Ethnography of Neoliberal Governmentality." American Ethnologist 29(4): 981-1002.

Fischer, Andrew. 2009. "The Political Economy of Boomerang Aid in China's Tibet." China Perspectives, 2009 (3), 38-54.

Fischer, Andrew. 2014. The Disempowered Development of Tibet in China: a Study in the Economics of Marginalization. (Studies of the Weatherhead East Asian Institute, Columbia University). Lanham, MD: Lexington (Rowman and Littlefield)

Fischer, Andrew. 2015. "Subsidizing Tibet: An Interprovincial Comparison of Western China up to the End of the Hu-Wen Administration." The China Quarterly 221: 1-27.

Fiskesjö, Magnus. 2006. "Rescuing the Empire: Chinese Nation-Building in the Twentieth Century." European Journal of East Asian Studies 5(2): 15-44.

Fiskesjö, Magnus, 2010. "Mining, History, and the Anti-State Wa: The Politics of Autonomy between Burma and China." Journal of Global History 5: 241-264.

Ford, Michele; Lyons, Lenore; Van Schendel, Willem (eds.) 2012. Labour Migration and Human Trafficking in Southeast Asia: Critical perspectives. London and New York: Routledge.

Foucault, Michel. 1979a. "On governmentality." Ideology and Consciousness 6: 5-19.

Foucault, Michel. 1979b. Discipline and Punish: the Birth of the Prison. New York: Vintage

Foucault, Michel. 1982. "The Subject and Power." Critical Inquiry 8(4): 777-795.

Foucault, Michel. 1991 [1978]. “Governmentality.” In: G. Burchell, C. Gordon, and P. Miller (eds.), The Foucault Effect: Studies in Governmentality. Chicago, IL: University of Chicago Press, pp. 87-104.

Foucault, Michael. 1996 [1984]. “An Aesthetics of Existence.” In: Sylvère Lotringer (ed.). Foucault Live: Collected Interviews, 1961-1984. New York: Semiotext(e).

Flower, John M. 2004. "A Road Is Made: Roads, Temples, and Historical Memory in Ya'an County, Sichuan." The Journal of Asian Studies 63(3): 649-685.

Fravel, Taylor. 2008. Strong Borders, Secure Nation: Cooperation and Conflict in China's Territorial Disputes. Princeton, NJ: Princeton University Press.

Fuller, G.E.; Lipman, J.N. 2004. “Islam in Xinjiang.” In Starr, S. (ed.). Xinjiang: China's Muslim Borderland. New York and London: M.E. Sharpe, 320-352.

Galemba, R. 2013. "Illegality and Invisibility at Margins and Borders." PoLAR 36 (2): 274-285.

Geertz, C. 1978. "The Bazaar Economy: Information and Searching in Peasant Marketing." American Economic Review 68: 28-32.

Gellner, Ernest. 1983. Nations and Nationalism. Ithaca, NY: Cornell University Press.

Gellner, D.N. (ed.). 2013. Borderland Lives in Northern South Asia. Durham, NC and London: Duke University Press.

Gibson, Richard M.; Chen, Wenhua. 2011. The Secret Army: Chiang Kai-shek and the Drug Warlords of the Golden Triangle. Singapore: John Wiley.

Gidwani, Vinay. 20o8. Capital, Interrupted: Agrarian Development and the Politics of Work in India. Minnesota University Press.

Giersch, C. Patterson. 2006. Asian Borderlands: The Transformation of Qing China's Yunnan Frontier. Cambridge, MA: Harvard University Press.

Giersch, C. Patterson. 2010. "Across Zomia with Merchants, Monks, and Musk: Process Geographies, Trade Networks, and the Inner-East-Southeast Asian borderlands." Journal of Global History 5(2): 215-239.

Gill, William. 1883. The River of Golden Sand:Being the Narrative of a Journey through China and Eastern Tibet to Burma. London: John Murray.

Gladney, Dru. 1991. Muslim Chinese: Ethnic Nationalism in the People's Republic. Cambridge, MA: Harvard University Press. 
Gladney, Dru. 1994. "Representing Nationality in China: Refiguring Majority/Minority Identities.” The Journal of Asian Studies 53(1): 92-123.

Gladney, Dru. 1998. "Internal Colonialism and the Uyghur Nationality: Chinese Nationalism and its Subaltern Subjects." Cahiers d'études sur la Méditerranée orientale et le monde turco-iranien [Online], 25, URL: http://journals.openedition.org/cemoti/48 (accessed May 2019).

Gladney, Dru. 2004. Dislocating China:Muslims, Minorities, and Other Subaltern Subjects. Chicago, IL: University of Chicago Press.

Global Times. 2018. "1.1 million civil servants in Xinjiang pair up with ethnic minority residents to improve unity." Global Times, 7 November 2018: http://www.globaltimes.cn/content/1126378. shtml (accessed May 2019).

Global Witness. 2005. A Choice for China: Ending the Destruction of Burma's Northern Frontier Forests. London, UK.

Goodman, David. 2004. "The Campaign to "Open Up the West": National, Provincial-level and Local Perspectives." The China Quarterly 178: 317-334.

Gootenberg, Paul. 2005. "Talking Like a State: Drugs, Borders, and the Language of Control." In: Willem van Schendel and Itty Abraham (eds.) Illicit Flows and Criminal Things: States, Borders, and the Other Side of Globalization. Bloomington, IN: Indiana University Press, 101-127.

Green, Sarah. 2005. Notes from the Balkans: Locating Marginality and Ambiguity on the GreekAlbanian Border. Princeton, NJ and Oxford: Princeton University Press.

Green, Sarah. 2009. "Lines, Traces and Tidemarks: Reflections on Forms of Borderlines". EastBordNet, COST Action ISo8oz Working Paper.

Green, S. 2012. "A Sense of Border." In Wilson, T.M., and H. Donnan (eds.) A Companion to Border Studies. Chichester: Wiley-Blackwell, 573-592.

Greenhalgh, S. and Winckler, E.A. 2005. Governing China's Population:From Leninist to Neoliberal Biopolitics. Stanford, CA: Stanford University Press.

Gregory, Christopher. 2015. Gifts and Commodities (Second Edition). Chicago, IL: HAU Books.

Grewal, Bhajan; Ahmed, Abdullahi. 2011. "Is China's Western Region Development Strategy on Track? An Assessment." Journal of Contemporary China 2o(69): 161-181.

Gros, Stéphane. 2004. "The Politics of Names: The Identification of the Dulong (Drung) of Northwest Yunnan." China information 18(2): 275-302.

Gros, Stéphane. 2010. "Economic Marginalization and Social Identity among the Drung People of Northwest Yunnan." In: J. Michaud and T. Forsyth (eds.) Moving Mountains: Highland Livelihood and Ethnicity in China, Vietnam, and Laos. Vancouver: University of British Columbia Press, 28-49.

Gros, Stéphane. 2014. "The Bittersweet Taste of Rice: Sloping Land Conversion and the Shifting Livelihoods of the Drung in Northwest Yunnan (China)." Himalaya, the Journal of the Association for Nepal and Himalayan Studies 34 (2): 81-96.

Gros, Stéphane. 2016. "Introduction to "Frontier Tibet: Trade and Boundaries of Authority in Kham."” Cross-currents e-Journal (no. 19): https://cross-currents.berkeley.edu/e-journal/ issue-19/gros-intro (accessed May 2019).

Gros, Stéphane. 2017. "Nature De-naturalised: Modes of Relation with the Environment among the Drung of Northwest Yunnan (China)." Anthropological Forum, DOI: 10.1080/00664677.2017.1297221.

Grose, Timothy. 2019. "Once Their Mental State Is Healthy, They Will Be Able to Live Happily in Society'." ChinaFile, 2 August 2019: http://www.chinafile.com/reporting-opinion/viewpoint/ once-their-mental-state-healthy-they-will-be-able-live-happily-society.

Guyer, Jane. 2016. Legacies, Logics, Logistics: Essays in the Anthropology of the Platform Economy. Chicago, IL: Chicago University Press. 
Habermas, J. 1981. Theorie des kommunikativen Handelns. Frankfurt am Main: Suhrkamp Verlag. Haider, Z. 2005. “Sino-Pakistan Relations and Xinjiang's Uighurs: Politics, Trade, and Islam along the Karakoram Highway". Asia Survey 45(4): 522-545.

Haines C. 2012. Nation, Territory and Globalization in Pakistan: Traversing the Margins. New York: Routledge.

Hameiri, Shahar; Jones, Lee; Zou, Yizheng. 2018. “The Development-Insecurity Nexus in China's Near-Abroad: Rethinking Cross-Border Economic Integration in an Era of State Transformation." Journal of Contemporary Asia 49(3): 473-499.

Han, Enze. 2016. Borderland Ethnic Politics and Changing Sino-Myanmar Relations. In: Mandy Sadan (ed.). War and Peace in the Borderlands of Myanmar: The Kachin Ceasefire, 1994-2011. Copenhagen: NIAS Press.

Han, Enze. 2017. "Geopolitics, Ethnic Conflicts along the Border, and Chinese Foreign Policy Changes toward Myanmar." Asian Security 13(1): 59-73.

Han, Enze. 2019. "The Chinese Civil War and Implications for Borderland State Consolidation in Mainland South-East Asia." The China Quarterly, 1-22. DOI: 10.1017/So305741019000729.

Hankins, Joseph. 2014. Working Skin: Making Leather, Making a Multicultural Japan. Berkeley, CA: University of California Press.

Hansen, Valerie. 2012. The Silk Road: A New History. Oxford and New York: Oxford University Press. Hardt, Michael; Negri, Antonio. 200o. Empire. Cambridge, MA: Harvard University Press.

Harrell, S. (ed.) 1995. Cultural Encounters on China's Ethnic Frontiers. Seattle, WA and London: University of Washington Press.

Harrell, Stevan. 2013. “China's Tangled Web of Heritage.” In: Tami Blumenfield and Helaine Silverman (eds.) Cultural Heritage Politics in China. New York: Springer, 285-294.

Harris, T. 2017. "The Mobile and the Material in the Himalayan Borderlands." In M. Saxer and J. Zhang (eds.) The Art of Neighbouring: Making Relations Across China's Borders. Amsterdam: Amsterdam University Press, 145-163.

Harris, Tina. 2018. "Cross-Border Commodities: Processual Histories, Commodity Chains, and the Yak Tail trade”. In: Horstmann, A., Saxer, M., Rippa, A. (eds). Routledge Handbook of Asian Borderlands. London and New York: Routledge, 104-113.

Harvey, David. 1989. The Condition of Postmodernity: An Enquiry into the Origins of Cultural Change. Cambridge, MA: Blackwell.

Harvey, David. 2005. A Brief History of Neoliberalism. Oxford: Oxford University Press.

Harvey, P. 2005. "The Materiality of State Effects: An Ethnography of a Road in the Peruvian Andes." In: Krohn-Hansen, C., and K.G. Nustad (eds.). State formation: anthropological perspectives. London: Pluto, 123-141.

Harvey, P., and H. Knox. 2012. "The Enchantments of Infrastructure." Mobilities 7(4): 521-536.

Harvey, Penny; Knox, Hannah. 2015. Roads. An Anthropology of Infrastructure and Expertise. Ithaca, NY and London: Cornell University Press.

Harvey, P.; Jensen, C.B.; Morita, A. (eds.) 2017. Infrastructure and Social Complexity: A Companion. London and New York: Routledge.

Harwood, R. 2013. China's New Socialist Countryside: Modernity Arrives in the Nu River Valley. Seattle, WA: University of Washington Press.

Hathaway, Michael. 2013. Environmental Winds: Making the Global in Southwest China. Berkeley, CA: University of California Press.

Heggelund, G. 2003. Environment and Resettlement Politics in China: The Three Gorges Project. Burlington, NY: Ashgate.

Hill, Ann Maxwell. 1998. Merchants and Migrants: Ethnicity and Trade among Yunnanese Chinese in Southeast Asia. New Haven, CT: Yale University. 
Hinton, P. 1998. Resource Management in the Yunnan Mekong Basin. Working Paper No. 72, Asia Research Centre or Murdoch University.

Hinton, P. 200o. "Where Nothing Is at It Seems: Between Southeast China and Mainland Southeast Asia in the "Post-Socialist" Era." In: Evans, Grant; Hutton, Christopher and Kuah Khun Eng (eds.) Where China Meets Southeast Asia: Social \& Cultural Change in the Border Regions. White Lotus, Bangkok; Institute of Southeast Asian Studies, Singapore, 7-27.

Ho, K. 2009. Liquidated:An Ethnography of Wall Street. Durham, NC and London: Duke University Press.

Hodder, R. 1996. Merchant Princes of the East: Cultural Delusions, Economic Success and the Overseas Chinese in Southeast Asia. London: John Wiley.

Hoffman, L. M. 2006. "Autonomous Choices and Patriotic Professionalism: On Governmentality in Late-Socialist China." Economy and Society 35(4), 550-70.

Holbig, H. 2004. "The Emergence of the Campaign to Open Up the West: Ideological Formation, Central Decision-Making and the Role of the Provinces." China Quarterly 178: 335-357.

Holmes, R. A. 1972. "Burma's Foreign Policy Toward China since 1962." Pacific Affairs, 45(2), 240-254. doi:10.2307/2755554.

Hope, Albie; Cox, John. 2015. "Development Corridors.” EPS-PEAKS Topic Guide: https://assets. publishing.service.gov.uk/media/57ao8995e5274a31eoooo16a/Topic_Guide_Development_Corridors.pdf (accessed May 2019).

Hopkirk P. 1992. The Great Game: The Struggle for Empire in Central Asia. New York: Kodansha International.

Horstmann, A., Saxer, M., Rippa, A. (eds.). 2018. Routledge Handbook of Asian Borderlands. London and New York: Routledge.

Hsing, You-tien. 2010. The Great Urban Transformation: Politics of Land and Property in China. Oxford: Oxford University Press.

Human Rights Watch. 2018. "China: Big Data Fuels Crackdown in Minority Region." Human Rights Watch, 26 February 2018: https://www.hrw.org/news/2018/o2/26/china-big-data-fuelscrackdown-minority-region (accessed May 2019).

Humphrey C. 2005. “Ideology in Infrastructure: Architecture and Soviet Imagination.” Journal of the Royal Anthropological Institute 11(1):39-58.

Ingold, T. 2007. Lines: A Brief History. London and New York: Routledge.

Ingold, T. 2009. “Against Space: Place, Movement, Knowledge.” In: P. Kirby (ed.), Boundless Worlds: An Anthropological Approach to Movement. Oxford, United Kingdom: Berghahn Books, 29-43.

Ingold, T. 2011. Being Alive: Essays on Movement, Knowledge and Description. London and New York: Routledge.

Ishikawa, Noboru. 2010. Between Frontiers: Nation and Identity in a Southeast Asian Borderland. Athens, OH: Ohio University Press.

Ispahani, M. Z. 1989. Roads and Rivals: The Politics of Access in the Borderlands of Asia. London: I.B. Tauris \& Co.

Jeffreys, Elaine; Sigley, Gary. 20o9. “Governmentality, governance and China.” In: Jeffreys E (ed.). China's Governmentalities: Governing Change, Changing Government. New York: Routledge, 1-23.

Jeong, Jihyeon. 2015. “Ethnic Minorities in China's Western Development Plan.” Journal of International and Area Studies. 22: 1-18.

Johnson, Christopher K. 2016. “President Xi Jinping's 'Belt and Road' Initiative.” Center for Strategic \& International Studies: https://www.csis.org/analysis/president-xi-jinping's-belt-and-roadinitiative (accessed May 2019). 
Johnson, Reginald Fleming. 1908. From Peking to Mandalay: A Journey from North China to Burma through Tibetan Such'uan and Yunnan. New York: E.P. Dutton and Company.

Jones, Reece. 2012. Border Walls: Security and the War on Terror in the United States, India, and Israel. London: Zed books.

Joniak-Lüthi, Agnieszka. 2015. "Roads in China's Borderlands: Interfaces of Spatial Representations, Perceptions, Practices, and Knowledges.” Modern Asian Studies, Available at CJO 2015 doi:10.1017/Soo26749X1500013X.

Jonsson, Hjorleifur. 2014. Slow Anthropology: Negotiating Difference with the Iu Mien. Ithaca, NY: Cornell University Press.

Judd, E.R. 2002. The Chinese Women's Movement between State and Market. Stanford, CA: University Press.

Kachin Development Networking Group (KDNG). 2010. Tyrants, Tycoons and Tigers: Yuzana Company Ravages Burma's Hugawng Valley. Chiang Mai, Thailand: Kachin Development Networking Group.

Kahrl, Fredrich; Su, Yufang; Weyerhaeuser, Horst. 2004. Navigating the Border: An Analysis of the China-Myanmar Timber Trade. Washington, DC: Forest Trends.

Kahrl, Fredrich, Su Yufang, and Horst Weyerhaeuser. 2005. An Overview of the Market Chain for China's Timber Product Imports from Myanmar. Washington, DC: Forest Trends.

Karrar, H. 2013. "Merchants, Markets, and the State." Critical Asian Studies 45 (3): 459-480.

Karrar, H. 2019. "Between Border and Bazaar: Central Asia's Informal Economy." Journal of Contemporary Asia 49 (2). DOI: 10.1080/00472336.2018.1532017.

Kau, Michael Y. M.; Leung, John K. 1986. (eds.), The writings of Mao Zedong, 1949-1976: Vol. II, January 1956-December 1957. Armonk, NY: M. E. Sharpe, 43-66.

Khalid, M.M. 2006. History of Karakoram Highway, Volume I. Rawalpindi: Hamza Pervez Printers.

Khalid, M.M. 2009. History of Karakoram Highway, Volume II. Rawalpindi: Hamza Pervez Printers.

Khan, Wasif. 2018. Haunted by Chaos: China's Grand Strategy from Mao Zedong to Xi Jinping. Cambridge, MA: Harvard University Press.

Kinzley, Judd. 2018. Natural Resources and the New Frontier: Constructing Modern China's Borderlands. Chicago, IL: Chicago University Press.

Kipnis, Andrew. 2006. "Suzhi: A Keyword Approach.” The China Quarterly 185(2): 295-313.

Kipnis, Andrew. 2007. "Neoliberalism Reified: Suzhi Discourse and Tropes of Neoliberalism in the People's Republic of China." Journal of the Royal Anthropological Institute 13(2): 383-400.

Kipnis, Andrew. 2011. "Subjectification and Education for Quality in China." Economy and Society 40(2): 289-306.

Klimesh, Ondřej. 2018. “Advancing 'Ethnic Unity' and 'De-Extremization': Ideational Governance in Xinjiang under New Circumstances (2012-2017)." Journal ofChinese Political Science 23: 1-24.

Klingberg, Travis. 2017. "Geographies of the Geo-Body: On the Birth, Pathology and Life of Chinese Territoriality." Unpublished paper presented at the "On The Edge” workshop, Kandersteg, Switzerland, 11 October 2017.

Kobi, Madlen. 2016. Constructing, Creating, and Contesting Cityscapes: A Socio-Anthropological Approach to Urban Transformation in Southern Xinjiang, People's Republic of China. Wiesbaden: Harrassowitz Verlag.

Kohrman, M. (2004) "Should I Quit? Tobacco, Fraught Identity, and the Risks of Governmentality in Urban China." Urban Anthropology 33(2-4): 211-45.

Kramer, Tom; Woods, Kevin. 2011. The Political Economy of Northern Burma: Chinese Investment, Alternative Development and Dispossession. The Netherlands: Transnational Institute.

Kreutzmann, H. 1991. "The Karakoram Highway: The Impact of Road Construction on Moun tain Societies." Modern Asian Studies 25(4): 711-736. 
Kreutzmann, H. 1998. "The Chitral Triangle: Rise and Decline of Trans-montane Central Asian Trade, 1895-1935." asien afrika lateinamerika 26: 289-327.

Kreutzmann, Hermann. 2012. "Kirghiz in Little Kara Köl: The Forces of Modernisation in Southern Xinjiang." In: Hermann Kreutzmann (ed.) Pastoral Practices in High Asia. Agency of "Development" Effected by Modernisation, Resettlement and Transformation. Dordrecht: Springer.

Kreutzmann, H. 2015. Pamirian Crossroads: Kirghiz and Wakhi of High Asia. Wiesbaden: Harrassowitz Verlag.

Kunaka, C.; Carruthers, R. 2014. Trade and Transport Corridor Management Toolkit. Washington, DC: World Bank.

Kuo, Lily. 2019. "Revealed: New Evidence of China's Mission to Raze the Mosques of Xinjiang." The Guardian, 7 May 2019: https://www.theguardian.com/world/2019/may/o7/revealed-newevidence-of-chinas-mission-to-raze-the-mosques-of-xinjiang (accessed May 2019).

Kusakabe, K. 2009. “The Politics of 'Opening Up': Female Traders in the Borderlands of Cambodia, Laos, Thailand, and Burma (Myanmar)." In: M. Gainsborough (ed.). On the Borders of State Power: Frontier in the Great Mekong Sub-Region. New York: Routledge, 66-74.

Lamb, A. 1964. The China-India Border: The Origins of the Disputed Boundaries. London: Oxford University Press.

Lamb, A. 1968. Asian Frontiers: Studies in a Continuing Problem. New York: Frederick A. Praeger.

Lamb, A. 1973. The Sino-Indian Border in Ladakh. Canberra: Australian National University Press.

Larkin, Brian. 2013. "The Politics and Poetics of Infrastructure." Annual Review of Anthropology 42: 327-343.

Laruelle, M., and S. Peyrouse. 2012. The Chinese Question in Central Asia:Domestic Order, Social Change, and the Chinese Factor. London: Hurst.

Latour, Bruno. 1993. We Have Never Been Modern. London: Harvester Wheatsheaf.

Latour, Bruno. 1996. "On Interobjectivity." Mind, Culture, and Activity 3(4): 228-245.

Lary, Diana (ed.). 2007. The Chinese State at the Borders. Vancouver: University of British Columbia Press.

Lattimore, Owen. 1967 [1940]. Inner Asian Frontiers of China. Boston, MA: Beacon Press.

Leach, Edmund. 1960. "The Frontiers of 'Burma." Comparative Studies in Society and History $3(1): 49-68$.

Lefebvre, Henri. 1991. The Production of Space. Oxford and Cambridge: Blackwell.

Leibold, James. 2006. "Competing Narratives of Racial Unity in Republican China." Modern China 32 (2): 181-220.

Leibold, James. 2007. Reconfiguring Chinese Nationalism: How the Qing Frontier and Its Indigenes Became Chinese. New York: Palgrave Macmillan.

Leibold, James. 2019. "The Spectre of Insecurity: The CCP's Mass Internment Strategy in Xinjiang." China Leadership Monitor, 1 March 2019: https://www.prcleader.org/leibold.

Li, Dehua. 2013. "Bajisitan weiwu'er huaren shu lüe [A brief account of Uyghur Overseas Chinese in Pakistan]." Xinjiang difang zhi 3.

Li, Jinming. 2008. "Shengtai Baohu, Minzu Shengji Kechixu Fazhan Wenti Yanjiu. Yi Dulongjiang Diqu Dulongzu Wei Li (On the problem of environmental protection, subsistence, and sustainable development: The example of the Dulong people of the Dulong Valley area)." Yunnan Shehui Kexue 3: 81-85.

Li, Tania. 2007. The Will to Improve: Governmentality, Development, and the Practice of Politics. Durham, NC and London: Duke University Press.

Li, Yi. 2017. Chinese in Colonial Burma: A Migrant Community in a Multiethnic State. New York: Palgrave Macmillan. 
Li, Yuanchao. 2015. Toward Win-win Cooperation Through Amity, Sincerity, Mutual Benefit and Inclusiveness. 12 June 2015: https://www.fmprc.gov.cn/mfa_eng/wjdt_665385/zyjh_665391/ t1274296.shtml.

Li, Menghe. 2017. "Xian tu bu wei lu chuanqing: Guanyu Xinjiang shengchang jianshe bingtuan 1968 nian zhi 1978 nian yuan ba gongren de koushu shi (An oral history of Xinjiang bingtuan workers in Pakistan, 1968-1978)." Sichuan University, available at: http://xbkfy.scu.edu.cn/ uploadfile/kindeditor/file/20181107/20181107114801_331.pdf (accessed May 2019).

Li, Yuhui. 2018. China's Assistance Program in Xinjiang: A Sociological Analysis. Lanham, MD: Lexington Books.

Lin, Alice Ping-Hsiu. 2017. “Chinese in Pakistan: Diasporic Identity, Faith and Practice.” Asian Anthropology 16(2): 133-147, DOI: 10.1080/1683478X.2017.1322741.

Lin, Hsiao-Ting. 2009a. "Tribal Diplomacy and Frontier Territoriality in Modern China: Hunza and Nationalist China, 1947-1948" Journal of Modern Chinese History 3(1): 27-43.

Lin, Hsiao-Ting. 20ogb. "The Tributary System in China's Historical Imagination: China and Hunza, ca. 1760-1960." Journal of the Royal Asiatic Society 19(4): 489-507.

Lintner, Bertil. 199o. The Rise and Fall of the Communist Party of Burma (CPB). Ithaca, NY: Cornell University Press.

Lintner, Bertil. 1999. Burma in Revolt: Opium and Insurgency Since 1948. Chiang Mai: Silkworm Books.

Lipman, Jonathan N. 1997. Familiar Strangers: A History of Muslims in Northwest China. Seattle, WA: University of Washington Press.

Litzinger, Ralph. 2000. Other Chinas: The Yao and the Politics of National Belonging. Durham, NC: Duke University Press.

Liu, W. D.; Dunford, M. 2016. “Inclusive globalization: Unpacking China's Belt and Road Initiative.” Area Development and Policy 1(3): 323-40.

Looney, K. E. 2015. "China's Campaign to Build a New Socialist Countryside: Village Modernization, Peasant Councils, and the Ganzhou Model of Rural Development." China Quarterly, 224, 909-932.

Lyttleton, Chris. 2009. Build It and They Will Come: Lessons from the Northern Economic Corridor: Mitigating HIV and other diseases. Manila: Asian Development Bank

Ma Dazheng (ed.). 2000. Zhongguo Bianjiangjinlüe shi (A history of China's borderlands administration). Zhengzhou: Zhongzhou guji chubanshe.

Ma, Dazheng; Liu, Ti. 1998. Ershi shiji de Zhongguo bianjiang yanjiu:yimen fazhan zhongguo de bianyuan xueke de yanjin licheng (China's Borderlands Research in the Twentieth Century). Ha'erbin: Heilongjiang jiaoyu chubanshe.

Ma, Dazheng; Shan, Patrick Fuliang. 2012. "Frontier History in China: A Scholarly Dialogue across the Pacific Ocean." The Chinese Historical Review 19(1): 65-78, DOI: 10.1179/2048782

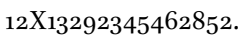

Mackerras, Colin. China's Minorities. Integration and Modernization in the Twentieth Century. Hong Kong, Oxford, New York: Oxford University Press, 1994.

Mallory, James P.; Mair, and Victor H. 200o. The Tarim Mummies: Ancient China and the Mystery of the Earliest Peoples from the West. London: Thames and Hudson.

Marcus, G. 1995. "Ethnography in/of the World System: The Emergence of Multi- Sited Ethnography." Annual Review of Anthropology 24: 95-117.

Marlow, Iain; Li, Dandan. 2018. "How Asia Fell out of love with China's Belt and Road Initiative." Bloomberg, 10 December 2018: https://www.bnnbloomberg.ca/how-asia-fell-out-of-love-withchina-s-belt-and-road-initiative-1.1181199 (accessed May 2019).

Marsden, M. 2015a. Trading Worlds: Afghan Merchants Across Modern Frontiers. London: Hurst \& Company. 
Marsden, M. 2015b. "From Kabul to Kiev: Afghan Trading Networks Across the Former Soviet Union." Modern Asian Studies 49 (4): 1-39.

Marsden, Magnus; Ibañez-Tirado, Diana; Henig, David. 2016. "Everyday Diplomacy: Introduction to Special Issue". Cambridge Journal of Anthropology 34 (2):2-22.

Massey, Doreen. 2005. For Space. Los Angeles, CA: SAGE.

McGranahan, Carole. 2010. Arrested Histories: Tibet, the CIA, and Memories of a Forgotten War. Durham, NC: Duke University Press.

McGrath, Thomas E., "A Warlord Frontier: The Yunnan-Burma Border Dispute, 1910-1937," Ohio Academy of History Proceedings, 2003, 7-29.

Megoran, Nick. 2017. Nationalism in Central Asia: A Biography of the Uzbekistan-Kyrgyzstan Boundary. Pittsburgh, PA: University of Pittsburgh Press.

Merkle, R. 2003. "Ningxia's Third Road to Rural Development: Resettlement Schemes as a Last Means to Poverty Reduction?" The Journal of Peasant Studies, 30, 160-191.

Michaud, Jean. 2010. "Editorial - Zomia and Beyond." Journal of Global History 5(2): 187-214.

Michell, George; Vicziany, Marika; Tsui Yen Hu; Gollings, John. 2008. Kashgar, Oasis City on China's Old Silk Road. London: Frances Lincoln Publishers.

Miller, Tom. 2017. China's Asian Dream: Empire Building along the New Silk Road. London: Zed Books.

Millward, J. 1998. Beyond the Pass: Economy, Ethnicity, and Empire in Qing Central Asia, 1759-1864. Stanford, CA: Stanford University Press.

Millward, J. 200o. "Historical Perspectives on Contemporary Xinjiang." Inner Asia 2(2): 121-135.

Millward, J. 2007. Eurasian Crossroads: A History of Xinjiang. New York: Columbia University Press.

Millward, James A. 2009. “Introduction: Does the 2009 Urumchi Violence Mark a Turning Point?" Central Asian Survey 28(4): 347-36o.

Millward, James. 2013. The Silk Road: A Very Short Introduction. Oxford and New York: Oxford University Press.

Ming, Zhonghai. 2016. “Tengchong kou'an zizhi tongdao shengji yan jiu baogao (Report on the Upgrading of the Tengchong Zizhi border crossing upgrade)." Modern Business Trade Industry $37(11)$.

Mitchell, T. 1999. "Society, Economy and the State Effect." In Steinmetz, G. (ed.). State/Culture: State Formation after the Cultural Turn. Ithaca, NY: Cornell University Press, 76-97.

Mitchell, T. 2002. Rule of Experts: Egypt, Techno-politics, Modernity. Berkeley, CA: University of California Press.

Moore, J. W. 200o. "Sugar and the Expansion of the Early Modern World Economy: Commodity Frontiers, Ecological Transformation, and Industrialization." Review - Fernand Braudel Center 23(3): 409-433.

Morris, J.; Polese, A. 2014. “Introduction: Informality - Enduring Practices, Entwined Livelihoods.” In: J. Morris and A. Polese (eds.) The Informal Post-Socialist Economy: Embedded Practices and Livelihoods. Oxford: Routledge, 1-18.

Moseley, George. 1973. The Consolidation of the South China Frontier. Berkeley, CA: University of California Press.

Mostowlansky, Till. 2017. Azan on the Moon: Entangling Modernity along Tajikistan's Pamir Highway. Pittsburgh, PA: University of Pittsburgh Press.

Mueggler, Erik. 2011. The Paper Road:Archive and Experience in the Botanical Exploration of West China and Tibet. Berkeley, CA: University of California Press.

Mullaney, Tom. 2010. Coming to Terms with the Nation: Ethnic Classification in Modern China. Berkeley, CA: University of California Press.

Murphy, R. 2004. "Turning Peasants into Modern Chinese Citizens: 'Population Quality' Discourse, Demographic Transition and Primary Education." The China Quarterly 177, 1-20. 
Murton, Galen; Lord, Austin. 2020. "Trans-Himalayan Power Corridors: Infrastructural Politics and China's Belt and Road Initiative in Nepal." Political Geography 77, DOI: https://doi. org/10.1016/j.polgeo.2019.102100.

NBC News. 2010. "Uighurs - Precariously Caught between Two Powers." NBC News. 9 November 2010: http://behindthewall.nbcnews.com/_news/2010/11/o9/5435051-uighurs-precariouslycaught-between-two-powers (accessed May 2019).

Ngo, T.-W.; Hung, E. 2019. “The Political Economy of Border Checkpoints in Shadow Exchanges.” Journal of Contemporary Asia 49 (2).

Nield, Robert. 2015. China's Foreign Places: The Foreign Presence in China in the Treaty Port Era, 1840-1943. Hong Kong: HKU Press.

Niu, Shaoyao (2001) "Zhuazhu zhongdian, chengshi er shang, wei ba Yunnan jiancheng Zhongguo lianjie Dongnanya Nanya guoji da tongdao er nuli fendou ('Grasp the main point, move on to the next level, struggle hard to make Yunnan the great international transit route connecting China and Southeast and South Asia')." in Yunnan Yearbook. Kunming: Yunnan Yearbook Press, 21-3.

Nordstrom, Carolyn. 200o. "Shadows and sovereigns." Theory, Culture and Society 17 (4):35-54. Nyíri , P. 1999. New Chinese Migrants in Europe: The Case of the Community in Hungary. Aldershot, Hants, England: Ashgate.

Nyíri , P. 2002. "From Class Enemies to Patriots: Overseas Chinese and Emigration Policy and Discourse in The People's Republic of China." In Nyíri , P., and I. Saveliev (eds.). Globalizing Chinese Migration: Trends in Europe and Asia. Aldershot: Ashgate, 208-241.

Nyíri, P.; Tan, Danielle. 2016. Chinese Encounters in Southeast Asia: How People, Money, and Ideas from China Are Changing a Region. Seattle, WA: Washington University Press.

Nyíri, Pál; Breidenbach, Joana. 2008. “The Altai Road: Visions of Development across the Russian-Chinese Border." Development and Change 39(1): 123-145.

O’Brien, K.J.; Li, L. 1999. “Selective Policy Implementation in Rural China.” Comparative Politics 31, 167-86.

O'Donnell, May Ann; Wong, Winnie; Bach, Jonathan. 2017. Learning from Shenzhen: China's Post-Mao Experiment from Special Economic Zone to Model City. Chicago, IL: The University of Chicago Press.

Oakes, Tim. 1998. Tourism and Modernity in China. London: Routledge.

Oakes, Tim. 2004. "Building a Southern Dynamo: Guizhou and State Power." The China Quarterly 178: $467-487$.

Oakes, Tim. 2012. "Heritage as Improvement: Cultural Display and Contested Governance in Rural China." Modern China 39(4): 380-407.

Ong, Aihwa. 2000. "Graduated Sovereignty in South-East Asia." Theory, Culture \& Society 17(4): 55-75.

Ond, Aihwa. 2006. Neoliberalism as Exception: Mutations in Citizenship and Sovereignty. Durham, NC: Duke University Press.

Ong, Aihwa. 2011. "Hyperbuilding: Spectacle, Speculation, and the Hyperspace of Sovereignty." In: Ananya Roy and Aihwa Ong (eds.) Worlding Cities: Asian Experiments and the Art of Being Global. Oxford: Wiley-Blackwell.

Ong, Aihwa; Zhang, Li. 2008. "Introduction: Privatizing China: Powers of the Self, Socialism from Afar.” In: Zhang, Li; Ong, Aihwa (eds). Privatizing China: Socialism from Afar. Ithaca, NY and London: Cornell University Press.

Ong, Aihwa; Collier, Stephen. 2005. Global Assemblages: Technology, Politics, and Ethics as Anthropological Problems. Oxford: Blackwell Publishing.

Osburg, John. 2013. “Global Capitalisms in Asia: Beyond State and Market in China.” The Journal of Asian Studies 72(4): 813-829. 
Paasi, A. 1999. "Boundaries as Social Processes: Territoriality in the World of Flows." Geopolitics $3(1): 69-88$.

Paasi, Anssi 2014. "Boundary: The Word, Concept and Practice (invited commentary, included as part of Mette Lovschal's article)." Current Anthropology 55(6): 42-43.

Pamir Times. 2013a. "Chinese Ambassador Visits Gojal Valley, Upper Hunza." Pamir Times, 15 October 2013: http://pamirtimes.net/2013/10/15/chinese-ambassador-visits-gojal-valleyupper- hunza/ (accessed May 2019).

Pamir Times. 2013b. "Hunza Will be "Gateway for Mega Development Projects", says Chinese Ambassador." Pamir Times, 15 October 2013: http://pamirtimes.net/2013/10/15/hunza-willgateway- mega-development-projects-says-chinese-ambassador/ (accessed May 2019).

Panah, M. 2014. A Comparison of the Border Communities of Pakistan and China. Pamir Times. http://pamirtimes.net/2014/10/15/comparison-border-communities-pakistan-china/ (accessed November 2014).

Pantucci, R.; Schwarck, E. 2014): Transition in Afghanistan: Filling the Security Vacuum: The Expansion of Uighur Extremism? CIDOB Policy Research Project.

Parham, Steven. 2017. China's Borderlands: The Faultline of Central Asia. New York: I. B. Tauris.

Pedersen MA. 2011. Not Quite Shamans: Spirit Worlds and Political Lives in Northern Mongolia. Ithaca, NY: Cornell University Press.

Pedersen, Morten Axel; Bunkenborg, Mikkel. 2012. "Roads that Separate: Sino-Mongolian Relations in the Inner Asian Desert." Mobilities 7 (4): 555-69.

Perdue, Peter. 2005. China Marches West: The Qing Conquest of Central Eurasia. Cambridge, MA: The Belknap Press of Harvard University Press.

Perry, E. J. 2011. "From Mass Campaigns to Managed Campaigns: 'Constructing a New Soicalist Countryside.'” In: S. Heilmann \& E. J. Perry (eds.) Mao's Invisible Hand: The Political Foundations of Adaptive Governance in China.. Cambridge, MA and London: Harvard Univeristy Asia Center, 30-61.

People's Daily. 2001. "Declaration of Shanghai Cooperation Organization", People's Daily, 15 June 2001: http://en.people.cn/english/200106/15/eng20010615_72738.html (accessed May 2019).

People's Daily. 2002. "East Turkistan Terrorist Forces Cannot Get Away with Impunity," People's Daily, 21 January 2002.

Permanent Mission of the People's Republic of China to the United Nations. 2001. "Terrorist Activities Perpetrated by 'Eastern Turkistan' Organizations and their Ties with Osama bin Laden and the Taliban." November 29: http://www.china-un.org/eng/zt/fk/t28937.htm (accessed May 2019).

Pieke, Frank. 2004. "Contours of an Anthropology of the Chinese State: Political Structure, Agency and Economic Development in Rural China." Journal of the Royal Anthropological Institute 10: 517-538.

Pieke, Frank. 2014. "Anthropology, China, and the Chinese Century." Annual Review of Anthropology $43: 123^{-138 .}$

Ptackova, Jarmila. 2016. "Making Space for Development: A Study on Resettlement from the Longyangxia Water Reservoir Area of Qinghai Province." Inner Asia 18: 152-166.

Pun, N. 2003. "Subsumption or Consumption? The Phantom of Consumer Revolution in 'Globalizing' China." Cultural Anthropology 18, 469-92.

Rabinow, P. 1984." Introduction." In P. Rabinow (ed.) The Foucault Reader. New York: Pantheon Books, 3-29.

Radio Free Asia. 2010. "Language School Shuts Down." Radio Free Asia, May 20, 2010: https:// www.rfa.org/english/news/uyghur/pressured-05192010164138.html (accessed May 2019). 
Radio Free Asia. 2011. "Pakistan: Uyghurs Face Travel Ban." Radio Free Asia, 23 June 2011: https:// www.refworld.org/publisher,RFA,PAK,4eoadeaoc,o.html (accessed May 2019).

Rahman, A. 2005. Sinicization Beyond the Great Wall: China's Xinjiang Uighur Autonomous Region. Leicester: Matador.

Ramzi, Austin; Buckley, Chris. 2019. “'Absolutely No Mercy': Leaked Files Expose How China Organized Mass Detentions of Muslims." New York Times, 16 November 2019: https://www. nytimes.com/interactive/2019/11/16/world/asia/china-xinjiang-documents.html (accessed February 2020).

Rasanayagam, J.; Beyer, J.; Reeves, M. 2014. “Introduction: Performances, Possibilities, and Practices of the Political in Central Asia." In: M. Reeves, J. Rasanayagam, and J. Beyer (eds.) Ethnographies of the State in Central Asia: Performing Politics. Bloomington, IN: Indiana University Press, 1-26.

Rashid, A. 2002. Jihad: The Rise of Militant Islam in Central Asia. New Haven, CT:Yale University Press. Reeves, Madeleine. 2014. Border Work: Spatial Lives of the State in Rural Central Asia. Ithaca, NY: Cornell University Press.

Rest, M.; Rippa, A. 2019. "Road Animist: Reflections of the Life of Infrastructure." HAU:Journal of Ethnographic Theory 9(2): 373-389.

Reuters. 2014. "China's President Warns against Growing Threats to National Security." Reuters, 26 April 2014: https://www.reuters.com/article/us-china-xi-security/chinas-president-warnsagainst-growing-threats-to-national-security-idUSBREA33PoDW20140426 (accessed May 2019).

Rezakhani, Khodadad. 2010. "The Road That Never Was: The Silk Road and Trans-Eurasian Exchange." Comparative Studies of South Asia, Africa and the Middle East 30(3): 420-433.

Rigby, R.; Taylor, B. 2014. "Whose Shared Destiny?" China Story Yearbook 2014: http://press-files. anu.edu.au/downloads/press/p328871/pdf/cho21.pdf (accessed May 2019).

Rigg, J. 2002. "Roads, Marketization and Social Exclusion in Southeast Asia. What do Roads do to People?" Bijdragen tot de Taal-, Land-en Volkennkunde 158(4): 619-636.

Rippa, A. 2014a. "Re-Writing Mythology in Xinjiang: The Case of the Queen Mother of the West, King $\mathrm{Mu}$, and the Kunlun." The China Journal 71: 43-64.

Rippa, A. 2014b. "From Uyghurs to Kashgaris (and back?): Migration and Cross-Border Interactions between Xinjiang and Pakistan." Crossroads Asia Working Paper Series, No. 23.

Rippa, A. 2015a. Cuore dell'Eurasia: Il Xinjiang dalla preistoria al 1949 [Heart of Eurasia:Xinjiang from prehistory to 1949]. Milano: Mimesis Edizioni.

Rippa, A. 2015b. Across the Khunjerab Pass: A Rhizomatic Ethnography along the Karakoram Highway, between Xinjiang (China) and Pakistan. University of Aberdeen, unpublished PhD thesis.

Rippa, A. 2017. "Centralising Peripheries: The Belt and Road Initiative and Its Role in the Development of the Chinese Borderlands." International Journal of Business Anthropology 7(1):1-21.

Rippa, A. 2018. “Old Routes, New Roads: Proximity across the China-Pakistan Border.” In: Horstmann, A., Saxer, M., Rippa, A. (eds.) Routledge Handbook of Asian Borderlands. London and New York: Routledge, 114-126.

Rippa, A. 2019a. "Cross-Border Trade and "the Market” between Xinjiang (China) and Pakistan." Journal of Contemporary Asia, DOI: 10.1080/00472336.2018.1540721.

Rippa, A. 2019b. "Zomia 2.o: Branding Remoteness and Neoliberal Connectivity in the Golden Triangle Special Economic Zone." Social Anthropology/Antropologie Sociale 27(2): 253-269.

Rippa, A. 2020. "Mapping the Margins of China's Global Ambitions: Economic Corridors, Silk Roads, and the end of Proximity in the Borderlands." Eurasian Geography and Economics 61(1): 55-76. 
Rippa, Alessandro; Saxer, Martin. 2016. 'Mong La: Business as Usual in the China-Myanmar Borderlands.' Cross-Currents: East Asian History and Culture Review 19: 240-52. https:// cross-currents.berkeley. edu/e-journal/issue-19/mong-la/essay (accessed 19 May 2017).

Rippa, A., Yang, Y. 2017. "The Amber Road: Cross-Border Trade and the Regulation of the Burmite Market in Tengchong, Yunnan.” TRaNS: Trans-Regional and-National Studies of Southeast Asia 5(2): 243-267.

Rippa, A., Murton, G., Rest, M. 2020. “Building Highland Asia in the 21st Century.” Verge: Studies in Global Asias (in print).

Rizvi, J. 1996. Ladakh: Crossroads of High Asia. Oxford: Oxford University Press.

Rizvi, J. 1999. Trans-Himalayan Caravans: Merchant Princes and Peasant Traders in Ladakh. Oxford: Oxford University Press.

Roberts, S.R. 2004. “A “Land of Borderlands”: Implication of Xinjiang's Trans-Border Interaction.” In: Starr, F. (ed.): Xinjiang: China's Muslim Borderland. New York and London: M.E. Sharpe, 216-237.

Roberts, S.R. 2012. "Imaginary Terrorism? The Global War on Terror and the Narrative of the Uyghur Terrorist Threat." Ponars Eurasia Working Paper. http://www.gwu.edu/ ieresgwu/ assets/docs/ponars/RobertsWP.pdf (accessed December 2014).

Roberts, Sean R. 2018. “The Biopolitics of China's 'War on Terror' and the Exclusion of the Uyghurs." Critical Asian Studies 50 (2): 232-258.

Rogers, S. 2014. "Betting on the Strong: Local Government Resource Allocation in China's Poverty Counties." Journal of Rural Studies, 36, 197-206.

Rogers, S.; Wang, M. 2006. "Environmental Resettlement and Social Dis/Re-Articulation in Inner Mongolia, China." Population \& Environment, 28, 41-68.

Rogers, S.; Li, J.; Lo, K.; Guo, H.; Li, C. 2019. “Moving Millions to Eliminate Poverty: China's Rapidly Evolving Practice of Poverty Resettlement”. Development Policy Review, DOI: https:// doi.org/10.1111/dpr.12435.

Rose, Archibald. 1912. "Chinese Frontiers of India." The Geographical Journal 39(3): 193-218.

Rose, Nikolas. 1999. Powers of Freedom: Reframing Political Thought. Cambridge: Cambridge University Press.

Rosenberg, L. 2015. "Why Do Local Officials Bet on the Strong? Drawing Lessons from China's Village Redevelopment Program." China Journal, 74.

Rossabi, Morris (ed.) 2004. Governing China's Multiethnic Frontiers. Seattle, WA: University of Washington Press.

Rousseau. Jean-François. 2014. “An Imperial Railway Failure: The Indochina-Yunnan Railway, 1898-1941." The Journal of Transport History 35(1): 1-17.

Rousseau. Jean-François. 2018. "A Failed Market Experiment and Ignored Livelihoods: Jatropha Expansion in the Sino-Vietnamese borderlands." In: Alexander Horstmann, Martin Saxer, Alessandro Rippa (eds.) Routledge Handbook of Asian Borderlands. London and New York: Routledge.

Ryder, C.H.D. 1903. "Exploration in Western China." The Geographical Journal 21(2): 109-120.

Ryzhova, N. 2018. "Invisible Trade: Sovereign Decisions on the Sino-Russian Border." In: A. Horstmann, A. Rippa, and M. Saxer (eds.) Routledge Handbook of Asian Borderlands. London: Routledge, 334-344.

Sadan, Mandy. 2010. "The Art of Not Being Governed: An Anarchist History of Upland Southeast Asia." Reviews in History no. 903.

Sadan, Mandy. 2013. Being and Becoming Kachin: Histories Beyond the State in the Borderworlds of Burma. Oxford: Oxford University Press.

Sadan, Mandy. 2015. “Ongoing Conflict in the Kachin State." Southeast Asian Affairs: 246-259. 
Sadan, Mandy (ed.). 2016. War and Peace in the Borderlands of Myanmar: The Kachin Ceasefire, 1994-2011. Copenhagen: NIAS Press.

Sahlins, Marshall. 1972. Stone age economics. Chicago, IL: Aldine-Atherton.

Saidula, Amier. 2014. A Last Refuge: National Law, Traditional Dispute Resolution and Tajik Experience in Xinjiang Today. University of Edinburgh, unpublished PhD thesis.

Samuel, Sigal. 2018. “China Is Treating Islam Like a Mental Illness.” The Atlantic, 28 August 2018: https://www.theatlantic.com/international/archive/2018/08/china-pathologizing-uighurmuslims-mental-illness/568525/ (accessed May 2019).

Saxer, Martin. 2009. "Herbs and Traders in Transit: Border Regimes and the Contemporary Trans-Himalayan Trade in Tibetan Medicinal Plants." Asian Medicine 5(2): 317-339.

Saxer, Martin. 2012. "The Moral Economy of Cultural Identity. Tibet, Cultural Survival, and the Safeguarding of Cultural Heritage", Civilisations 61 (1): 65-81.

Saxer, Martin. 2016a. "Pathways. A Concept, Field Site and Methodological Approach to Study Remoteness and Connectivity." Himalaya, the Journal of the Association for Nepal and Himalayan Studies 36(2): 104-119.

Saxer, Martin. 2016b. "A Spectacle of Maps Cartographic Hopes and Anxieties in the Pamirs." Cross-Currents e-journal 21: 111-136.

Saxer, Martin. Forthcoming. Place-Knots: Remoteness and Connectivity in the Himalayas and Beyond. Book manuscript in preparation.

Saxer, Martin; Andersson, Ruben. 2019. "The Return of Remoteness: Insecurity, isolation and Connectivity in the New World Disorder." Social Anthropology/Antropologie Sociale (accepted for publication).

Saxer, Martin; Zhang, Juan (eds.) 2016. The Art of Neighbouring: Making Relations Across China's Borders. Amsterdam: Amsterdam University Press.

Schein, Louisa. 1997. "Gender and Internal Orientalism in China." Modern China 23(1): 69-98.

Schein, Louisa. 200o. Minority Rules: The Miao and the Feminine in China's Cultural Politics. Durham, NC: Duke University Press.

Schmitz, Rob. 2017. "Who's Lifting Chinese People Out Of Poverty?" NPR, 17 January 2017: https:// www.npr.org/sections/goatsandsoda/2017/01/17/509521619/whos-lifting-chinese-people-outof-poverty (accessed May 2019).

Schoenberger, L.; Turner, S. 2008. "Negotiating Remote Borderland Access: Small-Scale Trade on the Vietnam-China Border." Development and Change 39(4): 667-696.

Schumpeter, Joseph A. 1934 [1926]. The Theory of Economic Development. Cambridge, MA: Harvard University Press.

Schüller , Margot; Schüller-Zhou, Yun. 2009. "China's Economic Policy in the Time of the Global Financial Crisis: Which Way Out?” Journal of Current Chinese Affairs 38(3): 165-181.

Schwenkel, Christina. 2015. "Spectacular Infrastructure and Its Breakdown in Socialist Vietnam." American Ethnologist 42(3): 520-534.

Scott, James C. 1985. Weapons of the Weak: Everyday Forms of Peasant Resistance. New Haven, CT and London: Yale University Press.

Scott, James C. 1990. Domination and the Arts of Resistance: Hidden Transcripts. New Haven, CT and London: Yale University Press.

Scott, James C. 1998. Seeing Like a State: How Certain Schemes to Improve the Human Condition Have Failed. New Haven, CT and London: Yale University Press.

Scott, James C. 2009. The Art of Not Being Governed: An Anarchist History of Upland Southeast Asia. New Haven, CT: Yale University Press.

Seagrave, S. 1995. Lords of the Rim: The Invisible Empire of the Overseas Chinese. New York: CP Putnam's Sons. 
Selth, Andrew. 2002. Burma's Armed Forces: Power without Glory. Norwalk, CT: Eastbridge.

Shan, Wei, and Weng Cuifen. 2013. "China's 'New Deal' in Xinjiang and Its Challenges." In: Gungwu Wang and Yong-Nian Zheng (eds.) China:Development and Governance. Singapore: World Scientific Publishing, 71-80.

Shen, Shicai, A. Wilkes, Jie Qian, Lun Yin, Jian Ren, and Fudou Zhang. 2010. "Agrobiodiversity and Biocultural Heritage in the Dulong Valley, China." Mountain Research and Development 30(3): $205^{-211 .}$

Shepherd, Robert. 2006 "UNESCO and the Politics of Cultural Heritage in Tibet." Journal of Contemporary Asia 36(2): 243-57.

Shi, W. (2009) Preliminary analysis of the Northern Plan. Vientiane: GTZ

Shichor, Y. 2004. "The Great Wall of Steel: Military and Strategy in Xinjiang." In: F. S. Starr (ed.) Xinjiang: China's Muslim Borderland. New York: M.E. Sharpe, 120-6o.

Shichor, Y. 2005. "Blow Up: Internal and External Challenges of Uyghur Separatism and Islamic Radicalism to Chinese Rule in Xinjiang." Asian Affairs: An American Review 32(2): 119-136.

Shields, Rob. 1999. Lefebvre, Love and Struggle: Spatial Dialectics. London and New York: Routledge.

Shih, Victor. 2004. "Development, the Second Time Around: The Political Logic of Developing Western China." Journal of East Asian Studies 4(3): 427-451.

Schneider, Friedrich; Enste, Dominik. 2002. The Shadow Economy. Cambridge: Cambridge University Press.

Shneiderman, S. 2013. "Himalayan Border citizen: Sovereignty and Mobility in the Nepal-Tibet Autonomous Region (TAR) of China Border Zone." Political Geography 35: 25-36.

Sidaway, James; Woon, Chih Yuan. 2017. "Chinese Narratives on 'One Belt, One Road' in Geopolitical and Imperial Contexts.” The Professional Geographer 0: 1-13.

Sigley, G. 1996. "Governing Chinese Bodies: The Significance of Studies in the Concept of Governmentality for the Analysis of Government in China." Economy and Society 25(4):457-82.

Sigley, Gary. 2013. "The Ancient Tea Horse Road and the Politics of Cultural Heritage in Southwest China: Regional Identity in the Context of a Rising China." In: Tami Blumenfield and Helaine Silverman (eds.) Cultural Heritage Politics in China. New York: Springer, 235-246.

Sigley, Gary. 2016. “From 'Backwater' to 'Bridgehead': Culture, Modernity and the Reimagining of Yunnan.” In: Clarke, Michel; Smith, Douglas. 2016. China's Frontier Regions: Ethnicity, Economic Integration and Foreign Relations. London and New York: I.B. Tauris, 171-203.

Sina. 2008. "Xīnjiāng hǎiwài jiāoliú xiéhuì wèiwèn bājīsītǎn huárén huáqiáo (Xinjiang Overseas Chinese Association salutes Pakistan's Overseas Chinese)." Sina, 17 July 2008: http://news. sina.com.cn/w/2008-07-17/163214178431s.shtml (accessed May 2019).

Small, Andrew. 2015. The China-Pakistan Axis: Asia's New Geopolitics. New York: Oxford University Press. Smith, Martin. 1991. Burma: Insurgency and the Politics of Ethnicity. London: ZED Books.

Solinger, Dorothy J. 1977. Regional Government and Political Integration in Southwest China, 1949-1954: A Case Study. Berkeley, CA: University of California Press.

Soja, E. 1985. 'The Spatiality of Social Life: Towards a Transformative Retheorisation'. In D. Gregory and J. Urry (eds.) Social Relations and Spatial Structures. London: Macmillan, 90-127.

Sökefeld, M. 2012. "The Attabad-Landslide and the Politics of Disaster in Gojal, Gilgit-Baltistan." In: U. Luig (ed.) Negotiating Disasters: Politics, Representation, Meanings. Frankfurt: Peter Lang, $175^{-204}$.

Su, Xiaobo. 2013. "From Frontier to Bridgehead: Cross-Border Regions and the Experience of Yunnan, China." International Journal of Urban and Regional Research 37(4): 1213-1232.

Srivastava, P. 2011. "Regional Corridors Development in Regional Cooperation." ADB Economics Working Paper Series: https://www.adb.org/sites/default/files/publication/28889/ewp-258. pdf (accessed May 2019). 
Starr, F. (ed.). 2004. Xinjiang: China's Muslim Borderland. New York \& London: M.E. Sharpe.

State Council of the PRC. 1985. "Guowuyuan guanyu kou'an kaifangde ruogan guiding" [Several provisions on the opening of border ports issued by the State Council of the PRC]. State Council, 18 September 1985 <http://www.gov.cn/zhengce/content/2013-01/o9/content_4803. htm $>$ (accessed December 2018).

State Council of the PRC. 2003. History and Development of Xinjiang. Available at: http://www. gov.cn/english/official/2005-07/28/content_17948.htm (accessed May 2019).

State Council of the PRC. 2009. Development and Progress in Xinjiang. Available at: http://www. china.org.cn/government/whitepaper/node_7077515.htm (accessed May 2019).

State Council of the PRC. 2015. Historical Witness to Ethnic Equality, Unity and Development in Xinjiang. Available at: http://english.gov.cn/archive/white_paper/2015/o9/24/content_281475197200182.htm (accessed May 2019).

Steenberg, Rune. 2014. "Network or Community? Two Tropes for Analysing Social Relations among Uyghur Traders in Kyrgyzstan." Crossroads Asia Working Paper Series 18.

Steenberg, Rune. 2016. "The Art of not Seeing like a State: On the Ideology of 'Informality'." Journal of Contemporary Central and Eastern Europe 24(3): 293-306.

Steenberg, R.; Rippa, A. 2019. "Development for all? State schemes, security and marginalisation in $21^{\text {st }}$-century Kashgar.” Critical Asian Studies 51(2): 274-295. DOI: 10.1080/14672715.2019.1575758.

Stein, Aurel M. 1904. Sand-Buried Ruins of Khotan:Personal Narrative of a Journey of Archaeological \& Geographical Exploration in Chinese Turkestan. London: T. Fisher Unwin.

Stein, A. 1907. Ancient Khotan:Detailed Report of Archaeological Explorations in Chinese Turkestan. Oxford: Clarendon Press.

Steinberg, D.; Fan, H. 2012. Modern China-Myanmar Relations: Dilemmas of Mutual Dependence. Copenhagen: NIAS Press.

Sturgeon, Janet C. 2005. Border Landscapes: The Politics of Akha Land Use in China and Thailand. Seattle, WA: University of Washington Press.

Summers, Tim. 2012. "(Re)positioning Yunnan: Region and Nation in Contemporary Provincial Narratives." Journal of Contemporary China 21(75): 445-59.

Summers, Tim. 2013. Yunnan-A Chinese Bridgehead to Asia: A Case Study of China's Political and Economic Relations with Its Neighbours. Cambridge: Chandos Publishing.

Sun, Y. 2012. "China's Strategic Misjudgement on Myanmar." Journal of Current Southeast Asian Affairs 31(1): 73-96.

Swanson, Ana. 2015. "How China used more cement in 3 years than the U.S. did in the entire 2oth Century." The Washington Post, 25 March 2015: https://www.washingtonpost.com/ news/wonk/wp/2015/03/24/how-china-used-more-cement-in-3-years-than-the-u-s-did-inthe-entire-2oth-century/?utm_term=.5c49fe3c7bo8 (accessed May 2019).

Tagliacozzo, Eric. 2005. Secret Trades, Porous Borders: Smuggling and States Along a Southeast Asian Frontier, 1865-1915. New Haven, CT: Yale University Press.

Tagliacozzo, Eric; Chang, Wen-chin. 2011. Chinese Circulations: Capital, Commodities, and Networks in Southeast Asia. Durham, NC and London: Duke University Press.

Tan, Y.;Zuo, A.; Hugo, G. 2013 "Environment-Related Resettlement in China: A Case Study of the Ganzi Tibetan Autonomous Prefecture in Sichuan Province." Asian and Pacific Migration Journal, 22, 77-107.

Thampi, M. 2010. Indian Traders in Xinjiang in the Nineteenth and Twentieth Centuries. China Report 46(4): 371-385.

The Economist. 2018. "China has Turned Xinjiang into a Police State like no Other." The Economist, 31 May: https://www.economist.com/briefing/2018/05/31/china-has-turned-xinjiang-into-apolice-state-like-no-other (accessed May 2019). 
The Express Tribune. 2013. "Safe passage: Additional check posts to be set up along Karakoram Highway." The Express Tribune, 26 September 2013: http://tribune.com.pk/story/6o9343/ safe-passage- additional-check-posts-to-be-set-up-along-karakoram-highway/ (accessed November 2014).

The Strait Times. 2018. "Chinese firms cash in on Xinjiang's growing police state." The Strait Times, 27 June 2018: https://www.straitstimes.com/asia/east-asia/chinese-firms-cash-in-onxinjiangs-growing-police-state (accessed May 2019).

Thongchai, Winichakul. 1994. Siam Mapped: A History of the Geo-body of a Nation. Honolulu: University of Hawaii Press, 1994.

Thum, Rian. 2018. “What Really Happens in China's 'Re-Education' Camps.” New York Times, 15 May: https://www.nytimes.com/2018/05/15/opinion/china-re-education-camps.html (accessed August 2018).

Tian, Q. 2004. “China Develops its West: Motivation, Strategy and Prospect.” Journal of Contemporary China 13(41): 611-636.

Tilt, B. 2015. "Dams, Displacement, and the Moral Economy in Southwest China." In: Carlos Rojas and Ralph Litzinger (eds.) "Ghost Protocol: Development and Displacement in Global China.” Durham, NC and London: Duke University Press, 87-108.

Tilt, B., \& Gerkey, D. 2016. "Dams and population displacement on China's Upper Mekong River: Implications for Social Capital and Social-Ecological Resilience.” Global Environmental Change 36, 153-162.

To, Phuc Xuan; Mahanty, Sango; Dressler, Wolfram. 2014. "Social Networks of Corruption in the Vietnamese and Lao Cross-Border Timber Trade." Anthropological Forum 24(2): 154-174.

Todorov V. 1994. Red Square, Black Square: Organon for Revolutionary Imagination. Albany, NY: State University New York Press.

Tsing, Anna. 2003. "Natural Resources and Capitalist Frontiers." Economic and Political Weekly $38(48): 5100-5106$.

Tsing, Anna. 2005. Friction: An Ethnography of Global Connections. Princeton, NJ and Oxford: Princeton University Press.

Tsing, Anna. 2015. The Mushroom at the End of the World: On the Possibility of Life in Capitalist Ruins. Princeton, NJ: Princeton University Press.

Twelfth Five-Year Programme. 2011. Zhonghua Renmin Gongheguo Guomin Jingji he Shehui Fazhan de Shi'er ge Wunian Guihua Gangyao (Outline Five-Year Programme for National Economic and Social Development of the People's Republic of China). Beijing: Renmin chubanshe.

Uberoi, Patricia. 2013. “The BCIM Forum: Retrospect and Prospect.” Delhi: ICS Working Paper \# 1. Available at: https://www.icsin.org/uploads/2015/04/12/df 72872d10c0497dadfb52322bafd9oo. pdf (accessed May 2019).

Van Assche, K.; Hornidge, A. 2014. "Hidden Mobilities in Post-Soviet Spaces. Boundaries, Scales, Identities and Informal Routes to Livelihood". Crossroads Asia Working Paper Series, No. 20.

Van Houtum, H.; Van Naerssen, T. 2002. "Bordering, Ordering and Othering." Tijdschrift voor Economische en Sociale Geografie 93(2): 125-136.

Van Schendel, W. 2005. The Bengal Borderland: Beyond State and Nation in South Asia. London: Anthem Press.

Van Spengen, Wim. 2000. Tibetan Border Worlds: A Geo-historical Analysis of Trade and Traders. New York: Kegan Paul International.

Vandergeest, Peter; Peluso, Nancy. 1995. Territorialization and state power in Thailand. Theory and Society $24(3): 385-426$. 
Vanderklippe, Kevin. 2017. "How China is targeting its Uyghur ethnic minority abroad." The Globe and Mail, 29 October 2017: https://www.theglobeandmail.com/news/world/uyghurs-aroundthe-world-feel-new-pressure-as-china-increases-its-focus-on-thoseabroad/article36759591/ (accessed May 2019).

Wade, Geoff. 2000. "The Southern Chinese Border in History.” In: Evans, Grant; Hutton, Christopher and Kuah Khun Eng (eds.) Where China Meets Southeast Asia: Social \& Cultural Change in the Border Regions. White Lotus: Bangkok; Institute of Southeast Asian Studies, Singapore, 28-35.

Waite, E. 2006. "The Impact of the State on Islam amongst the Uyghurs: Religious Knowledge and Authority in the Kashgar oasis." Central Asian Survey 25(3): 251-265.

Walker, Andrew. 1999. The Legend of the Golden Boat. Regulation, Trade and Traders in the Borderlands of Laos, Thailand, China, and Burma. Honolulu: University of Hawaii Press.

Walton, Matthew J. 2008. "Ethnicity, Conflict, and History in Burma: The Myths of Panglong," Asian Survey, 48:6: 889-910.

Wang, J.; Li, S.M. 2016. “State Territorialization, Neoliberal Governmentality: The Remaking of Dafen Oil Painting Village, Shenzhen, China.” Urban Geography 38: 708-728.

Wang, Sangui; Li, Zhou; Ren, Yanshun. 2004. The 8-7 National Poverty Reduction Program in China: The National Strategy and Its Impact. The World Bank: http://web.worldbank.org/ archive/websiteoo819C/WEB/PDF/CHINA_-4.PDF (accessed May 2019).

Wang, Xueye; Tang, Zihua; Wu, Jing; Wu, Xinhua; Wu, Yiqun; Zhou, Xinying. 2016. "Strontium Isotope Evidence for a Highly Mobile Population on the Pamir Plateau 250o Years Ago." Scientific Reports 6: https://www.nature.com/articles/srep35162 (accessed May 2019).

Warikoo, K. 1996. "Trade Relations between Central Asia and Kashmir Himalayas during the Dogra Period (1846-1947)." Cahiers D'Asie centrale 1 (2): 113-124.

Watts, M. 2014. Oil Frontiers: The Niger Delta and the Gulf of Mexico. In: R. Barrett and D. Worden (eds.) Oil Culture. Minneapolis, MN: University of Minnesota Press, 180-210.

Watts, M. 2015. "Specters of Oil: An Introduction to the Photographs of Ed Kashi". In: H. Appel, A. Mason, and M. Watts (eds.) Subterranean Estates: Life Worlds of Oil and Gas. Ithaca, NY: Cornell University Press, $165^{-188 .}$

Wen, Philip; Auyezov, Olzhas. 2018. Tracking China's Muslim Gulag. Reuters, 29 November 2018: https://www.reuters.com/investigates/special-report/muslims-camps-china/ (accessed May 2019).

Weyerhaeuser, H.; Wilkes, A.; Kahrl, F. 2005. "Local Impacts and Responses to Regional Forest Conservation and Rehabilitation Programs in China's Northwest Yunnan Province." Agricultural Systems 85: 234-253.

Weyerhaeuser, H.; Wen, S.; Kahrl, F. 2006. Emerging Forest Associations in Yunnan, China: Implications for Livelihoods and Sustainability. World Agroforestry Centre, ICRAF-China.

Wiemer, C. 2004. "The Economy of Xinjiang." In Starr, F. (Ed):Xinjiang: China's Muslim Borderland. New York and London: M.E. Sharpe, 163-189.

Wilson, T.M., Donnan, H. 1998. Border Identities: Nation State at International Frontiers. Cambridge: Cambridge University Press.

Wilson, T.M., Donnan, H. (2012). “Border and Border Studies”. In: Wilson, T.M., Donnan, H.(ed.), A Companion to Border Studies. Oxford: Wiley-Blackwell, 1-25.

Wong, Edward. 2016. "Chinese Modernization Comes to an Isolated People." New York Times, April 2016. https://www.nytimes.com/2016/04/25/world/asia/chinese-modernization-comesto-an-isolated-people.html (accessed May 2019). 
Woods, Kevin. 2011a. “Ceasefire Capitalism: Military-Private Partnership, Resource Concessions and Military-State Building in the Burma-China borderlands." The Journal of Peasant Studies 38(4): 747-770.

Woods, Kevin. 2011b. "Conflict Timber along the China-Burma Border: Connecting the Global Timber Consumer with Violent Extraction Sites." In: Eric Tagliacozzo and Wen-Chin Chang (eds.) Chinese Circulations: Capital, Commodities, and Networks in Southeast Asia. Durham, NC and London: Duke University Press, 480-506.

Woods, Kevin. 2013. "Analysis of the China-Myanmar Timber Trade." Forest Trends Policy Brief. Woods, Kevin. 2016. "The Commercialisation of Counterinsurgency: Battlefield Enemies, Business Bedfellows in Kachin State, Burma." In: Mandy Sadan (ed.) War and Peace in the Borderlands of Myanmar: The Kachin Ceasefire, 1994-2011. Copenhagen: NIAS Press, 114-146.

Xi, Jinping. 2014a. "New Asian Security Concept for New Progress in Security Cooperation," remarks at the Fourth Summit of the Conference on Interaction and Confidence Building Measures in Asia, 21 May 2014. http://www.fmprc.gov.cn/mfa_eng/zxxx_662805/t1159951.shtml (Accessed May 2019).

Xi, Jinping. 2014b. The Governance of China. Beijing: Foreign Languages Press.

Xiang, Biao. 2015. “'You've Got to Rely on Yourself ... and the State!': A Structural Chasm in the Chinese Political Moral Order." In: Carlos Rojas and Ralph Litzinger (eds.) Ghost Protocol: Development and Displacement in Global China. Durham, NC and London: Duke University Press, 131-149.

Xiao, Jianwen. 2005. "Dulongjiang Tuigeng Huanlin dui Nongye Shengwu Duoyangxing de Yingxiang: Chubu Diaocha Jieguo (Preliminary Survey of the Impact of Sloped Land Conversion on Agro-Biodiversity in Dulongjiang Township)." CBIK Report 24. Kunming: Center for Biodiversity and Indigenous Knowledge.

Xie, Philip Feifan. 2003. "The Bamboo-Beating Dance in Hainan, China: Authenticity and Commodification." Journal of Sustainable Tourism 11(1): $5^{-16 .}$

Xinhua. 2006. "Yunnan Public Security Border Defense Brigade takes actions to ensure the Yunnan-Burma timber and mineral trading cooperation." Xinhua, March 27.

Xinhua. 2008. "Xinjiang haiwai jiaoliu xiehui xiang ba Huaqiao huaren xiehui juanzeng 20 wan yuan (Xinjiang Overseas Chinese Association donates 200000 yuan to Pakistan's Overseas Chinese Association)." Xinhua, 17 July 2008: http://news.xinhuanet.com/newscenter/200807/17/content_8564149.htm (accessed May 2019).

Xinhua. 2013. "Minister Calls for Better Border Defense in Xinjiang." Xinhua, 15 October 2013: http://news.xinhuanet.com/english/china/2013-10/15/c_132801554.htm (accessed May 2019).

Xinhua. 2016. "China-Pakistan Logistics Complex Breaks Ground in Xinjiang”, Xinhua, 1 April 2016: http://news.xinhuanet.com/english/2016-04/o1/c_135243654.htm (accessed May 2016).

Xinhua. 2017. "Full Text of President Xi's Speech at Opening of Belt and Road Forum." Xinhua, 14 May 2017: http://www.xinhuanet.com/english/2017-05/14/c_136282982.htm (accessed May 2019).

Xinhua. 2018a. "Gongshan xian Dulongjiang xiang: jiajia you xinju huhu you gongye (Dulongjiang Township, Gongshan county: every family has a new home, every household a new occupation)." Xinhua, 15 January 2018: http://www.yn.xinhuanet.com/newscenter/201801/15/c_136896128.htm (accessed May 2019).

Xinhua. 2018b. "Full Transcript: Interview with Xinjiang Government Chief on Counterterrorism, Vocational Education and Training in Xinjiang." Xinhua, 16 October 2018: http://www. xinhuanet.com/english/2018-10/16/c_137535821.htm (accessed May 2019).

Xue, L., M. Wang and T. Xue 2013. "'Voluntary' Poverty Alleviation Rresettlement in China." Development and Change, 44, 1-22. 
Yan, H. 2003. "Neoliberal Governmentality and Neohumanism: Organizing Suzhi/Value Flow through Labor Recruitment Networks." Cultural Anthropology 18: 493-523.

Yan J. 2001. Zhongguo xibu da kaifa de zhanlüe yu duice (China's Great Opening of the West strategy and ways to deal with it). Beijing: Kexue chubanshe.

Yang, Bin. 1972. Between Winds and Clouds: The Making of Yunnan (Second Century BCE to Twentieth Century CE). New York: Columbia University Press.

Yang, J.; Siddiqi, R. 2011. "About an 'All-Weather' Relationship: Security Foundations of SinoPakistan Relations since 9/11." Journal of Contemporary China 20(71): 563-579.

Yeh, Emily. 20oga. "Greening Western China: A Critical View." Geoforum 40: 884-894.

Yeh, Emily. 2009b. "From Wasteland to Wetland? Nature and Nation in China's Tibet." Environmental History 14(1): 103-137.

Yeh, Emily. 2013. Taming Tibet: Landscape Transformation and the Gift of Chinese Development. Ithaca, NY: Cornell University Press.

Yeh, Emily; Wharton, Elizabeth. 2016. "Going West and Going Out: Discourses, Migrants, and Models in Chinese Development." Eurasian Geography and Economics 57(3): 286-315.

Zafar, Muhammad. 2016. "First Chinese Trade Convoy Arrives in Gwadar through CPEC." The Express Tribune, 12 November 2016: https://tribune.com.pk/story/122878o/first-chinesetrade-convoy-arrives-gwadar-cpec/ (accessed May 2019).

Zaloom, C. 2006. Out of the Pits: Traders and Technology from Chicago to London. Chicago, IL: Chicago University Press.

Zenz, Adrian. 2018. "Thoroughly Reforming Them Towards a Healthy Heart Attitude: China's Political Re-Education Campaign in Xinjiang." Central Asian Survey, doi:10.1080/02634937.

Zenz, Adrian; Leibold, James. 2017. "Chen Quanguo: The Strongman Behind Beijing's Securitization Strategy in Tibet and Xinjiang." China Brief 17 (12): https://jamestown.org/program/chenquanguo-the-strongman-behind-beijings-securitization- strategy-in-tibet-and-xinjiang/ (accessed May 2019).

Zhang, Juan. 2018. "Permissive Politics and Entrepreneurial Transgression in a Chinese Border Town." Sojourn:Journal of Social Issues in Southeast Asia 33(3): 576-601.

Zhou, Yongmin. 2013. "Branding Tengchong: Globalization, Road Building, and Spatial Reconfigurations in Yunnan, Southwest China.” In: Tami Blumenfield and Helaine Silverman (eds.) Cultural Heritage Politics in China. New York: Springer, 247-260.

Zhou, Zunyou. 2017. "Chinese Strategy for De-Radicalization. Terrorism and Political Violence." DOI: 10.1080/09546553.2017.1330199.

Zhuang, G. 1997. "Dui jin 20 nian lai huaren guoji yimin huodong de sikao [Analysis of the Activities of the Chinese Immigrants in the Last 20 Years]." Huaqiao huaren lishi yanjiu (Overseas Chinese History Research) 2: 1-6.

Zukosky, Michael. 2012. "Quality, Development Discourse, and Minority Subjectivity in Contemporary Xinjiang." Modern China 38(2): 233-264.

\title{
British Library Archive
}

\author{
IOR/L/PS/11/6 \\ IOR/L/PS/11/205 \\ IOR/L/PS/11/301 \\ IOR/L/E/9/233
}


IOR/L/PS/10/337

IOR/L/PS/11/228

IOR/L/PS/10/208

IOR/L/PS/11/301

\section{The National Archives}

WORK 10/633

FO $369 / 3087$

FO $228 / 3275$ 


\section{Index}

$21^{\text {st }}$ Century Maritime Silk Road $\quad 214$

8-7 strategy 23

Afghanistan $51,178,181,190,215$

Afghan dry fruit $68,71,175,205$

China-Afghanistan border 19,48

Agnew, John 69

Aksu $\quad 196$

Amber (Burmese amber, Burmite)

amber traders/trade $32,34,74,215-8$, 229-35

amber mines 230

See also Tengchong Amber Association

Anderson, Benedict $\quad 20,53$

Anthropology/anthropologists $16-7,62,70$, $112,145,156,170,207,218,222$

anthropology of infrastructure 30,40 , 63,247

anthropology of markets/trade $\quad 63-4,69,216$

anthropology of the state $18,43,216,248$

Archibald Rose 18-9,77-8, 225

Asia/Asian 29, 37, 200, 214, 248, $25^{1}$

highlands of 70

Asian Development Bank (ADB) 215, 219-21

Attabad (village, lake, landslide) $\quad 39-41,71$

Baman ethnicity 83

Bangladesh 25, 207, 221-3; See also BCIM

(Bangladesh-China-India-Myanmar

Economic Corridor)

Banwa See Diantan/Banwa

Barabantseva, Elena 184

BCIM (Bangladesh-China-India-Myanmar Economic Corridor) 104, 211, 213, 215-6, 219, 221-3, 249; See also Kunming Initiative

Becquelin, Nicolas 13

Beijing $128,133,145,154,180-1,184,189,192-3$, $202-4,210,219,221,226,237,245,247$

Bellér-Hann, Ildikó, $155^{-6}$

Belt and Road Initiative (BRI) 12-4, 18, 26, 30, $33-4,39,41,65,75,103,144,154,167,176,196$, 213-6, 218, 220, 228-9, 234, 236, 243-5, 251

Belt and Road Corridors 104, 207, 221, 226, 249

Belt and Road era $\quad 235,239$

Belt and Road fantasies/imaginaries 34, $103,112,200$

Belt and Road Forum $\quad 214,221$

Belt and Road projects $34,103,234,245$

Belt and Road rhetoric/language 33,200 , 204, 205, 219, 244, 247

BRI agenda/goals/vision 13, 17, 221, 234

Bhamo $76,78,84$

Bingtuan (Xinjiang Production and Construction Corps) 21, 81, 153
Border Pass

China-Burma border area exit and entry pass 98,101

Pak-China Border Pass 5o, 62

Building a New Socialist Countryside 113, 121- 5,144

Burma Road 85

Burmese Army / Tatmadaw $\quad 23,89,97-8,222$, 230

Byler, Darren 159

Central Asia $18,23,38,40,45-6,64,162$, 185n11, 189, 214, 221

Central Asian borders $54,28 n_{3} 0,64$

China and Central Asia 204n17, 215

Che, Zhimin $\quad 102,221 n_{7}$

Chen, Quanguo 177, 195

China market (Rawalpindi) 175-6, 189, 194

China Mobile 124, 131

China Road and Bridge Corporation $\quad 39,187$

China Southern Power Grid 131

China Telecom 131

Chinese Communist Party $11,19,21,24,42$, 81-2, 133-4, 139, 144, 152, 161, 192, 241-2, 251 Leaders $20,23 n 20,80,117,154,213,245$ local officials $16,98,118,128-9,241$ policies 146n1, 180, 204, 244

power 18 relations with $\mathrm{CPB} \quad 82,87,87 \mathrm{n} 16$

Chinese embassy Pakistan 178n1, 181-2, 191-3, 202-3

CIA $\quad 22,81$

Cliff, Tom 21

Cold War $\quad 23,86$

Communist Party of Burma (CPB) 22-3, 75, 82-91

CPEC 33, 38-41, 187, 201, 205, 208-9, 221, 235n17, 238n1, 239, 242

Dehong Dai and Jingpo Autonomous Prefecture $76 \mathrm{n} 3,101$

Deng, Xiaoping $\quad 23,48,84-5,91,188$

Diantan/Banwa $82,87,92-3,95-7,99-101$, $225^{-6}, 228$

Development security nexus $12-3,24,245,251$

Drung/Dulong 15, 32-3, 111, 114, 129, 138-41, $153,159-60,169-70,247$

agriculture $120-1,123,126$

Dulong township $115,117-8,121,123,125$, $127-8,130$

Dulong valley road $\quad 116-8$

ethnicity 119

marginalisation and modernisation 33 , $114,119-21,124,126,130,132,134-5$

and remoteness $\quad 112-3$ 
New Socialist Countryside in the Dulong valley $121-5,241$

and sushi $\quad 130-3$

Dulong See Drung/Dulong

Ethnography $11,15^{-7}, 44,54,119 n_{4}$

East Turkestan $177 \mathrm{n} 1$

East Turkestan Islamic Movement (ETIM) 189-90

Eurasia $38,41,45^{-6}, 246$

Europe $11,37,121,146$

Ferguson, James 170-1

Fischer, Andrew $\quad$ 170-1

Foucault, Michel $\quad$ 14, 43, 137, 159, 165, 206

Gaoligong Mountains $\quad$ 19, 90, 111-2, 116-7, 169 Gaoligong Mountains National Nature Reserve 120

Gilgit-Baltistan $39,50,55,59,62,67,71,182$, $185-7,194,202-3$

Going out strategy $\quad 25-6$

Gojal 39, 50,71

Gongshan 111-2, 115-7, 121, 126-7, 169

Governmentality $14,137-8$

Great Game 67

Greater Mekong Subregion (GMS 220

Gregory, Christopher 218

Guangzhou New City $38,186-8,197,210$

Harrell, Stevan $\quad 145,15^{2}$

Harvey, David $\quad 29,133$

Harvey, Penny 44

Heritage; heritage-making $\quad 33,139-40,152,166$ as disciplinary tool $145,15^{2-3}, 158-9,167,251$ preservation $144-5,150$

Himalaya 54, 208

Hong Yi Da company $\quad 213,223-4,228-9,249$

Houqiao/Kampaiti $82,88,90-8,103,231,233$, 248-9

Border Trade Zone $\quad 213-4,216,223-5,228-9$, 234

Road 95-7, 1-2

$\mathrm{Hu}$, Huanyong 73

Humphrey, Caroline 247

Hunza $40,46,50-1,54,203,239$

river 39

state/kingdom $19,52-3$

traders in Xinjiang $\quad 55^{-8}, 61-2,187$

India $18,19 n 9,21,25,29,37 \mathrm{n} 2,46-7,79,186$, $215,221-4$

Ingold, Tim 70

Inner Mongolia $\quad$ 14, 25, 73

Irrawaddy 76

Islamabad $38,41,51,66,180,210,237$

Chinese officials/embassy in $181-2,185^{-6}$, 203-4
Kachin Independence Organisation/Army (KIO/A) 82, 86-9, 96-8, 230

Kachin State $74,82,86-7,89-90,217,222,230$, 233, 249

Karachi $\quad 50,68-9,175,182,194,237$

Karakoram Highway (KKH) 15, 38-40, 74, 105, 177-180, 186, 194, 241 construction and securitisation of the 48 $9,187,196-202,206-9,237-9$ trade and traders along the $32,39,43-4$, 51, 6o-3, 66, 68-71, 102-3, 188-9, 210

Kashgar Central \& South Asia Commodity Fair $37-8,41,154,186$

Kashgari (Uyghurs of Pakistan) 15, 71, 175-94, 202-4, 209

Kashmir 18, 178-9

Kazakhstan $37 \mathrm{n} 2,39,184,214,244$

Khan, Imran 39

Khotan $15,105^{-6}, 179,186,238$ Khotan House (Rawalpindi) 177-8, 180-1, 191

Khunjerab Pass $\quad 14-5,42,46,49-50,57-8,61-2$, $66,105,176,178,187,194,196,200-1,205,210$

KMT (Kuomintang, Guomindang, Chinese Nationalist Party) 22, 79-84

Kreutzmann, Hermann 48

Kunming $79,86,87 \mathrm{n} 16,91-3,112,115,139$, $181 n_{5}, 219,224,226$

Kunming Initiative $\quad 216,219,221-2$

Kyrgyzstan 22, 25, 37n2, 184

Ladakh $\quad 46$

Lahore $39,46,182$

Laos $\quad 62,65 \mathrm{n} 14,82,86,91-2,94,220,235 \mathrm{n} 17$

Latour, Bruno 53

Lattimore, Owen 27

Leach, Edmund 27

Lefebvre, Henri 132

Li, Tania 137,144

Lintner, Bertil $\quad 82 \mathrm{n}_{3}, 83$

Liu, Jian 192

Liuku 111-2

Logistics $\quad 62-5,68,207,224,251$

centres $38,153,200,249$

companies 175

Ma, Dazheng 23

Mähälla 156

Mandalay $16-7,84$

Mao, Zedong $\quad 52,73,80,84,114,238$

Marx, Karl, 119n4; Marxist theories and policies $83,132,137,247$

Massey, Doreen 70

McMahon, Henry 19

Millward, James 22n18, 23n19, 45,

Minzu 102, 151, 159, 163-5, 171, 250

Minority nationality (shaoshu minzu) 19, $42 n 3,112$ 
minzu shibie $22 n 17,47,119 n 4$

Mitchell, Timothy $\quad 60,166-7$

MNDAA (Myanmar National Democratic

Alliance Army) 86

Myitkyina $16,74,90-3,96,98,102,222$

Nagar Valley $67,69,175$

Natural Forest Protection Program

(NFPP) 93-4

NDA-K (New Democratic Army - Kachin) 86, 89, 96-9

NDAA (National Democratic Alliance Army, Mong La) $\quad 82,86$

Nepal 54, 62

Nujiang Valley 111-2, 117, 127

Nujiang Lisu Autonomous Prefecture 1012,226

$\mathrm{Nu}$ (Salween) river $\quad 111,116$

Oakes, Tim $\quad$ 139, 144, 151-3

Ong, Aihwa 133, 246

Osburg, John 133, 217

Overseas Chinese Association Pakistan 117n1, $182 \mathrm{n} 6,182-6,190-1,202$

Pakistan Army Corps of Engineers 15, 237

Pamirs / Pamir Mountains 18-9, 42, 47-8, 105 Pamiri architecture 61

Panthay rebellion $\quad 76$

People's Liberation Army (PLA) 21, 22n18, 81, $178,203 n 16$

Peshawar $46,68-9,175,181 n_{4}, 182,186,190 n 13$, 209

Pianma (Hsipaw) 19, 102, 226

Pieke, Frank 43-4

Qing dynasty $\quad 77-8,131 n 9$ territorial extension/boundaries 20

Rangoon/Yangon $\quad 78,82,84$

Rasanayagam, Johan $\quad 44,60$

Rawalpindi $40,62,68-9,175,177,179,182,185$, 191-2, 194, 202, 205, 237

Reeves, Madeleine $\quad 28 n 30,44,53-4$

Roberts, Sean 161,190

Ruili 91, 93, 214

Russia $\quad 25,37 \mathrm{n} 2,73$

Sadan, Mandy $\quad 87$

Sarah Green $\quad 28,53-4$

Saxer, Martin $\quad 54,70-2,139 n 2,144-5,207-8$

Security-development nexus See development security nexus

September 11, 2001, 144, 181, 189, 202

Shan State 82,87

Shanghai $15,68,78,133,192,244$

Shanghai Cooperation Organization (SCO) $\quad 25$

Sharif, Nawaz 39
Shenzhen $\quad 41-2,133,153-4,213-4$

Silk Road $38,45-6,65,143,215,219$

New Silk Road(s) 14, 46, 66

Silk Road imaginaries/rhetoric $13,15,41$, 75, 201

Silk Road Economic Belt $\quad 200,214$

Skype 15, 62, 68-9, 205

Sloping Land Conversion Program (SLCP) 94, $120,126,138,225$

Social engineering $113,159-160$

Sost $56-60,62,205$

South Asia 91n18, 178-180, 224

Southeast Asia $\quad 29-30,74-5,78,91,102,183,215$, $221 n 7,230$

Soviet Union $\quad 22-3,48 n 9,138,141,190 n 13$

Special Economic Zone (SEZ) 26, 30, 42, 102, 202, 213-4, 224, 229, 247

Kashgar SEZ $37,39,65,153^{-6}$

Special Region 1 (War Zone 101) $\quad 82,86,88$

Steenberg, Rune 64

Stein, Aurel $46 \mathrm{n}_{7}, 53$

Stilwell/Ledo road $79,85,90-2,222,230$

Su, Xiaobo 75

Subsidies $12,23,26,33,48,113,121,124-31$, 157n4, 170-1, 193

Summers, Tim 91n18, 92

Suzhi 128, 130-4, 152, 171

Tajikistan 22, 25, 38n2, 48ng, 200 China-Tajikistan trade and traders 38 , 162, 204n17

Chinese Tajik minzu $\quad 42,42 \mathrm{n} 3,43,47,5^{\circ}$, 5on10, 54, 61, 197, $25^{\circ}$

Kulma Pass between China and Tajikistan $38 \mathrm{n} 2,162,200$

Tashkurgan $15-6,38,41-62,65,67,70-2,74,76$, $105,187-8,196-201,223,241-3,250$

Tengchong $15-8,32,34,72-104,111,213,215-9$, 222-35

Tengchong Amber Association $\quad$ 218, 232-5

Terrorism 11, 161, 189-90, 193-4, 241-2

Thailand $65^{\mathrm{n} 14}, 82,87,220,235 \mathrm{n} 17$

Three evil forces 11, 241-2

Three Parallel Rivers of Yunnan Protected Areas 120

Tibet Autonomous Region (TAR) 14, 25, 8on11, $81,143-4,154,156 \mathrm{n} 3,170,195$

Timber (Yunnan-Burma Timber trade) $\quad 32,75$, $85,87-8,93-104,215-8,225^{-30}, 234-5$

Ting Ying $\quad 82,86,88,93,96-7$

Todorov, Vladimir 141

Tongdao $\quad 91-2,96$

Tsing, Anna 27, 233

Turkestan Islamic Party (TIP) $\quad 1_{181 n_{5}}$

Umer Uyghur Trust 191

Urumqi $15,17,40-1,47,69,105^{-7}, 147,154,176$, $18 \mathrm{n}_{5}, 184,189,196 \mathrm{n}_{15}, 203$ 
Uyghur $12 \mathrm{n} 1,16,33,37,40,43,66,105-7,140-1$,

176, 184-7, 194, 199-200, 210

China's war on terror and the

Uyghurs 188-19o

Incarceration of Uyghurs in Xinjiang 11-2, $195,203-4,206$

Re-making of Uyghur identity in Kashgar $145^{-9}, 15^{2-3}, 155^{-6} 7$

Uyghurs of Pakistan See Kashgari

Uzbekistan $25,146,192$

Vietnam 62, 91-2, 94, 207, 220

von Richthofen, Ferdinand 45

Wa; Wa ethnic group $\quad 29,83$

United Wa State Army (UWSA) $\quad 86,88$

Wa State/hills in northern Burma 80,88

Wakhi $42 n 3,51,54,61,71$

language $5^{0-1,243}$

War on terror $144,161,163,181,189,194,202$

WeChat $15,62,68-70,124,205$
Whatsapp $56 \mathrm{n} 13,68 \mathrm{n} 1$

Woods, Kevin $\quad 88-9,101-2,217 \mathrm{n} 3$

World War Two $\quad 22,29,53 \mathrm{n} 12,63,79,84,90$

$\mathrm{Xi}$, Jinping $\quad 11,39,75,114,124,129,154,158 \mathrm{n}_{5}$, $194,196,213-5,219,221,236,243-4,247-8$

Xibu da kaifa (Open Up the West Campaign) $18,23-6,30,49,93,101,120,131,176$, 218

Xinhua 11

Yangtze River $\quad 93-4$

Yarkand 46, 53, 178, 190

Yeh, Emily $\quad 25,143,156 n_{3}$

Yiwu 15, 40, 62

Yunnan Academy of Social Sciences $\quad 25,221$

Zakir, Shohrat $\quad 11-2,14,251$

Zhongkun Group 145,153

Zhou, Enlai $\quad 81-2,237$

Zizhi $\quad$ 92-3, 95-97, 100-1, 103, 225-7 
Across the Chinese borderlands, investments in large-scale transnational infrastructure such as roads and special economic zones have increased exponentially over the past two decades. Based on long-term ethnographic research, Borderland Infrastructures addresses a major contradiction at the heart of this fast-paced development: small-scale traders have lost their historic strategic advantages under the growth of massive Chinese state investment and are now struggling to keep their businesses afloat. Concurrently, local ethnic minorities have become the target of radical resettlement projects, securitization, and tourism initiatives, and have in many cases grown increasingly dependent on state subsidies.

At the juncture of anthropological explorations of the state, border studies, and research on transnational trade and infrastructure development, Borderland Infrastructures provides new analytical tools to understand how state power is experienced, mediated, and enacted in Xinjiang and Yunnan. In the process, Rippa offers a rich and nuanced ethnography of life across China's peripheries.

Alessandro Rippa is Associate Professor of Chinese Studies at Tallinn University and "freigeist" Fellow (2020-2025) at the Rachel Carson Center for Environment and Society, LMU Munich. 